UNIVERSIDADE DE SÃO PAULO

ESCOLA DE ENFERMAGEM DE RIBEIRÃO PRETO

\title{
PREVENÇÃO DE COMPLICAÇÕES NOS PÉS DE PESSOAS COM DIABETES MELLITUS: UMA ABORDAGEM DA PRÁTICA BASEADA EM EVIDÊNCIAS
}

Kattia Ochoa Vigo

Ribeirão Preto 


\title{
Kattia Ochoa Vigo
}

\section{PREVENÇÃO DE COMPLICAÇÕES NOS PÉS DE PESSOAS COM DIABETES MELLITUS: UMA ABORDAGEM DA PRÁTICA BASEADA EM EVIDÊNCIAS}

\begin{abstract}
Tese apresentada ao Programa de Interunidades de Doutoramento em Enfermagem da Escola de Enfermagem de São Paulo e Escola de Enfermagem de Ribeirão Preto, Universidade de São Paulo, para obtenção do Título de Doutor, inserida na Linha de Pesquisa: Fundamentos Teóricos e Filosóficos do Cuidar.
\end{abstract}

Orientador: Profa. Dra. Ana Emilia Pace

\section{Ribeirão Preto}




\section{FOLHA DE APROVAÇÃO}

\section{Kattia Ochoa Vigo}

Prevenção de complicações nos pés de pessoas com diabetes mellitus: uma abordagem da prática baseada em evidências

Tese apresentada ao Programa de Interunidades de Doutoramento em Enfermagem da Escola de Enfermagem de São Paulo e Escola de Enfermagem de Ribeirão Preto, Universidade de São Paulo, para obtenção do Título de Doutor.

Aprovado em:

Banca Examinadora

Profa. Dra. Ana Emilia Pace

Instituição:

Assinatura:

Prof. Dr. Laércio Joel franco

Instituição:

Assinatura:

Dr. Maria Teresa da Costa Gonçalves Torquato

Instituição:

Assinatura:

Profa Dra. Maria Helena Larcher Caliri

Instituição:

Assinatura:

Profa Dra. Maria Luzia Zanetti

Instituição:

Assinatura: 
Autorizo a divulgação e reprodução total ou parcial deste trabalho, por qualquer meio convencional ou eletrônico, para fins de estudo e pesquisa desde que citada a fonte.

Ficha Catalográfica elaborada pela Biblioteca Central Campus USP - Ribeirão Preto

Ochoa-Vigo, Kattia

Prevenção de complicações em membros inferiores em pessoas com diabetes mellitus: uma abordagem da prática baseada em evidências. Ribeirão Preto, 2005.

165p.: il.; $30 \mathrm{~cm}$.

Tese (Doutorado) apresentado à Escola de Enfermagem e Escola de Enfermagem de Ribeirão Preto/USP. Programa de Interunidades de Doutoramento em Enfermagem.

Orientador: Pace, Ana Emilia.

1. Diabetes mellitus. 2. Revisão sistemática 3. Prevenção de úlceras 4. Educação. 
"Cada pessoa, em sua existência, pode ter duas atitudes:

Construir ou Plantar.

Os construtores podem demorar anos em suas tarefas, mas um dia terminam aquilo que estavam fazendo. Então param, e ficam limitados por suas próprias paredes.

$A$ vida perde sentido quando a construção acaba.

Os que plantam sofrem com as tempestades, as estações e raramente descansam.

Mas, ao contrário de um edifício, o jardim jamais para de crescer. E, ao mesmo tempo,que exige a atenção do jardineiro, também permite que, para ele, a vida seja uma grande aventura..." 


\title{
DEDICATÓRIA
}

\author{
Aos meus queridos pais : \\ Asunción e Jaime Javier \\ pelo carinho, pelos ensinamentos e por fazerem de tudo para nos \\ proporcionar educação como legado principal em nossas vidas, \\ obrigado por existirem;
}

Aos meus queridos irmãos:

Rosa Azucena

Juana de Jesús,

Juana del Carmen,

Connie Corina e

Jaime Javier,

pelo imenso carinho e apoio constante nesta minha caminhada 


\title{
AGRADECIMENTO ESPECIAL
}

\begin{abstract}
A Profa. Dra. Ana Emilia Pace, pela confiança outorgada no decorrer de nosso convívio profissional,pela orientação, apoio e estimulo constante no desenvolvimento deste trabalho, enfrentando cada obstáculo e fazendo dele um aprendizado, na busca do saber e do conhecimento. Além disso, pela amizade conquistada a cada dia de trabalho...
\end{abstract}




\section{AGRADECIMENTOS}

À Deus, por minha existência e por todos os dias iluminar o caminho na conquista dos meus objetivos e ideais.

À Fundação de Amparo à Pesquisa do Estado de São Paulo - FAPESP, pela concessão de bolsa estudo e apoio financeiro a este trabalho.

À Profa Dra Cláudia dos Santos, pela colaboração na parte estatística deste trabalho.

Ao Dr. Luis Carlos Raya, Secretário Municipal da Saúde de Ribeirão Preto, por ter permitido a realização deste estudo nas Unidades Distritais de Saúde Norte e Sul da Secretária Municipal de Saúde, in memorian.

Aos especialistas em diabetes, médicos e enfermeiros que participaram gentilmente da revisão da proposta de assistência neste trabalho: Dr. Domingos F. Malerbi, Dra. Helena Schimd, Dra. Hermelinda Pedrosa, Dra. Maria Teresa C.G. Torquato, Dra. Monica Antar Gambá, Dra. Sonia Aurora Alves Gross, Enf. Suely R. Thuler, Enf. Vera Ligia.

Ao Dr. Stenio Miranda, Gerente da UBDS Marco Antônio Sahão, distrito sul, pela disposição e gentileza em facilitar o desenvolvimento do ensaio clínico do presente estudo.

À Enf. Ilka Barbosa Pegoraro, Gerente da UBDS Alexander Fleming, distrito norte, pela disposição em facilitar o desenvolvimento do ensaio clínico do presente estudo.

À Dra. Margarethe Pecinato Cottas de Oliveira, Gerente da UBDS Sergio Arouca, distrito norte, pela gentileza e presteza em apoiar as atividades relacionadas com o desenvolvimento do ensaio clínico do presente estudo. 
Às enfermeiras e funcionários da UBSD Sergio Arouca do Quintino 2, pelo constante apoio em todos os momentos requeridos, em especial a Enf. Silvana, Tânia Maria, Maria Lucia e Maria Cristina; funcionárias Ivone, Lucia do Carmo, Maria Helena, Valeria Silva, Luzia Helena, Antonieta e Sal Silva.

Às enfermeiras e funcionários da UBSD Marco Antônio Sahão da Vila Virgínia, pelo constante apoio em todos os momentos requeridos, em especial para Enf. Cecília e funcionárias Maria Antônia, Ana, Mônica, Cidinha e Fabiana.

A todas as pessoas que participantes dos grupos de pesquisa, de ambas Unidades Distritais de Saúde, pela gentileza e coragem de me acompanharem durante o percurso de 12 meses, obrigada pelos ensinamentos compartilhados e pela entrega nos seus cuidados.

À Ketlyn e Martha, da Secretária da Pós-Graduação da EERP-USP, pela permanente disponibilidade e atenção prestada.

À Lourdes e Deolinda, da Biblioteca Glete de Alcântara da EERP-USP, pelo apoio permanente na busca dos materiais bibliográficos. 
Às amigas:

Roxana, pela oportunidade de te conhecer melhor e de apreender errando, nunca esquecerei nossas conversas e discussões, obrigada pelo convívio e pelo respeito as nossas diferenças.

Márcia, pela amizade incondicional doada a cada dia, sempre disposta a ajudar além de seus próprios limites, tua natureza é cândida e alegre, obrigada por compartir os nossos sonhos através da música e pelo convício diário, a oportunidade de te conhecer sempre me será grato lembrar.

Sandra, por sempre me acompanhar e compartilhar nos bons e maus momentos no decorrer deste caminhar;

Marita, pela amizade demonstrada nos momentos mais oportunos desta caminhada;

Mónica, pela gentileza e prontidão de se doar em qualquer momento, apesar do cansaço e do período breve de nos conhecer, apreendendo juntos a cada dia nesta vida;

Idalete e Ana Silvia, pela amizade e companheirismo conquistada nesta fase de nossas vidas, sempre estarão no meu coração;

Enfim, agradeço a todos que participaram e contribuíram de alguma maneira na realização deste trabalho. 


\section{Errata}

Página 146, título, onde se lê IMPLICÂNCIAS, leia IMPLICAÇÕES.

Página $146,1^{\circ}$ parágrafo, $1^{\text {a }}$ linha, onde se lê necessidade enfrentar, leia necessidade a enfrentar.

Página 146, $1^{\text {o }}$ parágrafo, $2^{\mathrm{a}}$ linha, onde se lê Dentre essas condições...., leia Dentre as doenças responsáveis pelas condições crônicas, destaca-se o diabetes mellitus, que vem....

Página 146, $3^{\circ}$ parágrafo, $2^{\mathrm{a}}$ linha, onde se lê cuidado e manejo dessa população...., leia cuidado e manejo das necessidades dessa população....

Página $147,3^{\circ}$ parágrafo, $1^{\mathrm{a}}$ linha, onde se lê $A$ implantação da consulta de enfermagem vem ao encontro....., leia A implantação da consulta de enfermagem, com ênfase na prevenção das complicações crônicas do diabetes, vem ao encontro...

Referências em falta:

ROHTMAN, R.L. et al. Influence of patients literacy on the effectiveness of a primary carebase diabetes diseases management Program. JAMA, v.292, n.14, p.1711-16, 2004.

THOMAS, L.H. et al. Clinical guidelines in nursing, midwifery and the therapies: a systematic review. J. Adv. Nursing, v.30, n.1, p.40-50, 1999. 
Ochoa-Vigo, K. Prevenção de complicações nos pés de pessoas com diabetes mellitus: uma abordagem da prática baseada em evidências. Ribeirão Preto. 2005. 166p. Tese (Doutorado). Escola de Enfermagem de São Paulo e Escola de Enfermagem de Ribeirão Preto, Universidade de São Paulo.

Mais de 50\% das amputações não-traumáticas em membros inferiores são atribuídas ao diabetes. Anualmente, 2 a 3\% dos pacientes desenvolvem úlceras nos pés e este risco aumenta para 15\% no transcurso de sua vida. Freqüentemente, úlceras nos membros inferiores precedem as amputações. Entre os casos graves hospitalizados, 85\% foram causados por úlceras superficiais acompanhadas de diminuição da sensibilidade, decorrente de neuropatia diabética. O objetivo do estudo foi elaborar uma proposta assistencial sistematizada para pessoas com diabetes tipo 2, a partir de uma revisão sistemática, visando a prevenir o risco de lesão/ulceração nos pés e avaliar a efetividade dessa proposta em unidades da rede básica. Estudos primários e diretrizes clínicas foram identificados em bases eletrônicas, sites específicos e referências. Para análise dos estudos e diretrizes, utilizaram-se critérios estabelecidos. Na aplicação da proposta de assistência, 101 pessoas com diabetes tipo 2 foram recrutadas para participar do ensaio prospectivo de 12 meses; 49 pessoas participaram de sensibilização e educação intensiva durante seis semanas e, após este período, compareceram a consultas mensais de enfermagem para reforços e cuidados com os pés; outras 52 receberam cuidado convencional e participaram de orientações grupais semestrais. A avaliação semestral dos resultados primários incluiu o conhecimento sobre diabetes e cuidados com os pés e calçados, condições dermatológicas dos pés e uso de calçado apropriado. Os resultados apresentaram a identificação de 3.941 artigos, sendo selecionados apenas 10 estudos primários e nove diretrizes, os quais envolviam a organização do serviço para o cuidado da pessoa com diabetes e intervenções educativas nos pacientes. Os estudos revisados foram inconclusivos, apresentando falhas na qualidade metodológica. As intervenções preventivas se concentraram na realização de screening para identificar alterações estruturais nos pés, comprometimento da sensibilidade protetora plantar, ressaltando antecedente de úlcera, controle glicêmico e aconselhamento sobre a propriedade dos calçados. No ensaio clínico, 20 pessoas abandonaram o estudo. Os grupos foram semelhantes em idade, sexo, escolaridade, tempo de doença, comorbidades e antecedentes de lesões nos pés. Ao final do primeiro semestre, houve melhora significativa apenas nas variáveis de conhecimento sobre diabetes $(p=0,005)$ e comportamentos de cuidados com os pés $(\mathrm{p}<0,000)$. Ao término do ensaio, houve melhora nas condições dermatológicas dos pés $(p<0,000)$ e na utilização de calçado apropriado $(p=0,005)$, sendo mantido o conhecimento atingido previamente $(\mathrm{p}<0,000)$. Este trabalho mostrou a importância do monitoramento dos fatores de risco nos pés para lesão/ulceração, destacando o processo educativo entre profissionais e pacientes como medida fundamental de prevenção. Além disso, este estudo proporcionou subsídios para uma proposta efetiva de assistência sistematizada na prevenção de lesões/ulcerações nos pés, com desenvolvimento de consultas mensais e cuidados básicos com os pés entre pessoas de baixo risco.

Palavras-chave: diabetes mellitus, revisão sistemática, prevenção de úlcera, educação. 
Ochoa-Vigo, K. Prevention of foot complications in diabetes mellitus patients: an evidencebased practice approach. Ribeirão Preto. 2005. 166p. Doctoral thesis. São Paulo College of Nursing and Ribeirão Preto College of Nursing, University of São Paulo.

Diabetes is considered responsible for more than $50 \%$ of non-traumatic lower limb amputations. Every year, about 2-3\% of patients develop foot ulcers, and this risk increases to $15 \%$ throughout their lives. Lower limb ulcers frequently precede amputations, 85\% of serious hospitalizations cases were caused by superficial ulcers, accompanied by decreased sensibility due to diabetic neuropathy. This study aimed to elaborate a systematic care proposal for patients with type 2 diabetes, based on a systematic review, with a view to preventing the risk of developing foot injury/ulceration, as well as to assess the efficacy of this proposal in district basic health units. Electronic databases, specific sites and references were used to identify primary studies and clinical guidelines. Established criteria were used to analyze the studies and guidelines. In the application of the care proposal, 101 diabetes type 2 patients were recruited to participate in the 12-month prospective trial; 49 persons participated in an intensive six-week educational awareness program, after which they attended monthly appointments for reinforcement and foot care; 52 other persons received conventional care and participated in six-monthly group orientations. The six-monthly evaluation of primary results included knowledge on diabetes, foot and footwear care, dermatological foot conditions and use of appropriate footwear. The results showed that 3,941 articles were identified, of which only 10 primary studies and nine guidelines were selected, which involved service organization for diabetes patient care and educational patient interventions. The reviewed studies were inconclusive and presented methodological flaws. Preventive interventions concentrated on screening to identify structural foot alterations, protective sensibility in the sole of the foot at risk, emphasizing history of ulcers; glycemic control and advice on appropriate footwear. In the clinical trial, 20 persons abandoned the study. The groups had similar age, gender, education, co-morbidity and foot injury antecedent characteristics. At the end of the first semester, only the knowledge variables on diabetes $(p=.005)$ and foot care behavior $(p<.000)$ revealed a significant improvement. At the end of the trial, the improvement in these two variables was maintained $(\mathrm{p}<.000)$, and accompanied by an improvement in dermatological foot conditions $(p<.000)$ and in the use of appropriate footwear $(p=.005)$. This research demonstrated the importance of monitoring risk factors for foot injuries/ulceration and highlighted the education process between professionals and patients as a fundamental prevention measure. Moreover, this study provided supported for an efficient systematic care proposal in the prevention of foot injuries/ulcerations, including monthly appointments and basic foot care, for low-risk patients.

Key words: diabetes mellitus, systematic review, ulcer prevention, education. 
Ochoa-Vigo, K. Prevención de complicaciones en los pies de personas con diabetes mellitus: un abordaje de la práctica basada en evidencias. Ribeirão Preto. 2005. 166p. Tese (Doctorado). Escuela de Enfermería de São Paulo e Escuela de Enfermería de Ribeirão Preto, Universidad de São Paulo.

El 50\% de las amputaciones no traumáticas en miembros inferiores es atribuido a la diabetes mellitus. Anualmente, 2-3\% de los pacientes desarrollarán úlceras en los pies y este riesgo se eleva a $15 \%$ en el transcurso de su vida. Frecuentemente úlceras en los miembros inferiores anteceden a las amputaciones. Entre los casos graves hospitalizados, 85\% fueron causados por úlceras superficiales acompañadas de disminución de la sensibilidad por neuropatía diabética. El objetivo del estudio fue elaborar una propuesta asistencial sistematizada para personas con diabetes tipo 2 a partir de una revisión sistemática con la finalidad de prevenir el riesgo de desarrollar lesión/ulceración en los pies y evaluar la efectividad de esa propuesta en unidades básicas distritales de salud. Estudios primarios y directrices clínicas fueron identificados en bases electrónicas, sites específicos y referencias. Para el análisis de los estudios y directrices se utilizaron criterios establecidos. En la aplicación de la propuesta de asistencia, 101 personas con diabetes tipo 2 fueron reunidas para participar del ensayo prospectivo de 12 meses; 49 personas participaron del programa de sensibilización educativa intensiva durante seis semanas y después comparecieron a las consultas mensuales para refuerzos y cuidados con los pies; otras 52 recibieron cuidado convencional y participaron de orientaciones grupales semestrales. La evaluación semestral de los resultados primarios evaluados incluyeron conocimientos sobre diabetes, conocimiento sobre cuidados con los pies y calzados, condiciones dermatológicas de los pies y uso de calzados apropiados. Se identificaron 3,941 artículos, seleccionándose apenas 10 estudios primarios y nueve directrices considerando la organización del equipo para el cuidado de la persona con diabetes e intervenciones educativas en los pacientes. Los estudios revisados fueron no conclusivos, presentando fallas en la calidad metodológica. Las intervenciones preventivas se concentraron en la realización de screening para identificar alteraciones estructurales en los pies, comprometimiento protectora plantar resaltando antecedente de úlcera; control glucémico y consejos sobre propiedad de los calzados. En el ensayo clínico, 20 personas abandonaron el estudio. Los grupos fueron semejantes en edad, sexo, escolaridad, tiempo de enfermedad, comorbidades y antecedentes de lesiones en los pies. Al final del primer semestre hubo mejora significativa apenas en las variables de conocimiento sobre diabetes $(p=0,005)$ y comportamientos de cuidados con los pies $(\mathrm{p}<0,000)$. Al término del ensayo, la mejora en las condiciones dermatológicas de los pies $(\mathrm{p}<0,000)$ y en la utilización de calzados apropiados $(\mathrm{p}=0,005)$ siendo mantenido el conocimiento alcanzado previamente $(\mathrm{p}<0,000)$. Este estudio mostró la importancia del monitoramiento de los factores de riesgo en los pies para la lesión/ulceración destacando el proceso educativo entre los profesionales y pacientes como medida fundamental de prevención y subsidios para una propuesta efectiva de asistencia sistematizada en la prevención de lesiones/ulceraciones en los pies, con consultas mensuales y cuidados básicos con los pies entre personas de bajo riesgo.

Palabras-clave: diabetes mellitus, revisión sistemática, prevención de úlcera, educación. 


\section{SUMÁRIO}

1 Introdução 1

2 Revisão da Literatura 9

$2.1 \quad$ Fisiopatologia 9

$\begin{array}{ll}2.2 & 11\end{array}$

3 Referencial Teórico 21

$\begin{array}{lll}3.1 & \text { Prática baseada em evidências } & 21\end{array}$

$\begin{array}{ll}3.1 .1 & \text { Revisão sistemática }\end{array}$

2.1.2 Diretrizes clínicas (guidelines) 36

4 Objetivos 42

4.1 Gerais 42

$\begin{array}{lll}4.2 & \text { Específicos } & 42\end{array}$

$5 \quad$ Metodologia 43

$5.1 \quad$ Revisão sistemática 43

$\begin{array}{lll}\text { 5.1.1 Desenho metodológico } & 43\end{array}$

5.1.2 Questão norteadora da pesquisa 43

5.1.3- $\quad$ Critérios para a seleção dos estudos 43

5.1.4 Estratégia de busca dos artigos 44

5.1.5 Procedimento da revisão sistemática 46

$\begin{array}{lll}\text { 5.1.6 Proposta assistencial sistematizada } & 48\end{array}$

$\begin{array}{lll}5.2 & \text { Estudo de intervenção } & 50\end{array}$

$\begin{array}{ll}5.2 .1 & \text { Delineamento do estudo }\end{array}$

5.2.2 Local de estudo 51

5.2.3 Aspectos éticos 53

5.2.4 População base 53

$\begin{array}{lll}5.2 .5 & \text { Critérios de inclusão } & 54\end{array}$

$\begin{array}{lll}\text { 5.2.6 } & \text { População de estudo } & 54\end{array}$

$\begin{array}{lll}5.2 .7 & \text { Definição das variáveis } & 56\end{array}$

$\begin{array}{lll}\text { 5.2.8 } & \text { Instrumento coleta de dados } & 61\end{array}$

5.2.9 Procedimento de coleta de dados 63

5.2.10 Processo de randomização dos grupos $\quad 64$

5.2.11 Procedimento da aplicação da intervenção 65

5.1.12 Análise dos dados 68

$6 \quad$ Resultados e discussão $\quad 69$

6.1 Revisão sistemática 69

6.1.1 Estudos relacionados às intervenções na organização do serviço $\quad 70$

6.1.2 Estudos relacionados às intervenções educativas entre pessoas com DM 81

6.1.3 Diretrizes clínicas para cuidados preventivos com os pés 90

$\begin{array}{lll}\text { 6.1.4 Proposta assistencial sistematizada } & 107\end{array}$

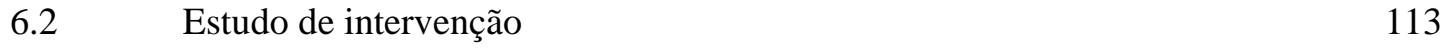

7 Conclusões 143

8 Implicações $\quad 146$

9 Referências $\quad 149$

10. Anexos 165 


\section{LISTA DE TABELAS}

1.2 Prevalência do DM em alguns estudos com base populacional de América 2 Latina, utilizando critérios da OMS de 1985

5.1 Níveo de Classificação da evidência nos estudos 48

5.2 Grau das recomendações propostas 49

5.3 Distribuição das pessoas com diabetes mellitus com tratamento oral ou 54 insulínico, segundo faixa etária e UBDS. Ribeirão Preto, 2003.

6.1 Estudos selecionados relacionados com intervenções na organização do cuidado 69 envolvendo profissionais

6.2 Estudos selecionados relacionados com intervenções educativas nas pessoas 79 com diabetes mellitus

6.3 Diretrizes clínicas selecionadas direcionadas à prevenção de complicações em 90 membros inferiores em pessoas com diabetes mellitus

6.4 Características socio-demográficas, clínicas, co-morbidades e antecedentes de 113 lesões nos pés, por grupos de estudo na avaliação basal.

6.5 Características dermatológicas, estruturais, circulatórias e neurológicas dos 115 membros inferiores nos participantes, por grupos de estudo na avaliação basal

6.6 Classificação de risco para pé diabético dos participantes, a partir da categoria de Sims, Cavanagh e Ulbrecht, por grupos de estudo na avaliação basal

6.7 Conhecimento sobre o diabetes e comportamento de cuidados com os pés e com os calçados e características dos calçados entre participantes, por grupos de estudo na avaliação basal

6.8 Parâmetros do controle metabólico e da pressão arterial dos participantes, por grupos de estudo na avaliação basal

6.9 Parâmetros do conhecimento dos participantes em relação à doença, cuidados com os pés e calçados, condições dos pés e condições apropriadas dos calçados, por grupos de estudo na Segunda e terceira avaliação

6.10 Parâmetros do controle metabólico e da pressão arterial dos participantes, por grupos de estudo na Segunda e terceira avaliação 


\section{LISTA DE FIGURA}

5.1 Esquematização do estudo

51

6.1 Número de estudos identificados nas bases de dados eletrônicas, sites de

70 interesse e busca de referência citadas. 


\section{INTRODUÇÃO}

O diabetes mellitus (DM) constitui atualmente uma das principais doenças crônicas que afeta o homem no mundo, devido às altas taxas de prevalência e morbimortalidade, representando um problema de saúde pública (MALERBI; FRANCO, 1992), pelas suas repercussões sociais e econômicas traduzidas em mortes prematuras, absenteísmo e incapacidade para o trabalho, como também pelos custos associados ao controle e ao tratamento das complicações (FRANCO et al., 1992).

A prevalência mundial do diabetes em adultos, maiores ou iguais a 20 anos de idade, foi estimada em 4\% para o ano de 1995, ou seja, 135 milhões de pessoas. A projeção para o ano 2025 é de 5,4\%, equivalendo a 300 milhões de pessoas com diabetes e a maior parte deste aumento ocorrerá nos países em desenvolvimento, os quais albergarão mais de $75 \%$ desse total, comparado ao $62 \%$, em 1995. O grupo etário mais afetado nesses países incluirá adultos entre 45 e 64 anos (KING; AUBERT; HERMAN, 1998).

Nas Américas, o número de pessoas que desenvolveu diabetes no ano 2000 foi estimado em 35 milhões, dos quais 19 milhões (54\%) viviam na América Latina e no Caribe (BARCELÓ; RAJPATHAK, 2001). A população urbana mostrou uma prevalência muito maior de diabetes do que a população da área rural, atingindo uma proporção de 7,5 (KING, AUBERT, HERMAN, 1998).

Para a América Latina, a Asociación Latinoamericana de Diabetes (ALAD, 2000) estabeleceu uma prevalência de 7 a $8 \%$ nas populações urbanas e de 1 a $2 \%$ para as populações rurais, a partir de estudos do Grupo Latinoamericano de Epidemiología de la Diabetes - GLED, os quais são apresentados na Tabela 1.1. Populações localizadas a mais de 3.000 metros de altitude, em relação ao nível do mar, apresentaram taxas menores de prevalência, comparadas com as encontradas em populações semelhantes, considerando as características étnicas e socioeconômicas, porém localizadas a menor altitude (ALAD, 2000). É possível que exista algum tipo de relação entre altitude e diabetes, porém não existem dados conclusivos a esse respeito. 
Tabela 1.1- Prevalência do DM em alguns estudos com base populacional da América Latina, utilizando critérios da OMS de 1985.

\begin{tabular}{|c|c|c|c|c|}
\hline \multirow[t]{2}{*}{ País } & \multirow{2}{*}{$\begin{array}{l}\text { Faixa } \\
\text { etária } \\
\text { (anos) }\end{array}$} & \multirow[t]{2}{*}{$\begin{array}{l}\% \text { Prevalência bruta } \\
\text { (IC } 95 \% \text { ) }\end{array}$} & \multicolumn{2}{|c|}{$\begin{array}{c}\% \text { prevalência ajustada à idade de } 30- \\
64 \operatorname{anos}(\text { IC } 95 \%)\end{array}$} \\
\hline & & & Homens & Mulheres \\
\hline Argentina (Córdoba) ${ }^{1}$ & $30-70$ & $8,2(2,7-5,5)$ & & \\
\hline Bolivia (Santa Cruz) ${ }^{1}$ & $\geq 30$ & $10,7(8,4-13)$ & & \\
\hline Bolivia (La Paz) & $\geq 30$ & $5,7(3,9-7,6)$ & & \\
\hline Bolivia (El Alto) ${ }^{5}$ & 30 & $2,7(1,4-4)$ & & \\
\hline Brasil (São Paulo) ${ }^{1}$ & $30-69$ & $7,3(6,1-8,4)$ & $7,0(5,2-8,9)$ & $8,9(7,1-10,7)$ \\
\hline Chile (Mapuches) ${ }^{4}$ & $\geq 20$ & $4,1(2,2-6,9)$ & & \\
\hline Chile (Aymaras) ${ }^{4}$ & $\geq 20$ & $1,5(0,3-4,5)$ & & \\
\hline Colombia (Bogotá) ${ }^{1}$ & $\geq 30$ & $7,5(5,1-9,8)$ & $7,3(3,7-10,9)$ & $8,7(5,2-12,3)$ \\
\hline Colombia (Choachí) & $\geq 30$ & $1,4(0-2,8)$ & & \\
\hline México (C. de M.) ${ }^{1}$ & $35-64$ & $12,7(10,1-15,3)$ & & \\
\hline México (S.L.. Potosí) ${ }^{1}$ & $\geq 15$ & $10,1(8,3-11,8)$ & & \\
\hline Paraguay (Asunción) $^{1}$ & $20-74$ & $8,9(7,5-10,3)$ & & \\
\hline Perú (Lima) $)^{1}$ & $\geq 18$ & $7,6(3,5-11,7)$ & & \\
\hline Perú (Tarapoto) ${ }^{2}$ & $\geq 18$ & $4,4(0,2-8,6)$ & & \\
\hline Perú (Huaraz) & $\geq 18$ & $1,3(0-3,8)$ & & \\
\hline
\end{tabular}

Fonte: ALAD, 2000. ${ }^{1}$ Urbana ${ }^{2}$ Suburbana ${ }^{3}$ Rural ${ }^{4}$ Indígena ${ }^{5}>3000 \mathrm{~m} \mathrm{SNM}$

Estima-se que para o ano 2025, existirão nas Américas 64 milhões de pessoas com diabetes e $62 \%$ delas estarão radicadas na América Latina e no Caribe. Este aumento é resultado de múltiplos fatores, como a migração progressiva das pessoas das áreas rurais para as grandes cidades, as mudanças no estilo moderno de vida e o aumento da expectativa de vida, sendo que o estilo de vida incentiva o sedentarismo e as dietas hiper-calóricas, desencadeando obesidade (BARCELÓ; RAJPATHAK, 2001). Ressalta-se que a taxa anual de crescimento populacional dos maiores de 60 anos, na América Latina, no ano 2000, oscilou entre 3 a 4\% versus 0,5\% na América do Norte (ALAD, 2000).

Dados epidemiológicos nacionais estimam que existem, no Brasil, cinco milhões de pessoas com DM e a metade delas desconhece o diagnóstico (SOCIEDADE BRASILEIRA DE DIABETES - SBD, 1997). O estudo multicêntrico de prevalência sobre diabetes no país, realizado com pessoas na faixa etária de 30 a 69 anos de idade, entre novembro de 1986 e julho de 1988, encontrou uma prevalência média de 7,6\% (MALERBI; FRANCO, 1992).

O Brasil encontra-se entre os dez países do mundo com maior população de pessoas com diabetes, sendo projetado que para o ano 2025 existirão no país 11.600 milhões de pessoas com diabetes e que, ainda, permanecerá nessa posição (KING; AUBERT; HERMAN, 1998). 
A doença atinge homens e mulheres da mesma forma e é a quarta causa de morte no país. No estado de São Paulo, a mortalidade por diabetes na população acima de quarenta anos é superada apenas pelas doenças cardiovasculares (SBD, 1997), sendo que o DM constitui fator de risco importante para o surgimento dessas doenças (CHACRA et al., 1996; STANDL, 1998; AMERICAN DIABETES ASSOCIATION - ADA, 2004).

O diabetes tipo 2 corresponde entre 90 e $95 \%$ dos casos e se apresenta, comumente, na maturidade, mantendo uma evolução lenta. Este tipo de diabetes é freqüente em pessoas com história familiar da doença e em obesas (D`ERASMO-MELKUS, 1993; LESSA; MENDONÇA; TEIXEIRA, 1996; ADA, 2004). No geral, a doença é assintomática nos estágios iniciais, fato que retarda seu diagnóstico durante muitos anos (HARRIS et al., 1992; STANDL, 1998; ADA, 2004) e favorece o risco do desenvolvimento de complicações crônicas microvasculares, neuropáticas e macrovasculares (ADA, 2004), apresentado-se na pessoas disfunções e falhas em vários órgãos, especialmente nos olhos, rins, nervos, coração e vasos sangüíneos.

Dessa forma, pessoas com diabetes tipo 2 têm maior risco para desenvolver doenças coronarianas, ataques de apoplexias e doenças vasculares periféricas, bem como maior probabilidade de dislipidemia, hipertensão e obesidade (STANDL, 1998; ADA, 2004). E, quando hospitalizadas por complicações crônicas, demandam geralmente, cuidados multidisciplinares especializados, pelo comprometimento de múltiplos sistemas. Nesse sentido, a pessoa com diabetes não controlada é susceptível de desenvolver complicações altamente incapacitantes, nos quais se destacam o pé diabético, a cegueira e a insuficiência renal crônica, impedindo-as a continuar realizando suas atividades diárias e laborais, acarretando alta ocupação de leitos e absenteísmo ao trabalho, pelas internações prolongadas e recorrentes (DAGOGO-JACK, 1995; LESSA; MENDOÇA; TEIXEIRA, 1996; PEDROSA et al., 1998).

Entre essas complicações incapacitantes, o pé diabético representa um estado fisiopatológico multifacetado caracterizado por úlceras, que ocorrem como conseqüência de neuropatia, doença vascular periférica e deformidades (PEDROSA et al., 1998). As úlceras geralmente decorrem de traumas e, freqüentemente, se complicam com gangrena e infecção, ocasionadas por falhas no processo de cicatrização (BILD et al. 1989; CAPUTO et al., 1994; LEVIN, 1996), as quais podem resultar em amputação, quando não se institui tratamento precoce e adequado (PEDROSA et al., 1998). 
Dessa forma, atribui-se ao diabetes $50 \%$ das amputações não-traumáticas de membros inferiores e o risco para amputação é 15 vezes maior do que na população geral (MOST; SINNOCK, 1983; BILD et al., 1989; PECORARO et al., 1990; HASS 1993; WUTSCHERT; BOUNAMEAUX, 1997; REIBER, 2002). Três anos após amputação de um membro inferior, a porcentagem de sobrevida do indivíduo é de $50 \%$, enquanto, no prazo de cinco anos, a taxa de mortalidade permanece de 39 a 68\% (REIBER, 1996).

Dados da América do Norte indicam que de 9 a 20\% das pessoas com diabetes precisaram ser submetidas a uma segunda amputação, após doze meses da primeira, e que, nos cinco anos seguintes à amputação inicial, de 28 a $51 \%$ dos que sobreviveram, precisarão submeter-se a uma segunda intervenção no mesmo membro (REIBER et al., 1995). Entretanto, outro estudo mais recente mostrou uma diminuição no percentual de novas e maiores amputações (na perna ou acima do joelho) no mesmo membro ou no contralateral, provavelmente, devido ao processo educativo instituído aos participantes sobre cuidados com os pés, bem como ao fornecimento de órtese, quando necessário (FAGLIA et al., 2001).

No Brasil, estudo retrospectivo realizado no município do Rio de Janeiro, mediante a técnica de captura-recaptura (de 1992 a 1994), quando comparada à vigilância passiva (de 1990 a 2000), encontrou incidência sete vezes maior na população diabética entre 55 e 74 anos, do que na população geral. A estimativa anual de amputações maiores de membros inferiores na população geral foi de 31,3/100.000 habitantes, porém, quando relacionada ao diabetes, a cifra elevou-se para 209/100.000 (SPICHLER et al., 2004).

Freqüentemente, as amputações de membros inferiores entre pessoas com diabetes são precedidas de úlceras (PECORARO et al., 1990; CAPUTO et al., 1994; REIBER et al., 1995; PEDROSA et al., 1998; GROSS et al., 1999), caracterizadas por erosões cutâneas com perda do epitélio, as quais se estendem até a derme ou a atravessam e chegam aos tecidos mais profundos e, algumas vezes, atingem os ossos e os músculos (BOULTON, 2004; REIBER, 2002; SUMPIO, 2000).

Anualmente, de 2 a $3 \%$ das pessoas com diabetes podem desenvolver úlceras em membros inferiores e este percentual se eleva a 15\% no transcurso de toda a sua vida (Reiber et al., 1995* apud REIBER et al., 1998; Palumbo e Melton, $1985^{\dagger}$ apud REIBER et al., 1998). ${ }^{*}$ REIBER, G.E.; BOYKO, E., Smith DG. Lower extremity ulcers and amputations in individuals with diabetes. In. HARRIS, M.L. Diabetes
in America, $2^{\text {nd }}$ Ed. Bethesda, MD: National Institute of Health 1995: 409-27. "PALUMBO, P.G.; MELTON, L.J. Peripheral vascular disease and diabetes. In: HARRIS, M.L.; HAMMAN, R.F. Diabetes in America. Bethesda. MD: National Institute of Health, 1985: 1-21. 
As úlceras em pessoas com diabetes são responsáveis por grande percentual de morbimortalidade e hospitalização (LEVIN, 1996), ocasionando um período de internação 59\% mais prolongado que pessoas sem processos ulcerativos (REIBER, 2002). As hospitalizações por pé diabético geralmente são recorrentes, exigindo grande número de consultas ambulatoriais e necessidade de cuidado domiciliar (RAMSEY et al., 1999; HARRINGTON, et al., 2000).

O processo de cicatrização das úlceras ocorre de seis a 14 semanas, requerendo um período de hospitalização de 30 a 40 dias em países desenvolvidos, enquanto no Brasil, essa média é aproximadamente de 90 dias. Estima-se que as taxas de recorrência das úlceras, em longo prazo, atingem $44 \%$ no primeiro ano, $61 \%$ no terceiro e $70 \%$ no quinto ano (PEDROSA et al., 1998).

Ramsey et al. (1999), ao realizar um estudo de coorte retrospectivo, incluindo pessoas com diabetes tipos 1 e 2, identificaram que o gasto com o cuidado das úlceras, no ano anterior a seu diagnóstico, aumentou de 1,5 a 2,4 vezes ao compará-lo com o dispendido entre pessoas sem úlceras e, no ano posterior ao diagnóstico, este custo se elevou 5,4 vezes.

No estudo de Harrintong et al. (2000), gastos relacionados com úlcera atingiram US\$ 3.609 por paciente e $74 \%$ deste foi atribuído à hospitalização na fase inicial. O gasto global dispendido nessas pessoas foi três vezes maior do que em qualquer beneficiário do Medicare, o qual proporciona assistência a pessoas idosas maiores de 65 e é coberto pelo plano governamental americano.

Estudo recente (STOCKL et al., 2004) realizado em 2.253 pessoas que apresentavam episódios de úlcera, as quais foram estratificadas segundo sua gravidade, identificou um gasto global de US\$ 13.179 por episódio, sendo que o custo variava de US\$ 1.892 a US\$ 27.721, conforme a gravidade da lesão. Maior gasto também foi observado com hospitalização na fase aguda da lesão (US\$ 10.188).

Dados nacionais sobre gastos com úlceras na população com diabetes são inexistentes. Entretanto, Pedrosa et al. (1998) estimam que o tratamento do pé diabético poderia estar em torno de US\$ 40.563. O custo médio, apenas com antibióticos e antifúngicos no Ambulatório de Pé Diabético da Fundação Hospitalar do Distrito Federal, foi de R \$31.405,76 por trimestre.

Oitenta e cinco por cento dos casos graves que necessitam de hospitalização são originados por úlceras superficiais ou lesões pré-ulcerativas em pacientes que apresentam diminuição da sensibilidade, devido à neuropatia diabética. Esses casos estão associados a 
pequenos traumas originados por uso de calçados impróprios, dermatose comum, manipulações incorretas dos pés ou unhas, seja pela própria pessoa ou por outras não habilitadas (GROSS et al., 1999).

Conforme se pôde observar, a problemática que representa o pé diabético na população com diabetes é preocupante, frente ao grande impacto socioeconômico, tanto para os serviços de saúde públicos e privados quanto para as pessoas com diabetes e sua família.

Ao considerar a importância dessa situação, a Declaração de Saint Vincent, realizada na Itália em 1989 (1990), estipulou, dentre outras metas, reduzir em 50\% as amputações nas pessoas com diabetes, mediante formação de programas preventivos, incentivando a constituição de equipes multi e interdisciplinares especializadas, com destaque na educação de profissionais, pacientes e familiares, bem como na sensibilização da população geral, para a grande ameaça que constitui o diabetes mellitus.

Em consonância com a meta apresentada na Declaração de Saint Vincent, a Fundação Hospitalar do Distrito Federal (FHDF) iniciou, em 1991, no Hospital Regional de Taguatinga, um processo de sensibilização junto à equipe multidisciplinar diabetologista (Programa de Educação e Controle do Diabetes), visando à implantação do "Ambulatório de Pé Diabético" (APD). Os objetivos estipulados pretendiam promover: a identificação do paciente com pé em risco, o tratamento adequado para evitar amputações desnecessárias e a referência para uma equipe especializada a partir do atendimento realizado no Centro de Saúde. Desta forma, iniciava-se a implantação do Projeto Salvando o Pé Diabético (PEDROSA et al., 1998).

Destaca-se que, na equipe multidisciplinar do APD, o pessoal de Enfermagem, previamente treinado, desenvolve papel fundamental no processo de educação dos pacientes e de seus familiares, bem como no rastreamento das pessoas com pé em risco e nos cuidados quiropódicos* básicos como desbridamentos de tecidos superficiais necrosados, cortes e modelação de unhas, cuidados com unhas encravadas, rachaduras e fissuras, além da redução de pontos de pressão pela remoção das calosidades (PEDROSA et al., 1998).

Atualmente, o referido ambulatório constitui o maior centro de referência para pé diabético no DF e tem incentivado a formação de outros APD em várias cidades e regiões do país, conforme as linhas estabelecidas pelo projeto. Assim, em Ribeirão Preto - São Paulo, existem dois ambulatórios da rede pública que possuem atendimento multiprofissional com ênfase na 
prevenção e no tratamento das complicações em membros inferiores entre pessoas com diabetes. Um deles encontra-se em unidade de referência terciária e outro, em unidade de referência secundária.

A unidade de referência terciária presta assistência multiprofissional à pessoa com diabetes (FERRAZ et al., 2000) e, em decorrência do Projeto Integrado do CNPq - Conselho Nacional de Pesquisa, intitulado "O enfermeiro na prevenção e detecção precoce das complicações em extremidades inferiores das pessoas portadoras de diabetes mellitus", vigência 1999-2001, a partir de 1999 intensificou-se a avaliação sistemática das pessoas com diabetes atendidas neste ambulatório, com o objetivo de identificar os fatores de risco para as lesões em pés (PACE, et al 2002) e, dessa forma, ampliar o desenvolvimento de ações preventivas para evitar/diminuir as amputações em membros inferiores, entre esta população.

Quanto ao atendimento multiprofissional na unidade de referência secundária, este se iniciou em 2001, com o objetivo principal de desenvolver ações curativas e preventivas de lesões/ulcerações em membros inferiores das pessoas com diabetes, com perspectivas de ampliar e consolidar a articulação com as demais unidades de saúde da rede básica, tornando-se, assim, uma importante referência de apoio no cuidado dessas pessoas.

Os resultados obtidos no estudo de Pace et al. (2002), no ambulatório da unidade de referência terciária, em relação à identificação de fatores de risco que poderiam ser monitorados com intervenções de baixa complexidade, tais como calosidades (61\%), rachaduras nos calcanhares e dedos (57\%), corte inadequado de unhas (51\%), unhas espessadas (42\%), anidrose (42\%), hálux valgo (21\%) e lesões descamativas interdigitais (20\%), mostram a necessidade dos serviços de saúde priorizarem estratégias de atendimento básico para a população com diabetes.

Nesse mesmo estudo, $14 \%$ dessa população apresentava ausência ou diminuição dos pulsos tibial e pedioso, $13 \%$ ausência de sensibilidade tátil pressórica plantar, $12 \%$ úlcera ativa e 5\% amputação. Destaca-se que 57\% da população estudada utilizavam calçados impróprios, os quais são apontados como importante fator de risco externo.

Recentemente, estudo de caso-controle, realizado no município de São Paulo com o objetivo de detectar fatores de risco associados às amputações de membros inferiores, mostrou que a falta de higiene, insensibilidade nos pés detectada por uso de calçados impróprios, corte de unhas inapropriado, onimicoses, onicriptoses, acidentes com pedicuros para retirada de calos plantares, bem como o tratamento incorreto de úlceras neuroisquêmicas e sinais súbitos de 
isquemia periférica constituem também fatores precursores das amputações em membros inferiores (GAMBA et al., 2004).

Os autores desse último estudo referido também apontaram que $60 \%$ das pessoas submetidas à amputação possuíam mau controle glicêmico, não tinham acesso a informações sobre cuidados preventivos, não aderiam ao tratamento clínico e apresentavam dificuldades econômicas. Destacaram, no entanto, que esses problemas são passíveis de soluções, mediante medidas e tecnologias apropriadas, principalmente por serem de baixa complexidade assistencial.

Destaca-se também no presente estudo que, o enfermeiro possui um papel fundamental na prevenção e diminuição das úlceras e amputações de membros inferiores entre pessoas com diabetes mellitus e reforçando a necessidade de consolidar e ampliar a consulta de enfermagem como meio importante para a prevenção e monitoramento dos fatores de risco associados, pretende-se neste estudo avaliar uma proposta de assistência sistematizada as pessoas com diabetes, incluindo intervenções básicas de cuidado e rastreamento dos fatores de risco, e fundamentada nos padrões da prática baseada em evidências, que visam a prevenir o desenvolvimento de lesão/ulceração nos pés.

O presente estudo foi desenvolvido em duas Unidades Básicas Distritais de Saúde (UBDS) da rede e, dessa forma, pretende-se colaborar com a consolidação da proposta de articulação e expansão de atendimento na rede pública, com ênfase na prevenção de complicações em pés e, assim, contribuir com a redução da taxa de úlcera e amputação de membros inferiores entre pessoas com diabetes.

Entretanto, previamente, realizou-se uma revisão da literatura, que é apresentada na próxima seção, sobre aspectos fisiopatológicos das complicações nos pés e as medidas preventivas que vêm sendo sugeridas e utilizadas em instituições de saúde, na perspectiva de qye a equipe multidisciplinar possa prevenir complicações em membros inferiores de pessoas com diabetes. 


\section{REVISÃO DA LITERATURA}

\section{1- Fisiopatologia}

As úlceras do pé diabético resultam da combinação de dois ou mais fatores de risco que atuam concomitantemente e podem ser desencadeadas, tanto por traumas intrínsecos como extrínsecos, associados à neuropatia periférica, à doença vascular periférica e à alteração biomecânica (PEDROSA et al., 1998).

A neuropatia periférica constitui-se no fator significante nesses casos, conduzindo à lesão/ulceração do membro inferior. Encontra-se presente em 80 a $85 \%$ dos casos e pode comprometer as fibras sensitivas, as motoras e as autonômicas (PEDROSA et al., 1998, REIBER et al., 1998).

O componente sensitivo produz perda gradual da sensibilidade à dor, percepção da pressão plantar, temperatura e propriocepção. O componente motor contribui para atrofia e fraqueza dos pequenos músculos dorsais, desencadeando desequilíbrio nos tendões flexores e extensores dos metatarsos, deformidades e alterações no modo de caminhar. Quanto ao componente autonômico, esse reduz ou suprime o suor nos pés deixando-os secos e predispondo-os a rachaduras e fissuras, além de desencadear alterações arteriovenosas (PEDROSA et al., 1998; REIBER et al., 1998; SUMPIO, 2000). No que diz respeito às mudanças neuropáticas em geral, estas afetam primeiramente os pés e, posteriormente, progridem em direção à perna (BOIKE; HALL, 2002).

No que se refere à doença vascular periférica representa uma das principais causas de comprometimento das úlceras nos pés das pessoas com diabetes, devido à aterosclerose das artérias periféricas, podendo levar à gangrena e à amputação, pelo comprometimento da perfusão sangüínea em membros inferiores, em conseqüência do inadequado fornecimento de oxigênio, nutrientes e antibióticos aos tecidos, prejudicando a cicatrização das úlceras (LEVIN, 1996).

A doença vascular periférica é quatro vezes mais provável de ocorrer em pessoas com diabetes do que na população em geral e sua incidência aumenta, gradualmente, com a idade e com a duração da doença, com desencadeamento precoce e rápida evolução (LEVIN, 2001). Esse processo aterosclerótico acelerado produz hipercoagulação e aumento da resistência vascular (FRITSCHI, 2001; LEVIN, 2001), precipitando a obstrução das artérias e arteríolas distais que, 
conseqüentemente, dificulta o fluxo sangüíneo. Inicialmente são obliteradas as pequenas artérias tibial e fíbular, na altura do joelho e tornozelo, que podem ser agravadas pelo tabagismo e dislipidemia (LEVIN, 2001).

Após trauma, pode surgir uma úlcera dolorosa essencialmente isquêmica ou neuroisquêmica, às vezes indolor, quando associada à insensibilidade. Os dedos podem tornar-se isquêmicos ou necrosados diante de trombose séptica, traumas, edemas leves ou infecções por comprometimento de arteríolas semi-ocluídas (PEDROSA et al., 1998; REIBER et al., 1998; SUMPIO, 2000). Podem-se identificar, nessa situação ainda, pulsos nas artérias dorsais do pé ou tibial posterior, mesmo em presença de isquemia nos dedos, pois nem sempre a doença dos grandes e pequenos vasos progride na mesma velocidade (LEVIN, 2001).

Em conseqüência da perda da sensibilidade protetora, devido à polineuropatia simétrica distal associada ao diabetes, podem adicionar-se a este quadro fatores de risco relacionados à biomecânica da marcha, causando/agravando a lesão/ulceração nos pés pelo trauma repetitivo.

Entre as alterações biomecânicas estão as relacionadas com o movimento do corpo, incluindo as forças verticais, horizontais e de acomodação. Na avaliação da biomecânica corporal, destacam-se a força reação do solo e a distribuição da pressão plantar que ocorreu durante a fase de apoio (AMADIO; SACCO, 1999). Qualquer limitação, na extensão do movimento das articulações do pé, interrompe a mecânica da marcha, o que leva a pessoa a desenvolver um passo disfuncional o qual, certamente, produzirá um dano estrutural maior no pé (SUMPIO, 2000).

Nas pessoas com neuropatia periférica, as deformidades ósseas desenvolvidas nas cabeças metatarsianas dos pés e no antepé representam áreas de excessiva pressão durante a fase de propulsão do calcâneo e de apoio plantar no ciclo da marcha (SUMPIO, 2000). Isso porque, quando o calcâneo se eleva do chão, transfere-se o peso do corpo para o antepé e dedos. Assim, a força de pressão gerada depende da velocidade na marcha, ou seja, quanto maior a velocidade, maiores serão a força de reação e a pressão.

Normalmente, a região plantar é protegida por um coxim adiposo, o qual dissipa as forças do peso por todas as direções. Deslocamentos ou atrofias nesses coxins, em conseqüência da neuropatia motora e autonômica, provocarão aumento da pressão nessa área, principalmente sob as cabeças metatarsianas com deformidade rígida, elevando a pressão nessa região (SUMPIO, 2000). 
A estrutura e a função do coxim adiposo também podem estar comprometidas em conseqüência de disfunção metabólica do diabetes. O estado hiperglicêmico pode levar à glicosilação protéica não-enzimática, com redução da elasticidade tecidual e enrijecimento articular que alteram a biomecânica da marcha (CAVANAGH et al., 2002).

Dessa forma, se a magnitude de forças for suficientemente elevada em uma região plantar, a ocorrência de qualquer perda de pele ou hipertrofia do estrato córneo (calos) aumentará o risco de ulceração por duas ordens de magnitude (SUMPIO, 2000).

O risco de ulceração é proporcional ao número de fatores de risco, em pessoas com diagnóstico de neuropatia periférica esse risco está aumentado em duas vezes, elevando-se para 12 vezes nas pessoas com neuropatia e limitação da mobilidade articular ou deformidade nos pés e, para 36, na pessoa com neuropatia, deformidade e úlcera ou amputação prévia, quando comparados a pessoas sem fatores de risco (ARMSTRONG; HARKLESS, 1998).

\section{2- Medidas preventivas}

Estudos vêm ressaltando a necessidade de os profissionais de saúde avaliarem os pés das pessoas com diabetes, de forma minuciosa e com freqüência regular, bem como desenvolverem atividades educativas, visando a melhorar seu autocuidado, destacando a manutenção de um bom controle glicêmico (BILD et al., 1989; LEVIN, 1996; BOULTON, 1998; MAYFIELD et al., 1998; PEDROSA et al., 1998; SPOLLETT, 1998; MASON et al., 1999; FRITSCHI, 2001; ADA, 2004).

A avaliação dos pés é um componente essencial na identificação de fatores modificáveis que poderão reduzir o risco de ulceração e amputação de membros inferiores nas pessoas com diabetes (MAYFIELD et al., 1998).

Uma das mais importantes alterações a ser identificada nos pés é a diminuição ou ausência da sensibilidade protetora plantar, caracterizada pela redução da sensação dolorosa conseqüente ao trauma na pele (HARRIS et al., 1993; CAPUTO et al., 1994; KUMAR et al., 1994; YOUNG et al., 1994; McNEELY et al., 1995; LITZELMAN et al., 1997; LAVERY et al., 1998; WUNDERLICH et al., 1998; GROSS et al., 1999; SOSENKO et al., 1999; PHAN et al., 2000; ZAVALA; BRAVER, 2000; DAHMEN et al., 2001). 
A perda dessa sensibilidade protetora constitui um dos principais sinais de futuros processos ulcerativos nos pés das pessoas com diabetes. Essa alteração pode ser identificada, utilizando vários tipos de instrumentos, desde os mais sofisticados até os mais simples.

Entretanto, apenas dois instrumentos têm demonstrado maior precisão em estudos prospectivos, principalmente quando utilizados de forma associada. Assim, o teste com Monofilamento Semmes-Weistein (SW) 5.07 e o Biotensiômetro (VPT) apresentam-se como os melhores preditores de processos ulcerativos, atingindo uma sensibilidade de $100 \%$ e uma especificidade de 77\% (ARMSTRONG, 1999).

O monofilamento SW é um instrumento manual composto por um fio de nylon que pesa 10 gramas, o qual se aplica na sola do pé, conservando um ângulo de 90 graus (SOSENKO et al., 1999), mediante a técnica de resposta sim-não ao toque do aparelho em dez regiões do pé (primeiro, terceiro e quinto dígitos plantar; primeira, terceira e quinta cabeça dos metatarsos plantar; lateral esquerda e direita do meio plantar; calcâneo e dorso entre primeiro e segundo dedos). A técnica instrui a pessoa a dizer sim, a cada vez que perceber a aplicação do fio. A inabilidade para perceber o monofilamento SW em quatro pontos ou mais é indicativa de perda da sensibilidade protetora (COLLIER; BRODBECK, 1993, YOUNG et al., 1994; WUNDERLICH et al., 1998; ARMSTRONG, 1999; SOSENKO et al., 1999).

O VPT é um dispositivo manual que contém um sensor que vibra a $100 \mathrm{~Hz}$ ao entrar em contato com a pele, conectado a uma unidade-base por meio de um cordão elétrico. Esta unidade possui uma escala linear expressa através de voltagens que oscilam entre 0 (zero) e 50 (cinqüenta) volts. O dispositivo, aplicado à polpa do hálux, começa a se balancear verticalmente e a voltagem vai aumentando na unidade-base até que a pessoa seja capaz de perceber a vibração (ARMSTRONG, 1999). O padrão de vibração considerado normal é menor que 25 volts e as voltagens com vibrações mais intensas ou iguais indicam comprometimento neuropático (YOUNG et al., 1994; FRYKBERG et al., 1998; ARMSTRONG, 1999; PHAM et al., 2000).

A segunda alteração considerada relevante na avaliação dos pés é a ausência parcial ou total do reflexo de Aquileu (McNEELY et al., 1995; ABBOTT et al., 1998 BOULTON, 2004), a qual também aparece como conseqüência da disfunção neuropática.

Esse reflexo pode ser avaliado ao colocar a pessoa ajoelhada sobre a margem de uma cadeira com respaldo alto, e o examinador por trás posicionará o pé em suave dorsiflexão, de modo a causar estiramento muscular, e percutirá o tendão (TANENBERG et al., 2002). 
Um terceiro aspecto a se considerar na avaliação é a alteração biomecânica ou osteoarticular dos pés (RICHARD, 1997; MAYFIELD et al., 1998; ADA, 2000; DAHMEN et al., 2001; CAVANAGH et al., 2002), a qual é decorrente da disfunção neuropática motora distal e produz deformidades nos pés (hálux valgo, dedos em garra, pé plano, pé cavo), expondo-os a uma distribuição anormal da pressão plantar em regiões, às vezes, não protegidas anatomicamente (RICHARD, 1997). Esta constante pressão contribui para o desenvolvimento de calosidades nas pessoas com diabetes (COLLIER; BRODBECK, 1993) e, paralelamente, pode atuar como feedback positivo, no sentido de acentuar/agravar as calosidades (CAVANAGH et al., 2002).

Altas pressões em pontos ósseos na região plantar, associadas a calosidades, são grandes preditores de úlceras (VEVES et al., 1992; COLLIER; BRODBECK, 1993; MURRAY et al., 1996; STESS et al., 1997; FRYKBERG et al., 1998; LAVERY et al., 1998; AHRONI et al., 1999; PHAM et al., 2000), por isso, é necessário determinar os locais específicos da hiperpressão, para implementar atividades de prevenção e controle.

Vários modelos de sistemas comercialmente disponíveis vêm sendo utilizados para esse fim (sistema de impressão de Harris-Beath, Pedobarografia, sistema F-scan, sistema EMED-SF, Mikro EMED, Pedar, sistema Paromed, sistema Ormes, sistema COSINOS EDV, sistema Pedcad, sistema HALM, sistema Scram-Mel-Card, Planscan platform, dentre outros), considerando diferentes tipos de sensores que quantificam a pressão plantar (AMADIO; SACCO, 1999; BOULTON, 2004). Métodos semiquantitativos também são propostos, como uma alternativa mais simples para o dia-a-dia, e dentre eles destaca-se o Podotrack footprint system que quantifica a pressão plantar por meio da observação da intensidade da impressão cinzenta em uma papeleta (BOULTON, 2004). Porém, o mecanismo para medir a pressão plantar ainda não está bem definido, havendo necessidade de maiores pesquisas a respeito (AHRONI et al., 1999; CAVANAGH et al., 2002). Contudo, um exame clínico que inclua avaliação de calosidades na região plantar, por meio de simples inspeção e palpação, pode ser outra prática alternativa (YOUNG et al., 1992; RICHARD, 1997), devendo-se levar em conta outros fatores que contribuem com o aumento da pressão plantar (CAVANAGH et al., 2002).

Autores identificaram que a média da pressão plantar entre os diferentes pontos avaliados foi mais elevada entre pessoas diabéticas com problemas neuroisquêmicos, quando comparadas àquelas somente com neuropatia. No estudo, destacou-se que os primeiros possuem calosidades em menor quantidade, fato que pode estar relacionado à baixa supressão de sangue nos membros 
inferiores, o que levou os autores a concluir que o aumento da pressão plantar em diabéticos isquêmicos, incluídos os neuroisquêmicos, nem sempre está associado a futuros processos ulcerativos na região plantar, demonstrando que existem diferentes mecanismos para a formação das úlceras, tanto em pés neuroisquêmicos, como nos neuropáticos (PITEL et al., 1999).

A elevação da pressão plantar também está associada à limitação da mobilidade articular (FERNANDO et al., 1991; BIRKE et al., 1995; LAVERY et al., 1998; PHAM et al., 2000; CAVANAGH et al., 2002). Portanto, esse aspecto é a quarta alteração a ser identificada na avaliação dos pés e dentre eles se destacam o metatarsofalagiano, subtalar e tornozelo.

O movimento da articulação subtalar é de especial interesse, quando se trata de pés de pessoas com diabetes, pois qualquer redução na sua mobilidade poderá causar aumento da pressão plantar durante a marcha (FERNANDO et al., 1991), especialmente ao se considerar que sua função é absorver o impacto do calcâneo no chão, no momento do choque (DONATELLI, 1985). Se a essa condição associarem-se a postura e os movimentos instáveis, presentes em pessoas com diabetes (SIMONEAU et al., 1994; CORRIVEAU et al., 2000), o risco de sofrer qualquer prejuízo durante a marcha poderá elevar-se.

O fator essencial, entre limitação da mobilidade articular do pé e deformidade que levam à ulceração, parece estar associado à pressão plantar elevada e à neuropatia periférica. Altas pressões de forma isolada não desencadeiam processos ulcerativos, pois para sua ocorrência é necessária a co-existência de neuropatia. Dessa forma, a limitação da mobilidade articular constitui-se no maior fator de alta pressão plantar e pode contribuir para o desencadeamento de ulceração em pés susceptíveis de neuropatia, nos quais a insensibilidade periférica e microangiopatia, quando associadas, representam fatores permissivos (FERNANDO et al., 1991).

Para avaliar a articulação subtalar, inicialmente coloca-se a pessoa em supino, deixando a articulação em postura neutra; a seguir, traçar uma linha vertical do calcâneo até o meio da panturrilha e, com ajuda de um goniômetro especializado, procede-se à realização de movimentos passivos de inversão e eversão máxima do pé (FERNANDO et al., 1991).

Quanto à articulação metatarsofalagiana, esta pode ser avaliada por meio da dorsiflexão do hálux, mensurada com goniômetro simples, em uma amplitude de 50 graus. Reduções extremas da dorsiflexão do hálux em pessoas com diabetes e neuropatia elevam a pressão sob o dedo e podem desencadear úlceras (CAVANAGH et al., 2002). 
O quinto aspecto a considerar na avaliação dos pés compreende a doença vascular periférica, a qual deve incluir a palpação dos pulsos periféricos, além de um interrogatório sobre história de claudicação (SPOLLETT, 1998; ADA, 2000; ZAVALA; BRAVER, 2000; ADA, 2001; FRITSCHI, 2001).

$\mathrm{Na}$ avaliação vascular periférica, o profissional deve interrogar a pessoa com diabetes sobre claudicação intermitente, dor ao repouso ou durante a noite (SPOLLET, 1998). A dor de claudicação aparece durante a marcha e cessa assim que esta termina. Sua gravidade depende da distância percorrida e da região afetada, tendo pior prognóstico quando aparece em caminhadas curtas e em regiões mais distais aos pés (ZAVALA; BRAVER, 2000). Além desses, outros sinais isquêmicos podem estar presentes, tais como rubor de declive, palidez com a elevação da perna; espessamento de unhas, pele atrofiada, fria e reluzente e diminuição de pêlos no dorso das extremidades (SPOLLET, 1998).

$\mathrm{Na}$ palpação dos pulsos, considera-se o tibial posterior e o pedioso que podem ser classificados em palpáveis ou não. Caso se identifique pulso diminuído ou ausente, é aconselhada uma segunda avaliação por um outro profissional (FRITSCHI, 2001). Para confirmar comprometimento arterial, indica-se a mensuração do índice da pressão braquial-tornozelo (ABI) com o Doppler, o qual relaciona o fluxo sangüíneo do membro superior com o inferior (FRITSCHI, 2001). O valor normal deve ser igual a um (1), sendo que valores entre $0,5-0,9$ determinam presença de isquemia clínica. Entretanto, esses resultados devem ser considerados com precaução, devido à possibilidade dos mesmos estarem falsamente elevados pela calcificação das artérias (EMANUELE et al., 1981).

Antecedentes de úlcera e amputação constituem o sexto aspecto a considerar na avaliação dos pés. Essas informações são relevantes e devem ser julgadas como fatores de alto risco nas pessoas com diabetes (BILD et al., 1989; PEDROSA et al., 1998; ADA, 2001; FRITSCHI, 2001), exigindo a adoção de todas as intervenções possíveis de prevenção, a fim de garantir um adequado cuidado co os problemas apresentados.

Entre essas intervenções, salienta-se o uso constante de calçados apropriados de acordo com a necessidade de cada pessoa, os quais desempenham um papel fundamental na etiologia da lesão/ulceração, principalmente daquelas que aparecem no dorso dos pés (CAVANAGH et al., 2002). 
Pontos de alta pressão, calosidades, deformidades nos pés, amputação de dedos, ou mesmo transmetatarsianos são problemas que podem ser corrigidos com calçados confortáveis ou confeccionados sob medida e coadjuvado com palmilhas (UCCIOLI et al., 1995; LEVIN, 1996; LAVERY et al., 1997; MUELLER et al., 1997; MAYFIELD et al., 1998; ADA, 2001; FAGLIA et al., 2001; FRITSCHI, 2001; CAVANAGH et al., 2002).

Estudo prospectivo, realizado pelo King's College em Londres, mostrou uma recorrência de $83 \%$ de úlceras entre pessoas com diabetes que usaram calçados convencionais e $27 \%$ naquelas com calçados especialmente confeccionados (EDMONDS et al., 1986). Um outro estudo, realizado em hospital de ensino para avaliar pessoas com diabetes de alto risco, identificou, também, menor recorrência de úlceras no grupo que recebeu calçados especialmente confeccionados (UCCIOLI et al., 1995). Faglia et al. (2001) mostraram também menor recorrência de úlceras e amputações, naquelas pessoas que usaram calçados terapêuticos e receberam intenso treinamento educativo.

Em contrapartida, ensaio clínico randomizado (REIBER et al., 2002) não apresentou diferença significativa quanto à recorrência de úlceras em pessoas que utilizaram calçados terapêuticos, comparando dois tipos de solados e aqueles que continuaram a utilizar calçados convencionais. Porém, o estudo destacou que calçados especiais podem ser benéficos a pacientes que não dispõem de assistência especializada dos pés e àqueles com deformidades graves nessa mesma região.

Dessa forma, pessoas com diabetes devem ser aconselhadas a utilizar calçados apropriados que se ajustem à anatomia de seus pés. Quando identificada neuropatia, mesmo sem presença de deformidades estruturais, recomenda-se uso de palmilhas, para reduzir e amortecer o efeito da tensão repetitiva. Entretanto, indicam-se calçados especiais conforme avaliação dos peritos, quando há deformidades (COLEMAN, 2002; FRITSCHI, 2001).

Dahmen et al. (2001) sugerem quais características devem ser consideradas nos calçados terapêuticos, mediante o desenvolvimento de um algoritmo. Enfatizam que a palmilha, unicamente, influencia na distribuição da pressão, visto que a redução da fricção exigiria uma ótima fixação dos pés aos calçados.

Outras intervenções, destacadas como meio importante de prevenção, são as ações educativas para o autocuidado, principalmente, as direcionadas ao exame e cuidado dos pés e calçados (BILD et al., 1989; LEVIN, 1996; GROSSI, 1998; PEDROSA et al., 1998; SPOLLETT, 
1998; ADA, 2000; FRITSCHI, 2001) e o controle glicêmico apropriado (GASTER; HIRSCH, 1998; O'CONNOR; SPANN; WOOLF, 1998; CULLETON, 1999; HERMAN, 1999; CLARK, 2001; ADA, 2004).

A educação objetiva sensibilizar, motivar e mudar atitudes das pessoas com diabetes, as quais devem incorporar a informação recebida ao seu dia-a-dia (PEDROSA et al. 1998), para reduzir o risco de ferimento, úlcera e infecção nos seus pés (SPOLLET, 1998).

Entretanto, revisões prévias sobre educação com esse propósito identificaram evidências inconsistentes em ensaios clínicos randomizados (MASON et al., 1999; VALK; KRIEGSMAN; ASSENDELFT et al., 2002). É possível que o cuidado regular oferecido por equipes bem estruturadas e encaminhamento precoce para equipes especializadas, na ocorrência de sinais de úlcera, contribuam substancialmente na redução de úlcera (MASON et al., 1999). E que a educação apenas seja eficiente em grupos de alto risco (VALK; KRIEGSMAN; ASSENDELFT et al., 2002).

Porém, é necessário considerar outros componentes que podem interferir nas habilidades de autocuidado dos pés, tais como acuidade visual, obesidade, mobilidade limitada e os problemas cognitivos (MAYFIELD et al., 1998), incluindo as condições socioeconômicas que, somadas às outras, podem determinar o estilo e a qualidade de vida das pessoas com DM (ZAVALA; BRAVER, 2000).

Quanto ao controle glicêmico ou metabólico, estudos referem que um controle pobre aumenta o risco de neuropatia e, conseqüentemente, de amputação entre pessoas com diabetes (NELSON et al., 1988; MASER et al. 1989; MOSS et al., 1992; LEE et al., 1993; SELBY; ZHANG, 1995; LEHTO et al., 1996).

Nesse sentido, o Wisconsin Epidemiologic Study of Diabetic Retinopathy - WESDE (KLEIN, 1996), sobre a incidência e progressão da retinopatia diabética e outras complicações associadas ao diabetes de longa duração, demonstrou que existe relação entre hiperglicemia e incidência de amputação em extremidades inferiores. Esta incidência atingiu 5,4\% de sua população com diabetes tipo 1 e 7,3\% no tipo 2 em um período de 10 anos.

O Diabetes Control and Complications Trial - DCCT (1995), ensaio clínico multicêntrico randomizado, realizado entre pessoas com diabetes tipo 1, durante um período de cinco anos, demonstrou que o controle metabólico mediante terapia intensiva com insulina de três ou mais injeções/infusões por dia, comparado com terapia convencional de duas injeções por dia, reduz 
substancialmente o risco de neuropatia em $64 \%$. A redução foi confirmada mediante exames clínicos e laboratoriais, incluindo sintomas, déficit sensorial, diminuição dos reflexos de tendões profundos e anormalidades na condução nervosa e no sistema nervoso autonômico.

Outro ensaio randomizado realizado pela Universidade de Kumamoto (OHKUBO et al., 1995) entre pessoas com diabetes tipo 2, durante um período de seis anos, mostrou também que o controle glicêmico, mediante terapia intensiva com insulina de três a quatro injeções por dia, conforme monitorização da glicemia, comparado com terapia convencional de duas injeções por dia, pode retardar o início e a progressão das complicações microvasculares, tais como retinopatia, nefropatia e neuropatia.

O mais recente, United Kingdom Prospective Diabetes Study - UKPDS (1998), que recrutou mais de 3.800 pessoas com diagnóstico recente de diabetes tipo 2, as quais foram acompanhadas durante um período de 10 anos, identificou que as complicações microvasculares são beneficiadas com redução dos níveis de glicemia mediante terapia intensiva (insulina ou sulfonilureas ou metformina), atingindo valores médios de $\mathrm{HbA}_{1 \mathrm{c}}$ de $7,0 \%$ comparado à terapia convencional (dieta) de 7,9\%. A proporção total de redução dessas complicações foi de $25 \%$ e, a cada porcentual de ponto diminuído, houve $35 \%$ de redução do risco.

Destaca-se que, nesse ensaio, foram realizadas crossing-over e combinações de tratamentos entre os diversos grupos alocados, quando o participante apresentava hiperglicemia marcante ou recorrente. Entretanto, seus resultados foram condizentes com os obtidos pelo DCCT (1993), quanto ao desenvolvimento e progressão de complicações crônicas.

Dessa forma, os achados anteriores são reiterados pela ADA (2004), ao referir-se que a manutenção dos valores glicêmicos mais próxima do normal com tratamento intensivo é melhor do que com tratamento convencional.

Verificam-se, portanto, evidências consistentes mostrando que os níveis glicêmicos, mantidos o mais próximo dos padrões de normalidade, reduzem o risco de retinopatia, nefropatia e neuropatia nas pessoas com diabetes. Dessa forma, o controle glicêmico se constitui em uma das pedras angulares para retardar o desencadeamento e/ou controlar as doenças associadas ao DM de longa duração, com conseqüente melhora da qualidade de vida.

A manutenção do controle glicêmico e, a conseqüente melhora nas condições de vida da pessoa com diabetes representam a grande meta no cuidado da doença. No entanto, constitui um grande desejo, não apenas para a pessoa e família, como também para o profissional, 
necessitando, portanto, da organização de um trabalho integrado, colaborativo e responsável para enfrentar os problemas reais e de risco advindos do diabetes e que acompanharão a pessoa ao longo do tempo.

Perante a situação exposta anteriormente, reforça-se a necessidade de consolidar um trabalho em equipe interdisciplinar de saúde, para gerenciar o cuidado da pessoa com diabetes, garantindo um fluxo contínuo nos diferentes níveis de atenção à saúde, principalmente no que se refere aos cuidados com os pés (BILD et al., 1989; KUMAR et al., 1994; CAPUTO et al., 1994; LEVIN, 1996; MASON et al., 1999).

Estudos prospectivos verificaram diminuição da incidência e recorrência de úlceras e amputações entre pessoas com diabetes, quando assistidas por equipe interdisciplinar (EDMONDS et al., 1986; LARSSON et al., 1995; RITH-NAJARIAN et al., 1998; ARMSTRONG; LAWRENCE; HARKLESS, 1998; DARGIS et al., 1999; CALLE-PASCUAL et al., 2002).

A equipe interdisciplinar deve atuar junto às pessoas com diabetes, identificando, precocemente, anormalidades nos pés, proporcionando educação contínua conforme necessidades individuais e oferecendo apoio na prevenção de úlcera e infecção nos membros inferiores, nas pessoas com fatores de risco.

Os programas educativos são destacados como fundamentais, em todos os níveis de prevenção e intervenção, assim como os cuidados com os pés, unhas e calosidades fornecidos pela equipe interdisciplinar. Esses cuidados devem ser oferecidos à pessoa com diabetes e aos familiares, mediante demonstrações e assistência propriamente dita, direcionando esforços entre pessoas que possuem limitações para realizar ações de autocuidado (idosas, obesas, acuidade visual diminuída, que vivem sós, dentre outras).

A equipe deve estar constituída, basicamente, por médico generalista, enfermeiro especialista/educador e podiatra*, os quais devem ter rápido acesso ao ortotista - para apoiar com o desenho apropriado de palmilhas e calçados, vascular radiologista - com facilidades para realizar angioplastias intra-arteriais não invasivas, cirurgião vascular - para reconstrução das artérias e cirurgião ortopedista - para realizar correções de anormalidades ortopédicas graves

\footnotetext{
* Diante da inexistência de profissionais especializados no Brasil, tais como quiropodistas e podiatras, com formação universitária, os cuidados quiropódicos/podiátricos básicos com as lesões podem ser efetuados em nível primário e secundário, por médicos generalistas, enfermeiros e diabetologistas previamente treinados (GTIPD, 2001).
} 
(EUROPEAN DIABETES ASSOCIATION; WHO, 1998; GRUPO DE TRABALHO INTERNACIONAL SOBRE PÉ DIABÉTICO - GTIPD, 2001).

Portanto, reforça-se a conformação de uma equipe interdisciplinar, prioritariamente no nível ambulatorial, capaz de detectar, precocemente, alterações neuropáticas e vasculares nas pessoas com diabetes e, assim, planejar intervenções de forma individualizada, centrada em suas necessidades e condizentes com a prevenção secundária no diabetes.

Reiterando a importância do tema, buscaram-se por meio da revisão sistemática, quais estratégias ou intervenções se apresentaram consistentes na prevenção de lesão/ulceração nos pés de pessoas com diabetes. estas estratégias/intervenções poderiam embasar a prática clínica. Por essa razão, consideraram-se no quadro teórico as normas envolvidas na prática baseada em evidências a qual será apresentada a seguir. 


\section{QUADRO TEÓRICO}

\section{1- Prática baseada em evidências}

A Prática Baseada em Evidências (PBE), associada à Medicina Baseada em Evidências (BEM), surgiu no Canadá e integrou-se ao Sistema de Nacional de Saúde do Reino Unido (MADIGAN, 1998). O movimento foi impulsionado pelo avanço científico e tecnológico da disponibilidade da informação, em conseqüência do aumento do número de pesquisas e da facilidade de sua divulgação e acesso por meio de bancos de dados informatizados (CALIRI, 2002). Os avanços da MBE estiveram associados à utilização de conhecimentos da área de epidemiologia, principalmente a Epidemiologia Clínica, que inclui métodos bem definidos para avaliação crítica do conhecimento existente e assim dar suporte às decisões profissionais.

O referencial da MBE apresentou-se na década de 1990, como uma "nova forma" de exercer a prática (assistencial e ensino), com base em evidências e não apenas em tradições, mitos e preferências do profissional. O movimento foi visto como um novo paradigma assistencial e pedagógico que, se usado apropriadamente, pode aumentar a qualidade da assistência e reduzir os custos dos serviços de saúde (CALIRI, 2002).

A MBE foi proposta e desenvolvida, inicialmente no Canadá, por um grupo de epidemiologistas das Faculdades de Ciências da Saúde da Universidade de McMaster (HamiltonOntario) na década de 1980, os quais estavam preocupados com a efetividade e eficiência da prática clínica, apontada pelas publicações científicas (SANTANA, 2004). Esses epidemiologistas estavam interessados em descobrir como analisar corretamente as provas relacionadas às evidências que sustentam a assistência e, no decorrer dos anos, conseguiram publicar vários artigos relacionados a este assunto na comunidade científica, os quais foram consolidando os princípios da MBE.

Assim, o referencial da MBE ganhou maior dimensão e se expandiu a outros países, incluindo o Reino Unido, onde se consolidou ao se estabelecer como Centro Cochrane em 1992, destinado a facilitar e a coordenar o preparo e a manutenção de revisões sistemáticas da literatura, meta-análises e recomendações para a prática clínica (CALIRI, 2002). 
O Serviço Nacional de Saúde do Reino Unido adotou o referencial da MBE como modelo para prestação de seus serviços de saúde, integrando tanto a assistência médica, quanto à de enfermagem, no propósito de assegurar, por meio dos recursos disponíveis, a maior melhoria possível da saúde física e psicológica de sua população, orientadas pela evidência do custo das intervenções e da efetividade clínica (COLYER; KAMATH, 1999).

$\mathrm{Na}$ América do Norte, o referencial da PBE foi incorporado pelas agências governamentais para criar diretrizes clínicas e nortear as políticas de assistência em diversas áreas, proporcionando direcionamentos aos profissionais da saúde sobre uma variedade de condições crônicas e agudas prevalentes no país (MADIGAN, 1998).

A Agência de Pesquisa e Políticas de Cuidados em Saúde (Agency for Health Care Policy and Research - AHCPR) cumpre um papel importante na elaboração e divulgação das diretrizes clínicas. Esta entidade pertence ao Instituto Nacional de Saúde, cuja missão é promover a pesquisa para melhorar a qualidade da saúde, reduzindo custos e ampliando o acesso aos serviços essenciais. Os programas da AHCPR advêm da pesquisa prática e das informações embasadas na ciência (MADIGAN, 1998).

Posteriormente, a AHCPR foi transformada em Agência para Pesquisa e Qualidade do Cuidado em Saúde (Agency for Healthcare Research and Quality - AHRQ), cujas diretrizes continuam levando em consideração as evidências oriundas de pesquisas, bem como do conhecimento de especialistas (GOODE, 2000; NATIVIO, 2000; JENNINGS; LOAN, 2001).

A PBE foi introduzida recentemente e focaliza um cuidado baseado na literatura mais recente e válida (OXMAN et al., 1993). Seu conceito deriva da MBE, que é definida como "o uso consciencioso, explícito e criterioso da melhor evidência atual para tomar decisões sobre o cuidado individualizado dos pacientes. A prática da MBE significa a integração da perícia clínica individual com a melhor evidência clínica externa disponível, proveniente de revisão sistemática" (SACKETT et al., 1996).

Closs e Cheater (1999) aclaram que o termo "uso criterioso da melhor evidência atual" nesta definição implica a necessidade de incorporar habilidade clínica e circunstâncias únicas no paciente como um componente integral da decisão da qualidade clínica. A essência da PBE é determinada pelo julgamento pessoal do pesquisador com relação aos objetivos, relevância, praticabilidade, limites e variáveis significativas associadas ao tema da pesquisa em particular (FRENCH, 1999). 
No Brasil, Mendes (1998) apresenta a MBE articulada com o "movimento por resultados", utilizando a definição descrita por Sackett et al. (1996). Para esse autor, a capacidade clínica advém da experiência na prática clínica; a evidência clínica externa é conseqüência das pesquisas básicas em medicina, mas, especialmente, sobre as pesquisas clínicas na precisão de diagnósticos, a potência dos prognósticos e a eficácia e segurança dos procedimentos preventivos, curativos e reabilitadores.

Para Drummond e Silva (1998), a MBE pode ser conceituada como um processo que diante de uma situação definida, clínica ou não procura responder aos quesitos elencados, por meio da pesquisa, orientada por critérios preestabelecidos de evidências de raciocínios e de dados, os quais embasarão suas ações, ou seja, seu produto final.

Atallah e Castro (1999) referem que a MBE não considera a prática fundamentada apenas na intuição, na experiência crítica não-sistematizada e nas teorias fisiopatológicas. Enfatizam uma análise acurada de métodos, por meio dos quais as informações médicas foram obtidas, dando especial valor ao delineamento da pesquisa, à condução e a análise estatística.

A PBE surgiu para representar, de modo comum, a todas as disciplinas dentro de uma equipe multiprofissional, na qual a ênfase não está apenas na prática médica, mas sim, nas intervenções de toda a equipe. Em tal sentido, Muir Gray ${ }^{*}$ (1997, apud CLOSS; CHEATER, 1999) define a PBE como uma abordagem de tomada de decisão, na qual os clínicos usam a melhor evidência disponível, em consulta com o paciente, para decidir sobre a melhor opção que se ajusta ao mesmo.

Closs e Cheater (1999) salientam que a combinação dessas duas definições (MBE e PBE) proporciona uma aproximação mais clara para a decisão da qualidade clínica, pois associa a utilização da melhor evidência atual, a experiência clínica do profissional e a preferência do paciente. O que pode contribuir para as decisões dos cuidados a serem realizados nessa abordagem, considerando que a experiência do paciente (família) pode ser fundamental, especialmente ao referir-se aos problemas de saúde de longa duração, como o diabetes, esquizofrenia e artrite reumatóide os quais, freqüentemente, acumulam considerável nível de habilidades sobre seu próprio cuidado.

\footnotetext{
* MUIR GRAY, J.A. Evidence-Based Healthcare: How to make health policy and management decisions. Edinburgh: Churchill Livingstone, 1997.
} 
A PBE enfatiza a utilização de parâmetros, para determinar as intervenções mais apropriadas a serem utilizadas, estabelecendo uma hierarquia de evidências. No ápice desta hierarquia, encontram-se os resultados de ensaios clínicos randomizados e controlados, representando a forma mais robusta e forte da evidência; seguido dos estudos de coorte e casocontrole (STOTTS, 1999).

Stetler et al. (1998) propuseram uma definição alternativa da PBE para a enfermagem, considerando que, nem sempre, os critérios de evidência levantados por esta se ajustam à natureza dos serviços da enfermagem. Destacam que a evidência é caracterizada por alguma coisa que fornece uma prova para se tomar uma decisão, integrando os resultados da pesquisa formal, bem como do consenso de peritos e profissionais especializados. No interior de uma organização, devem-se incluir, também, fatos ou dados relacionados às atividades e às operações para a melhoria da assistência, que sejam verificáveis e acreditáveis, coletados mediante métodos de pesquisa.

Em tal sentido, a PBE constitui a utilização dos achados nas pesquisas e, quando apropriados, da melhora da qualidade dos dados e da avaliação operacional dos mesmos, do consenso entre especialistas e da experiência clínica fundamentada na prática, ao invés de experiências isoladas e não sistemáticas, rituais e opiniões sem base (STETLER et al., 1998).

Para Driever (2002), a PBE envolve uma explícita e criteriosa tomada de decisão sobre a assistência prestada à saúde das pessoas ou grupo de pessoas, fundamentada no consenso da mais relevante evidência proveniente da teoria, derivada de pesquisas e informações de base de dados, que respondem às preferências do cliente e às expectativas sociais.

O conceito da $\mathrm{PBE}$ atribui significado importante à perícia clínica e ao contexto no qual o profissional está inserido, no propósito de minimizar o hiato entre teoria e prática. Ambos critérios desempenham um rol importante no processo de determinar quais pesquisas são relevantes (FRENCH, 1999).

A PBE exige do profissional a competência clínica desenvolvida na universidade e na prática assistencial, incluindo conhecimento atualizado de áreas como fisiologia, patologia e psiquiatria para determinar se os resultados das pesquisas são aplicáveis ao paciente ou não. Esta estratégia não substitui a perícia clínica, pelo contrário, a aumenta (STOTTS, 1999).

Rosswurn e Larrabee (1999) afirmam que a PBE poderá melhorar a qualidade do cuidado oferecido ao paciente e aumentar o julgamento clínico. Os profissionais da saúde devem saber 
como obter, interpretar e integrar as melhores evidências oriundas de pesquisas com os dados dos pacientes e as observações clínicas.

O resultado dessa abordagem faz diferença entre PBE e pesquisa tradicional; na primeira, o pesquisador deve manifestar aquilo que é específico para seu próprio contexto e não propor generalizações vagas sobre a relevância de seus achados para outros profissionais ou comunidade acadêmica. A acumulação de evidências identificadas por vários pesquisadores, pode levar a uma meta-análise e à subseqüente generalização dos achados para outros contextos da enfermagem (FRENCH, 1999).

Dessa forma, a PBE se constitui na interconexão sistemática de evidências generalizadas cientificamente com o conhecimento tácito de peritos para alcançar mudança em uma prática específica, em benefício de um determinado cliente ou grupo de pacientes (FRENCH, 1999).

Humphris (1999) destaca que a qualidade das evidências representa um aspecto crucial na PBE, o profissional de enfermagem deve ser capaz de fazer julgamentos reconhecendo o bom e o ruim, saber as forças e fraquezas para poder generalizar a evidência, avaliar e utilizá-la criticamente, não tomá-la com absoluta confiança.

Para avaliar a qualidade das evidências, o profissional de saúde deve conhecer e compreender a abordagem metodológica na qual a pesquisa está inserida (GALVÃO, 2002). Isto é essencial para a escolha da abordagem quantitativa ou qualitativa, a qual deve responder com propriedade à questão da pesquisa.

Questões de pesquisa direcionadas para a causa, prognóstico, diagnóstico, prevenção, tratamento ou custos, relacionadas com os problemas de saúde são respondidas de melhor forma utilizando abordagens quantitativas; questões sobre significado ou experiência de doença e compreensão dos sentimentos do paciente sobre os efeitos de uma intervenção são respondidas utilizando abordagens qualitativas (DICENSO; CULLUM, 1998; ROBERTS; DICENSO, 1999).

Nos termos da PBE, o entendimento da força e da fraqueza das diferentes abordagens de pesquisa é essencial. Portanto, o profissional deve ser capaz de ponderar os méritos dos vários tipos de evidência (CLOSS; CHEATER, 1999).

Dessa forma, Muir Gray (1997, apud CLOSS; CHEATER, 1999) apresenta a classificação da evidência hierarquizada em cinco níveis, organizada de forma decrescente conforme a força da evidência. Para esse autor, a evidência mais robusta está constituída pelo menos de uma revisão sistemática de múltiplos ensaios clínicos randomizados bem delineados (Nível I), os quais são 
apropriados para avaliar a efetividade das intervenções no cuidado da saúde. Porém, Closs e Cheater (1999) apontam que muitos aspectos da enfermagem não podem ser avaliados freqüentemente neste nível, mesmo porque aqueles que existem, ainda são insuficientes.

Continuando na classificação proposta por Muir Gray (1997, apud CLOSS; CHEATER, 1999), no segundo lugar dessa hierarquia localiza-se a evidência resultante de pelo menos um ensaio clínico randomizado, de apropriado tamanho e delineado com propriedade (Nível II). Evidência resultante de estudos bem delineados sem randomização, estudos de pré e pós-teste, coorte, série temporal ou caso-controle ocupam o terceiro lugar (Nível III). Evidência resultante de estudos não-experimentais bem delineados desde um centro de pesquisa ou grupo de pesquisa corresponde ao quarto lugar (Nível IV). Finalmente, localizam-se as opiniões de autoridades respeitáveis, baseadas em evidência clínica, estudos descritivos ou conclusões de comitês de especialistas (Nível V).

Note-se que pesquisas qualitativas não foram mencionadas nessa classificação, a menos que estudos descritivos incluam essa abordagem. Métodos qualitativos são particularmente valiosos explorando novos e complexos assuntos e desenvolvem teorias a partir de uma hipótese (CLOSS; CHEATER, 1999). Entretanto, alguns pesquisadores argumentam que os resultados das pesquisas qualitativas apenas são restritos aos sujeitos estudados e não podem ser generalizáveis, nem combináveis através da meta-análise; outros já acreditam que verdades generalizáveis podem ser extraídas de experiências individuais (SACKETT et al. 2003).

Stleter et al. (1998) também propuseram uma classificação das evidências hierarquizadas em seis níveis junto à qualificação dos estudos. A classificação constitui uma adaptação da AHRQ e inclui pesquisas de abordagem qualitativa.

Nessa hierarquização, os níveis de evidência representam os tipos de delineamentos utilizados em cada pesquisa (Nível de I - VI); cada nível de evidência, a sua vez (do Nível I a V), possui uma qualificação que vai desde $\mathrm{A}$ até $\mathrm{D}$, a qual reflete a credibilidade científica da pesquisa, ou seja, a propriedade e o controle de sua validade interna. Se o estudo for qualificado com "D" significa que o delineamento da pesquisa possui uma grande falha e seus resultados podem ser severamente questionados, portanto, o estudo não é confiável e deve ser automaticamente desconsiderado. Por outro lado, estudos qualificados com " $\mathrm{A}$ " demonstram uma validade interna apropriada e seus resultados podem recomendar-se com confiabilidade. 
Assim, as autoras (STETLER et al., 1998) colocam, também no Nível I, a metanálise de múltiplos estudos controlados, desenvolvidos na população-alvo ou em outras populações relevantes; no Nível II, encontra-se o estudo individual experimental desenvolvido na populaçãoalvo ou em outras populações relevantes; no Nível III, estão os estudos quase-experimentais tais como estudos com grupo único pré e pós-teste, coorte, série temporal ou caso-controle, desenvolvidos na população-alvo ou em outras populações relevantes; no Nível IV, localizam-se os estudos não-experimentais, tais como pesquisas descritivas comparativas e correlacionais, além de pesquisas qualitativas ou estudos de caso, desenvolvidas na população-alvo ou em outras populações relevantes; no Nível $\mathrm{V}$, incluem-se os estudos de avaliação de programas, utilização de pesquisas ou projetos de melhoramento da qualidade ou relatórios de casos; e no Nível VI, localizam-se as opiniões de respeitáveis autoridades ou opinião do comitê de especialistas, que inclui a interpretação de informações baseadas apenas na experiência.

O modelo de PBE proposta pelo Hospital Universitário do Colorado (GOODE, 2000) enfatiza que todos os tipos de pesquisas podem ser avaliados para determinar sua contribuição na evidência. Quando a efetividade de um medicamento é testada, o ensaio clínico randomizado pode ser apropriado para determinar se a droga é eficaz e segura, entretanto, quando é necessário determinar a responsabilidade e os fatores estressantes dos cuidadores de crianças incapacitadas, o estudo descritivo pode ser mais apropriado.

Limitar a validade das pesquisas apenas a ensaios controlados randomizados pode impelir aos enfermeiros embasar sua prática na intuição, no hábito, em ensaios e erros, pois muitos problemas enfrentados pela enfermagem não podem ser testados com ensaios clínicos randomizados. Desse modo, a utilização de pesquisas experimentais, não-experimentais e qualitativas é necessária (GOODE, 2000).

Closs e Cheater (1999) destacaram que, em alguns casos, estudos denominados como "fracos" produzem evidência mais convincente que aqueles derivados de ensaios clínicos. Delineamentos quase experimentais ou não-experimentais são menos controlados, porém com freqüência prestam mais atenção ao contexto onde o estudo foi desenvolvido, e esta situação pode ser crucial na interpretação dos desfechos nas pesquisas.

Ensaios clínicos randomizados, certamente, informam sobre a eficácia das intervenções na população estudada, porém, não são capazes de explorar, nem de esclarecer, as barreiras do 
paciente para concordar com a intervenção, ou como esse tratamento afeta sua vida, ou mesmo qual o significado da doença para ele (DICENSO; COLLUM, 1998).

Portanto, cada delineamento de pesquisa tem sua finalidade, forças e limitações; o importante é assegurar que o delineamento seja apropriado para responder à questão formulada na pesquisa (DICENSO; CULLUM, 1998).

Caliri e Marziale (2000) apontaram que a PBE tem recebido atenção por parte dos pesquisadores, educadores e enfermeiros da assistência no âmbito internacional. As autoras direcionam várias fontes de informações que podem ser adquiridas on-line, especialmente, no que se refere a protocolos de atenção com base na PBE, os quais poderiam facilitar o trabalho de enfermeiros pesquisadores e educadores ou daqueles que apenas buscam melhorar a prática diária.

Estudos vêm sendo realizados a nível internacional, na enfermagem, abordando a PBE em diversos aspectos do cuidado à saúde (JOHNSON, 2000; NATIVIO, 2000; SOUKUP, 2000; ROSSWURM; LARRABEE, 1999; FRENCH, 1999; STOTTTS, 1999), indicando que os enfermeiros estão preocupados com a qualidade de sua assistência e sua capacitação para responder, com critério, às necessidades dos pacientes, quanto aos problemas que possam apresentar e quais seriam os riscos e benefícios que poderiam acarretar, caso se submetam a alguma intervenção clínica ou cirúrgica, em qualquer ambiente de cuidado à saúde, ou mesmo no meio familiar.

Dessa forma, salienta-se a relevância dessa abordagem para a assistência da pessoa com DM e também para o Sistema de Saúde Brasileiro. Entendendo que a enfermagem, ainda na construção de seu corpo de conhecimentos, precisa reforçar sua sapiência e promover a utilização dos resultados de suas pesquisas, especialmente considerando a responsabilidade de oferecer à pessoa adoecida um cuidado seguro, fundamentado em evidências externas, identificadas no contexto real e correlacionado-as com a literatura científica atualizada.

A necessidade é relevante, ao considerar que a enfermagem tem-se dedicado, por bastante tempo, à compreensão das circunstâncias emocionais das pessoas, em relação aos fatos que acometem sua saúde. Nesse sentido, o seu acervo de pesquisas inclui, majoritariamente, estudos qualitativos e descritivos, com poucos desenhos de intervenção. Esses últimos ajudam a determinar quais intervenções mostraram-se efetivas, quanto à prevenção de complicações em membros inferiores, para evitar o desenvolvimento de úlcera e/ou amputação, caso não fossem instituídas medidas apropriadas de cuidado e rastreamento. Assim, pretende-se contribuir com a 
promoção do conhecimento científico na área de interesse, para fortalecer a enfermagem, em prol da melhor assistência às pessoas com diabetes.

Caliri e Marziale (2000) referiram que a assistência de enfermagem no Brasil pouco tem mudado no decorrer da história, devido a grande parte dos profissionais que embasam sua assistência em rituais, tradições ou conhecimento comum, apesar dos avanços na formação profissional, no crescente número de pós-graduandos e pesquisadores e nos inúmeros artigos publicados. Demonstrando que o conhecimento científico produzido nas diversas especialidades, pouco se tem revertido à prática, bem como pouco tem ajudado aos profissionais de enfermagem a desenvolver pensamento crítico e maiores habilidades.

Para isso é fundamental conhecer e entender as contribuições que as pesquisas podem trazer ao conhecimento da enfermagem, no sentido de melhorar a qualidade da assistência clínica e comunitária. Dessa forma, a PBE propõe o câmbio no contexto da prática, embasado nas melhores evidências identificadas nas pesquisas, junto à produção e à disseminação do conhecimento.

A seguir, descreve-se o processo de elaboração de uma revisão sistemática que constitui o principal recurso para sintetizar, com propriedade, as melhores evidências a respeito de um tópico específico, considerando o rápido acúmulo do volume da literatura na área da saúde e o tempo limitado dos profissionais, para acompanhar a quantidade e variedade das informações disponíveis.

Posteriormente, também é descrita a importância desse recurso, na elaboração das diretrizes clínicas (guidelines), destacando suas etapas, dificuldades e limitações que sua implantação pode acarretar nos serviços de assistência à saúde, além dos critérios que devem ser considerados ao avaliar a consistência de uma diretriz clínica.

\subsection{1- Revisão sistemática}

Em 1995, um grupo de vinte cientistas de nove países, congregados em Potsdam, Alemanha, definiu a revisão sistemática como a aplicação de estratégias científicas que limitem o viés de seleção de artigos, avaliem com espírito crítico os artigos e sintetizem todos os estudos relevantes em um tópico específico (PERISSÉ; GOMES; NOGUEIRA, 2001).

Para Cook, Mulrow e Haynes (1997), a revisão sistemática constitui uma investigação científica, com métodos planejados antecipadamente, que integra estudos originais, bem como 
seus "sujeitos". Nela se sintetizam os resultados de múltiplas investigações primárias, usando estratégias que restringem os vieses e os erros aleatórios. As estratégias incluem uma busca abrangente de todos os artigos potencialmente relevantes e uso explícito de critérios reproduzíveis na seleção dos artigos. Na revisão, o delineamento e características dos estudos são avaliados, os dados sintetizados e os resultados interpretados.

Coutinho (2003) destacou que a utilização de uma metodologia claramente definida na revisão sistemática permitirá minimizar os erros nas conclusões. Portanto, as estratégias de identificação dos estudos, os critérios de inclusão e exclusão e as variáveis a serem consideradas devem ser explicitados na metodologia; isto é importante para que o estudo possa ser reproduzido por outros pesquisadores.

Para a Cochrane Collaboration, a revisão sistemática constitui uma revisão abrangente, direcionada para identificar e sintetizar toda a literatura relacionada com um tópico (algumas vezes chamada de overview). A unidade de análise é o estudo primário e este deve ser submetido a um princípio científico rigoroso, sendo que todos os estudos devem avaliar-se da mesma forma (MCKINNELL; ELLIOTT, 1998).

Quando os resultados dos estudos são resumidos sem realizar uma combinação estatística, a revisão pode ser chamada de revisão sistemática qualitativa. A revisão sistemática quantitativa, ou meta-análise, constitui uma revisão que faz uso de métodos estatísticos para combinar os resultados de dois ou mais estudos. O termo overview, algumas vezes, é utilizado para nomear uma revisão sistemática, quer qualitativa ou quantitativa. Pesquisas sumárias que carecem da descrição explícita da metodologia utilizado na revisão, em geral, denominam-se revisão narrativa (COOK; MULROW; HAYNES, 1997).

Conforme Atallah e Castro (1999), a revisão sistemática constitui um método moderno para avaliar um conjunto de dados simultaneamente. O método pode ser aplicado na área da medicina ou da biologia, porém, é freqüentemente utilizada para se obter prova científica de intervenções na saúde.

Na enfermagem, Maloney e Maggs (1999) ressaltam a importância da revisão sistemática, para identificar os efeitos benéficos e nocivos de diferentes intervenções da prática assistencial; pode ser útil para determinar lacunas no conhecimento da enfermagem e identificar as áreas que necessitam de futuras investigações. 
Ao identificar ausência de estudos suficientes para concretizar, por exemplo, o efeito de uma intervenção, a revisão sistemática sugere a realização de estudos metodologicamente consistentes, que respondam de modo mais apropriado à questão formulada (ATALLAH; CASTRO, 1999; PERISSÈ; GOMES; NOGUEIRA, 2001).

Uma revisão sistemática permite avaliar se os possíveis benefícios encontrados são importantes o suficiente, para contrabalançar os possíveis danos e custos para o paciente ou para o sistema público de saúde (PERISSÉ; GOMES; NOGUEIRA, 2001).

A revisão sistemática pode minimizar algumas barreiras para a utilização de resultados de pesquisas na prática assistencial. Segundo Ciliska, Cullum e Marks (2001), o enfermeiro tem mostrado dificuldades para se apropriar desses resultados, devido ao tempo reduzido de que dispõe, a falhas na busca e as habilidades limitadas para avaliar e sintetizar as pesquisas.

As características-chaves da revisão sistemática são: 1) título e objetivos descritos com clareza; 2) estratégia da busca de estudos abrangentes, direcionados ao objetivo da revisão estudos relevantes, incluindo os publicados e não publicados; 3) critérios explícitos que justifiquem a inclusão ou exclusão de qualquer estudo; 4) lista abrangente de todos os estudos identificados; 5) apresentação clara das características de cada um dos estudos incluídos na análise da qualidade metodológica; 6) lista abrangente de todos os estudos excluídos, justificando a causa de sua exclusão; 7) análise clara dos resultados de todos os estudos elegíveis, utilizando síntese estatística dos dados (metanálise), quando apropriados e, se possível; 8) análise de sensibilidade dos dados sintetizados, quando apropriados; 9) relatório estruturado da revisão esclarecendo a meta, descrevendo materiais e métodos e se reportando aos resultados (MCKINNELL; ELLIOTT, 1998).

Para Stotts (1999), a elaboração da revisão sistemática compreende: 1) definição da questão; 2) identificação da necessidade de informação; 3) condução da busca da literatura; 4) avaliação crítica da literatura; 5) identificação da aplicabilidade clínica dos dados; 6) determinação da adaptabilidade dos dados à situação e 7) aplicação dos dados no paciente/situação, quando apropriados. A seguir, apresentam-se, de forma sucinta, as fases consideradas na elaboração de uma revisão sistemática, sendo que a maioria dos autores concorda em incluir seis fases básicas. 
Fase $\mathrm{n}^{0} 1$ : definição da questão ou formulação da pergunta

Perguntas mal focalizadas conduzem a decisões pouco claras e confusas acerca de que estudos convêm incluir na revisão e como resumir os dados (COUTINHO, 1998; OXMAN; CLARKE, 2001). A questão do estudo deve ser precisa e objetiva, em coerência biológica com o estado atual do conhecimento médico, além de utilidade, de modo geral, quanto à saúde (PERISSÉ; GOMES; NOGUEIRA, 2001).

$\mathrm{Na}$ questão, consideram-se três componentes fundamentais: uma questão bem definida deve explicar o tipo de pessoas (participantes), o tipo de intervenções ou de exposições e o tipo de resultados que são de interesse para a revisão (OXMAN; CLARKE, 2001; PERISSÉ; GOMES; NOGUEIRA, 2001). Magarey (2001) e Silva (1998) adicionam um elemento a mais na elaboração da questão: as intervenções comparativas ou alternativas.

Que tipo de participante? Com freqüência, resulta útil considerar dois aspectos no tipo de pessoas que são de interesse na revisão. Primeiro, devem-se definir as doenças ou condições que são de interesse, estabelecendo critérios que sejam suficientemente explícitos. Segundo, devem-se identificar a população e o âmbito de interesse, ou seja, deve-se decidir se há interesse em um grupo específico da população, em relação a fatores tais como idade, sexo, raça, nível educativo, local, dentre outros (OXMAN; CLARKE, 2001).

Que tipo de intervenções? Neste componente especificam-se as intervenções que são de interesse. Pode ser importante definir as intervenções com as quais serão comparadas, ou seja, o tipo do grupo-controle que será aceitável para a revisão, considerando se estas pessoas podem estar recebendo outras intervenções distintas ao placebo que poderiam interferir com a intervenção avaliada (OXMAN; CLARKE, 2001).

Que tipo de resultados? Uma questão bem definida deve especificar os resultados (outcomes) que sejam de interesse, de forma concreta. Evitando considerar dados que não são relevantes, porém, cuidando para não omitir dados importantes. Especificar, também, se dentro dos resultados se considerarão aqueles resultados que se apresentam combinados com outros (OXMAN; CLARKE, 2001).

Ao definir a questão, também se pode estabelecer o tipo de desenho dos estudos que serão pertinentes para respondê-la. Muitos consideram que ensaios clínicos randomizados controlados são uma condição sine qua non para tratar assuntos referentes à eficácia terapêutica. Outro aspecto importante a considerar nos desenhos dos estudos, desde o início, é descrever se os 
estudos que têm grupo-controle com placebo, tempo específico de seguimento e tipo de avaliação dos resultados serão revisados ou não (OXMAN; CLARKE, 2001). Considerando esses componentes, a questão conduz à especificação dos critérios que se utilizarão na segunda fase para selecionar os estudos.

Fase $n^{0} 2$ : identificação da necessidade de informação ou busca na literatura

Esta deve ser exaustiva e não enviesada, o que faz a diferença-chave entre revisão sistemática e revisão tradicional (OXMAN; CLARKE, 2001). Devem-se especificar os métodos usados para identificar os artigos, demonstrando que toda literatura importante foi incluída. Consideram-se fontes de busca as bases eletrônicas de dados, busca manual, referências bibliográficas de outros artigos e também dos próprios artigos primários; os livros, as dissertações de mestrado e doutorado; relatos governamentais; órgãos de registros de ensaios clínicos; consultas às agências financiadoras de ensaios e, finalmente, consulta direta aos especialistas de interesse (PERISSÉ; GOMES; NOGUEIRA, 2001). A busca manual ficará interrompida quando não forem mais achados estudos de interesse, em cinco anos consecutivos.

Os revisores devem controlar a lista de referências de todos os artigos relevantes identificados, incluindo referências de revisões sistemáticas publicadas anteriormente (OXMAN; CLARKE, 2001).

Bases eletrônicas importantes constituem a Cochrane LIbrary (CENTRAL/CCTR Central Cochrane Controllled Trial Register) da Cochrane Collaboration; MEDLINE da Index Medicus, publicado pela National Library Medicine; EMBASE da Excerpta Médica, publicada pela Elsevier; SCISEARCH (Science Citation Index) acessado pela ISI WEB SCIENCE. Outras bases podem ser acessadas tais como The Gale Directory of Online, Portable e Internet (OXMAN; CLARKE, 2001).

Denomina-se busca manual ao fato de examinar cada número de revista não indexada com leitura progressiva dos títulos, resumos e artigos, até ser possível determinar se contém, ou não, algum ensaio clínico controlado randomizado (RCT) ou ensaio clínico controlado (CCT). A Cochrane Collaboration tem criado uma estratégia de busca manual mundial de toda a literatura médica, a qual é registrada na Master List of Journals Being Searched e pode ser acessada na $<$ www.cochrane.org> (OXMAN; CLARKE, 2001).

Todas as estratégias de busca da literatura devem ser utilizadas, quando possível, para diminuir o chamado viés de publicação. Autores identificam este viés como a maior probabilidade 
de uma pesquisa ser publicada por apresentar resultados estatisticamente significativos e positivos, em detrimento daquelas com resultados não significativos ou nulos, o que não significa que sejam de baixa qualidade técnica, pelo contrário, existe tendência deles serem, ainda, de melhor qualidade.

Fase $n^{0} 3$ : condução da busca da literatura ou seleção dos artigos

A população dos estudos para conduzir a revisão sistemática constitui todos os artigos que abordam o tópico a ser investigado (GALVÃO, 2002). No protocolo da revisão, deve-se descrever o processo mediante o qual serão selecionados os artigos para sua inclusão no trabalho, explicitando as estratégias de busca; quanto mais rigoroso, maior possibilidade de reduzir os riscos de erro e de viés (OXMAN; CLARKE, 2001).

$\mathrm{Na}$ revisão sistemática, a exaustividade é mais importante que a precisão. Aumentar a exaustividade em, uma busca, implica reduzir sua precisão e identificar mais artigos não relevantes, porém, é necessário manter equilíbrio entre exaustividade e precisão. Uma estratégia da busca exaustiva se inicia utilizando termos múltiplos que descrevem a condição ou doença de interesse, combinando-a com o operador lógico "OR". Posteriormente, se pode reduzir a busca utilizando o operador lógico “AND” (OXMAN; CLARKE, 2001), além de outros necessários, combinando-os com os termos apropriados em cada base de dados.

Elementos considerados para a seleção dos estudos são: desenho do estudo, tamanho da amostra e o desfecho de interesse (PERISSÉ; GOMES; NOGUEIRA, 2001). A primeira etapa de revisão dos resultados da busca eletrônica implica a avaliação detalhada dos títulos e resumos, para determinar sua inclusão ou não, entre os potencialmente selecionados. Na segunda etapa, artigos duvidosos devem ser lidos na íntegra para determinar sua inclusão ou exclusão definitiva (OXMAN; CLARKE, 2001).

Fase $n^{\circ} 4$ : avaliação crítica da literatura

A utilidade de qualquer revisão sistemática depende, muito, da qualidade dos estudos incluídos nela (GALVÃO, 2002). Os fatores que justificam uma avaliação estão relacionados com a aplicabilidade dos resultados, validade dos estudos individuais e certas características do desenho que afetam a interpretação desses resultados (OXMAN; CLARKE, 2001).

$\mathrm{Na}$ revisão sistemática, a validez do estudo refere-se à capacidade de evitar os erros sistemáticos ou vieses, mediante o desenho e a realização do estudo. Diferenças na validez dos estudos incluídos podem explicar a variabilidade de seus resultados. Certamente, estudos mais 
rigorosos têm maior probabilidade de produzir resultados mais próximos da "verdade" ao contrário dos menos rigorosos que podem sobreestimar a eficácia da intervenção (OXMAN; CLARKE, 2001).

Nos erros sistemáticos ou vieses são considerados: viés de seleção - diferenças sistemáticas nos grupos, ao compará-los; viés de realização - diferenças sistemáticas na assistência proporcionada (contaminação e co-intervenção), independente da intervenção-objeto de estudo; viés de desgaste - diferenças sistemáticas nas perdas dos participantes e viés de detecção - diferenças sistemáticas na avaliação dos resultados (OXMAN; CLARKE, 2001).

Existem métodos para resumir a validez dos estudos. O método mais simples consiste em assinalar valores como "se cumpre", "não se cumpre" ou "é pouco claro" aos critérios, individualmente. Escalas e listagens de checklist também podem ser utilizadas. Porém, ainda não se dispõe de um instrumento "padrão-ouro" para determinar a validez "real" dos estudos (OXMAN; CLARKE, 2001).

Fase $n^{0}$ 5: Coleta dos dados

Uma vez selecionados os estudos a serem incluídos na revisão, os dados dos mesmos devem ser coletados por um processo que permita sua documentação rigorosa em um formulário eletrônico ou impresso. É possível ainda, nesta fase, verificar a elegibilidade dos estudos.

O formulário de coleta dos dados constitui uma ponte entre o que informaram os pesquisadores dos estudos primários e o que finalmente informa o revisor. O formulário serve para três funções importantes: primeiro, ele está diretamente relacionado com a questão formulada na revisão e com a avaliação planejada para os estudos selecionados; segundo, ele é um registro histórico das múltiplas decisões (câmbios de decisões) que ocorrem em todo o processo da revisão e terceiro, constitui o armazém dos dados, de onde surgirá a análise (OXMAN; CLARKE, 2001).

Nesta fase, as características dos estudos devem ser salientadas, agrupando a informação em: métodos, participantes, intervenções e medidas dos resultados. A informação sobre os participantes pode incluir detalhes relacionados ao âmbito do estudo, além dos critérios diagnósticos para a condição de interesse (OXMAN; CLARKE, 2001).

Perissé, Gomes e Nogueira (2001) salientam que esta fase pode estar sujeita ao erro de análise sistemático do pesquisador, devido à análise dos tópicos dos escores ser subjetiva, podendo ser influenciada, por exemplo, pelo conhecimento que o pesquisador tem sobre o assunto em questão, analisando, com isso, de forma parcial, artigos que cheguem a conclusões que 
estejam de acordo com seu pensamento. Uma forma apropriada para controlar este viés é dispondo de mais de um revisor, os quais devem manter-se cegos ao autor principal do estudo, à instituição que pertence e à revista que o publicou. Posteriormente, deve haver consenso entre revisores em relação à qualidade dos estudos.

Fase $n^{0}$ 6: Análise e síntese dos dados

A finalidade desta fase é sintetizar os dados resultantes de cada estudo para fornecer uma estimativa da eficácia da intervenção pesquisada. O principal a ser analisado nesta fase é o grau de concordância entre os estudos, ou seja, a homogeneidade, o que faz com que o resultado final da revisão tenha mais credibilidade. Agrupar resultados em que as diferenças entre eles não sejam apenas devidas ao acaso, pode ser complicado (PERISSÉ, GOMES, NOGUEIRA, 2001). De acordo com Evans (2001), a síntese dos dados pode ser realizada por meio de uma análise descritiva ou estatística.

A utilização de métodos estatísticos (meta-análise) é apropriada, quando os estudos apresentam a mesma questão de pesquisa, em população semelhante, a qual recebeu, também, uma intervenção semelhante e os resultados mensurados da mesma forma, utilizando o mesmo desenho metodológico (EVANS, 2001). Assim, os métodos estatísticos, quando usados, apropriadamente, proporcionam uma ferramenta potente para chegar a conclusões coerentes e ajudam a evitar erros de interpretação (OXMAN; CLARKE, 2001).

Quando os resultados diferem em um ou mais aspectos apontados por Evans (2001), será apropriado realizar uma análise descritiva (qualitativa), a qual sempre estará sujeita à introdução de viés. Oxman e Clarke (2001) referem que é fácil cometer o erro de comparar o número de estudos "positivos" com o número de "negativos". Isto é pouco confiável, devido a que um estudo considera-se "positivo" ou "negativo" dependendo de como os revisores interpretaram seus resultados. Certamente, a utilização de métodos estatísticos não garante que os resultados de uma revisão sejam válidos.

\subsection{2- Diretrizes clínicas}

As diretrizes clínicas constituem um método cada vez mais utilizado para orientar a conduta médica no contexto atual. São documentos desenvolvidos sistematicamente para auxiliar os profissionais e pacientes, na tomada de decisão sobre condições específicas de saúde, e podem 
influenciar, tanto no processo, como no resultado do cuidado ao paciente (Field; Lohr ${ }^{\dagger}$ 1990, apud TROWBRIDGE; WEINGARTEN, 2001).

Apesar de que o desenvolvimento das diretrizes e sua implementação tradicionalmente têm-se focalizado em garantir um cuidado padronizado ao paciente, existe uma ênfase crescente nos resultados e na segurança do mesmo (TROWBRIDGE; WEINGARTEN, 2001).

Potencialmente, as diretrizes clínicas têm grande impacto na segurança dos pacientes, pois podem facilitar, amplamente, a disseminação de práticas que diminuem, os erros médicos. Fato evidenciado na auditoria realizada em Connecticut nos registros de Medicaid, em que foi identificado que apenas $50 \%$ dos pacientes com infarto agudo de miocárdio receberam aspirina e beta-bloqueadores no dia de admissão, apesar da substancial evidência de que essa prática reduz a mortalidade. Outro estudo estimou que, anualmente, 3.500 infartos poderiam ter sido evitados e 4.300 vidas salvas, se os beta-bloqueadores fossem apropriadamente utilizados (TROWBRIDGE; WEINGARTEN, 2001).

Dessa forma, entende-se a importância da contribuição das diretrizes no cuidado aos pacientes, principalmente quando fundamentadas na $\mathrm{PBE}$, pois podem ajudar a melhorar a assistência e fortalecer a segurança dos mesmos, com uma correspondente diminuição dos erros na prática clínica.

A elaboração das diretrizes clínicas varia grandemente em termos de método e formato desenvolvido. Algumas consistem, relativamente, de uma declaração direta que resguarda uma prática clínica particular, outras compreendem um complexo algoritmo que requerem de múltiplas variáveis clínicas. Muitas diretrizes são desenvolvidas por especialistas e organismos de proteção que focalizam sua atenção na revisão sistemática conduzida rigorosamente. Outras, simplesmente, podem refletir o padrão do cuidado local (TROWBRIDGE; WEINGARTEN, 2001).

Especialistas examinam a literatura utilizando uma abordagem científica, no propósito de desenvolver diretrizes que focalizam uma doença, em particular, ou grupo de doenças relacionadas a seus respectivos tratamentos. Nas diretrizes, são propostas recomendações práticas, elaboradas por associações profissionais, instituições de saúde, equipes multidisciplinares e companhias seguradoras, as quais sintetizam as melhores evidências disponíveis, relacionadas a uma condição de saúde (BEYEA; NICOLL, 1998).

${ }^{\dagger}$ FIELD MJ, LOHR KN. (Eds). Clinical practice guidelines: directions for a new program. Washington, DC: Institute of Medicine National Academy Press, 1990. 
Historicamente, as diretrizes clínicas proporcionam um mecanismo para promover a PBE e uma passagem clara para buscar uma auditoria sistemática, a qual é alcançada em conseqüência da diretriz escrita, que documenta o "estado da ciência", com relação a uma doença em particular ou condição de tratamento (BENTON, 1999).

As diretrizes clínicas atuam como instrumentos de comunicação entre a comunidade científica, a qual produz e sintetiza o conhecimento embasado na pesquisa, e os profissionais clínicos e pacientes, os quais usam e tiram vantagens do melhor conhecimento sobre as diferentes modalidades de tratamento existentes, diante de uma determinada doença (BENTON, 1999).

De acordo com Thomas (1999), no desenvolvimento das diretrizes, intercalam-se quatro etapas. Na primeira etapa, orienta-se a busca de pesquisas utilizando estratégias que possibilitem a identificação das evidências que se relacionam com o tema a investigar; na segunda etapa, elaboram-se as diretrizes propriamente ditas, as quais se fundamentam nas evidências oriundas das pesquisas; no geral, são conformados pequenos grupos de trabalho envolvendo profissionais de diversas áreas. Na terceira etapa, as diretrizes clínicas são submetidas a teste entre profissionais que atuam na área, os quais avaliam a clareza, consistência interna e aceitabilidade das mesmas, podendo também ser aplicadas entre pacientes, para verificar sua praticabilidade. Isto é relevante para corroborar a utilidade das diretrizes na prática assistencial. Finalmente, na quarta etapa, realiza-se revisão periódica das diretrizes clínicas, a fim de adaptá-las a novos conhecimentos.

Para favorecer a incorporação das diretrizes na prática profissional, é importante considerar duas etapas cruciais: a disseminação e a implementação (THOMAS, 1999).

A primeira refere-se aos métodos empregados para difundir as diretrizes, permitindo que sejam acessíveis aos usuários potenciais. Estratégias de disseminação consistem na publicação em periódicos, envio das diretrizes ao público-alvo, incluindo profissionais e pacientes ou, mediante intervenções educativas. A segunda inclui as estratégias de implementação propriamente ditas, pois apenas a disseminação não garante mudanças na prática profissional (THOMAS, 1999).

Estratégias de implementação são essenciais para promover mudanças de comportamento entre usuários das diretrizes (profissionais e pacientes), considerando a existência de obstáculos, tanto de ordem estrutural (sobrecarga de trabalho ou falta de recursos financeiros), como atitudinal (aceitabilidade das diretrizes ou disponibilidade para mudanças), as quais dificultam a sua implantação eficaz na assistência (THOMAS, 1999). 
Entretanto, estudos sobre resultados de estratégias efetivas de implementação das diretrizes para avaliar sua aceitação entre profissionais são escassos (BENJAMIN; SCHNEIDER; HINCHEY, 1999).

Cabana et al. (1999) apontaram barreiras que dificultam a praticabilidade das diretrizes clínicas entre médicos, mediante uma revisão da literatura. Nos resultados, foram destacadas importantes barreiras que permeiam o processo de mudança, envolvendo o conhecimento, atitudes e condutas. Dentre as barreiras destacaram-se a falta de familiaridade, de conhecimento, de concordância com a precisão das diretrizes, de expectativa nos resultados, de auto-efetividade e de motivação. Outras constituíram as barreiras externas relacionadas com o paciente (como inabilidade para conciliar as preferências do mesmo com as recomendações), os fatores que envolvem as diretrizes (características e presença de contradições) e os fatores ambientais (falta de tempo, de recursos e de reembolso, de coação organizacional e de responsabilidade profissional).

As diretrizes clínicas devem ser consideradas, unicamente, como fonte de informação potencial, elas são efetivas na modificação de condutas dos profissionais, quando acopladas a medidas apropriadas de implementação (TROWBRIDGE; WEINGARTEN, 2001). Portanto, devem-se considerar estratégias que levem em consideração as barreiras que dificultam ou impossibilitam sua implementação.

A AHRQ estabeleceu alguns processos específicos para o desenvolvimento das diretrizes clínicas. Esse organismo tem cumprido uma função importante na elaboração das diretrizes desde 1989. Dessa forma, no desenvolvimento da primeira diretriz sobre o manejo da dor aguda, consideraram-se três processos básicos: uma revisão clinica interdisciplinar das atuais necessidades, das práticas, das diretrizes e dos princípios do cuidado; uma revisão vasta das pesquisas publicadas e uma revisão realizada pelos especialistas, clínicos e paciente (BEYEA; NICOLL, 1998).

De acordo com Beyea e Nicoll (1998), um fato que se destacou no desenvolvimento dessa diretriz foi ter sido submetida à revisão de pares o seu desenho inicial, permitindo-se, assim, que especialistas em dor fizessem comentários sobre a mesma. As autoras destacaram a participação de pacientes, enfermeiros e médicos, no processo de desenvolvimento e na fase de revisão da diretriz, o que contribuiu na clareza e utilidade das recomendações finais. 
O painel interdisciplinar de especialistas, que conformam o grupo de trabalho do desenvolvimento das diretrizes, deve ser envolvido em todas e em cada uma das fases de sua elaboração, avaliando, discutindo e criticando a literatura e sintetizando a melhor evidência.

A classificação da evidência nas recomendações é hierarquizada de acordo com a força da evidência identificada, conforme os pressupostos da PBE, indo desde a meta-análise até o consenso dos especialistas. Assim, ao examinar uma diretriz, nela deve ser possível identificar, claramente, quais recomendações ou intervenções foram fortemente apoiadas em pesquisas e quais foram apoiadas apenas na opinião de especialistas. Esse resultado de classificação proporciona aos usuários claro entendimento da confiabilidade e validade das evidências nas quais se fundamentam as recomendações (BEYEA; NICOLL, 1998).

$\mathrm{Na}$ avaliação das diretrizes clínicas segue-se, a orientação geral da avaliação de artigos originais, certamente, com particularidades específicas, onde são destacadas a experiência pessoal e a praticidade das recomendações. É fundamental se questionar se as recomendações são válidas e quais seriam elas, diante de uma resposta afirmativa; se elas são clinicamente importantes e qual sua utilidade nos cuidados do paciente (PERISÉ; GOMES; NOGUEIRA, 2001). Ressaltando-se, paralelamente, a importância da reavaliação periódica e da atualização das diretrizes (BEYEA; NICOLL, 1998; PERISÉ; GOMES; NOGUEIRA, 2001).

$\mathrm{Na}$ validade das recomendações, julga-se necessário identificar a especificação de todas as opções importantes e os efeitos clínicos, se foi utilizado processo explícito e sensível para identificar, selecionar e combinar as evidências, bem como se houve descrição de um processo explícito e sensível para considerar o valor relativo dos diversos efeitos clínicos identificados. Deve incluir, também, as últimas descobertas e ter sido submetida à revisão de peritos e à testagem (HAYWARD et al. 1995; PERISÉ; GOMES; NOGUEIRA, 2001).

No geral, ao avaliar a informação de uma diretriz, é importante considerar como ela foi desenvolvida, se o processo foi sistemático, se utilizou método apropriado e se as recomendações refletem os conhecimentos mais recentes do tópico abordado (BEYEA; NICOLL, 1998).

Outras considerações, relacionadas com o cuidado do paciente, focalizam a praticidade e custo-efetividade das recomendações, se as evidências são suficientemente capazes de produzir mudanças na prática e como a diretriz, com um todo, pode influir nos resultados do paciente e na prática de enfermagem (BEYEA; NICOLL, 1998). 
De acordo com Thomas (1999), grande parte das diretrizes está baseada em revisão de literatura, não sendo habitual a descrição dos métodos empregados para identificar e acessar as evidências relevantes ou os critérios utilizados para avaliar a qualidade das mesmas. Fato que pode subtrair sua credibilidade e confiança.

O desenvolvimento da maioria das diretrizes tem ocorrido na medicina, entretanto, o interesse dos enfermeiros está aumentando frente ao recurso facilitador da PBE (GALVÃO, 2002).

$\mathrm{Na}$ prática, é sabido que a enfermagem vem participando nos grupos de trabalho interdisciplinar para o desenvolvimento das diretrizes clínicas, e especialmente, da aplicação no cuidado aos pacientes.

Após publicação da primeira diretriz clínica pela AHRQ sobre dor aguda, houve uma dramática explosão na disponibilidade das diretrizes. O seu acesso depende de onde elas estão publicadas e de como estão sendo disseminadas (BEYEA; NICOLL, 1998).

A AHRQ tem realizado grandes esforços para que profissionais tenham acesso às diretrizes clínicas, mesmo assim, os clínicos admitem não estarem familiarizados com elas. Em decorrência dessa situação, a AHRC tem estabelecido a iniciativa de publicar as diretrizes online, como uma forma de disseminação.

A National Guideline Clearinghouse pôde incrementar o acesso às últimas informações sobre algumas condições de saúde, disponibilizando a informação para qualquer usuário de computador. Atualmente, as diretrizes publicadas pela AHRQ estão disponíveis no web site $<$ http:/www.guideline.gov>, no qual se podem encontrar resumos e textos completos de cada diretriz, incluindo informação adicional sobre sua estruturação e desenvolvimento. Às vezes, proporciona informação dos procedimentos para adquiri-las.

Reiterando a relevância do tema proposto e a significância da contribuição que a revisão sistemática traz para o embasamento da prática do cuidado, realizou-se este estudo cujos objetivos estão a seguir. 


\section{OBJETIVOS}

\section{Gerais}

Elaborar uma proposta assistencial sistematizada para pessoas com diabetes mellitus tipo 2, a partir de uma revisão sistemática, visando a prevenir o risco de desenvolver lesão/ulceração nos pés e,

Avaliar a efetividade dessa proposta assistencial sistematizada em um grupo de pessoas com diabetes tipo 2 acompanhadas em unidades básicas distritais de saúde e compará-las com um grupo-controle.

\section{Específicos}

1. Identificar e analisar as principais ações de prevenção de lesão/ulceração nos pés de pessoas com diabetes mellitus, fundamentadas na prática baseada em evidência;

2. Elaborar uma proposta assistencial sistematizada para pessoas com diabetes mellitus tipo 2 visando a prevenir o risco de desenvolver lesão/ulceração nos pés;

3. Verificar as diferenças entre grupos intervenção e controle em diferentes momentos do desenvolvimento da proposta assistencial, em relação ao conhecimento sobre o diabetes, comportamento sobre cuidados com os pés, comportamento sobre cuidados com os calçados, condições dermatológicas dos pés e características dos calçados usados por ocasião da avaliação;

4. Verificar as diferenças entre grupos intervenção e controle em diferentes momentos do desenvolvimento da proposta assistencial, em relação aos parâmetros de controle metabólico e da pressão arterial (PA) sangüínea. 


\section{METODOLOGIA}

A partir dos objetivos gerais estabelecidos no projeto, considerou-se o desenvolvimento de dois estudos que se complementam, os quais serão descritos separadamente, de acordo com suas especificações metodológicas.

O primeiro estudo consiste da revisão sistemática que proporcionou subsídios para a elaboração da proposta assistencial sistematizada com ênfase na prevenção de lesão/ulceração nos pés. O segundo, trata-se do estudo de intervenção tipo ensaio clínico, considerado estudo piloto, com a finalidade de viabilizar o desenvolvimento dessa proposta na prática clínica e subsidiar a ampliação para outras unidades da rede pública municipal, bem como, futuros estudos nessa temática.

\section{1- REVISÃO SISTEMÁTICA}

\subsection{1- Desenho metodológico}

Trata-se de uma análise retrospectiva de estudos primários que focalizam o tópico específico utilizando uma abordagem sistemática (COUTINHO, 2003), complementada com a revisão de diretrizes clínicas.

\subsection{2- Questão norteadora da pesquisa}

- Quais estratégias/intervenções* ${ }^{*}$ devem ser implementadas para prevenir o risco de desenvolver lesão ou úlcera nas extremidades inferiores distais entre pessoas adultas com diabetes mellitus?

\subsection{3- Critérios para seleção dos estudos}

- $\quad$ Tipo de participantes

Pessoas maiores de dezoito (18) anos de idade, com diabetes mellitus tipos 1 ou 2, independente do sexo.

\footnotetext{
* Neste estudo estratégias referem-se à organização da equipe do serviço que oferece cuidado às pessoas com diabetes e intervenções, às atividades diretamente proporcionadas aos pacientes.
} 
- Tipos estratégias/intervenções:

Educação/prevenção/intervenção/manejo/organização do atendimento a pacientes, que objetivaram prevenir complicações em extremidades inferiores distais ou lesão/úlcera nos pés de pessoas com diabetes mellitus e, consideraram paralelamente, pelo menos um grupo controle como referência;

As estratégias ou intervenções deveriam:

Estar incluídos em outros programas maiores ou complexos, que objetivaram o manejo integral à pessoa com diabetes mellitus;

Estar focalizados nos níveis primário e secundário de assistência à saúde e não incluírem medidas terapêuticas medicamentosas como meio de comparação;

Acompanhar os participantes, por no mínimo, seis meses nos programas de educação/prevenção/intervenção/manejo/organização;

Considerou-se também, as diretrizes clínicas direcionadas ao manejo da pessoa com diabetes mellitus, que incluíram nas suas recomendações, intervenções preventivas para complicações nas extremidades inferiores ou prevenção de lesão/úlcera nos pés.

- Tipos de desfechos:

Freqüência de exames dos pés;

Incidência de lesão/úlceração e de infecção local;

Produção ou resolução de calosidades/rachaduras;

Avaliação do conhecimento de cuidados com os pés;

Avaliação do comportamentos de cuidados com os pés;

- Tipos de estudos incluídos:

Ensaios clínicos randomizados controlados que avaliaram pelo menos um dos cinco desfechos selecionados neste estudo; revisões sistemáticas; diretrizes clínicas elaboradas a partir de revisão sistemática;

Artigos publicados em idioma inglês, português ou espanhol.

\subsection{4- Estratégia de busca dos artigos}

$\checkmark$ Os estudos foram identificados nas bases de dados eletrônicas MEDLINE, EMBASE, Cochrane Library, Lilacs, Cinahl e ISI Web of Science, no período de novembro de 2002 a fevereiro de 2003; 
$\checkmark$ Dissertações e teses foram revisadas no DEDALUS, incluindo aquelas da Universidade de São Paulo;

$\checkmark$ Outras buscas foram realizadas no site da National Guidelines Clearing House; Royal College of General Practitioners; unimeds.com.br; diabetesresource.com/html/footcare; diabetes.org.br/diabetes; dentre outros;

$\checkmark$ Artigos identificados na referência dos estudos, também foram localizadas;

$\checkmark$ Palavras chave usadas para a buscar os artigos por base de dados:

MEDLINE -1966 a 2002.

"diabetes mellitus" or "diabetes mellitus tipo 1" or "diabetes mellitus tipo 2" [Descritor de Assunto] and (((("pé diabético") or "neuropatias diabéticas" or "neuropatias periféricas") or "deformidades do pé") or "dermatoses da perna" or "dermatoses do pé") or "doenças do pé" [Descritor de Assunto] and ((()((("estudos de intervenção" or "intervenção precoce (educação)") or "prevenção primaria") or "/prevenção \& controle") or "educação do paciente") or "educação" or "gerenciamento da doença") or "estudos de avaliação" or "avaliação de processos (cuidados de saúde)" or "avaliação de programas" or avaliação de risco-beneficio" or "avaliação educacional") or "diretrizes" or "adesão a diretrizes" or "diretrizes para a prática clínica" [Descritor de Assunto].

EMBASE -1976 a 2001.

"diabetic-foot"/ complications, clinical-trial, prevention, therapy - período de 2000 a 2001. "diabetic foot (foot disease, diabetes mellitus, skin ulcer) and complications (co), diseases management (dm), prevention (pe), therapy (th) - período de 1994-1999. Busca manual por meio das revistas do "Excerpta Médica" - período de 1976 a 1993.

COCHRANE LIBRARY -1966 a 2002.

((("diabetes mellitus") or "diabetes") or "diabetic") or "hyperglycemia" [Assunto] and ("DIABETIC FOOT" or "diabetic neuropathies" or "diabetic neuropathy" or "diabetic neuropathy/co [complication]") or "foot deformities" or "foot dermatoses" or "foot diseases" or "foot injuries" or "foot ulcer" [Assunto] and ((()(("intervention" or "intervention studies" or "intervention: nursing care interventions") or "prevention" or "prevention \& control" or "prevention\&" or "prevention and control" or "prevention, primary") or "patient care" or "patient care management" or "patient education" or "patient monitoring") or "education" or "education program" or "education system" or "education, 
nursing") or "management") or "evaluation" or "evaluation research" or "evaluation studies") "guidelines" [Assunto].

LILACS -1982 a 2002.

"DIABETES melito" or "DIABETES mellitus" or "DIABETES mellitus de inicio no adulto" or "DIABETES mellitus estável" or "DIABETES mellitus insulino-dependente" or "DIABETES mellitus não insulino-depedente" or "DIABETES mellitus tipo 1" or "DIABETES mellitus tipo 2" [Descritor do Assunto] and ((("PE DIABETICO") or ("DERMATOSES da perna" or "DERMATOSES do pe") or "NEUROpATIAs diabeticas" or "NEUROPATIAs perifericas") or "DEFORMIDADES do pe" [Descritor do Assunto] and (((("estudos de intervenção" or "intervenção precoce (educação)") or "prevenção primaria") or "educação" or "educação primária e secundária") or "DIRETRIZES") or "avaliação de risco" or "avaliação do risco-beneficio" or "avaliação educacional" [Descritor do Assunto].

CINAHL -1982 a 2003.

DIABETIC-FOOT.MJX,MNX.WITH (CO or ED or NU or OG or PC or PR or TH); FOOT-DISEASES.MJX,MNX. WITH (CO or ED or NU or OG or PC or TH).

ISI WEB OF SCIENCE -1945 a 2003.

"diabetic foot" or "diabetic neuropathies" or "diabetic neuropathy" or "diabetic neuropathy/es [complications]" or "foot deformities" or "foot ulcers" or "foot ulcers" and "randomized control" or "case control" or "guidelines" or "systematic review" or "systematic overview".

DEDALUS - do inicio até 2003.

"diabetes" or "diabetes mellitus" or "diabete melito" or "diabetes melito" or "hiperglicemia" or "diabetes tipo 1" or "diabetes tipo 2" [Assunto].

\subsection{5- Procedimento da revisão sistemática}

A identificação dos estudos potenciais foi realizada pela pesquisadora, a qual por meio da leitura dos resumos realizou a primeira pré-seleção dos artigos. Posteriormente, a pesquisadora e a orientadora, de forma independente, analisaram esses resumos conforme critérios estabelecidos e, em um terceiro momento, verificaram a concordância da seleção dos artigos. Quando houve 
discordância nessa seleção procedeu-se à leitura conjunta do resumo para a decisão final, na ocasião foram excluídos outros resumos, por se tratar de estudos descritivos ou narrativos ou por abordar ainda, tópicos específicos não relacionados à temática. Pré-selecionou-se então 68 artigos, incluindo estudos prospectivos primários, revisões e diretrizes clínicas, os quais foram adquiridos na íntegra.

Os artigos primários pré-selecionados foram submetidos a uma seqüência de análise utilizando os critérios de Hadorn et al. (1996), referentes à qualidade dos estudos controlados (anexo 1) e foram excluídos aqueles que apresentaram mais de uma "falha maior".

Para avaliar os estudos selecionados elaborou-se uma tabela para armazenar os dados a partir dos critérios de Stotts (1999) direcionados para os "estudos sobre terapias ou prevenção" (anexo 2), complementados com os de Verhagen et al. (1998) e Tulder Van et al. (1997) (anexos 3 e 4).

$\mathrm{Na}$ avaliação, os autores acima citados consideram, principalmente, aspectos metodológicos dos estudos. Tulder Van et al. (1997) consideraram, por exemplo, os critérios da validade interna, os critérios descritivos e os critérios estatísticos. A validade interna incluiu 10 critérios [seleção de viés (critério $b$ ); execução de viés (critérios $e, f, g, h$ ); desgaste de viés (critérios $l, p$ ) e detecção de viés (critérios $i, j, n)]$ para definir a qualidade metodológica na revisão (metanálise). Os critérios descritivos (critérios $a, c, d, k, m)$ referem-se à validade externa dos estudos e podem ser usados para análise de sensibilidade e de subgrupos, quando apropriado. Quanto aos critérios estatísticos, estes indicam se podem ser produzidos cálculos e extraídas novas conclusões, independente da opinião dos autores do artigo original.

Cada estudo foi avaliado de acordo com a existência de informação suficiente e a probabilidade de viés potencial em cada critério, ou seja, se a avaliação da informação fosse suficiente e o viés considerado improvável, o critério foi categorizado como "Sim"; se o viés fosse considerado como provável, o critério foi categorizado como "Não"; e quando a informação fosse considerada insuficiente, foi categorizado como "Não se sabe".

Quanto à avaliação das diretrizes clínicas selecionadas, os dados também foram armazenados em tabela elaborada a partir dos critérios de Hayward et al. (1995), os quais mantém as mesmas "guias primárias" e "guias secundárias" (anexo 5) apresentadas por Stotts (1999). Nas diretrizes, as recomendações devem ser produto de uma ampla busca de evidências, apresentando todas as opções de práticas razoáveis e todos os resultados potenciais, discutindo os benefícios e 
danos, se possível, com análise de custo-benefício. Deixando claro, se o grupo envolvido na elaboração da diretriz foi constituído por equipe multiprofissional e/ou multidisciplinar, e como eles determinaram o nível de evidência dos estudos e o grau das recomendações; além de descrever, como se resolveram incongruências na equipe e a falta de evidências.

Nessa avaliação, consideraram-se também as informações proporcionadas nas próprias diretrizes, ou seja, quando a informação era suficiente e o viés considerado improvável, o critério foi categorizado como "Sim"; quando o viés era considerado como provável, o critério foi categorizado como "Não" e quando a informação era considerada insuficiente, o critério foi categorizado como "Não se sabe".

\subsection{6- Proposta assistencial sistematizada}

A partir da revisão elaborou-se uma proposta assistencial sistematizada para as pessoas com diabetes na perspectiva de prevenir e/ou diminuir o risco de desenvolver lesão/ulceração nos pés, a qual foi apreciada por especialistas (médicos e enfermeiros) e re-estruturada, a partir das sugestões.

As recomendações descritas na proposta fundamentam-se na classificação do nível de evidência e o grau de recomendação de Hutchinson et al. (2000), as quais são condizentes com outras classificações (ALAD, 2000; NEW ZEALAND GUIDELINES GROUP, 2000; SCOTTISH INTERCOLLEGIATE GUIDELINES NETWORK, 2001; SOARES; ATALLAH, 2002) e estão apresentadas nas Tabelas 5.1 e 5.2 para melhor apreciação.

Tabela 5.1 - Nível de classificação da evidência nos estudos.

\begin{tabular}{|c|c|}
\hline $\begin{array}{l}\text { Nível da } \\
\text { evidência }\end{array}$ & Descrição \\
\hline $\mathrm{Ia}$ & $\begin{array}{l}\text { Evidência desde metanálise de ensaios controlados } \\
\text { randomizados }\end{array}$ \\
\hline $\mathrm{Ib}$ & $\begin{array}{l}\text { Evidência desde no mínimo um ensaio controlado } \\
\text { randomizado }\end{array}$ \\
\hline IIa & $\begin{array}{l}\text { Evidência de no mínimo um estudo controlado sem } \\
\text { randomização }\end{array}$ \\
\hline $\mathrm{IIb}$ & $\begin{array}{l}\text { Evidência de no mínimo outro tipo de estudo quase } \\
\text { experimental }\end{array}$ \\
\hline III & $\begin{array}{l}\text { Evidência desde estudos descritivos não experimentais, tais } \\
\text { como estudos comparativos, estudos de correlação e estudos } \\
\text { de caso-controle }\end{array}$ \\
\hline IV & $\begin{array}{l}\text { Evidência desde relatório de comitê de especialistas e/ou a } \\
\text { experiência clínica de autoridades respeitadas na área }\end{array}$ \\
\hline
\end{tabular}


Tabela 5.2 - Grau das recomendações propostas.

\begin{tabular}{cl}
\hline $\begin{array}{c}\text { Grau da } \\
\text { recomendação }\end{array}$ & \multicolumn{1}{c}{ Descrição } \\
\hline $\mathrm{A}$ & $\begin{array}{l}\text { Embasado diretamente na categoria de Evidência I, ou este grau } \\
\text { foi assinado pelos organizadores, explicando e documentado as } \\
\text { razões dessa recomendação. }\end{array}$ \\
B & $\begin{array}{l}\text { Embasado diretamente na categoria de Evidência II, ou este grau } \\
\text { foi assinado pelos organizadores, explicando e documentado as } \\
\text { razões dessa recomendação. }\end{array}$ \\
C & $\begin{array}{l}\text { Embasado diretamente na categoria de Evidência III, ou este } \\
\text { grau foi assinado pelos organizadores, explicando e } \\
\text { documentado as razões dessa recomendação. }\end{array}$ \\
Dmbasado diretamente na categoria de Evidência IV, ou este \\
grau foi assinado pelos organizadores, explicando e \\
documentado as razões dessa recomendação.
\end{tabular}




\section{2- ESTUDO DE INTERVENÇÃO}

\subsection{1- Delineamento do estudo}

Trata-se de um ensaio clínico randomizado controlado, envolvendo manipulação de variáveis independentes, constituído pela instituição de intervenções (POLIT; HUNGLER, 1999), no caso, a proposta assistencial sistematizada.

Esta proposta foi desenvolvida em duas fases (Figura 5.1). Inicialmente a intervenção foi direcionada às pessoas com diabetes participantes no estudo (grupo A), mediante um programa de sensibilização de cuidados com os pés, destacando os fatores de risco para úlcera. Após seis meses de início do estudo, as intervenções também foram direcionadas aos profissionais das respectivas unidades (médicos e enfermeiros), mediante um programa de sensibilização referente aos fatores de risco para complicações nas extremidades inferiores distais nas pessoas com diabetes, destacando as medidas de prevenção e rastreamento.

No percurso do estudo, realizado em um período de 12 meses, as pessoas do grupo de intervenção, foram agendadas mensalmente para reforçar o programa de sensibilização e avaliar suas necessidades de cuidado com os pés.

Destaca-se que o profissional responsável pela Assessoria Técnica do Programa de diabetes da Secretaria Municipal de Saúde de Ribeirão Preto esteve envolvido neste estudo, desde a fase de planejamento. 


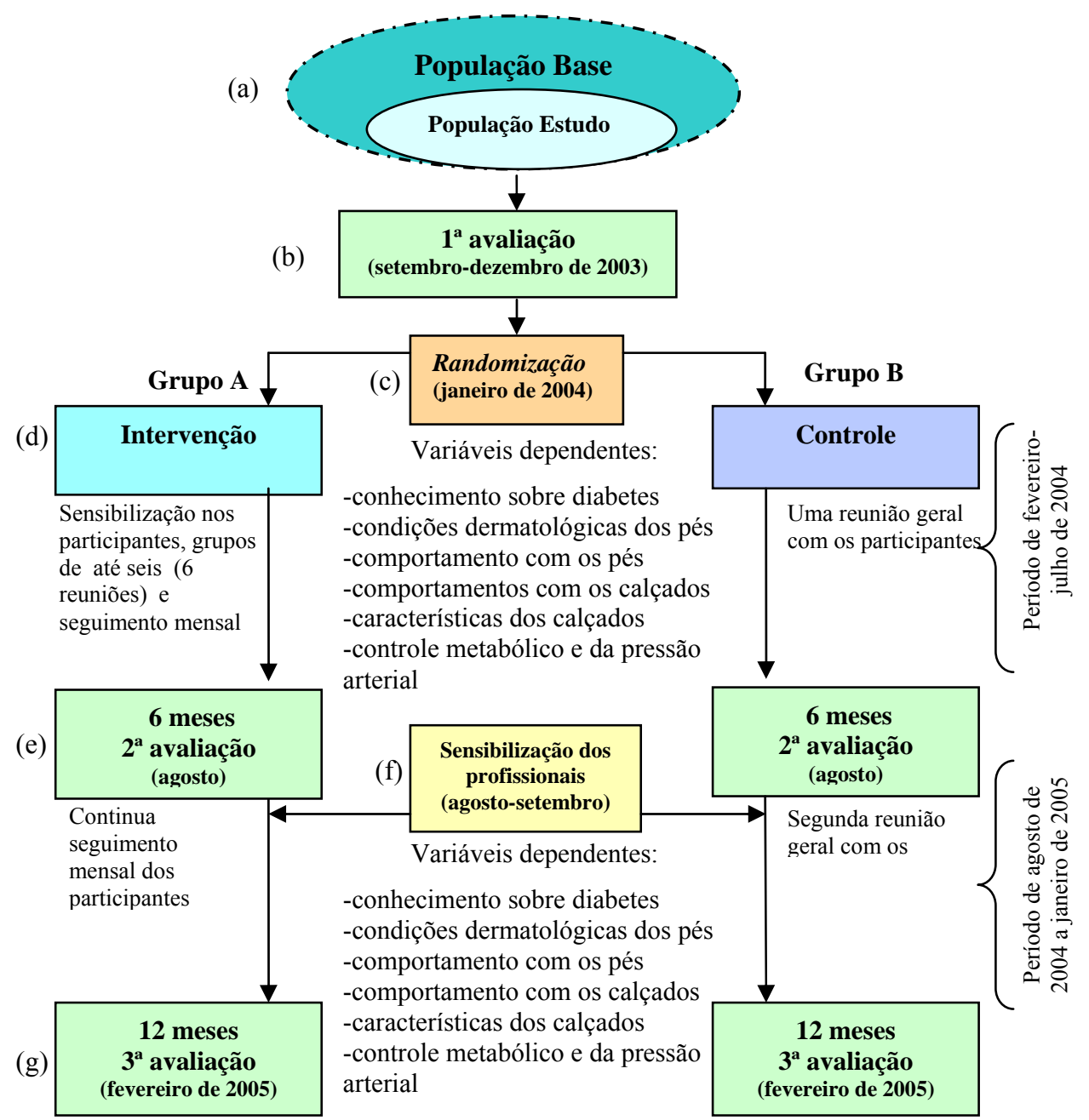

Figura 5.1. Esquematização do estudo: (a) determinação da população base; (b) primeira avaliação; (c) randomização; (d) intervenção nos participantes do grupo A; (e) segunda avaliação; (f) intervenção nos profissionais de ambas unidades; (g) terceira avaliação.

\subsection{2- Local de estudo}

A pesquisa foi desenvolvida na cidade de Ribeirão Preto, situada na região Nordeste do Estado de São Paulo, a qual ocupa uma área de $627 \mathrm{~km}^{2}$ e possui uma população de 505.012 habitantes, dos quais 99,5\% encontram-se na área urbana (PLANO MUNICIPAL DE SAÚDE PMS, 2001). A taxa de prevalência para o DM foi estimada em $12,1 \%$ no estudo realizado nesse município em 1997, entre as pessoas de 30 a 69 anos de idade, com projeções para o ano de 2003, de 27.739 pessoas com diagnóstico de diabetes (TORQUATO et al., 2003).

A Rede Municipal de Saúde possui cinco Unidades Básicas e Distritais de Saúde (UBDS), 27 Unidades Básicas de Saúde (UBS), um Ambulatório Regional de Especialidades (Núcleo de Gestão Assistencial - NGA-59), um Ambulatório Geral de Especialidades Pediátricas (PAM II), 
um Núcleo de Atenção Psicossocial para Farmacodependentes (NAPSF) e um Ambulatório Regional de Saúde Mental (PMS, 2001).

A Secretária Municipal de Saúde desenvolve atualmente quinze programas de saúde conforme as diretrizes do Ministério da Saúde e da Secretaria Estadual da Saúde, com ênfase na saúde coletiva que contempla uma atenção integral do indivíduo. Cada unidade ambulatorial possui atendimento básico nas áreas de medicina, odontologia e enfermagem.

No propósito de obter uma população de estudo que apresentasse características sociodemográficas similares e que, paralelamente, possuíssem programas de diabetes, com equipe de assistência médica especializada, excluindo-se as unidades escolas, o presente estudo foi desenvolvido em duas UBDS da Secretaria Municipal de Ribeirão Preto: UBDS Dr. Marco Antônio Sahão - bairro Vila Virgínia e UBDS ${ }^{\ddagger}$ - bairro Simioni. Ambas, localizam-se em bairros de classe média baixa e pertencem, respectivamente, aos distritos Sul e Norte da cidade e abrangem uma população aproximada de 170 mil habitantes (82.239 - Vila Virgínia e 96.402 Simioni).

A UBDS Alexander Fleming, no período inicial do estudo, integrava seis UBS localizadas nos bairros Quintino Facci I, Quintino Facci II, Valentina Figueiredo, Marincek, Vila Mariana e Jardim Aeroporto. Atualmente, a UBDS do Distrito Norte funciona no Quintino II, tendo sido desativada a UBS e integrada o bairro Parque Ribeirão Verde e uma Base de Apoio Comunitário (BAC). Quanto a UBDS Dr. Marco Antônio Sahão, esta inclui três UBS localizadas no bairro Adão do Carmo Leonel, Parque Ribeirão Preto e Jardim Maria das Graças.

As UBDS oferecem atendimento no período das 07:00 às 22:00 horas com atendimento de emergência durante 24:00 horas às crianças e adultos, incluindo o serviço de odontologia. A UBDS Dr. Marco Antônio Sahão, no bairro da Vila Virginia, além do atendimento básico, oferece também atendimento de especialidades em Cardiologia, Endocrinologia, Fonoaudiologia e Psicologia, programas de Hipertensão Arterial, Diabetes, Hanseníase e Tisiologia, serviços de Assistência Social e Carteira de Saúde e exames de Eletrocardiografia e Ultra-sonografia. A UBDS Alexander Fleming, no bairro do Simioni, incluía Cardiologia, Endocrinologia, Fonoaudióloga, Psicologia, Assistência Social, Carteira de Saúde, Eletrocardiografia e Ultrasonografia (PMS, 2001).

\footnotetext{
‡ Atualmente constitui uma Unidade Básica de Saúde - UBS, em virtude que a UBDS da região Norte foi transferida para o bairro Quintino II, próximo ao Simioni e denomina-se UBDS Dr. Sergio Arouca (inaugurada em abril de 2004).
} 
O atendimento às pessoas com diabetes nas respectivas UBDS é realizado pelo endocrinologista, cardiologista ou clínico geral nas consultas agendadas. Ao comparecer à consulta, o paciente é acolhido pelo auxiliar de enfermagem, o qual realiza a aferição da pressão arterial e controle do peso na sala de triagem. Se necessário, após a consulta médica, o paciente é orientado pela equipe de enfermagem, em relação aos exames laboratoriais e outros exames específicos, quando solicitados, e agendamento para o retorno médico. O agendamento da consulta, em geral, é efetuado na recepção e depende da vaga disponível verificada no sistema informatizado de agendamento da Secretaria de Saúde de Ribeirão Preto (HYGIA). O atendimento pelo profissional enfermeiro é feito quando há necessidade ou quando encaminhado pelo médico, por alguma condição especial.

\subsection{3- Aspectos éticos}

O projeto foi aprovado pelo Comitê de Ética e Pesquisa da Escola de Enfermagem de Ribeirão Preto da Universidade de São Paulo - Protocolo 0242/002 (anexo 6). Os participantes foram esclarecidos quanto aos objetivos do estudo, procedimentos, riscos e benefícios da investigação e assinaram o "Termo de Consentimento Livre e Esclarecido" (anexo 7). A identificação dos mesmos no instrumento foi mediante códigos para garantir os seus anonimatos, sendo que cada um pôde sair da pesquisa no momento que assim o considerou conveniente e necessário.

\subsection{4- População base}

A população foi composta pelas pessoas com diagnóstico de DM tipo 2 de ambos os sexos, que estavam em tratamento oral ou insulínico até agosto de 2003 nas UBDS selecionadas, verificado nos registros da lista de entrega de medicamentos pela farmácia nas respectivas UBDS, considerando um período retrospectivo de seis meses. Dados sobre idade, sexo, residência e unidade de referência para atendimento foram obtidos no sistema HYGIA.

No total foram identificadas 1.561 pessoas com diabetes cadastradas na farmácia da rede municipal (821 da Vila Virgínia e 740 do Simioni). Desse número, 970 pessoas residiam nos bairros selecionados (542 na Vila Virgínia e 428 no Simioni). Outras 591 residiam nos bairros vizinhos dos respectivos distritos. A seguir apresenta-se na Tabela 5.3, a distribuição das 970 pessoas conforme as respectivas UBDS e a faixa etária. 
Tabela 5.3 - Distribuição das pessoas com diabetes mellitus em tratamento oral ou insulínico, segundo faixa etária e UBDS. Ribeirão Preto, 2003.

\begin{tabular}{lccccccc}
\hline & \multicolumn{2}{c}{ UBDS } & \multicolumn{2}{c}{ Vila Virgínia } & \multicolumn{2}{c}{ Simioni } & \multicolumn{2}{c}{ Sub-total } & \multirow{2}{*}{ Total } \\
\cline { 2 - 7 } Faixa etária & $\mathrm{M}$ & $\mathrm{F}$ & $\mathrm{M}$ & $\mathrm{F}$ & Virgínia & Simioni & \\
\hline $01-10$ & 1 & 1 & 5 & 2 & 2 & 7 & 9 \\
$11-20$ & 2 & 3 & 1 & 6 & 5 & 7 & 12 \\
$21-30$ & 5 & 5 & 5 & 3 & 10 & 8 & 18 \\
$31-40$ & 7 & 11 & 9 & 12 & 18 & 21 & 39 \\
$41-50$ & 34 & 41 & 28 & 54 & 75 & 82 & $\mathbf{1 5 7}$ \\
$51-60$ & 41 & 85 & 56 & 64 & 126 & 120 & $\mathbf{2 4 6}$ \\
De 61 a mais & 89 & 217 & 77 & 106 & 306 & 183 & $\mathbf{4 8 9}$ \\
\hline Total & 179 & 363 & 181 & 247 & 542 & 428 & 970 \\
\hline
\end{tabular}

Dessa forma, a população base ficou constituída por 970 pessoas com DM, as quais foram submetidas aos critérios de inclusão e exclusão estabelecidas para definir a população de estudo.

\subsection{5- Critérios de inclusão e exclusão}

A maioria dos critérios de inclusão e exclusão foi verificada no momento do primeiro contato com as pessoas, com exceção da idade e do local de residência.

- Critérios de inclusão:

pessoas recebendo tratamento nas respectivas UBDS, cujo diagnóstico de diabetes mellitus foi realizado após 30 anos de idade, acima de 40 anos de idade, perfusão tissular periférica preservada em membros inferiores, função renal preservada, raciocínio e juízo conservados, residentes na cidade de Ribeirão Preto - São Paulo e que concordaram em participar do estudo.

- Critérios de exclusão:

diabetes mellitus tipo 1, tratamento hemodialítico, amputações prévias em qualquer nível do membro inferior, processo de lesão ou úlcera ativa em membros inferior, ter como unidade de referência outras unidades de saúde, contar com plano de saúde privado e pessoas em cadeira de rodas ou acamados.

\subsection{6- População de estudo}

Das 970 pessoas que constituíram a população base, 892 tinham idade acima de 40 anos. Dessas, 134 da UBDS Vila Virgínia e 174 da UBDS Simioni utilizavam outras unidades de saúde 
como unidade de referência para acompanhamento da doença, porém, recebiam medicamentos nas respectivas UBDS, portanto, as mesmas foram também excluídas. O percentual mais elevado observado na UBDS Simioni, pode estar relacionado à ausência transitória da especialidade de endocrinologia na referida unidade.

Dessa forma, 584 pessoas compuseram a população de estudo (371 cadastradas na UBDS Vila Virgínia e 213 na UBSD Simioni) e foram convocadas às respectivas unidades, mediante carta em nome da gerência, solicitando seu comparecimento em datas e horários préestabelecidos (das 7:30 às 10:00 horas; 14:00 às 16:00 horas; 18:00 às 20:00 horas).

Das 584 cartas emitidas, aproximadamente $50 \%$ das pessoas compareceram, por tal motivo, optou-se por realizar uma segunda convocação àquelas que não se apresentaram. Assim, 876 cartas foram enviadas entre setembro e dezembro de 2003, as quais foram entregues pelo correio local ou mediante visitas domiciliares realizadas pela pesquisadora no bairro da Vila Virgínia e pelos Agentes Comunitários de Saúde no bairro Simioni. Não houve diferença no percentual de comparecimento das pessoas convocadas por meio de correspondência ou visita domiciliar, por tal motivo, a partir de outubro as cartas foram entregues apenas pelo correio.

No período das convocações, o prédio da UBDS Vila Virgínia estava em reforma, a qual foi iniciada em julho de 2003; este fato levou os profissionais e funcionários da unidade a oferecerem assistência à saúde em outros locais, tais como Pronto Socorro - bairro Centro, NGA59 - bairro Campos Elíseos e sede do Conselho Tutelar - bairro Vila Virgínia, dificultando o desenvolvimento dessa fase, pois não havia local apropriado para o atendimento individualizado nos horários programados. No período diurno estava disponível a sala de reuniões do NGA-59 e no noturno, o auditório do CEMEI Prof. Eduardo Romualdo de Souza (bairro Vila Virgínia).

Das 584 pessoas convocadas, 416 compareceram entre ambas UBDS, sendo que 35 não atenderam aos critérios de inclusão, 158 não mostraram interesse no estudo e 93 consideraram interessante, porém alegaram falta de disponibilidade pelo horário de trabalho. Assim, 130 pessoas concordaram em participar voluntariamente do estudo e tiveram retorno agendado em data próxima para proceder à coleta de dados.

Todas as pessoas que compareceram às respectivas UBDS foram orientadas quanto à justificativa, objetivos e métodos do estudo. Nesses encontros, também foi realizado uma apresentação geral sobre o diabetes e suas complicações crônicas, verificando-se a glicemia capilar e a pressão arterial, como forma de estimular a participação das pessoas. 


\subsection{7- Definição das variáveis}

\subsubsection{1-Variável Independente}

\section{Proposta assistencial sistematizada}

Trata-se da aplicação da proposta sistematizada às pessoas com diabetes participantes do grupo de intervenção, mediante o desenvolvimento de um programa de sensibilização educativa, fundamentada na prática baseada em evidências, destacando os componentes básicos de cuidados com os pés. Paralelo a este processo foi coordenado com as respectivas gerências das UBDS, a periodicidade dos retornos às consultas com médicos endocrinologistas, conforme proposta. $\mathrm{Na}$ sensibilização educativa direcionada aos profissionais foram destacadas às atividades de prevenção e rastreamento do risco para lesão/ulceração nos pés e a importante contribuição dos enfermeiros nesse propósito (página 107).

\subsubsection{2-Variáveis Dependentes}

\section{Conhecimento sobre o diabetes (sintomas de descompensação)}

Compreende informações relatadas pelo participante em relação aos sinais e sintomas que podem indicar hipoglicemia e hiperglicemia, sendo que esse conhecimento, pode auxiliar na aquisição de habilidades para o automanejo da doença.

\section{Comportamento com os pés}

Compreende informações relatadas pelo participante em relação a comportamentos habituais que realiza no cuidado de seus pés.

\section{Comportamento com os calçados}

Compreende informações relatadas pelo participante em relação a comportamentos habituais que realiza no cuidado de seus calçados e o tipo de calçado que usa habitualmente.

\section{Condições dermatológicas dos pés}

Compreende as condições identificadas nos membros inferiores distais mediante a realização do exame físico utilizando as técnicas de observação e palpação.

\section{Características dos calçados}

Compreende as características dos calçados que o participante está usando no dia da entrevista, os quais são avaliados mediante observação do modelo, tamanho e material. 


\section{Parâmetros do controle metabólico}

Compreende os resultados de exames sangüíneos que avaliam a condição de controle do diabetes, incluindo componentes associados à doença que podem indicar presença de algum grau de alteração decorrente do diabetes.

\section{Valores da pressão arterial}

Compreende o resultado da aferição da pressão arterial com aparelho de pressão manual.

\subsubsection{3 -Indicadores das Variáveis Dependentes}

\section{Em relação ao conhecimento sobre o diabetes}

Foram classificados em respostas dicotômicas entre "sim" e "não". Cada resposta considerada apropriada foi pontuada com o valor "2" e, imprópria com "1". A seguir descreve-se cada um dos indicadores:

\section{Auto-relato de parâmetros normais de glicemia}

Foi considerada apropriada quando o participante relatava o parâmetro de valor de 70 a $110 \mathrm{mg} / \mathrm{ml}$ e imprópria, quando apenas relatou um valor ou qualquer outro não relacionado.

\section{Auto-relato de sintomas de hipoglicemia e hiperglicemia}

Foi considerada apropriada quando o participante relatava pelo menos três sintomas corretos para cada critério. Na hipoglicemia podia-se referir tontura, confusão, dor de cabeça, palpitações ou batedeira, tremor, fraqueza, suor frio e fome súbita. E, na hiperglicemia muita sede, garganta seca, urina muito e freqüentemente, visão embaçada, debilidade, mal-estar geral, sonolência, náuseas e vômitos.

\section{Auto-relato de sintomas de alterações em membros inferiores}

Foi considerada apropriada quando o participante relatava pelo menos três sintomas corretos. Dentre as alterações podia-se referir insensibilidade plantar, pele ressecada, calosidades, rachaduras, formigamento, dor tipo queimação ou pontada, ferida que não "sara" ou úlcera ou amputação.

\section{Em relação ao comportamento com os pés e calçados}

Também foram classificados em respostas dicotômicas entre "sim" e "não", sendo que cada resposta considerada apropriada foi pontuada com o valor " 2 " e imprópria com valor "1". Nos casos cuja resposta apropriada era a negação, a resposta "não" recebeu a pontuação "2". 
Quando a pergunta possibilitava múltiplas escolhas de respostas, estas foram agrupadas mediante critérios estabelecidas, entre apropriadas e impróprias. Em cada resposta múltipla, uma ou mais delas podiam ser referidas determinando o valor "2" ou "1". Se o participante referia-se a uma ou mais respostas da apropriada e imprópria, a pontuação era "1". A seguir descreve-se cada um dos indicadores:

\section{Auto-relato de cuidados com os pés}

Foi considerada apropriada quando o participante relatava "sim" para cada questão apresentada. Para a referência de antecedentes ou presença atual de calos considerou-se resposta apropriada quando o participante relatou "não".

\section{Auto-relato de cuidados com os calçados}

Foi considerada apropriada quando o participante relatava "sim" para cada questão apresentada. Embora, usar o mesmo calçado todo dia foi considerado resposta apropriada quando o participante relatou "não".

\section{Auto-relato do tipo de calçado que usa habitualmente}

Tratando-se de resposta de múltiplas escolhas, estas foram agrupadas mediante critérios estabelecidos, entre apropriadas impróprias. Em cada resposta múltipla, uma ou mais delas podiam ser referidas determinando o valor "2" ou "1". Se o participante referia-se a uma ou mais respostas da apropriada e imprópria, a pontuação era “1”.

\section{Em relação à condição dermatológica dos pés}

Incluem respostas dicotômicas entre "apropriada/ausente" e "imprópria/presente". A cada resposta apropriada foi atribuído o valor "2" e à imprópria “1”. Quando a resposta tinha múltiplas escolhas, na presença de uma delas o valor era "1". A seguir descreve-se cada um dos indicadores:

\section{Higiene de pés e corte de unhas apropriados}

Considerou-se higiene apropriada quando os pés apresentaram-se limpos, com fragrância natural ou perfumado, sendo que as unhas deviam estar aparadas de forma reta ou quadradas, sem ser muito rente. Cutículas podiam estar integras e ausente de lesão.

\section{Ausência de pele ressecada/descamativa}

Considerou-se nessa condição à pele que se apresentava hidratada e macia em toda a extensão do membro inferior, incluindo pernas e pés, área plantar e dorsal. 


\section{Ausência de unha espessada/aspecto farináceo/onicomicose}

Considerou-se ausência dessas alterações quando as unhas apresentavam-se na sua estrutura natural, íntegra, com lâmina córnea flexível, ligeiramente transparente.

\section{Ausência de maceração nos espaços interdigitais/dermatite fúngica}

Considerou-se essa condição quando os espaços interdigitais estavam íntegros, secos, com coloração natural à pele e ausentes de prurido.

\section{Ausência de calos/rachaduras}

Considerou-se essa condição quando a pele dos pés, tanto dorsal, como plantar estiveram ausentes de áreas de hiperqueratose ou fissuras, as quais podiam ser leves ou grossas/profundas, principalmente na área do calcanhar e das cabeças metatarsianas.

\section{Ausência de bolha/úlcera ou cicatrização das prévias}

Considerou-se essa condição quando os pés apresentavam-se com pele íntegra e aparentemente sadias, sem lesão/ulceração ativa.

\section{Em relação às características dos calçados}

Incluem respostas dicotômicas entre "apropriada" e "imprópria". A cada resposta apropriada foi atribuída o valor "2" e a imprópria o valor “1". Nos calçados consideraram-se quatro características: estilo (modelo), largura, comprimento e material de fabricação. O estilo foi apropriado quando era fechado, preferencialmente, protegendo todo o pé; na largura e comprimento, considerou-se o de tamanho adequado, com espaço de um centímetro e, no material, aquele confeccionado em couro macio ou lona/algodão. Portanto, o calçado era apropriado quando todas essas características foram observadas.

\section{Em relação aos parâmetros do controle metabólico}

Nesses resultados foram considerandos os parâmetros convencionais de "normalidade", conforme método utilizado nos respectivos Laboratórios de Referência para cada UBDS, em concordância com as recomendações da SBD (2003), os quais foram equiparados para apresentação no estudo, quando houve diferença no método utilizado. O exame de hemoglobina glicosilada $\mathrm{A}_{1 \mathrm{c}}\left(\mathrm{HbA}_{1 \mathrm{c}}\right)$ realizou-se no Laboratório de Endocrinologia do Hospital das Clinicas da Faculdade de Medicina de Ribeirão da Universidade de São Paulo, pelo fato de outros 
laboratórios não realizarem este tipo de exame. A seguir descreve-se cada um dos indicadores incluídos:

\section{Taxa de glicemia plasmática em jejum}

Corresponde à dosagem de glicose do participante em jejum, de pelo menos oito horas. Esse dado representa a condição de glicose por um curto período de tempo (horas). O método utilizado nesse exame foi o Automatizado, com valor de referência saudável de 70 a110 mg/dl.

\section{Taxa de hemoglobina glicosilada $A_{1 c}\left(H_{b} A_{1 c}\right)$}

Corresponde à concentração média da glicose do participante por um longo período de tempo, entre dois a três meses. O nível de $\mathrm{HbA}_{1 c}$ é proporcional à soma da concentração de glicose e o tempo de vida da hemoglobina na circulação. O método utilizado nesse exame foi a Cromatografia Líquida de Pressão Baixa de Troca Iônica (LPLC), mediante o analisador DiaSTAT $^{\mathrm{TM}}$ - Bio-Rad, com valor de referência saudável de 4,3 a 6,4\%.

\section{Taxas de colesterol total}

O colesterol é considerado precursor de diversas substâncias importantes no organismo tais como hormônios esteróides, vitamina D e sais biliares. Seu incremento está associado ao risco de aterosclerose junto a outros fatores como diabetes, hipertensão arterial e tabagismo. O método utilizado nesse exame foi Enzimático Automatizado e Labetest, com valor de referência desejável $<200 \mathrm{mg} / \mathrm{dl}$.

\section{Taxa de colesterol de alta densidade (HDL colesterol)}

Alta concentração de HDL colesterol relaciona-se com proteção para doenças cardiovasculares, devido a sua ação na dissolução de depósitos lipídicos ou ateromas formados nas paredes dos vasos. O método utilizado nesse exame foi Precipitação Seletiva e Labetest, com valores de referências desejáveis $>65 \mathrm{mg} / \mathrm{dl}$ e $>60 \mathrm{mg} / \mathrm{dl}$, respectivamente.

\section{Taxas de triglicerídeos}

Alta concentração de triglicerídeos constitui fator de risco para doenças vasculares e pode estar presente, secundariamente, na obesidade, no diabetes, na síndrome renal, na insuficiência renal crônica, dentre outras. O método utilizado nesse exame foi Enzimático Colorimétrico e Automatizado, com valor de referência limítrofe $<200 \mathrm{mg} / \mathrm{dl}$

\section{Taxa de creatinina}

A elevação da creatinina relaciona-se com graus de insuficiência renal, podendo ser decorrente do diabetes. O método utilizado nesse exame foi o Jaffe Automatizado e 
Automatizado, com valor de referência saudável de 0,7-1,7 mg/dl e 0,4-1,3 mg/dl, respectivamente.

\section{Em relação à pressão arterial}

O resultado de aferição da pressão arterial devia estar em consonância com a recomendação do Consenso da SBD (2003), embasado na proposta The Seventh Report of the Joint National Committee on Prevention Detection, Evaluation, and Treatment of High Blood Pressure (CHOBANIAN et al., 2003; ADA, 2003), sendo que o valor da pressão sistólica é $<120$ mmHg e da pressão diastólica $<80 \mathrm{mmHg}$.

\subsection{8- Instrumento de coleta de dados}

Elaborou-se o instrumento (anexo 8) a partir do estudo de Pace et al. (2002), o qual é composto de duas partes. A primeira parte, inclui aspectos descritivos da população (identificação do participante, dados socio-demográficos e dados relacionados à doença e antecedentes clínicos) e as variáveis que analisam o conhecimento que possuíam os participantes em relação à doença comportamento de cuidados com os pés. A seguir detalham-se os dados descritivos:

\section{Anos de escolaridade}

A escolaridade foi dividida em quatro opções: (1) iletrado; (2) ensino fundamental - maior que 1 ano; (3) ensino médio - maior que 9 anos; (4) ensino superior - maior que 12 anos.

\section{Estado civil}

No estado civil foi considerado quatro condições: (1) solteiro (a); (2)casado/amasiado (a); (3) divorciado/separado (a); (4) viúvo (a).

\section{Peso}

O peso corporal foi obtido em quilogramas utilizando balanças de pé disponibilizadas para esta finalidade em cada UBDS, prévia verificação de sua precisão. Os participantes foram mensurados com vestimenta usual e descalços.

\section{Altura}

A altura corporal foi obtida em centímetros utilizando as balanças de pé disponibilizadas em cada UBDS depois de mensurar-se o peso.

\section{Pressão Arterial}

Esta medida foi realizada com auxílio de esfigmomanômetro (braçadeira de 24 a $30 \mathrm{~cm}$ ) e estetoscópio para adulto (BD, Brasil). Após 10 minutos de repouso, com o participante sentado, 
procedia-se à mensuração da pressão em um dos braços. Quando havia dúvida a esse respeito, realizava-se mensuração em ambos braços e considerava-se a média das medidas como valor final.

\section{Dados sobre a doença e parâmetros de controle metabólico}

Dados sobre a doença foram questionados diretamente aos participantes. Em relação aos dados do controle metabólico, esses foram obtidos dos prontuários médicos.

\section{História médica}

Esses dados também foram questionados aos participantes e, posteriormente, verificados nos prontuários médicos de cada UBDS. Este último fato nem sempre foi possível, devido à falta de registro nos prontuários.

Destaca-se que as variáveis sobre sintomas de descompensação no diabetes, cuidados com os pés e calçados (item 01 até 18) subsidiaram a identificação das necessidades dos participantes e contribuíram no direcionamento do processo de sensibilização.

A segunda parte do instrumento contemplou dados relacionados com a avaliação dos membros inferiores incluindo as condições dermatológica, estrutural, circulatória e neuropática e as características do calçado no momento da entrevista (item 19 até 38). Esses dados permitiram identificar o grau de risco para lesão/ulceração nos pés dos participantes utilizando a classificação de Sims, Cavanagh e Ulbrecht (1988), constituída por seis categorias, de zero a 5.

$\mathrm{Na}$ categoria zero, incluem-se pessoas com sensibilidade tátil pressórica plantar preservada; na categoria 1, pessoas com perda da sensibilidade tátil pressórica plantar; na categoria 2, pessoas com perda da sensibilidade tátil pressórica plantar/deformidade estrutural/aumento da pressão plantar; na categoria 3, pessoas com perda da sensibilidade tátil pressórica plantar e história de úlcera prévia; na categoria 4, pessoas com perda da sensibilidade tátil pressórica plantar/úlcera prévia/deformidade estrutural/aumento da pressão plantar e na categoria 5, pessoas com de fratura neuropática ou pé de Charcot.

O processo da avaliação dermatológica, estrutural, circulatória e neurológica estão descritos no item coleta de dados, nos quais especificam-se os critérios para determinar a preservação ou não da sensibilidade tátil pressórica plantar e sensibilidade vibratória. 
O instrumento foi reformulado a partir da revisão sistemática. Outras modificações também se realizaram depois de ter-se aplicado em quatro pessoas, com o objetivo de avaliar sua coerência interna, nesse momento, o instrumento foi aplicado pela pesquisadora e outra enfermeira, em pessoas que não fizeram parte da população de estudo.

\subsection{9-Procedimento de coleta de dados}

A primeira entrevista e avaliação foram realizadas pela pesquisadora e uma enfermeira treinada, em consultório de cada UBDS. Das 130 pessoas que tiveram retorno agendado, 29 não compareceram aos agendamentos e ao contato telefônico referiram problema de saúde e/ou familiares. Dessa forma, 101 pessoas com diabetes tipo 2 compareceram às respectivas unidades para proceder à coleta de dados.

A cada participante foi apresentado o termo de consentimento livre e esclarecido e após sua assinatura, procedia-se à entrevista e exame dos pés. Nesse momento também era fornecido orientação sobre a importância do controle do diabetes e cuidados com os pés de modo específico. A seguir descrevem-se os procedimentos utilizados nessa avaliação:

Avaliação dermatológica

Com o participante em decúbito dorsal, com os sapatos e meias, previamente descalçados, o avaliador procedia ao exame minucioso das pernas e pés utilizando técnicas de observação e palpação, para identificar presença ou ausência alterações dermatológicas.

Avaliação estrutural

Com o participante em decúbito dorsal, o avaliador observava a presença alterações plantares e de dedos, além de proeminências ósseas.

Avaliação circulatória

Com o participante em decúbito dorsal, o avaliador procedia a identificar presença de edema de membros inferiores utilizando a técnica de fóvea, posteriormente, procedia-se à palpação digital dos pulsos tibial posterior e pediosos, nos membros direito e esquerdo. Claudicação era questionada ao participante indagando sobre presença de dor na panturrilha às caminhadas de um ou mais quarteirões e si esta melhorava ou permanecia ao repouso. Para avaliar a temperatura dos pés utilizou-se um termômetro laser manual (Raytek-Minitemp, Brasil), localizando o ponto de aferição no dorso médio do pé, durante aproximadamente três minutos. 


\section{Avaliação neurológica}

Para a sensibilidade tátil pressórica plantar e dorsal, utilizou-se o monofilamento SW 5.07 (Sorri-Bauru, Brasil), o qual foi aplicado perpendicularmente em dez pontos de cada pé (conforme instrumento), com o participante em decúbito dorsal. Essa sensibilidade foi considerada comprometida, quando houve insensibilidade em quatro pontos do pé. À presença de sensibilidade foi atribuído o valor "2" e à ausência ou diminuição “1”. Ambos pés somariam 40 e, conseqüentemente, valores acima de 32 consideraram-se como sensibilidade preservada.

Para a sensibilidade vibratória dorsal utilizou-se o diapasão de 128 Hz (Graham-Field Company, América do Norte), o qual foi aplicado perpendicularmente em quatro pontos de cada pé (conforme instrumento), intercalando o instrumento com e sem vibração. Essa sensibilidade foi considerada comprometida, quando houve insensibilidade em dois pontos do pé. À presença de sensibilidade foi atribuído o valor "2" e, à ausência ou diminuição "1". Ambos pés somariam 16 e, conseqüentemente, valores acima de 12 consideraram-se como sensibilidade vibratória preservada.

A segunda e terceira avaliação realizaram-se em agosto de 2004 e fevereiro de 2005, respectivamente, por duas pessoas externas ao estudo, previamente treinadas, utilizando o mesmo instrumento aplicado no basal, apenas desconsiderando os dados socio-demográficos e dados relacionados à doença e antecedentes clínicos. Estas duas pessoas foram cegadas ao tipo de estudo em desenvolvimento e não tinham nenhum tipo de envolvimento com as respectivas UBDS.

Nos três momentos da aplicação dos instrumentos, caso o participante não tivesse resultado sobre o controle metabólico recente no seu prontuário (correspondente aos últimos três meses), era verificado junto ao médico, a possibilidade de solicitação dos exames necessários (conforme estudo).

\subsubsection{0-Processo de randomização dos grupos}

Ao término da coleta de dados, os instrumentos de ambas unidades foram embaralhados para proceder à alocação randômica dos participantes nos grupos previstos. Para isto foi utilizada a técnica de blocos $(2 \times 3)$ mediante sistema informatizado disponível on-line $<$ http://www.randomization.com>, por se tratar de população de base pequena (CUMMINGS; 
GRADY; STEPHEN, 2003). Posteriormente, utilizando uma moeda, sorteou-se qual dos grupos deveria receber a intervenção proposta.

\subsubsection{1- Procedimento da aplicação da intervenção}

\section{Atividades de sensibilização e educação para os pacientes}

No grupo intervenção:

Foram desenvolvidas atividades de sensibilização educativa pelo pesquisador, conforme os princípios de teoria de educação para adultos (DOAK; DOAK; ROOT, 1995; COATE, 1999). Nessa abordagem destaca-se que os adultos se interessam por resolver ou manejar seus próprios problemas, com a conseqüente satisfação de seu autocuidado, no qual participam ativamente (DOAK; DOAK; ROOT, 1995). Os princípios considerados na abordagem são os seguintes:

1) A necessidade de conhecimento: os adultos precisam saber inicialmente, por que eles necessitam de conhecimento, para logo se dispor a aprender.

2) $\mathrm{O}$ conceito de auto-aprendizagem: os adultos têm o autoconceito de que eles são responsáveis pelas decisões de sua própria vida. Em tal sentido é importante considerar sua autopercepção na elaboração do plano de ensino. Isto determinará o tipo de interrelação a ser estabelecida entre o profissional e o receptor (participante do estudo).

3) O papel da experiência na aprendizagem: os adultos chegam a um ambiente educativo com experiências passadas que desejam manter acima de uma situação imediata. É importante considerar portanto, os conhecimentos, habilidades e percepções do mesmo. Isto pode ajudar a promover uma parceria entre profissional e receptor, assumindo que o participante não é leigo a toda informação e que pode, certamente, trazer ensinamentos ao profissional.

4) Vontade para aprender: os adultos aprendem rapidamente aquilo que eles precisam conhecer e são capazes de ter disposição para lidar efetivamente com situações de sua vida real. É prudente não sobrecarregar ao participante com informações excessivas; pequenas e freqüentes sessões podem ser mais efetivas que uma sessão prolongada. Evitar propor plano de ensino a pessoas que não estão dispostas a aprender. 
5) Orientação para aprender: ao contrário da orientação às pessoas jovens, que focalizam sua atenção em aprender; adultos focalizam-se na vida. Eles são motivados a aprender algo, se acreditam que aquilo lhes ajudará a entender as situações da vida real.

6) Motivação: embora os adultos sempre correspondem a alguma motivação externa, tal como um melhor trabalho, a maior parte de suas motivações são de ordem interna (exemplo: aumentar a satisfação no trabalho, a qualidade de vida). Comentário verbal e sugestão não verbal ajudam a determinar como a pessoa pode estar bem motivada e conforme com o plano educativo. Se uma pessoa não está bem motivada, tentar descobrir quais as razões subjacentes (COATE, 1999).

Dessa forma, planejaram-se seis sessões de sensibilização durante um período de seis semanas, de fevereiro a março de 2004, com previsão de uma sessão semanal para cada grupo de 5 a 7 participantes. O programa foi comunicado aos participantes por contato telefônico. Desta forma, em cada UBDS foram programadas sessões de duas horas para quatro grupos durante a semana, divididos em dias alternados e em dois horários, das 8:00 às 10:00 e das 16:00 às 18:00 horas.

As sessões foram realizadas mediante exposição oral com auxílio de projetor de slides. Nos primeiros 15 minutos, os participantes eram estimulados a interagirem uns com outros verbalizando suas dúvidas e inquietações para criar um ambiente favorável e descontraído. Nos próximos 15 minutos apresentavam-se os objetivos do tema a ser desenvolvido no dia e também se indagava os conhecimentos e experiências prévias dos participantes com relação ao tema a tratar. A partir da segunda sessão, neste momento também foram revistos aspectos apontados na sessão anterior.

Durante a apresentação de cada conteúdo, permitia-se que os participantes formulassem suas dúvidas a qualquer momento, considerando que a troca de experiências poderia favorecer a interação grupal. Nos últimos 15 minutos das sessões, a partir da segunda reunião, por solicitação dos participantes, era realizado o teste de glicemia capilar. Ao final de cada sessão, proporcionava-se aos participantes panfletos coloridos com informações, predominantemente, em desenhos resumindo os conteúdos.

Quanto aos conteúdos, nas primeiras três sessões foram abordados, de forma simplificada, assuntos relacionados com a fisiopatologia do diabetes, importância do autocuidado perante a manutenção de uma vida saudável (alimentação apropriada e atividade física), complicações 
agudas e crônicas. Nas três subseqüentes, destacaram-se as complicações em membros inferiores e cuidados preventivos com os pés, os quais desenvolveram-se com demonstrações e práticas. $\mathrm{Na}$ quarta sessão, observaram-se as habilidades e limitações de cada participante para realizar o autocuidado dos pés e na quinta, cada participante recebeu um kit de cuidado, composto de um espelho, toalha e lixa de papel para os pés.

Após seis semanas de concluídas as sessões, foi agendada uma consulta mensal para cada um dos participantes, até a conclusão dos 12 meses do ensaio, a fim de reforçar as ações de autocuidado e observar as condições dos pés. Nestas consultas, durante os primeiros meses, também foram realizados cuidados básicos com as unhas e pés, reforçando com demonstrações. Posteriormente, esses cuidados apenas eram supervisionados observando as condições dos membros inferiores e calçados. Entretanto, esta fase de supervisão não se concretizou entre pessoas idosas, obesas, com déficit visual ou de mobilidade, que moravam sozinhas ou apenas com parceiro (a), devido à necessidade inerente, da realização do cuidado pelo profissional, observada a cada retorno.

No grupo-controle:

Foram realizadas duas sessões de orientação geral pelo pesquisador, nos meses de março e setembro, com um tempo médio de duas horas de duração, abordando na primeira as complicações crônicas do diabetes e na segunda, as complicações nos membros inferiores, destacando-se também a rotina de atendimento da UBDS.

\section{Atividades de sensibilização e educação para os profissionais}

A programação do curso para a sensibilização e educação dos profissionais foi organizada no mês de junho de 2004, em parceria com a responsável da Assessoria Técnica do Programa de Diabetes e a Direção de Enfermagem da Secretaria Municipal de Saúde de Ribeirão Preto (anexo 9).

A sensibilização dos profissionais foi desenvolvida nos meses de agosto (Vila Virgínia) e setembro (Quintino) no ambiente de cada UBDS, mediante um curso programado com três reuniões para cada unidade, incluindo a participação da pesquisadora e de outros profissionais. Cada reunião teve uma duração de três horas, totalizando nove horas entre teoria e prática, que incluiu demonstração da avaliação dos membros inferiores na última reunião, na qual colaboraram duas pessoas com diabetes em cada UBDS. 
No desenvolvimento do curso, pelo menos um médico e/ou enfermeiro da cada UBDS esteve presente, além dos profissionais de cada UBS das respectivas áreas distritais.

\subsubsection{2-Análise dos dados}

Os dados obtidos nos grupos foram digitados e processados eletronicamente. Para as comparações entre os grupos foi utilizado o teste estatístico t de Student, para as variáveis contínuas, quando apropriado e o teste de $\mathrm{X}^{2}$ ou teste exato de Fisher e Mann-Whitney, para as variáveis qualitativas. $O$ nível de significância usado em todos os testes será de $\alpha=0,05$. Os cálculos das análises estatísticas foram realizados com auxilio do Programa SPSS/CP (versão 10.1). 


\section{RESULTADOS E DISCUSSÃO}

\section{1- REVISÃO SISTEMÁTICA}

Inicialmente identificaram-se 3.941 artigos relacionados à temática proposta, os quais foram submetidos à análise dos resumos, excluindo-se 3.323 estudos, por apresentarem tópicos não considerados na pesquisa.

Dessa forma 618 artigos pré-selecionados foram analisados de forma independente por duas pesquisadoras conforme critérios estabelecidos. Nesse momento excluíram-se outros 550 artigos e selecionou-se apenas 68, entre estudos prospectivos primários, revisões e diretrizes clínicas.

Desses artigos, todos foram lidos na íntegra exceto três estudos, os quais foram impossíveis de adquiri-los por não serem acessíveis. Assim, dos 65 artigos restantes excluíram-se outros 44. As causas dessas exclusões foram: 16 abordaram intervenções educativas entre pessoas com diabetes (seis classificaram os pacientes segundo categoria de risco e avaliaram adesão ao programa; dois foram controles de si mesmo; dois secundários de estudos prévios; quatro não randomizados e dois randomizados, porém incluiu pacientes de alto risco) e nove intervenções na organização do cuidado dessas pessoas entre profissionais (três de tipo antes e depois; um não randomizado e cinco randomizados, destes últimos, dois não avaliaram os pés e três avaliaram aos profissionais e/ou registros). Outros 19 estudos excluídos corresponderam às revisões sistemáticas (nove) e às diretrizes clínicas (10). Os primeiros incluíram revisões amplas ou envolviam outros tipos de intervenções ou tinham descrição metodológica incompleta e, os segundos, omitiram na metodologia detalhes importantes do seu desenvolvimento. No Gráfico 6.1 apresenta-se o processo da seleção dos estudos.

Dessa forma, incluíram-se no estudo 10 artigos, duas revisões e nove diretrizes, os quais compuseram a revisão sistemática. Com relação às revisões sistemáticas, estas foram utilizadas como estudos de referência na discussão. 


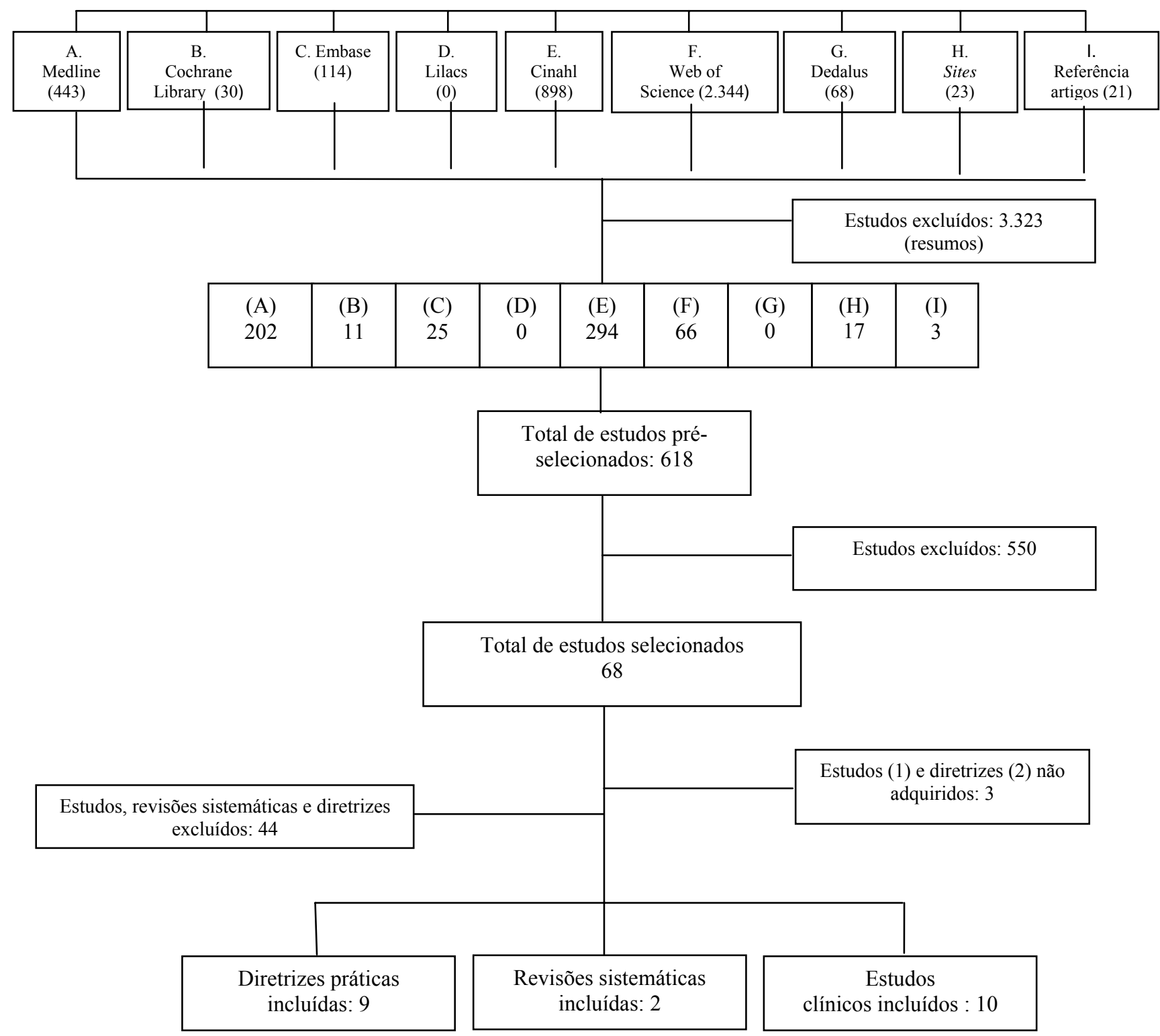

Gráfico 6.1. Número de estudos identificados nas bases de dados eletrônicas, sites de interesse e busca de referências citadas.

\subsection{1- Estudos relacionados às intervenções na organização do serviço}

Intervenções direcionadas à organização do serviço para o cuidado das pessoas com diabetes envolvendo profissionais, totalizaram 13 artigos de ensaios clínicos, com ênfase na prevenção de complicações do diabetes e/ou melhora à adesão terapêutica. Desses, nove não atenderam aos critérios de inclusão e encontram-se listados na referência bibliográfica, na sessão estudos excluídos. 
Os ensaios clínicos incluídos nesta revisão estão apresentados na Tabela 6.1, a qual contém informações sobre o (s) autor (s), ambiente de desenvolvimento do ensaio, descrição dos tipos de assistência proporcionadas em ambos os grupos (quando presente a informação), avaliação da propriedade dos resultados e resultados, propriamente ditos.

$\mathrm{Na}$ avaliação da propriedade dos resultados consideraram-se seis critérios. Os três primeiros correspondem às guias primarias (alocação randomizada, população representativa, cruzamento entre grupos) e os três subseqüentes, às guias secundárias (mascaramento dos avaliadores, semelhança entre grupos e presença de co-intervenção) de acordo com Stotts (1999). 
Tabela 6.1 - Estudos de ensaio clínicos relacionados com intervenções na organização do serviço para o cuidado envolvendo profissionais.

\begin{tabular}{|c|c|c|c|c|c|c|c|c|c|}
\hline \multirow[t]{2}{*}{ Autor (es) } & \multirow{2}{*}{$\begin{array}{c}\text { Ambientes de } \\
\text { ensaio }\end{array}$} & \multirow[t]{2}{*}{ Tipo de assistência } & \multicolumn{6}{|c|}{ Avaliação da Propriedade dos resultados } & \multirow{2}{*}{$\begin{array}{c}\text { Resultados } \\
\text { Estimativa do efeito do tratamento }\end{array}$} \\
\hline & & & Randomização & População & \begin{tabular}{|l|l} 
Cruzamento \\
\end{tabular} & Mascaramento & Semelhança & Co-intervenç. & \\
\hline Porter (1982) & $\begin{array}{l}\text { Clinica Geral vs. } \\
\text { Clínica Diabética } \\
\text { do Hospital } \\
\text { Seguimento: } \\
24 \text { meses }\end{array}$ & $\begin{array}{l}\text { Intervenção (Int.). Padronização de registros } \\
\text { dos cuidados desenvolvidos pelo clínico geral } \\
\text { e sistema de convocação aos pacientes em } \\
\text { seguimento. Foram agendadas reuniões } \\
\text { regulares antes e durante o desenvolvimento } \\
\text { do estudo entre os profissionais da Clínica } \\
\text { Geral ee do Hopsital (consultores, } \\
\text { nutricionistas, enfermeiros, médicos en } \\
\text { quiropodistas). } \\
\text { Controle (Cont.). Cuidado convencional } \\
\text { oferecido pelo médico do hospital. }\end{array}$ & $\begin{array}{l}\text { Não claro } \\
\text { Int. ?** } \\
\text { Cont. ? }\end{array}$ & $\begin{array}{l}\text { Insulino- } \\
\text { dependentes } \\
\text { Considerados: ? } \\
\text { Inclúídos: } \\
197 \\
\text { Concluíram:? } \\
\text { Perdas:? } \\
\text { Mortalidade: } \\
\text { Int. 17/\%? } \\
\text { Cont. 8 } \% \% ?\end{array}$ & Não se sabe & Não se sabe & Não se sabe & Não se sabe & $\begin{array}{l}\text { Diferenças não significativas entre } \\
\text { grupos. } \\
\text { Indicadores: sintomas, função de de } \\
\text { membros inferiores, fundoscopia, pressão } \\
\text { arterial sanguínea, peso, glicemia e exame } \\
\text { de urina. }\end{array}$ \\
\hline $\begin{array}{l}\text { Hurwitz, } \\
\text { Goodman e } \\
\text { Yudkin (1993). }\end{array}$ & $\begin{array}{l}\text { Clinica Geral vs. } \\
\text { Clínica de } \\
\text { Diabetes do } \\
\text { Hospital } \\
\text { Seguimento: } \\
24 \text { meses. }\end{array}$ & $\begin{array}{l}\text { Int. Sistema de informação automatizada de } \\
\text { cuidado ao paciente pelo clínico geral, } \\
\text { conforme diretrizes para unidades } \\
\text { ambulatoriais clínicas de diabetes de hospital. } \\
\text { O sistema lembrava ao médico solicitar a cada } \\
\text { seis meses, exames de sangue e de urina. Os } \\
\text { resultados eram registrados no prontuário e } \\
\text { encaminhados ao paciente, o qual deveria } \\
\text { consultar ao profissional em 10 dias. Poder-se- } \\
\text { iam utilizar os serviços de nutricãao, quiropodia } \\
\text { e da clínica do hospital. Anualmente, o } \\
\text { paciente realizava fundoscopia com } \\
\text { optometrista, quem poderia encaminhá-lo ao } \\
\text { hospital. O sistema devia ser alimentado } \\
\text { conforme novos dados e enviar relatório do } \\
\text { paciente a outros serviços de atendimento. } \\
\text { Cont. Cuidado convencional pelo médico do } \\
\text { hospital, com avaliação anual de peso, } \\
\text { glicemia, albuminúria, pressão arterial, exame } \\
\text { de pés e acuidade visual, além de fundoscopia. } \\
\text { Porém, pés e olhos apenas eram avaliados } \\
\text { quando necessário. }\end{array}$ & $\begin{array}{l}\text { Não claro } \\
\text { Int, } 89 \\
\text { Cont. } 92\end{array}$ & $\begin{array}{l}\text { Diabetes tipo } 2 . \\
\text { Considerados: } \\
415 \\
\text { Incluídos: } 181 \\
\\
\text { Concluíram: } \\
\text { Int. 78/88\% } \\
\text { Cont. } 86 / 93 \% \\
\text { Perdas: } \\
17 / 9,4 \% \\
\\
\text { Mortalidade: } \\
\text { Int. 7/8\% } \\
\text { Cont. 7/8\% }\end{array}$ & Sim & Não & $\begin{array}{l}\text { Sim, } \\
\text { exceto pela } \\
\text { maior pressão } \\
\text { sistólica no } \\
\text { grupo Cont. } \\
\text { (p<0.011) e } \\
\text { presença de } \\
\text { isquemia em } \\
\text { membro } \\
\text { inferior no } \\
\text { grupo Int } \\
\text { (p<0,017). }\end{array}$ & Sim & $\begin{array}{l}\text { Int. vs. Cont. (\%): } \\
\text { Pacientes sem consulta médica } \\
3 / 89 \text { vs } 14 / 92 \mathrm{p}<0,013 \text {. } \\
\text { Int. vs. Cont. (média): } \\
\text { Pacientes com um ou + consultas médicas } \\
1,7 \text { vs. } 2,0 \mathrm{p}<0,005 \\
\text { Consulta médica (paciente/médico) } \\
3,2 \text { vs. } 2,2 \mathrm{p}<0,001 \\
\text { Albuminúria (paciente/ano) } \\
3,0 \text { vs. } 2,3 \mathrm{p}<0,03 \\
\text { Glicose (paciente/ano) } \\
3,1 \text { vs. } 2,3 \mathrm{p}<0,003 \\
\mathrm{HbA}_{\text {lc }} \text { (paciente/ano) } \\
2,4 \text { vs. } 0,9 \mathrm{p}<0,001\end{array}$ \\
\hline
\end{tabular}




\begin{tabular}{|c|c|c|c|c|c|c|c|c|c|}
\hline DICE (1994) & $\begin{array}{l}\text { Clinica Geral vs. } \\
\text { Clínica de } \\
\text { Diabetes do } \\
\text { Hospital. } \\
\text { seguimento: } \\
24 \text { meses. }\end{array}$ & $\begin{array}{l}\text { Int. Pacientes foram avaliados a cada } 3 / 4 \\
\text { meses pela clinica geral e anualmente na } \\
\text { clínica de diabetes do hospital. Médicos } \\
\text { receberam diretrizes do cuidado integrado ao } \\
\text { paciente e sistema de informaçãa automatizada } \\
\text { de convocacão dos mesmos as consultas. O } \\
\text { clínico geral otimizava a glicemia, registrava o } \\
\text { peso e resultado de urina. Anualmente deveria } \\
\text { avaliar a pressão arterial, pulsos arteriais, } \\
\text { acuidade visual, condiçoses dos pés, reflexos } \\
\text { tendinosos e sensoriais. O sistema devia ser } \\
\text { alimentado com novos dados. } \\
\text { Cont. Cuidado convencional no hospital, a } \\
\text { intervalos irregulares de quatro meses. Sistema } \\
\text { informatizado apenas emitiu cartas para } \\
\text { lembrar aos pacientes, da rotina das consultas. }\end{array}$ & $\begin{array}{l}\text { Não claro } \\
\text { Int. } 139 \\
\text { Cont. } 135 \\
\\
\end{array}$ & $\begin{array}{l}\text { Diabetes tipo } 2 . \\
\text { Considerados: } \\
311 \text { I1 } \\
\text { Inclúdos: } \\
274 \\
\text { Concluíram: } \\
\text { Int. } 117 / 84 \% \\
\text { Cont. } 103 / 76 \% \\
\text { Perdas: } \\
54(20 \%) \\
\text { Mortalidade: } \\
\text { Int 11/110\% } \\
\text { Cont. } 10 / 7 \%\end{array}$ & Não se sabe & Não & Sim & Não se sabe & $\begin{array}{l}\text { Int. vs. Cont. (média })(p<0,05) \text { : } \\
\text { Freqüência de exames e avaliação na } \\
\text { visita de rotina } 5,3 \text { vs. } 4,8 \\
\text { HbA }_{1 \mathrm{c}} 4,5 \text { vs. } 1,3 \\
\text { Pressão arterial } 4,2 \text { vs. } 1,2 \\
\text { Acuidade visual } 2,6 \text { vs. } 0,7 \\
\text { Fundoscopia } 1,1 \text { vs. } 0,9 \\
\text { Pulsos periféricos } 1,9 \text { vs. } 0,5 \\
\text { Exame neurológico } 1,9 \text { vs. } 0,5 \\
\text { Exame de pés } 1,4 \text { vs. } 0,5 \\
\text { Int. vs. Cont. (\%): } \\
\text { Consulta quiropodia } 58 \text { vs. } 26\end{array}$ \\
\hline $\begin{array}{l}\text { Donohoe et al. } \\
\text { (2000) }\end{array}$ & $\begin{array}{l}\text { Clínica Geral. } \\
\text { Seguimento: } \\
6 \text { meses. }\end{array}$ & $\begin{array}{l}\text { Int. Profissionais (médicos/enfermeiros) } \\
\text { avaliavam anualmente os pés dos pacientes. } \\
\text { Desenvolveu-se de processo educativo } \\
\text { mediante visitas e demonstraçóes de avaliação } \\
\text { e manejo do "pé em alto risco" para os } \\
\text { profissionais, enfatizando responsabilidades } \\
\text { partilhadas entre eles e pacientes. } \\
\text { Monofilamento } 5,07 \text { e diretrizes clínicas de } \\
\text { encaminhamento para quiropodia e clínica de } \\
\text { pés foram relevantes. Quiropodistas também } \\
\text { participaram do processo educativo } \\
\text { especializado. Folhetos de cuidado com os pés } \\
\text { foram difundidos entre pacientes. } \\
\text { Cont. Cuidado convencional pelo clínico geral. } \\
\text { Profissionais participaram de intervenção } \\
\text { educativa, abordando outro tema (nefropatia). }\end{array}$ & $\begin{array}{l}\text { Sim } \\
\text { Int. } 981 \\
\text { Cont. } 958 \\
\\
\end{array}$ & $\begin{array}{l}\text { Diabetes tipo } 1 \\
\text { e 2. } \\
\text { Considerados: } \\
\text { 2028 } \\
\text { Incluídos: } 1939 \\
\text { Concluíram: } \\
\text { Int. } 667 / 68 \% \\
\text { Cont.623/65\% } \\
\text { Perdas: } \\
649 / 33 \% \\
\text { Mortalidade: } \\
?\end{array}$ & Não & Não & $\begin{array}{l}\text { Sim. } \\
\text { Porém, } \\
\text { comparação } \\
\text { entre aqueles } \\
\text { que concluíram } \\
\text { o estudo e as } \\
\text { perdas mostrou } \\
\text { diferença } \\
\text { significativa em } \\
\text { HbA } 1 \text { ic idade e } \\
\text { diabetes tipo } 1 \\
\text { (p<0,001). }\end{array}$ & Não se sabe & $\begin{array}{l}\text { Int. vs. Cont. (n/média): } \\
\text { Conhecimento de cuidado pé diabético } \\
638 / 1,09 \text { vs. } 580 / 1,32 \mathrm{p}>0,5 \\
\text { Atitude geral para cuidado do pé } \\
629 / 3,91 \text { vs. } 586 / 0,68 \mathrm{p}=0,010 \\
\text { Atitude para autocuidado do pé } \\
629 / 2,49 \text { vs. } 586 /-0,17 \mathrm{p}=0,027 \\
\text { Atitude para cuidado do pé diabético } \\
629 / 3,00 \text { vs. } 586 / 1,82 \mathrm{p}>0,05 \\
\text { Int. vs. Cont. (n/\%): } \\
\text { Avaliação anual pé } \\
652 / 76 \text { vs. } 642 / 67 \mathrm{p}=0,35 \\
\text { Encaminhamento à clínica especializada } \\
\text { aumentou no grupo Int. nos pacientes com } \\
\text { "pé em alto risco" (p=0,046), porém, sem } \\
\text { diferença entre grupos. }\end{array}$ \\
\hline
\end{tabular}


Na Tabela 6.1, a maioria dos ensaios clínicos incluídos foi também considerado na revisão previamente realizada por Mason et al. (1999), exceto o estudo de Donohoe et al. (2000). Entretanto, os ensaios de Hayes e Harries (1989) e Hoskins et al. (1993) foram excluídos, pois estes dois ensaios não direcionaram suas intervenções, de modo geral ou específico, à prevenção de complicações nos pés, conforme os dados considerados nos desfechos.

Pelos dados descritos em cada ensaio, a população inserida nos diversos estudos que abordaram a organização do serviço apresentava baixo risco para úlceras, exceto no ensaio de Porter (1982), o qual não fornecia maiores detalhes metodológicos, possivelmente, por tratar-se de uma carta.

Todas as intervenções propostas foram desenvolvidas em unidades de assistência primária aplicando modelos de cuidado integrado às pessoas com diabetes. Porter (1982), Hurwitz, Goodman e Yudkin (1993) e DICE (1994) compararam seus resultados com o tipo de assistência oferecida nas clínicas especializadas de diabetes dos hospitais, sendo que nos dois últimos ensaios, as intervenções incluíram assistência compartilhada com as referidas clínicas. Dessa forma, os pacientes também puderam ser atendidos no hospital, anualmente, conforme o programa de intervenção ou quando era necessário.

De acordo com Mason et al. (1999), o cuidado compartilhado foi definido como uma participação articulada entre hospital e unidade primária, para oferecer assistência às pessoas com doenças crônicas, na perspectiva de intensificar o intercâmbio de informação entre ambos locais.

No atendimento às pessoas com diabetes, este modelo foi adaptado para destacar a comunicação como meio de coordenação estruturada no cuidado dos mesmos, bem como para demonstrar que as unidades primárias, se bem organizadas, podem cuidar efetivamente do controle metabólico do DM tipo 2 e, possivelmente, com menores recursos financeiros.

Este fato, certamente, ainda é inconclusivo. Existem vários estudos interessados em avaliar a qualidade de cuidado oferecido tanto pelas clinicas especializadas em diabetes, quanto pelas unidades primárias, os quais apontam que as clínicas especializadas oferecem cuidado de melhor qualidade para as pessoas com diabetes, principalmente, por incluírem médicos especialistas e cuidados padronizados, mediante a utilização de diretrizes clínicas (HO et al. 1997; CHIN; ZAN; MERRELL, 1999; GREENFIELD et al., 2002; BERARDIS et al., 2004). Entretanto, o controle metabólico, o indicador do controle da doença e, especialmente, de suas 
complicações crônicas, tem sido considerado pouco relevante nesses estudos e, em geral, não apresentaram maiores diferenças comparando o atendimento entre ambas unidades.

Desse modo, é necessário que ensaios clínicos randomizados bem estruturados incluindo grande população de pacientes e médicos sejam desenvolvidos, entendendo a interferência de muitas variáveis de confusão, principalmente entre a população médica envolvida, os quais conscientes de sua participação, podem tendênciar os resultados a favor próprio, independente da unidade de atendimento.

Quanto à revisão, os programas implementados consideraram a melhor documentação dos registros sobre os pacientes, de forma informatizada ou impressa, com consultas regulares e sistema de agendamento estruturado (PORTER, 1982; HURWITZ; GOODMAN; YUDKIN, 1993; DICE, 1994), sendo que a organização do cuidado embasada em diretrizes clínicas direcionadas para o manejo do diabetes em ambulatório de unidade hospitalar - identificado como unidade especializada em diabetes, foi utilizado em dois ensaios (HURWITZ; GOODMAN; YUDKIN, 1993, DICE, 1994), nos quais se mantiveram as mesmas especificidades do manejo da doença, porém com maior freqüência de consultas conforme observado na Tabela 6.1.

Em ambos os ensaios, o sistema informatizado reforçava o atendimento do paciente mediante a programação automatizada, para lembrar aos médicos sobre as necessidades pendentes e favorecer o fluxo de informação entre seus diversos atendimentos. Fato que, conseqüentemente, deveria melhorar o atendimento dessas pessoas e de modo geral, o controle metabólico.

No ensaio clínico de Donohoe et al. (2000), a organização do cuidado esteve direcionada, especificamente, ao manejo de complicações nos pés, destacando a participação consciente da equipe multiprofissional na unidade primária. Assim, o reconhecimento e manejo do "pé em alto risco" foram focalizados valorizando o encaminhamento de pessoas nessa condição para a clinica “especializada em pé”.

$\mathrm{O}$ envolvimento da equipe multiprofissional no cuidado das pessoas com diabetes foi apresentado nos ensaios de Porter (1982) e Donohoe et al. (2000), com participação principalmente, de médicos, enfermeiros e quiropodistas.

Esse envolvimento é fundamental, especialmente, frente ao risco de complicações em membros inferiores das pessoas com diabetes, devido à multiplicidade de fatores intrínsecos e extrínsecos envolvidos no seu desencadeamento. È relevante destacar o monitoramento adequado do controle metabólico, bem como as necessidades e condutas de autocuidado da doença e de suas 
complicações e que o enfermeiro, com treinamento específico, tem participado desse cuidado em todas as fases de prevenção e intervenção.

No ensaio de Donohoe et al. (2000), o enfermeiro também foi responsável pelo rastreamento das pessoas com diabetes em risco de lesão/ulceração mediante a avaliação anual dos participantes. Esta habilidade deve levá-lo a detectar alterações neurológicas e vasculares periféricas, além de outros agravantes que podem precipitar processos ulcerativos.

Quanto aos cuidados relacionados com os pés, especificamente, em três ensaios clínicos foi considerada avaliação anual dos membros inferiores incluindo circulação periférica e neuropatia periférica (HURWITZ; GOODMAN; YUDKIN, 1993, DICE, 1994; DONOHOE et al., 2000). Entretanto, apenas um deles descreveu o monofilamento SW como instrumento para identificar risco para úlcera nos pés (DONOHOE et al., 2000).

$\mathrm{Na}$ avaliação metodológica dos ensaios identificaram-se limitações na validade interna conforme se pode observar na tabela 6.1 . O processo de randomização não foi descrito de forma explícita em Porter (1982), Hurwitz, Goodman e Yudkin (1993) e Dice (1994). O ensaio clínico de Donohoe (2000), que incluiu 10 unidades de assistência, o "cluster randomization" ou randomização por grupos pode ter sido apropriado, devido às unidades estarem localizadas em diferentes cidades e as mesmas compuseram os sujeitos de randomização.

Em três ensaios, a população incluída foi em média 217 pessoas (PORTER, 1982; HURWITZ; GOODMAN; YUDKIN, 1993; DICE, 1994). Ao todo se incluíram 2.591 pessoas com diabetes, com idades médias entre 58,1 a 66,7 anos.

Perdas por abandonos e óbitos variaram entre 9 e 33\%. Hurwitz, Goodman e Yudkin (1993) apresentaram menor número de perdas durante o período de seguimento. Entretanto, DICE (1994) referiram perdas de 3\% no grupo intervenção e $10 \%$ no grupo-controle, porém apresentação de dados basais em ambos os grupos mostrou perdas, de aproximadamente 16 e $24 \%$, respectivamente. Donohoe et al. (2000) obtiveram, aproximadamente, 33\% de perdas cujas causas não foram descritas. Perdas acima de $20 \%$ nos grupos podem afetar a avaliação dos desfechos nos estudos, principalmente, se essas perdas foram diferenciais entre grupos e, se o tamanho da amostra, não foi estimada com propriedade (BROWNER et al., 2003).

Observa-se, no entanto, que na maioria dos ensaios clínicos incluídos na revisão a população estudada foi selecionada dos registros de unidades predeterminadas, desse modo 
apenas àqueles que satisfizeram os critérios de inclusão foram considerados. Representado, de modo geral, $40 \%$ dessa população.

Cruzamento ou não dos participantes entre grupos não foi referido nos ensaios, nem de como esse viés foi controlado. Entretanto, no ensaio clínico de DICE (1994), 35 pacientes trocaram de grupo após processo de randomização. Hurwitz, Goodman e Yudkin (1993) referiram também que cinco participantes do grupo intervenção foram encaminhados para a clínica especializada em diabetes do hospital, após episódios de internação hospitalar, por solicitação voluntária.

Não houve descrição sobre o mascaramento dos avaliadores para o grupo intervenção. Procedimento importante para estudos abertos, devido à possibilidade de tendênciar os resultados a favor da intervenção proposta que, associado ao efeito Hawthorne, potencializam os desfechos, interferindo no real efeito da intervenção. No ensaio clínico de DICE (1994), o efeito Hawthorne parece ter sido provável, pelo fato de 35 pacientes terem trocado de grupo após randomização apresentando, certamente, melhores prognósticos nos desfechos.

Outro viés a considerar nos desfechos dos estudos é que todos os participantes vinham sendo acompanhados nas respectivas unidades antes de iniciar as intervenções e essa condição é relevante nos ensaios clínicos abertos. $\mathrm{O}$ fato das pessoas estarem cientes de participar do estudo, também potencializa a sensação de melhora e disposição para os procedimentos testados, em conseqüência, os desfechos esperados podem ser potencializados (MASON et al., 1998).

Os ensaios clínicos não fizeram referência ao controle das co-intervenções, nem de como elas foram minimizadas ou evitadas durante o desenvolvimento dos mesmos. Entretanto, o viés de aferição pode ser considerado nesta fase, o qual possivelmente ocorreu nos ensaios de Hurwitz, Goodman e Yudkin (1993) e DICE (1994), onde médicos envolvidos na pesquisa, paralelamente, prestaram assistência aos pacientes de ambos grupos, considerando a execução de cuidado compartilhado. Nesse sentido, é possível que esses médicos tenham prestado maior atenção às queixas e problemas das pessoas do grupo intervenção, em detrimento das necessidades daquelas do grupo controle e isso também constitui uma co-intervenção.

A co-intervenção poderia ocorrer ao encaminhar o paciente à clínica especializada em diabetes por alguma necessidade especifica (HURWITZ; GOODMAN; YUDKIN, 1993) ou quando realizado a avaliação anual (DICE, 1994). Ressalta-se que os participantes foram selecionados dos registros hospitalares e certamente, médicos e pacientes tiveram consultas 
prévias, sugerindo prováveis encontros posteriores entre ambos, sem necessariamente pertencerem ao mesmo grupo (MASON et al., 1999).

No ensaio de Donohoe et al. (2000), esse fato parece ter sido menos provável de ocorrer, devido às unidades possuírem apenas um tipo de intervenção. Os autores referiram que o período de seis meses do ensaio foi apropriado para controlar esse viés de intervenção.

Quanto aos resultados propriamente ditos, o ensaio clínico de Porter (1982) não mostrou diferença entre ambos os tipos de atendimentos. Os ensaios que implantaram sistema informatizado observaram aumento da freqüência do atendimento e avaliação entre pacientes do grupo intervenção, bem como do exame de $\mathrm{HbA}_{1 \mathrm{c}}$ (HURWITZ; GOODMAN; YUDKIN, 1993, DICE, 1994), porém não apresentaram mudanças no controle metabólico.

DICE (1994) mostrou aumento na freqüência de exame dos pés entre pacientes do grupo intervenção, paralelo à avaliação neurológica e de pulsos periféricos $(\mathrm{p}<0,05)$. Enquanto no ensaio clínico de Donohoe et. al. (2000), mais da metade dos pacientes do grupo intervenção tiveram seus pés examinados em relação aos dados basais $(\mathrm{p}<0,001)$, porém não houve diferença significativa entre grupos.

O serviço de quiropodia/podiatria foi considerado nos quatro ensaios clínicos, como componente importante das atividades de prevenção. Esse serviço dedica-se ao estudo e assistência dos pés, incluindo cuidado e tratamento. Entretanto, como referido previamente, no Brasil, não existe esta especialidade (GIPD, 2001) e profissionais previamente treinados, estão se envolvendo nessa área, frente à necessidade apresentada pelas pessoas com diabetes em relação aos problemas nos pés, que podem conduzir a amputação não-traumática do membro inferior.

O ensaio clínico de DICE (1994) mostrou aumento de encaminhamentos para o serviço de quiropodia. Donohoe et al. (2000) referiram que o curto período de seguimento dos pacientes, não permitiu avaliar esta melhora, devido, possivelmente, a longa fila de espera para essa especialidade de atendimento.

Alterações nos pés, tais como calosidades, fissuras, rachaduras, alterações estruturais, dermato-micose e/ou onicomicose, dentre outras, não foram apontadas nos ensaios clínicos. Donohoe et al. (2000), entretanto, descreveram as condições de alto risco dos pacientes que deveriam ser encaminhados para a clínica especializada de pé diabético.

Donohoe et al. (2000) mostraram também maior disposição dos pacientes para o cuidado e autocuidado dos pés no grupo intervenção. Nesse ensaio clínico, os pacientes receberam folhetos 
padronizados de cuidados com os pés, para reforçar a educação proporcionada pela equipe de atendimento primário, no entanto, o desenvolvimento desse processo educativo não foi descrito no estudo.

Conforme os critérios considerados na avaliação da propriedade dos resultados dos ensaios clínicos randomizados, deve-se ter cautela em sua interpretação, devido aos vieses apontados, conforme apresentados na Tabela 6.1.

Falhas metodológicas podem ser identificadas em todos os ensaios clínicos, que comprometem as conclusões, principalmente, relacionadas com carência de informações importantes, que enfraquecem a consistência de seus resultados, demonstrando que não há evidência do efeito.

Todos os ensaios clínicos incluídos na revisão, pelo menos, falharam a um critério relacionado nas guias primárias e secundárias da avaliação metodológica. O ensaio de Donohoe et al. (2000), parece ter controlado alguns vieses por ter incluído 10 unidades de observação, porém os avaliadores não foram mascarados aos grupos de intervenção e controle. No geral, não houve mascaramento dos avaliadores para os grupos de estudo.

Os ensaios clínicos não descrevem a evolução das possíveis complicações nos pés, que poderiam estar relacionadas com as intervenções propostas, provavelmente, devido à baixa condição de risco dos participantes.

É possível também, que o número reduzido de participantes e o curto período de seguimento dos ensaios, possam ter influenciado nesses resultados. Donohoe et al. (2000), apesar de acompanhado mais de 1.800 pessoas com diabetes teve um período de seguimento curto. Este último fato pode ter limitado a identificação de dados mais precisos a respeito da prevenção de complicações nos pés ou de melhoramento das condições nos pés.

Estudo sobre prevalência de úlcera nos pés entre pessoas da assistência primaria mostrou uma taxa de 1,8\% durante o período de observação (SONNAVILLE et al., 1997). Estudo mais recente realizado na população holandesa mostrou uma incidência anual de úlcera de 1,2\% a 3,0\%, com uma média de 2,1\% entre pessoas em risco (MULLER et al., 2002). Estes dados indicam que as taxas de incidência anual de úlceras realmente são baixas, precisando-se portanto, de grande número de pessoas com diabetes para obter resultados concretos.

Dessa forma, é necessário que ensaios clínicos direcionados à prevenção de complicações nos pés entre pessoas com diabetes tenham um período mais longo de seguimento, incluindo 
maior numero de participantes por grupos, além de profissionais de saúde, tais como médicos, enfermeiros, quiropodistas, dentre outros, para avaliar a efetividade do cuidado organizado considerando o trabalho sincronizado de uma equipe básica de atendimento, atenta a identificação precoce de sinais de comprometimento nos pés e no controle metabólico, no geral.

Por outro lado, previsão de custos elevados, perdas no seguimento, vieses de seleção, intervenção e avaliação, deveriam ser, rigorosamente considerados em futuros ensaios clínicos randomizados controlados e, concomitantemente, as variáveis de confusão inerente ás condições dos participantes, tais como idade, escolaridade, gravidade da doença, enfermidades crônicas, dentre outras.

Entretanto, é possível que nesta revisão possa estar presente o viés de publicação, considerando que a busca dos ensaios clínicos randomizados foram restritos à língua inglesa, portuguesa e espanhola, tendo sido desconsiderado também a busca manual e na grey literature. Porém, lembra-se que de todos os ensaios clínicos randomizados incluídos na revisão sistemática, nenhum deles reportou dados com desfechos significantes, fato que diminui a possibilidade desse viés estar presente.

Outro aspecto a considerar na revisão, relaciona-se à quantidade de revisores participantes na avaliação na fase de coleta do conteúdo dos ensaios clínicos. Em geral, é recomendável que, pelo menos, dois revisores desenvolvam todas as fases da revisão, de forma independente, para diminuir as subjetividades na interpretação dos dados conforme a óptica e experiência pessoal, esta parceria estaria favorecendo a discussão de dúvidas e discordâncias de opiniões, em prol de uma análise mais acurada. Não obstante, ressalta-se a participação de especialistas no método de revisão sistemática e na área de diabetes que aborda o estudo, na análise final desta revisão.

Conforme exposto, ainda não está claramente definido, qual o melhor modelo de organização que a equipe de assistência primária deve implantar, nem qual a periodicidade das consultas para prevenir lesão/ulceração nos pés das pessoas com DM de baixo risco. Em conseqüência, devem-se estruturar novos estudos de intervenções que possam contribuir na concretização da atuação dessa equipe, visando a prevenir complicações nos pés e principalmente, incluindo ensaios clínicos randomizados controlados de qualidade metodológica apropriada. 


\subsection{2- Estudos relacionados com intervenções educativas entre pessoas com DM}

Nos estudos relacionados com as intervenções educativas identificaram-se na literatura 22 artigos prospectivos, com ênfase na prevenção de complicações nos pés da pessoa com diabetes. Desses, 16 não atenderam aos critérios de inclusão e encontram-se listados na referência bibliográfica, na sessão estudos excluídos.

Os seis estudos incluídos na revisão foram desenvolvidos no nível de assistência primária e secundária, com ou sem participação da equipe multiprofissional. Na Tabela 6.2 apresentam-se os detalhes metodológicos e os resultados desses estudos. 
Tabela 6.2 - Estudos de ensaios clínicos relacionados com intervenções educativas nas pessoas com diabetes.

\begin{tabular}{|c|c|c|c|c|c|c|c|c|c|}
\hline \multirow[t]{2}{*}{ Autor (es) } & \multirow{2}{*}{$\begin{array}{l}\text { Ambiente de } \\
\text { estudo }\end{array}$} & \multirow[t]{2}{*}{ Tipo de assistência } & \multicolumn{6}{|c|}{ Avaliação da Propriedade dos resultados } & \multirow{2}{*}{$\begin{array}{c}\text { Resultados } \\
\text { Estimativa do efeito do tratamento }\end{array}$} \\
\hline & & & Randomização & População & Cruzamento & Mascaramento & Semelhança & Co-intervenç. & \\
\hline $\begin{array}{l}\text { Mazzuca } \\
(1986)\end{array}$ et al. & $\begin{array}{l}\text { Clinica Geral do } \\
\text { Centro Médico da } \\
\text { cidade afiliada à } \\
\text { Universidade de } \\
\text { Indiana. } \\
\text { Seguimento: } \\
14 \text { meses }\end{array}$ & 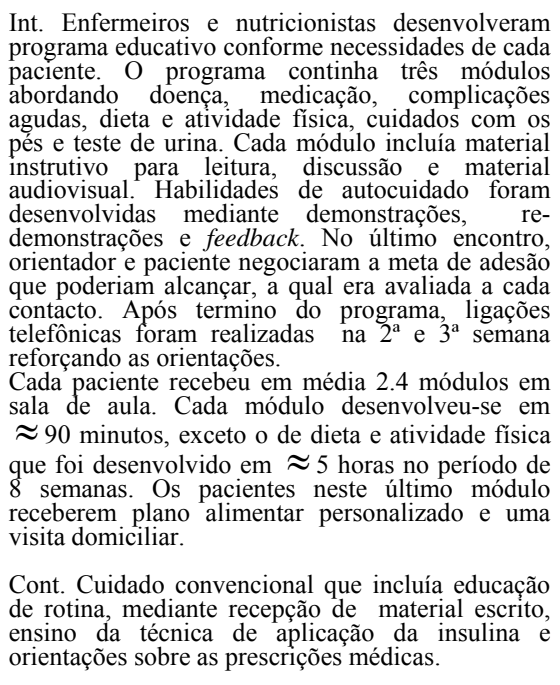 & $\begin{array}{l}\text { Não claro } \\
\text { Int. } 263 \\
\text { Cont. } 269\end{array}$ & $\begin{array}{l}\text { Diabetes tipo } 1 \\
\text { e } 2 \text {. } \\
\text { Considerados: } \\
1800 \text { Incluídos: } \\
532 \\
\text { Concluíram: } \\
\text { Int.135/51\% } \\
\text { Cont.140/52\% } \\
\text { Perdas: } \\
256 / 48 \% \\
\text { Mortalidade: } \\
\text { 30/6\% }\end{array}$ & Não se sabe & Não & $\begin{array}{l}\text { Não } \\
\text { Grupo } 1 \text { teve } \\
\text { melhor controle } \\
\text { da glicemia e }< \\
\text { peso corporal. } \\
\text { Grupo } 4 \text { teve }> \\
\text { glicemia e }> \\
\text { peso. } \\
\text { Ambos grupos } \\
\text { tinham valores } \\
\text { elevados de } \\
\text { creatinina em } \\
\text { relação aos } \\
\text { grupos } 2 \mathrm{e} 3 . \\
\text { Dados de } \\
\text { análise foram } \\
\text { ajustados para } \\
\text { essas variações. }\end{array}$ & Não se sabe & $\begin{array}{l}\text { Int. vs. Conto. (\%/n): } \\
\text { Conhecimentos: } \\
\text { Lista pelo menos } 2 \text { causas de } \\
\text { hiperglic. } 51,1 / 133 \text { vs. } 30,9 / 139 \\
\text { p=0,005 } \\
\text { Conhece condicões do teste de urina } \\
\text { com necessidade de cuidado } \\
\text { profissional } 92,5 / 133 \text { vs. } 78,8 / 137 \\
\text { p=0,001. } \\
\text { Habilidades: } \\
\text { No teste de urina espera tempo certo } \\
47,7 / 132 \text { vs. } 30,8 / 130 \mathrm{p}=0,003 \text { e } \\
\text { Interpreta corretamente resultado } \\
93,2 / 132 \text { vs. } 82,3 / 130 p=0,005 \text {. }\end{array}$ \\
\hline $\begin{array}{l}\text { Rettig et al. } \\
\text { (1986) }\end{array}$ & $\begin{array}{l}\text { Residencia vs. } \\
\text { Hospital } \\
\text { Seguimento: } \\
12 \text { meses }\end{array}$ & $\begin{array}{l}\text { Int. Enfermeiros de agências visitadoras contataram } \\
\text { os pacientes para determinar as necessidades } \\
\text { especificas de automanejo do diabetes a serem } \\
\text { melhoradas. Programa educativo desenvolveu-se } \\
\text { conforme número de visitas que o profissional } \\
\text { determinava, porem, não podiam exceder a } 12 \text {. } \\
\text { Profissionais participaram de curso intensivo sobre } \\
\text { autocuidado do diabetes, previo às visitas. O } \\
\text { programa avaliou conhecimento de autocuidado, } \\
\text { habilidades e aparencia dos pés ao } 6^{\circ} \text { mês. } \\
\text { Internacōes por doenças relacionadad foram } \\
\text { avaliadas ao } 2^{\circ} \text { mês. Paralalamente, os pacientes } \\
\text { também podiam participar de qualquer outro } \\
\text { programa de educação em diabetes. } \\
\text { Cont. Cuidado convencional e os pacientes estavam } \\
\text { liberados para participar de qualquer outro tipo de } \\
\text { educação em diabetes. }\end{array}$ & $\begin{array}{l}\text { Não claro } \\
\text { Int. } 228 \\
\text { Cont. } 243\end{array}$ & $\begin{array}{l}\text { Diabetes tipo } 1 \\
\text { e 2. } \\
\text { Considerados: } \\
? \\
\text { Incluídos: } \\
471 \\
\text { Concluíram: } \\
\text { Int.180/79\% } \\
\text { Cont.193/79\% } \\
\text { Perdas: } \\
\text { 98/21\% } \\
\text { Mortalidade ? }\end{array}$ & Não se sabe & Sim & Sim & Não se sabe & $\begin{array}{l}\text { Int. vs. Cont. (média) } \\
\text { Escore de conhecimento: } \\
\text { Dieta } 53,7 \text { vs. } 46,2 \mathrm{p}=0,001 \\
\text { Teste de urina } 57,3 \mathrm{vs} .45 \mathrm{p}=0,001 \\
\text { Medicação } 68,8 \text { vs. } 59,8 \mathrm{p}=0,001 \\
\text { Cuidado de pé } 62,2 \text { vs. } 53,1 \mathrm{p}=0,001 \\
\text { Escore de habilidade: } \\
\text { Teste de urina } 74,4 \text { vs. } 70,8 \mathrm{p}=0,01 \\
\text { Medicação } 65,2 \text { vs. } 62,2 \mathrm{p}=0,04 \\
\text { Cuidado com pés } 71,8 \text { vs. } 68,9 \\
\mathrm{p}>0,05 \\
\text { Aparência dos pés e freqüência de } \\
\text { hospitalizaçôes, sem diferença } \\
\text { significativa entre grupos. }\end{array}$ \\
\hline
\end{tabular}




\begin{tabular}{|c|c|c|c|c|c|c|c|c|c|}
\hline $\begin{array}{l}\text { Bloomgarden et } \\
\text { al. (1987). }\end{array}$ & $\begin{array}{l}\text { Clínica de } \\
\text { Diabetes do } \\
\text { Centro Médico } \\
\text { afiliado ao } \\
\text { Hospital de } \\
\text { Ensino } \\
\text { Metropolitano. } \\
\text { Seguimento: } \\
18 \text { meses. }\end{array}$ & 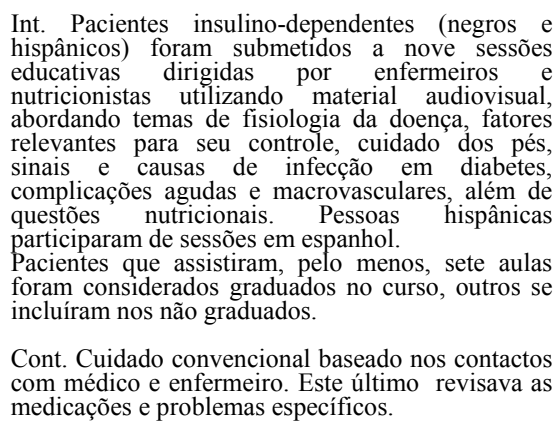 & $\begin{array}{l}\text { Não claro } \\
\text { Int. } 165 \\
\text { Cont. } 180\end{array}$ & $\begin{array}{l}\text { Diabetes tipo } 1 \\
\text { e 2. } \\
\text { Considerados: } \\
749 \\
\text { Inclú́dos: } \\
345 \\
\text { Concluíram: } \\
\text { Int. 127/77\% } \\
\text { Cont. } 139 / 77 \% \\
\text { Perdas: } 79 / 23 \% \\
\text { Mortalidade } \\
\text { Int. 5/3\% } \\
\text { Cont. } 6 / 3 \%\end{array}$ & Não se sabe & Não se sabe & $\begin{array}{l}\text { Sim, } \\
\text { exceto pela } \\
\text { maior } \\
\text { ocorrência de } \\
\text { lesões no pé no } \\
\text { grupo Cont. e } \\
\text { glicose } \\
\text { elevada em } \\
\text { jejum e maior } \\
\text { numero de } \\
\text { hospitalizacãos } \\
\text { no ano prévio } \\
\text { no grupo Int. } \\
\text { (p<0.05). }\end{array}$ & Não se sabe & $\begin{array}{l}\text { Int. vs. Cont. (média): } \\
\text { Escore conhecimento } 5,8 \text { vs. } 5,3 \\
\text { p=0,007 } \\
\text { Escore conduta } 4,3 \text { vs. } 4,1 \mathrm{p}=0,104 \\
\mathrm{HbA}_{\mathrm{lc}} 6,1 \text { vs. } 6.3 \mathrm{p}=0,199 \\
\begin{array}{l}\text { Lesões nos pés diminuíram nos } \\
\text { grupos, porem sem diferença } \\
\text { significativa. }\end{array} \\
\text { Graduados e não graduados (média): } \\
\text { Escore conhecimento } \mathrm{p}=0,001 \\
\text { Escore de conduta } \mathrm{p}=0,003\end{array}$ \\
\hline Barth et al. (1991) & $\begin{array}{l}\text { Centro de } \\
\text { Diabetes do } \\
\text { Hospital São } \\
\text { Vicente. } \\
\text { seguimento: } \\
6 \text { meses (avaliação } \\
\text { ao } 1^{\circ}, 3^{\circ} \text { e } 6^{\circ} \text { mês) }\end{array}$ & 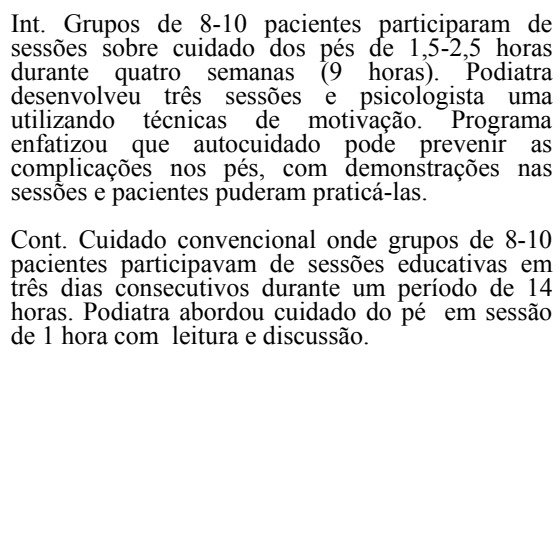 & $\begin{array}{l}\text { Não claro } \\
\text { Int. } 38 \\
\text { Cont. } 32\end{array}$ & $\begin{array}{l}\text { Diabetes tipo } 2 . \\
\text { Considerado: } \\
86 ? \\
\text { Incluídos: } \\
70 \\
\text { Concluíram: } \\
\text { Int. 33/87\% } \\
\text { Cont. 29/91\% } \\
\text { Perdas: } 8 / 11 \% \\
\text { Mortalidade: } \\
\text { Não }\end{array}$ & Não se sabe & Sim. & $\begin{array}{l}\text { Sim, } \\
\text { exceto pela } \\
\text { maior presença } \\
\text { de doença } \\
\text { vascular } \\
\text { periférica no } \\
\text { Int. }(p<0,05) \text {. }\end{array}$ & Não se sabe & $\begin{array}{l}\text { Conhecimento de cuidado dos pés } \\
\text { Int. vs. Cont. } \mathrm{p}=0,001 \\
\text { Melhora do conhecimento foi } \\
\text { semelhante nos grupos no } 1^{\circ} \text { mês } \\
\mathrm{p}=0,001 \text { (c/basal) } \\
\text { Adesão ao cuidado de rotina } \\
\text { Int.vas. Cont. } \mathrm{p}=0,012 \\
\text { Adesão melhorou no Int. ao } 1^{\circ} \text { mês } \\
\mathrm{p}<0,001 \text { e no Cont. ao } 3^{\circ} \text {. } \\
\text { Diminuição de problemas nos pés } \\
\text { Int. vs. Cont. } \mathrm{p}<0,006 \text { só ao } 1^{\circ} \text { mês. } \\
\text { Diminuição foi melhor no Int. no } 1^{\circ} \\
\text { mês } \mathrm{p}<0,001 \text { e no Cont. ao } 3^{\circ} \\
\mathrm{p}=0,005 \\
\text { Consulta com podiatra } \\
\text { Int. vs. Cont.p }=0,008 \text { só ao } 1^{\circ} \text { mês. }\end{array}$ \\
\hline $\begin{array}{l}\text { Litzelman et al. } \\
\text { (1993). }\end{array}$ & $\begin{array}{l}\text { Clínica Geral do } \\
\text { Centro Médico } \\
\text { Resgenstrief em } \\
\text { Indianápolis. } \\
\text { Seguimento: } \\
12 \text { meses }\end{array}$ & 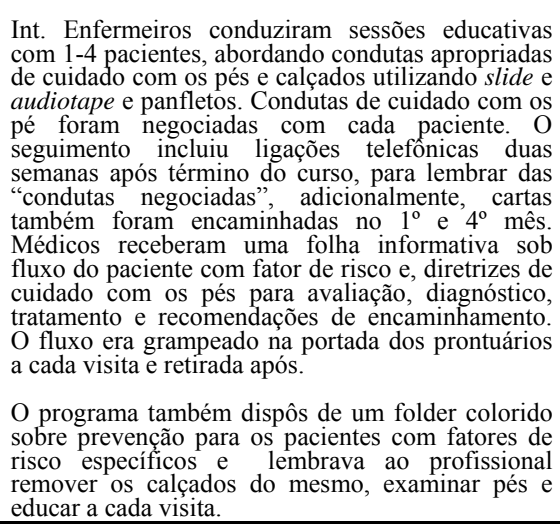 & $\begin{array}{l}\text { Não claro } \\
\text { Int. } 191 \\
\text { Cont. } 205\end{array}$ & $\begin{array}{l}\text { Diabetes tipo } 2 . \\
\text { Considerados: } \\
728 \\
\text { Incluídos: } \\
395 \\
\text { Concluíram: } \\
\text { Total 352 } \\
\text { Int.? } \\
\text { Cont. ? } \\
\text { Perdas: } 43 / 11 \% \\
\text { Mortalidade: } \\
11 / 3 \%\end{array}$ & Não se sabe & Sim. & $\begin{array}{l}\text { Sim, } \\
\text { exceto pela } \\
\mathrm{HbA}_{1 \mathrm{c}} \text { maior no } \\
\text { Int. } \mathrm{p}=0,01 . \\
\text { Comparando } \\
\text { variáveis entre } \\
\text { continuando e } \\
\text { perdas a } \mathrm{HbA} \mathrm{A}_{1 \mathrm{c}} \\
\text { foi elevada nas } \\
\text { perdas } \mathrm{p}<0,01\end{array}$ & Não se sabe & 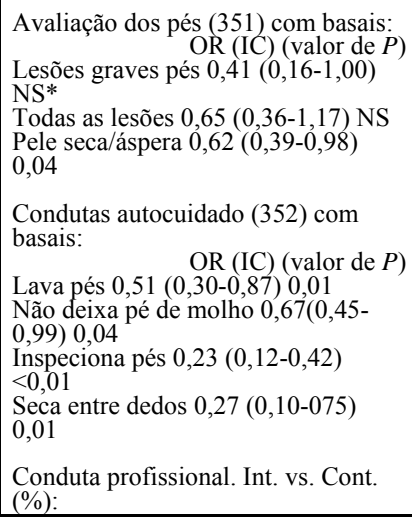 \\
\hline
\end{tabular}




\begin{tabular}{|c|c|c|c|c|c|c|c|c|c|}
\hline & & Cont. Cuidado convencional. & & & & & & & $\begin{array}{l}\text { Remover calçados e meias: } \\
\text { Enfermeiro } 55 \text { vs. } 17 \mathrm{p}<0,001 \\
\text { Médicos } 28 \text { vs. } 14 \text { p }<0,001 \\
\text { Educação sobre cuidado dos pés } \\
42 \text { vs. } 18 \text { p }<0,001 \\
\text { Amputação (n): Int } 1 \text {, Cont. } 4\end{array}$ \\
\hline $\begin{array}{l}\text { Rönnemaa et al. } \\
\text { (1997) }\end{array}$ & $\begin{array}{l}\text { Ambulatório de } \\
\text { Diabetes vs } \\
\text { Ambulatório de } \\
\text { Podiatria. } \\
\\
\text { seguimento: } \\
12 \text { meses. }\end{array}$ & 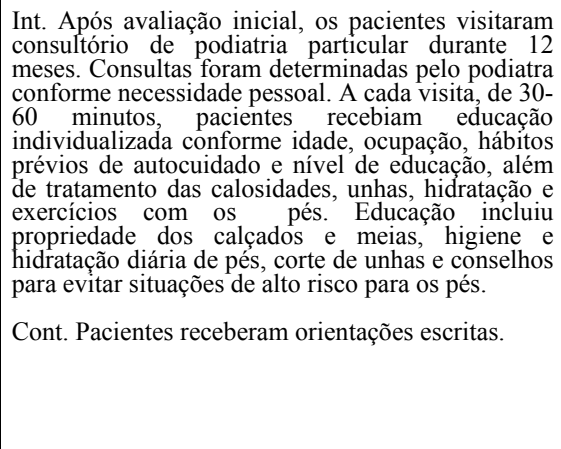 & $\begin{array}{l}\text { Não claro } \\
\text { Int. } 267 \\
\text { Cont } 263\end{array}$ & $\begin{array}{l}\text { Diabetes tipo } 1 \\
\text { e } 2 . \\
\text { Considerados: } \\
733 \text { I3 } \\
\text { Incluídos: } \\
530 \\
\text { Concluíram: } \\
\text { Int. } 233 / 87 \% \\
\text { Cont.226/86\% } \\
\text { Perdas: } \\
71 / 13 \% \\
\text { Mortalidade: } \\
\text { Int. 5/2\% } \\
\text { Cont. } 7 / 3 \%\end{array}$ & Não se sabe & Não se sabe & Não se sabe & Não se sabe & $\begin{array}{l}\text { Int. vs. Cont. (média): } \\
\text { Número de visitas ao podiatra } \\
4,7 \text { vs } 0,4 \\
\text { Conhecimento de cuidado de pé } \\
32,1 \text { vs. } 29,2 \mathrm{p}=0,004 \\
\text { Escore de autocuidado } \\
7,0 \text { vs. } 6,0 \mathrm{p}<0.001 \\
\text { Uso de palmilhas (\%) } \\
16,4 \text { vs. } 3,1 \mathrm{p}<0.001 \\
\text { Prevalência de achados podiátricos } \\
\text { (\%) } \\
\text { Calosidades no calcanhar } \\
2,0 \text { vs. } 1.5 \mathrm{p}=0,14 \\
\text { Calosidades em outras regiões } \\
39,5 \text { vs. } 48,2 \text { p }=0,009\end{array}$ \\
\hline
\end{tabular}


Na Tabela 6.2, a maioria dos ensaios clínicos incluídos foi também considerada na revisão previamente realizada por Mason et al., (1998) e Valk, Kriegsman e Assendelft (2002). Entretanto, Kruger, Guthrie e Faan (1992) e Malone et al. (1989) foram excluídos. O ensaio de Kruger, Guthrie e Faan (1992) perante avaliação com os critérios de Hadorn et al. (1995), não se enquadrou como ensaio clínico randomizado, considerando que a primeira semana da coleta de dados foi destinada para os pacientes do grupo controle. Quanto ao estudo de Malone et al. (1986), este incluiu pacientes de alto risco para amputação.

Pelos dados descritos em cada ensaio, a população inserida apresentava condições variadas de risco para úlcera, desde pessoas sem risco (RÖNNEMAA et al., 1997; LITZELMAN et al., 1993; BARTH et al., 1991; BLOOMGARDEM et al., 1987; MAZZUCA et al., 1986), com baixo risco (RÖNNEMAA et al., 1997; LITZELMAN et al.,1993; BARTH et al., 1991; MAZZUCA et al., 1986) e com risco elevado (LITZELMAN et al., 1993; BLOOMGARDERM et al., 1987). No estudo de Rettig et al (1986), não foi possível identificar esta condição das pessoas.

Dois ensaios foram desenvolvidos em clínica geral na assistência primária (LITZELMAN et al., 1993; MAZZUCA et al., 1986), dois em clínica especializada de diabetes (BARTH et al., 1991; BLOOMGARDEM et al., 1987), sendo que o primeiro localizava-se no hospital e o segundo, na assistência primária; um foi desenvolvido na residência (RETTIG et al., 1986) e outro em ambulatório especializado de podiatria (RÖNNEMAA et al., 1997).

As intervenções de educação propostas nos ensaios clínicos de Litzelman et al. (1993), Barth et al. (1991), Bloomgardem et al. (1987) e Mazzuca et al. (1986) foram realizadas mediante sessões grupais com os pacientes, incluindo de duas a 10 pessoas por grupo. Em quatro ensaios, essas atividades foram desenvolvidas por enfermeiros (LITZELMAN et al., 1993; BLOOMGARDEM et al., 1987; RETTIG et al., 1986; MAZZUCA et al., 1986) e em dois, por podiatras (RÖNNEMAA et al., 1997; BARTH et al., 1991).

Rönnemaa et al. (1997), Rettig et al. (1986) e Mazzuca et al. (1982) consideraram relevante conhecer, previamente, as necessidades e habilidades dos pacientes para proceder a desenvolver as atividades educativas. Em dois ensaios clínicos, técnicas de demonstrações e redemonstrações foram utilizadas para estimular as habilidades de autocuidado (BARTH et al., 1991; MAZZUCA et al., 1986).

As intervenções propostas foram comparadas com o atendimento convencional nos estudos de Litzelman et al. (1993), Barth et al. (1991), Bloomgardem et al. (1987) e Mazzuca et 
al. (1986), sendo que essa assistência foi descrita em três deles (BARTH et al., 1991; BLOOMGARDEM et al., 1987; MAZZUCA et al., 1986).

Em dois ensaios, os profissionais da assistência primária também participaram das intervenções. No ensaio clínico de Litzelman et al. (1993) médicos foram estimulados a avaliar a condição de risco dos pacientes, mediante lembretes dispostos nos prontuários a cada visita. No estudo de Mazzuca et al. (1986), um grupo de médicos foram inseridos em programa de educação sistematizada para manejo do diabetes facultado para diabetologistas. Em ambos os ensaios, contatos telefônicos foram estabelecidos com os pacientes para reforçar as orientações e lembrar dos cuidados, com o objetivo de atingir a meta pactuada com cada participante. Litzelman et al. (1993) também emitiram cartas para o mesmo propósito.

Em três ensaios clínicos, os programas de diabetes desenvolvidos foram abrangentes, conteúdos incluíram compreensão da doença, complicações agudas, medicamentos, dieta, atividade física, cuidados com os pés e teste de urina (BLOOMGARDEM et al., 1987; RETTIG et al., 1986; MAZZUCA et al., 1986).

Programas direcionados, especificamente, aos pés incluíram complicações nos pés, higiene e cuidado (RÖNNEMAA et al., 1997; BARTH et al., 1991), identificação de problemas que precisam de cuidado profissional (BLOOMGARDEM et al., 1991; LITZELMAN et al., 1993), condutas apropriadas de autocuidado com os pés e calçados (RÖNNEMAA et al., 1997; LITZELMAN et al., 1993; BARTH et al., 1991).

$\mathrm{Na}$ avaliação das intervenções de educação Rettig et al. (1986) e Mazzuca et al. (1986) consideraram conhecimento geral da doença e habilidades para seu cuidado; Bloomgardem et al. (1987), conhecimento geral da doença e condutas de autocuidado com os pés; Rönnemaa et al (1997), Litzelman et al. (1993) e Barth et al. (1991), conhecimento e autocuidado com os pés e Rönnemaa et al. (1997), Litzelman et al. (1993), Barth et al. (1991), Bloomgarden et al. (1987) e Rettig et al., (1986) problemas nos pés.

$\mathrm{Na}$ avaliação metodológica dos ensaios clínicos identificaram-se algumas limitações na validade interna. De forma geral, nos ensaios não foram descritos de forma explícita o processo de randomização. Em cinco ensaios, a população incluída foi em média 457 (RÖNNEMAA et al., 1997; LITZELMAN et al., 1993; BLOOMGARDEM et al., 1987; RETTIG et al., 1986; MAZZUCA et al., 1986). Ao todo participaram 2.343 pessoas com diabetes, com uma média de idade entre 43,9 e 60,9 anos. 
Perdas no seguimento superaram 20\% nos ensaios de Bloomgardem et al. (1987), Rettig et al. (1986) e Mazzuca et al. (1986), sendo que neste último as perdas alcançaram 48\%. Causas das perdas apenas foram descritas, apropriadamente, em Rönnemaa et al., (1997), Barth et al (1991) e Bloomgarden et al. (1987).

Cruzamento ou não dos participantes entre grupos não foi referido nos ensaios clínicos, nem de como esse viés foi controlado durante o desenvolvimento dos mesmos.

Considerando a importância do mascaramento dos avaliadores em ensaios clínicos randomizados abertos, identifica-se que esse processo foi apropriadamente desenvolvido por Litzelman et al. (1993), Barth et al. (1991) e Rettig et al. (1986). No ensaio clínico de Rönnemaa et al. (1997) esse processo não foi claramente definido.

De modo geral, as características basais foram semelhantes em cinco ensaios clínicos, exceto pelo ensaio de Mazzuca et al., (1986). Entretanto, teste estatístico foi utilizado para ajustar essas diferenças ao finalizar o seguimento dos participantes.

Em relação às co-intervenções, nenhum ensaio fez referência de como se controlaram ou atenuaram, a influência desse viés de intervenção durante o desenvolvimento dos mesmos. Entretanto, avaliadores que não foram mascarados ao grupo intervenção podem prestar atenção extra aos participantes que estão recebendo a intervenção ativa (viés de aferição), e essa condição já constitui uma co-intervenção (CUMMINGS; GRADY; HULLEY, 2003).

Quanto aos resultados propriamente ditos, Bloomgardem et al. (1987), Rettig et al. (1986) e Mazzuca et al. (1982) apresentaram aumento do nível de conhecimento em relação à doença, de forma geral, em pelo menos, dois de seus itens considerados, principalmente, para reconhecimento das características do teste de urina $(\mathrm{p}<0,005)$.

Conhecimento relacionado ao cuidado com os pés melhorou em Rönnemaa et al. (1997), Barth et al. (1991) e Rettig et al. (1982), o que não necessariamente incluiu observação de condutas com os pés $(\mathrm{p}<0,005)$.

Essas condutas apenas foram conseqüentes em três ensaios clínicos (RÖNNEMAA et al., 1997; LITZELMAN et al., 1993; BARTH et al., 1991), nos quais os participantes referiram executar atividades de autocuidado com os pés $(\mathrm{p}<0,05)$. No ensaio de Barth et al. (1991) essas condutas foram observadas também no grupo-controle, porém os participantes precisaram de tempo maior para aderi-las. 
No ensaio clínico de Litzelman et al., (1993), os dados mensurados na segunda avaliação foram ajustados aos dados basais da população estudada utilizando análise de covariância e regressão logística. Assim, os autores estimaram se a diminuição das anormalidades clínicas nos pés e o aumento de condutas apropriadas, estiveram relacionados com a intervenção proposta.

Nesse sentido, os resultados do ensaio clínico não foram apresentados de forma clara, que permita avaliar a efetividade da intervenção contrastando com o cuidado convencional. Porém, evidenciou-se que as pessoas do grupo intervenção tiveram menos probabilidade de apresentar anormalidades nos pés.

A condição física dos pés foi considerada em cinco ensaios clínicos (RÖNNEMAA et al., 1997; LITZELMAN et al. 1993; BARTH et al., 1991; BLOOMGARDEM et al., 1987; RETTIG et al., 1986), nos quais foram apontadas pele seca/áspera, calosidades plantares, unhas grossas, maceração interdigital, fissuras, infecção fúngica, lesões menores e úlceras, dentre outras. No ensaio de Retting et al (1986), não se descreve quais as características que se incluíram na aparência dos pés.

O ensaio clínico de Bloomgardem et al. (1987) referiu que as lesões nos pés diminuíram em ambos os grupos observados, porém, sem diferença significativa entre eles. Barth et al. (1991) obtiveram diminuição de problemas nos pés no grupo intervenção apenas ao primeiro mês $(\mathrm{p}<0,006)$. Litzelman et al (1993) referiram que houve menor probabilidade dos participantes do grupo intervenção apresentarem lesões graves nos pés e pele seca/áspera( $\mathrm{p} \leq 0,05)$. Rönnemaa et al. (1997) mostraram melhora nas calosidades nos pés, exceto nas do calcanhar $(\mathrm{p}<0,009)$.

Conforme os critérios incluídos na avaliação da propriedade dos resultados nos ensaios clínicos, os mesmos devem ser considerados com certo grau de cautela, devido aos vieses apontados na Tabela 6.2.

Falhas metodológicas foram identificadas em todos os ensaios, que diminuem a força de suas conclusões, principalmente, relacionados com a carência de informações importantes, que enfraquecem a consistência dos resultados, demonstrando que não há evidência do efeito.

Todos os ensaios clínicos incluídos na revisão, pelo menos, falharam a um critério relacionado nas guias primárias e secundárias da avaliação metodológica. Informações sobre cruzamento entre grupos e co-intervenções foram absolutamente ausentes nos ensaios, que impossibilitam afirmar se houve ou não controle desse viés. O mascaramento dos avaliadores foi apropriadamente descrito em três ensaios clínicos. 
Conforme Valk, Kriegsman e Assendelft (2002) é pouco provável que o viés de publicação tenha afetado as conclusões no estudo, visto que, a maioria dos ensaios clínicos randomizados incluídos não reportou dados com desfechos significantes.

É possível que o reduzido número de participantes incluídos em cada ensaio clínico possa ter limitado a capacidade de detectar diferenças clínicas importantes entre participantes observados. Segundo Valk, Kriegsman e Assendelft (2002) haveria necessidade de observar, de pelo menos, 430 a 870 pessoas com diabetes por grupo, durante o período de um ano, para detectar $50 \%$ de redução da incidência de úlcera nos pés, considerando uma incidência anual de 2 a $4 \%$.

Entretanto, ensaios clínicos dessa magnitude exigem custos elevados, considerando que a recuperação desse investimento na potencial redução da incidência está associada a tratamentos prolongados. Dessa forma, é pouco provável que o papel da educação no cuidado dos pés possa ter resultados claros em curto período de tempo, principalmente, pela diversidade dos ambientes nos quais se inserem os pacientes e as distintas formas de mensurar os desfechos nos ensaios clínicos, os quais impossibilitam realizar combinações entre eles (VALK; KRIEGSMAN; ASSENDELFT, 2002).

Nos ensaios incluídos na revisão, três deles referiram que condutas de autocuidado com os pés melhoraram (RÖNNEMAA et al., 1997; LITZELMAN et al., 1993; BARTH et al., 1991). Entretanto, essas condutas nem sempre se manifestavam na aparência dos pés de forma clara. No ensaio de Barth et al. (1991) as condições dos pés melhoraram ao primeiro mês.

Röonnemaa et al. (1997) realizaram uma segunda avaliação dos participantes de ambos os grupos, depois de transcorrido sete anos (HÄMÄLÄINEN et al., 1998). Nessa avaliação, conhecimento de cuidados com os pés e condutas de autocuidado continuaram apresentando melhoria em relação aos dados basais, sem diferença entre grupos. Quanto à condição física dos pés, não identificaram diferença entre grupos, exceto pela presença de unha encravada, que atingiu maior quantidade de pessoas no grupo-controle.

Esses dados demonstram que melhor conhecimento de cuidado com os pés, pode melhorar condutas de autocuidado apenas por curto período de tempo, o que também pode ser uma resposta à motivação dos pacientes estar formando parte da intervenção proposta, o chamado efeito Hawthorne.

É possível que mensagens importantes e condutas de cuidados com os pés tenham necessidade de serem reforçadas permanentemente, tanto entre pacientes como entre profissionais 
(MASON et al., 1999), para garantir a adesão aos novos comportamentos, sem fazer dessa atividade uma rotina inconsciente.

Entre os métodos de educação utilizados nos ensaios clínicos, não foi possível identificar qual deles pôde ser eficaz, considerando que os resultados não mostraram forte consistência na prevenção de lesão/ulceração nos pés.

Dessa forma, é desconhecida ainda a eficiência dos programas educativos em relação à prevenção de complicações nos pés entre pessoas com diabetes que apresentam baixo risco para úlcera, mais ainda porque os resultados em longo período de tempo não foram comprovados.

Mason et al. (1999) referem que, provavelmente a condução de programas educativos de forma isolada, sem estarem integrados a sistemas organizacionais que promovam estratégias de cuidado com os pés, pode ser, certamente, improdutivas. Visto que as complicações nos pés, também são conseqüência do manejo da doença em si, especialmente, do controle metabólico, no qual também podem estar inter-relacionadas a idade, o sexo, escolaridade, a condição socialeconômica, a gravidade da doença, dentre outras variáveis.

Nesse contexto, é necessário estruturar novos ensaios clínicos randomizados que possam trazer dados consistentes sobre o efeito da educação na população com diabetes integrados a sistemas organizacionais e que, ademais, considerem os critérios importantes desse tipo de estudos, como adequado processo de randomização, cruzamento, mascaramento e controle das co-intervenções, os quais devem descrever-se de maneira explícita, sem deixar margem a dúvidas e questionamentos.

Considerando a necessidade de grandes populações de estudo, que exigem custos elevados, é prudente pensar, na possibilidade de estruturar estudos multicêntricos, que paralelamente avaliem os mesmos desfechos, com aplicação de metodologias semelhantes e em populações homogêneas. Desta forma, poder-se-ia rever no futuro próximo, a consistência e importância das intervenções educativas na redução de úlceras e amputações entre pessoas com diabetes, que se têm mostrado violenta e mutiladora na sociedade atual.

\subsection{3- Diretrizes clínicas para os cuidados preventivos com os pés.}

A revisão das diretrizes clínicas para cuidado preventivo com os pés constituiu uma complementação das revisões anteriormente apresentadas, considerando que os estudos relacionados ao modo de se organizar da equipe e a implementação de intervenções educativas ainda são insuficientes, não apenas pela inconsistência dos estudos clínicos randomizados controlados avaliados, mas também, pela necessidade de identificar outras práticas clínicas que 
podem contribuir na prevenção de lesão/ulceração em membros inferiores distais entre pessoas com diabetes.

Nesse sentido, intervenções para identificar fatores de risco e de prognóstico devem ser implementadas, paralelas a outras atividades preventivas. Dessa forma as diretrizes clínicas direcionadas à prevenção de complicações em pés de pessoas com diabetes, freqüentemente incluem na revisão, estudos de coorte que evidenciaram os efeitos dessas medidas/ações, na tentativa de propor um cuidado integralizado. Resultados que contribuíram na elaboração da proposta assistencial sistematizada.

Entre as 19 diretrizes clínicas identificadas neste propósito, observou-se que estas focalizavam, no geral, recomendações relacionadas com tratamento da doença, manejo/cuidado da doença, tratamento e prevenção de complicações, além de abordar também diabetes em crianças e na gestação.

Desse total de diretrizes clínicas, selecionaram-se nove, conforme os critérios de inclusão considerados no estudo, sendo que as outras se encontram na lista de referência de excluídos.

As diretrizes clínicas incluídas consideraram para a elaboração de suas recomendações, uma equipe multiprofissional, composta por médicos e enfermeiros especialistas em diabetes, cirurgiões vasculares, ortopedistas, podiatras e ortotistas, além de especialistas em revisão sistemática (HUTCHINSON et al., 2003; U.S. PREVENTIVE SERVICES TASK FORCE, 2003; DIABETES COALITION OF CALIFORNIA; CALIFORNIA DIABETES CONTROL PROGRAM， 2002; INSTITUTE FOR CLINICAL SYSTEMS IMPROVEMENT; 2002; SCOTTISH INTERCOLLEGIATE GUIDELINES NETWORK, 2001; VHA/DOD CLINICAL PRACTICE GUIDELINES WORKING GROUP, 2003; NEW ZEALAND GUIDELINES GROUP, 2000; MELTZER et al. 1998; UNVERSITY OF MICHIGAN HEALTH SYSTEMS, 1998).

As recomendações foram direcionadas aos diferentes níveis de assistência à saúde, principalmente, ao ambiente primário. Dados relacionados às diretrizes clínicas são apresentados na Tabela 6.3, na qual se considerou importante descrever os assuntos abordados por cada diretriz, a fim de mostrar a abrangência de seus objetivos. Seguidamente, identifica-se a avaliação da propriedade das recomendações e as recomendações, propriamente ditas.

Dentre as propriedades das recomendações encontram-se também as guias primárias (especificação de todas as opções importantes e efeitos clínicos; processo explícito e sensível para 
identificar, selecionar e combinar as evidências) e guias secundárias (processo explícito e sensível para considerar o valor relativo dos diferentes efeitos clínicos; consideração das descobertas recentes; submissão à revisão de peritos e teste).

Quanto às recomendações propriamente ditas, nelas se consideram se as mesmas foram aplicáveis e clinicamente importantes, o grau definido de recomendação e qual o impacto da incerteza associada à evidência dos valores utilizados. 
Tabela 6.3 - Diretrizes clínicas selecionadas direcionadas à prevenção de complicações em membros inferiores em pessoas com diabetes mellitus.

\begin{tabular}{|c|c|c|c|c|c|c|c|c|c|}
\hline \multirow[b]{2}{*}{ Autor (es) } & \multirow[b]{2}{*}{ Assuntos abordados } & \multicolumn{5}{|c|}{ Avaliação da Propriedade das Recomendações } & \multicolumn{3}{|c|}{ Recomendações } \\
\hline & & $\begin{array}{l}\text { Especificação de todas } \\
\text { as opçóes importantes e } \\
\text { seus efeitos clínicos }\end{array}$ & $\begin{array}{l}\text { Processo explíitito da } \\
\text { identificação, seleção e } \\
\text { combinaçâo da evid. }\end{array}$ & $\begin{array}{l}\text { Processo explícito do } \\
\text { valor relativo dos efeitos } \\
\text { clínicos }\end{array}$ & $\begin{array}{l}\text { Inclusão de descobertas } \\
\text { importantes e recentes }\end{array}$ & $\begin{array}{l}\text { Revisão de peritos e } \\
\text { teste }\end{array}$ & $\begin{array}{l}\text { Práticas e } \\
\text { clinicamente } \\
\text { importantes }\end{array}$ & Grau definido & $\begin{array}{l}\text { Incerteza } \\
\text { associada } \\
\text { evidência }\end{array}$ \\
\hline $\begin{array}{lr}\text { Hutchinson } & \text { et al } \\
\text { (2003). } & \text { Royal } \\
\text { College } & \text { of } \\
\text { General } & \\
\text { Practitioners } & \end{array}$ & $\begin{array}{l}\text { - Cuidado de pé } \\
\text { - Cuidado de olho } \\
\text { - Nível elevado de } \\
\text { lipídios } \\
\text { - Cuidado renal } \\
\text { - Controle glicêmico }\end{array}$ & 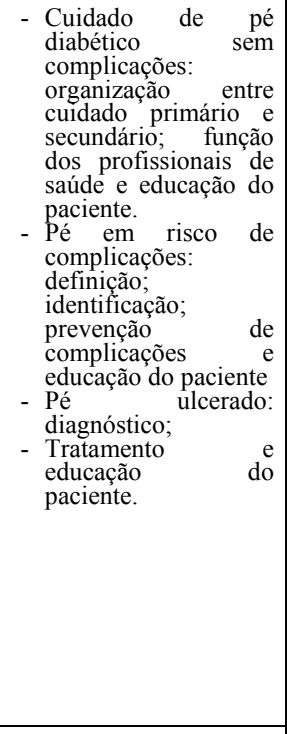 & 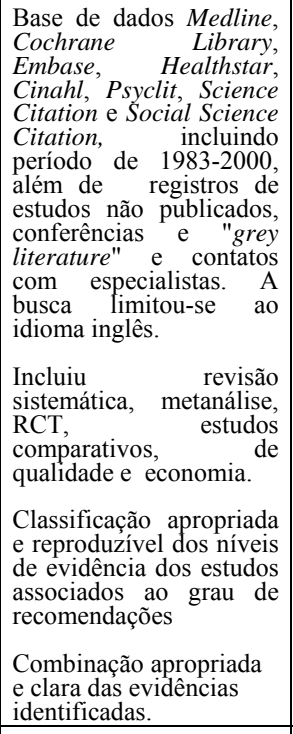 & 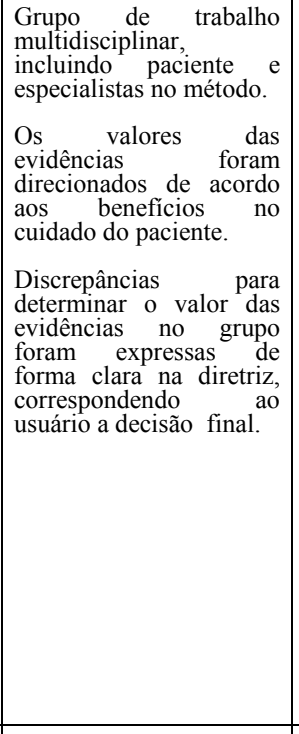 & $\begin{array}{l}\text { Literatura revisada foi } \\
\text { publicada entre } 1987 \text { e } \\
1999 .\end{array}$ & $\begin{array}{l}\text { Revisão de pares } \\
\text { internos e externos. } \\
\text { Teste prévio das } \\
\text { diretrizes, porém, } \\
\text { não } \\
\text { comentários houve } \\
\text { como foi realizado. }\end{array}$ & $\begin{array}{l}\text { Apresentação das } \\
\text { recomendações } \\
\text { compropriedade e } \\
\text { coerencia. }\end{array}$ & \begin{tabular}{|l} 
Grande parte das \\
recomendações \\
propostas foi \\
decorrente de de \\
estudos \\
controlados \\
randomizados, \\
porém, ressaltou- \\
se que resultados \\
foram \\
inconclusivos.
\end{tabular} & $\begin{array}{l}\text { Sim, } \\
\text { especialmente } \\
\text { pelas } \\
\text { características da } \\
\text { validade interna } \\
\text { dos estudos } \\
\text { considerados. }\end{array}$ \\
\hline $\begin{array}{l}\text { Instituter for } \\
\text { Clinical Systems } \\
\text { Improvement } \\
\text { (2003). }\end{array}$ & $\begin{array}{l}\text { - Diagnóstico } \\
\text { tratamento inicial } \\
\text { - Controle glicêmico } \\
\text { - Controle de Pressão } \\
\text { Arterial } \\
\text { Manejo de lipííios } \\
\text { Manejo contínuo e } \\
\text { seguimento: mantendo } \\
\text { metas de tratamento, } \\
\text { avaliação anual de, } \\
\text { complicações, tratamento } \\
\text { e encaminhamento de } \\
\text { complicações }\end{array}$ & $\begin{array}{l}\text { - Educação do cuidado } \\
\text { dos pés } \\
\text { - Inspeção anual dos } \\
\text { pés } \\
\text { - Avaliação de fatores } \\
\text { de risco. }\end{array}$ & $\begin{array}{l}\text { Base de dados eletrônica. } \\
\text { Classificação apropriada } \\
\text { e reproduzivel dos níveis } \\
\text { de evidência dos estudos } \\
\text { associados ao grau de } \\
\text { recomendações } \\
\text { Combinação da } \\
\text { evidência não foi } \\
\text { considerada. }\end{array}$ & \begin{tabular}{|l} 
Grupo de trabalho \\
multidisciplinar, \\
incluindo especialistas \\
no método. \\
\multicolumn{4}{c}{} \\
Não se descreveu como \\
se resolveram as as \\
discrepâncias rara \\
determinar o valor das \\
evidencias no grupo de \\
trabalho.
\end{tabular} & $\begin{array}{l}\text { Literatura revisada foi } \\
\text { publicada entre } 1998 \text { - } \\
2002 \text { (reporte de } \\
\text { consenso). }\end{array}$ & $\begin{array}{l}\text { Revisão de pares } \\
\text { internos. } \\
\text { O teste prévio foi } \\
\text { realizado entre os } \\
\text { profissionais de } \\
\text { vários locais*. }\end{array}$ & \begin{tabular}{ll|} 
& Algumas \\
recomendações & \\
foram & \\
apresentadas & com \\
propriedade & $\mathrm{e}$ \\
coerência. &
\end{tabular} & $\begin{array}{l}\text { Recomendações } \\
\text { foram decorrentes } \\
\text { de consenso de } \\
\text { especialistas. }\end{array}$ & Não se sabe \\
\hline
\end{tabular}




\begin{tabular}{|c|c|c|c|c|c|c|c|c|c|}
\hline $\begin{array}{l}\text { U.S. Preventive } \\
\text { Services } \\
\text { Force (2003). }\end{array}$ & $\begin{array}{l}\text { - Acurácia para o } \\
\text { screening de DM tipo } \\
2 \\
\text { - Deterioração visual } \\
\text { - Amputaçao de } \\
\text { extremidade inferior } \\
\text { - Eventos de doença } \\
\text { cardiovascular }\end{array}$ & \begin{tabular}{|lr} 
Não & encontraram \\
evidências & que \\
programas de prevenção \\
tenham impacto no \\
desenvolimento & de \\
amputacão & de \\
extremidade inferior. &
\end{tabular} & $\begin{array}{l}\text { Base de dados Medline e } \\
\text { Cochrane Library de } \\
\text { artigos publicados em } \\
\text { idioma inglês entre } \\
\text { janeiro de } 1994 \text { e julho } \\
\text { de } 2002, \text { alem de busca } \\
\text { das referências citadas } \\
\text { nos artigos e contatos } \\
\text { com especialistas. }\end{array}$ & \begin{tabular}{|l|} 
Grupo de trabalho \\
interdisciplinar, \\
incluindo especialistas \\
no método **.
\end{tabular} & - & - & - & - & - \\
\hline $\begin{array}{l}\text { Diabetes Coalition } \\
\text { of California and } \\
\text { the California } \\
\text { Diabetes Control } \\
\text { Programm (2002). }\end{array}$ & 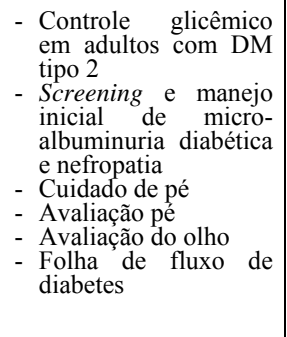 & $\begin{array}{l}\text { - Neuropatia: sinais e } \\
\text { sintomas, avaliação e } \\
\text { manejo } \\
\text { - Cuidado preventivo } \\
\text { - Doença vascular: } \\
\text { sinais, sintomas, } \\
\text { avaliação p para } \\
\text { referencia e manejo } \\
\text { - Identificação de pé } \\
\text { em alto risco. }\end{array}$ & 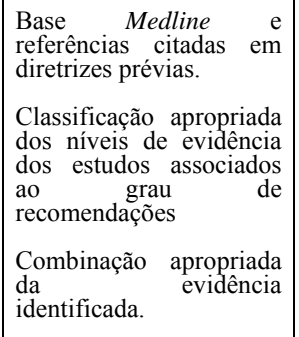 & Não se sabe & $\begin{array}{l}\text { Literatura revisada foi } \\
\text { publicada entre } 1993- \\
1998 .\end{array}$ & Não se sabe. & $\begin{array}{l}\text { Apresentação das } \\
\text { recomendações de } \\
\text { forma prática. }\end{array}$ & 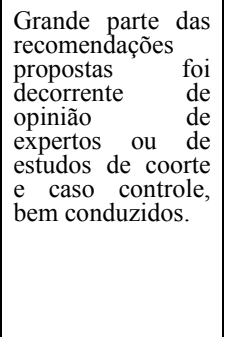 & Não se sabe. \\
\hline $\begin{array}{l}\text { New Zealand } \\
\text { Guidelines Group } \\
(2000)\end{array}$ & $\begin{array}{l}\text { - Controle glicêmico } \\
\text { - Screening de retina } \\
\text { - Screening de micro- } \\
\text { albuminuria } \\
\text { - Screening para pé } \\
\text { diabético }\end{array}$ & $\begin{array}{l}\text { - Avaliação de fatores } \\
\text { de risco para } \\
\text { úlcera/amputação } \\
\text { - Avaliação de fatores } \\
\text { de risco para doença } \\
\text { cardiovascular } \\
\text { - Identificação de } \\
\text { fatores associados } \\
\text { com úlcera/amputação } \\
\text { - Diminuição do risco } \\
\text { de úlcera/amputação } \\
\text { mediante educação } \\
\text { - Tratamento com } \\
\text { antibiótico e cuidado } \\
\text { diário da ferida }\end{array}$ & $\begin{array}{l}\text { Base de dados Medline, } \\
\text { diretrizes desenvolvidas } \\
\text { por outros países es } \\
\text { organismos, e referencias } \\
\text { citadas nas publicações. } \\
\text { Classificacaão apropriada } \\
\text { dos níveis de evidência } \\
\text { dos estudos. } \\
\\
\end{array}$ & \begin{tabular}{|l|} 
Grupo de trabalho \\
multidisciplinar. \\
Quando a evidência foi \\
insuficiente, fraca ou \\
ausente, a opinião de \\
expertos foi relevante. \\
Não se descreveu como \\
se resolveram as as \\
discrepâncias para \\
determinar o valor das \\
evidências no grupo de \\
trabalho.
\end{tabular} & \begin{tabular}{|l} 
Grande parte da \\
literatura considerada foi \\
publicada entre $1990-$ \\
1993.
\end{tabular} & $\begin{array}{l}\text { Revisão de pares } \\
\text { internos e externos } \\
\text { das diretrizes. } \\
\text { Teste prévio } \\
\text { realizado entre os } \\
\text { profissionais do } \\
\text { ambiente primário. }\end{array}$ & $\begin{array}{l}\text {. Apresentação das } \\
\text { recomendaçôes foi } \\
\text { de forma prática. }\end{array}$ & $\begin{array}{|ll|}\text { A grande maioria } & \\
\text { das } & \text { recomendações } \\
\text { propostas } & \text { foi } \\
\text { decorrente } & \text { da } \\
\text { opinião } & \text { de } \\
\text { expertos/ } & \\
\text { consenso, em } & \\
\text { outras se } & \\
\text { considerou } & \\
\text { estudos não } & \\
\text { experimentais } & \end{array}$ & Não se sabe. \\
\hline
\end{tabular}




\begin{tabular}{|c|c|c|c|c|c|c|c|c|c|}
\hline $\begin{array}{l}\text { Scottish } \\
\text { Intercollegiate } \\
\text { Guidelines } \\
\text { Network (2001). }\end{array}$ & $\begin{array}{l}\text { - Crianças e jovens } \\
\text { com diabetes } \\
\text { - Manejo do estilo de } \\
\text { vida } \\
\text { - Manejo da doença } \\
\text { cardiovascular } \\
\text { diabética } \\
\text { - Manejo da nefropatia } \\
\text { diabética } \\
\text { - Prevenção } \\
\text { deterioração visual da } \\
\text { - Manejo da doença pé } \\
\text { diabético } \\
\text { - Manejo do diabetes } \\
\text { na gravidez }\end{array}$ & $\begin{array}{l}\text { Manejo do cuidado: } \\
\text { educação do paciente } \\
\text { - Revisâo estruturada } \\
\text { do pé: avaliação do } \\
\text { risco, estrutura do pé, } \\
\text { calçado, ótrese, gesso } \\
\text { de contato total e } \\
\text { reconstrução arterial } \\
\text { - Tratamento: terapia } \\
\text { farmacológica, } \\
\text { substituição de tecido } \\
\text { humano } \\
\text { neuropatia vivo, diabética } \\
\text { dolorosa, pé de } \\
\text { Charcot pert de }\end{array}$ & 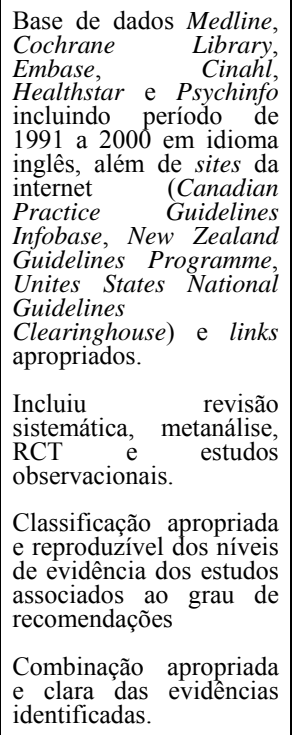 & 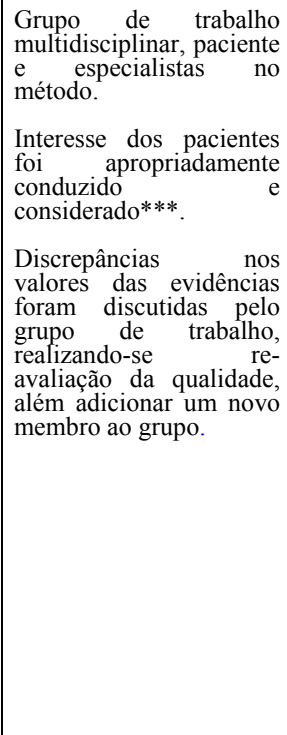 & \begin{tabular}{|l} 
Grande parte da \\
literatura considerada foi \\
publicada entre 1987 - \\
1999. \\
Literatura mais recente \\
esteve relacionada com \\
terapia de substituição de \\
tecidos vivos e larvas nas \\
feridas/úlceras. \\
\\
\end{tabular} & 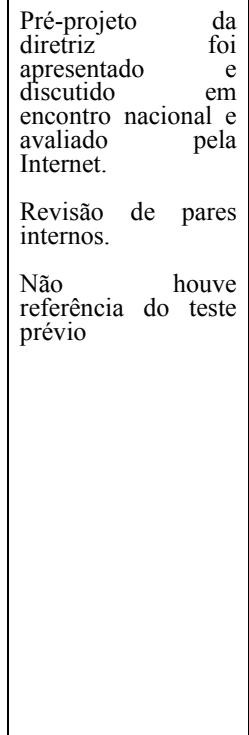 & $\begin{array}{l}\text { Apresentação das } \\
\text { recomendaçōes } \\
\text { com propriedade e } \\
\text { coerência. }\end{array}$ & 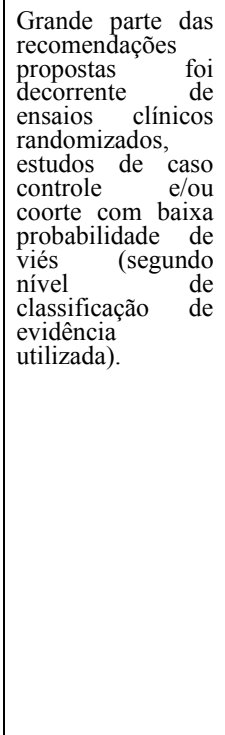 & \begin{tabular}{|lr} 
Comentários & a \\
respeito & das \\
incertezas & das \\
evidências & em \\
relação & ao \\
screening do & pé \\
em risco. & \\
& \\
& \\
& \\
&
\end{tabular} \\
\hline $\begin{array}{l}\text { Meltzer et al. } \\
\text { (1998). Canadian } \\
\text { Diabetes } \\
\text { Association }\end{array}$ & 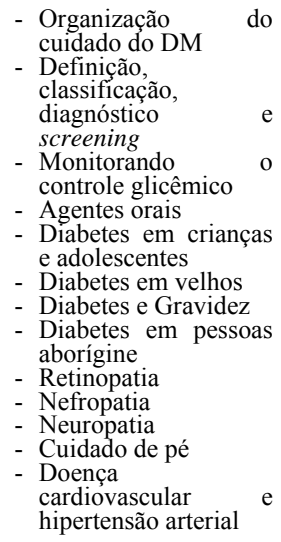 & $\begin{array}{l}\text { - Avaliação de risco do } \\
\text { pé } \\
\text { - Educação do cuidado } \\
\text { dos pés, calçado, } \\
\text { prevenção de de } \\
\text { traumas, deixar de } \\
\text { fumar e referência do } \\
\text { paciente, quando } \\
\text { necessário de úlcera } \\
\text { - Tratamento de ú } \\
\text { no pé }\end{array}$ & $\begin{array}{l}\text { Não foram consideradas } \\
\text { as estratégias de busca de } \\
\text { dados. } \\
\text { Classificacãa apropriada } \\
\text { e reproduźvivel dos níveis } \\
\text { de evidência dos estudos } \\
\text { de acordo à metodologia } \\
\text { utilizada associados ao } \\
\text { grau de recomendações } \\
\text { Combinação apropriada } \\
\text { e clara da evidência } \\
\text { identificada. }\end{array}$ & $\begin{array}{l}\text { Grupo de trabalho } \\
\text { multidisciplinar, } \\
\text { incluindo paciente e } \\
\text { especialistas no método. } \\
\text { Os valores das fos } \\
\text { evidenncias foram } \\
\text { direcionados conforme } \\
\text { os benefícios/prejuizos } \\
\text { no cuidado do paciente. } \\
\text { Incertezas a respeito dos } \\
\text { estudos foram resolvidas } \\
\text { pelo comitê de expertos } \\
\text { perante discussões, para } \\
\text { determinar o valor das } \\
\text { evidencias nas } \\
\text { recomendaços finais. }\end{array}$ & $\begin{array}{l}\text { A literatura revisada foi } \\
\text { publicada entre 1989- } \\
1993 \\
\end{array}$ & $\begin{array}{l}\text { Revisão de pares } \\
\text { internos e externos. }\end{array}$ & $\begin{array}{l}\text { Apresentação das } \\
\text { recomendações foi } \\
\text { apresentada r com } \\
\text { propriedade } \\
\text { coererncia. }\end{array}$ & \begin{tabular}{|lr} 
Grande parte & das \\
recomendações \\
propostas & foi \\
decorrente & da \\
opinião & de \\
expertos, & em \\
outras & se \\
consideraram & \\
estudos & \\
controlados & \\
randomizados.
\end{tabular} & Não se sabe. \\
\hline
\end{tabular}




\begin{tabular}{|c|c|c|c|c|c|c|c|c|c|}
\hline $\begin{array}{l}\text { VA/DoD Clinical } \\
\text { Practice Guideline } \\
\text { Working Group } \\
\text { (2000) }\end{array}$ & $\begin{array}{l}\text { - Controle glicêmico } \\
\text { - Manejo } \\
\text { hipertensão arterial } \\
\text { - Cuidado do olho } \\
\text { - Cuidado do pé } \\
\text { - DM e dislipidemia } \\
\text { - Doença renal, } \\
\text { - Automanejo } \\
\text { educação }\end{array}$ & 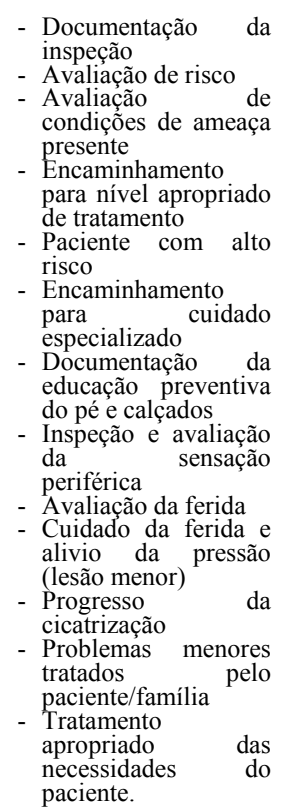 & $\begin{array}{l}\text { Base de dados Medline } \\
\text { entre de } 1992 \text { e } 1999 \text {. } \\
\text { Revisão de diretrizes } \\
\text { publicadas por outros } \\
\text { organismos. } \\
\text { Classificação apropriada } \\
\text { e reproduzível dos níveis } \\
\text { de evidência dos estudos } \\
\text { associados ao grau de } \\
\text { recomendações } \\
\text { Combinação apropriada } \\
\text { e clara da evidência } \\
\text { identificada. }\end{array}$ & $\begin{array}{l}\text { Grupo de trabalho } \\
\text { multiprofissional, incluiu } \\
\text { especialistas no método. } \\
\text { Quando literatura foi } \\
\text { considerada insuficiente, } \\
\text { conflitante e ambígua, } \\
\text { opinião de expertos foi } \\
\text { relevante. } \\
\text { Não se descreveu como } \\
\text { se resolveram as } \\
\text { discrepâncias para } \\
\text { determinar o valor das } \\
\text { evidências no grupo de } \\
\text { trabalho. }\end{array}$ & $\begin{array}{l}\text { Grande parte } \\
\text { literatura considerada } \\
\text { foi publicada } \\
1990-1993 .\end{array}$ & $\begin{array}{l}\begin{array}{l}\text { Revisão de pares } \\
\text { internos. }\end{array} \\
\begin{array}{l}\text { Não } \\
\text { referência do houve } \\
\text { prévio }\end{array}\end{array}$ & $\begin{array}{l}\text { Apresentação das } \\
\text { recomendações foi } \\
\text { apropriada e } \\
\text { coerente. }\end{array}$ & 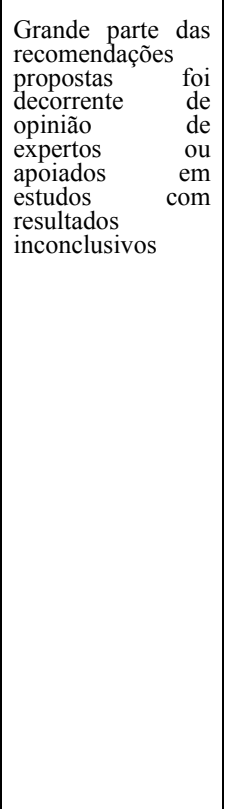 & Não se sabe \\
\hline $\begin{array}{l}\text { University of } \\
\text { Michigan Health } \\
\text { System (1998) }\end{array}$ & $\begin{array}{l}\text { - Manejo do DM: } \\
\text { prevenção, screening } \\
\text { e tratamento de } \\
\text { fatores de risco } \\
\text { cardiovascular; } \\
\text { prevenção, screening } \\
\text { e manoejo de } \\
\text { complicaçôes } \\
\text { microvasculares; } \\
\text { monitoramento } \\
\text { glicêmico } \\
\text { - Problemas clínicos e } \\
\text { dilemas atuais. }\end{array}$ & $\begin{array}{l}\text { - Avaliação do pé: } \\
\text { estrutura, neuropatia, } \\
\text { ulceração. }\end{array}$ & 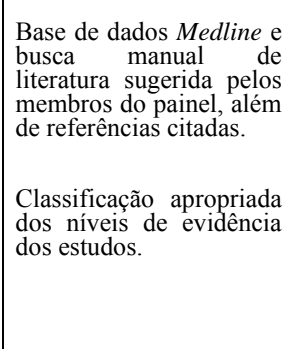 & Não se sabe & $\begin{array}{l}\text { Literatura revisada foi } \\
\text { publicada entre } 1995 \text { - } \\
1997 \text {. }\end{array}$ & $\begin{array}{l}\text { Revisão de pares } \\
\text { internos. }\end{array}$ & $\begin{array}{l}\text { Apresentação das } \\
\text { recomendações foi } \\
\text { de forma prática. }\end{array}$ & $\begin{array}{|lr|}\text { Grande parte das } \\
\text { recomendações foi } \\
\text { decorrente r de } \\
\text { opinião } & \text { de } \\
\text { expertos e revisão } \\
\text { narrativa }\end{array}$ & Não se sabe \\
\hline
\end{tabular}

www.guidelines.org/guideline comparison *
HARRIS et al. (2001) ***

SIGN $50(2002)^{* * * *}$ 
Observa-se na Tabela 6.3 que a U.S. Preventive Services Task Force (2003) não encontrou evidência, que programas de prevenção sejam eficientes no desenvolvimento de úlcera e amputação em membros inferiores, portanto, não propuseram recomendações. Na diretriz refere que, possivelmente, o controle glicêmico e da pressão arterial possam reduzir as complicações em longo prazo, tais como neuropatia sensorial periférica e doença vascular periférica.

Seis diretrizes direcionaram-se à assistência primária com indicação de encaminhamento para o nível correspondente, quando identificada pessoa com diabetes em alto risco (MELTZER et al., 1998; UNIVERSITY OF MICHIGAN HEALTH SYSTEMS, 1998; NEW ZEALAND GUIDELINES GROUP, 2000; VHA/DOD CLINICAL PRACTICE GUIDELINE WORKING GROUP, 2000; DIABETES COALITION OF CALIFORNIA; CALIFORNIA DIABETES CONTROL PROGRAM, 2002; INSTITUTE FOR CLINICAL SYSTEMS IMPROVEMENT, 2002) e duas desenvolveram recomendações tanto para profissionais da assistência primária, quanto para a secundária, indistintamente (SCOTTISH INTERCOLLEGIATE GUIDELINES NETWORK, 2001; HUTCHINSON et al., 2003).

Entre os assuntos abordados nas diretrizes, screening e intervenções para prevenção de problemas nos pés foram apontadas em Meltzer et al. (1998), Diabetes Coalition of California e California diabetes Control Programm (2002) e Institute for Clinical Systems Improvement (2002). E, screening, intervenções para prevenção e manejo de problemas nos pés em University of Michigan Health Systems (1998), VHA/DoD Clinical Practice Guideline Working Group (2000), New Zealand Guidelines Group (2000), Scottish Intercollegiate Guidelines Network (2001) e Hutchinson et al. (2003).

Screening de problemas nos pés incluiu avaliação das anormalidades estruturais, a neuropatia periférica e presença de úlcera (UNIVERSITY OF MICHIGAN HEALTH SYSTEMS, 1998), além da doença vascular periférica e historia prévia de úlcera/amputação (MELTZER et al., 1998; NEW ZEALAND GUIDELINES GROUP, 2000; VHA/DOD CLINICAL PRACTICE GUIDELINE WORKING GROUP, 2000; SCOTTISH INTERCOLLEGIATE GUIDELINES NETWORK, 2001; DIABETES COALITION OF CALIFORNIA; CALIFORNIA DIABETES CONTROL PROGRAMM, 2002; INSTITUTE FOR CLINICAL SYSTEMS IMPROVEMENT, 2002; HUTCHINSON et al., 2003).

O monofilamento SW foi considerado instrumento de screening na identificação de risco para úlcera em Meltzer et al. (1998), University of Michigan Health Systems (1998), New 
Zealand Guidelines Group (2000), Scottish Intercollegiate Guidelines Network (2001), Diabetes Coalition of California e California Diabetes Control Programm (2002), Institute for Clinical Systems Improvement (2002) e Hutchinson et al. (2003).

$\mathrm{Na}$ avaliação deve-se observar também presença de calos/calosidades plantares (NEW ZEALAND GUIDELINES GROUP, 2000; DIABETES COALITION OF CALIFORNIA; CALIFORNIA DIABETES CONTROL PROGRAMM, 2002; INSITITUTE FOR CLINICAL SYSTEMS IMPROVEMENT, 2002; HUTCHINSON et al., 2003).

Acuidade visual e incapacidade física, tais como limitações próprias dos idosos, apoplexia e obesidade foram consideradas em duas diretrizes (SCOTTISH INTERCOLLEGIATE GUIDELINES NETWORK, 2001; HUTCHINSON et al., 2003), além da observação dos calçados (VHA/DOD CLINICAL PRACTICE GUIDELINE WORKING GROUP, 2000; INSTITUTE FOR CLINICAL SYSTEMS IMPROVEMENT, 2002; HUTCHINSON et al., 2003).

Todas as diretrizes indicaram que screeening deve ser realizado pelo menos uma vez por ano entre pessoas sem risco de úlcera/amputação. A maior freqüência dessa avaliação dependerá dos fatores de risco identificados na inspeção em cada visita de rotina, conforme as necessidades e condições da pessoa com diabetes.

Entre as atividades de intervenção, houve consenso nas diretrizes em destacar a educação para o cuidado diário dos pés e aconselhamento sobre uso de calçados apropriados para prevenir úlcera/amputação, ainda que não há evidência de efeito, devendo ser reforçada na presença de pessoas de alto risco.

Os calçados desempenham uma função mecânica importante na prevenção de úlcera, pelo fato de aliviar os pontos de altas pressões, seja dorsais ou plantares (VHA/DOD CLINICAL PRACTICE GUIDELINE WORKING GROUP, 2000; SCOTTISH INTERCOLLEGIATE NETWORK, 2001; HUTCHINSON et al., 2003). Nesse sentido, a Scottish Intercollegiate Guidelines Network (2001) descreveu que os calçados tipo tênis com palmilhas acolchoadas, podem reduzir a pressão plantar mais que calçados convencionais. Para Hutchinson et al. (2003), o fornecimento de calçados e sua recomendação são importantes, mesmo na ausência de evidência de efeito e de sua avaliação custo-benefício.

O controle glicêmico e da pressão arterial também foram destacados como medidas coadjuvantes na prevenção de úlcera/amputação pela University of Michigan Health Systems (1998), VHA/DoD Clinical Practice Guideline Working Group (2000), Diabetes Coalition of 
Califórnia; Califórnia Diabetes Control Programm (2002) e Institute for Clinical Systems Improvement (2002) e, apenas o controle glicêmico pela New Zealand Guidelines Group (2000).

Meltzer et al. (1998), New Zealand Guidelines Group (2000) e Diabetes Coalition of California; California Diabetes Control Programm (2002) adicionaram a necessidade de abandonar o tabagismo.

Assistência pelo podiatra a intervalos regulares quando identificados fatores de risco como diminuição da sensibilidade protetora/vibratória, ausência de pulsos (ou prévia cirurgia vascular), perda significante da acuidade visual, presença de calosidades, alterações de unha, incapacidade física, dentre outros, foi considerada uma ação preventiva relevante (VHA/DOD CLINICAL PRACTICE GUIDELINE WORKING GROUP, 2000; NEW ZEALAND GUIDELINES GROUP, 2000; SCOTTISH INTERCOLLEGIATE GUIDELINES NETWORK, 2001).

Quanto às intervenções de tratamento para o cuidado dos pés em presença de processo ulcerativo, duas diretrizes destacaram o encaminhamento imediato da pessoa para equipe especializada em cuidado do pé diabético (MELTZER et al., 1998; DIABETES COALITION OF CALIFORNIA; CALIFORNIA DIABETES CONTROL PROGRAMM, 2002).

Outras, entretanto, referiram que na presença de úlcera, ferida perfurante, calos hemorrágicos, unha encravada, edema, celulite, abscesso, isquemia ou infecção sistêmica, o encaminhamento deve ser para o nível médico especializado, tais como vascular, podiatria, ortopedia, dentre outros, conforme necessidade (VHA/DOD CLINICAL PRACTICE GUIDELINE WORKING GROUP, 2000; SCOTTISH INTERCOLEGIATE GUIDELINES NETWORK, 2001; INSTITUTE FOR CLINICAL SYSTEMS IMPROVEMENT, 2002).

O encaminhamento também deve realizar-se, quando a pessoa não cuida apropriadamente do próprio pé, quando houver necessidade de prescrição de calçado e/ou em presença de lesões graves como pé de Charcot (INSTITUTE FOR CLINICAL SYSTEMS IMPROVEMENT, 2002).

Lesões menores como bolhas, erosões, pequenos cortes e úlceras superficiais sem comprometimento dos tecidos subcutâneos, com presença de pulsos, sem sinais de infecção, em ausência de dor intensa ou em repouso e sem sinais de agravamento, poderiam ser tratadas na assistência primária (VHA/DOD CLINICAL PRACTICE GUIDELINE WORKING GROUP, 2000).

A University of Michigan Health Systems (1998), VHA/DoD Clinical Practice Guideline Working Group (2000), New Zealand Guidelines Group (2000),. Scottish Intercollegiate 
Guidelines Network (2001) e Hutchinson et al (2003) referiram que, na presença de infecção superficial é aconselhável iniciar terapia com antibiótico oral apropriado aliviando-se, concomitantemente, o peso do membro inferior afetado, com acompanhamento contínuo e intensivo para evitar agravamento

Em relação aos curativos e agentes tópicos, não foi identificada evidência custoefetividade, portanto, a sua seleção no cuidado das úlceras, dependerá da experiência profissional e das preferências das pessoas com DM (HUTCHINSON et al., 2003). Outros tipos de curativos* também não tiveram suficiente força de evidência para serem recomendados.

$\mathrm{Na}$ avaliação metodológica das diretrizes (Tabela 6.3), identificaram-se que algumas apresentaram limitações, que podem restringir a confiabilidade nas suas recomendações. Entretanto, trazem ainda, contribuições importantes para a prática clínica, considerando o vazio existente no embasamento científico das intervenções de prevenção de lesão/ulceração nos pés entre pessoas com diabetes mellitus de baixo risco.

Observa-se na metodologia que a especificação das opções fundamentais foram abrangentes em três diretrizes, considerando as possíveis intervenções de prevenção de problemas nos pés - inspeção física de pés e calçados; avaliação neuropática e vascular; identificação de incapacidades e limitações; atividades educativas; uso de calçados e acessórios; cuidado com a pele e unhas; debridamento e curativo; necessidades de referência, dentre outras (VHA/DOD CLINICAL PRACTICE GUIDELINE WORKING GROUP, 2000; SCOTTISH INTERCOLLEGIATE GUIDELINES NETWORK, 2001; HUTCHINSON et al., 2003).

Entretanto, os efeitos clínicos dessas intervenções, apenas foram descritas e discutidas pela Scottish Intercollegiate Guidelines Network (2001) e Hutchinson et al. (2003), relacionandoos com a inconsistência dos resultados nos estudos identificados.

Em ambas diretrizes, ao realizar comparações dos resultados entre estudos, destacaram a qualidade da validade interna dos ensaios clínicos randomizados e concluíram que os ensaios analisados não mostraram resultados conclusivos.

Avaliação custo-benefício foi descrita em relação ao monofilamento SW e VPT, destacando-se que ambos instrumentos atingem bons resultados na identificação de risco para

\footnotetext{
* gesso de contato total, câmara hiperbárica, cultura de dermes humano (fibroblastos dermatológicos neonatais cultivados in vitro - tecido metabolicamente ativo que contem matriz de proteínas dermatológicas e citoquinas), Ketanserin (receptor antagonista serotogêncio 5HT2 promove a agregação plaquetaria, bloqueia a vasoconstrição, melhora a perfusão do tecido e incrementa a formação de tecido de granulação) e fatores de crescimento
} 
úlcera, porém SW parece ser mais acessível pelo seu custo e fácil aplicação (SCOTTISH INTERCOLLEGIATE GUIDELINES NETWORK, 2001; HUTCHINSON et al., 2003).

Tratamento com antibióticos e curativos foi discutido apropriadamente em uma diretriz. Entretanto, análise de custo-benefício não mostrou evidência clara e consistente (HUTCHINSON et al., 2003).

Programa educativo intensivo de cuidado com os pés foi destacado para pessoas com elevados fatores de risco para ulceração, mesmo que os estudos, ainda, sejam inconclusivos, devido à redução de custos em relação aos cuidados e tratamentos que demandam as úlceras e amputações (SCOTTISH INTERCOLLEGIATE GUIDELINES NETWORK, 2001; HUTCHINSON et al., 2003).

Para Meltzer et al. (1998) e Hutchinson et al. (2003), a implantação de um sistema de convocação regular, para observar às pessoas com DM deve ser considerada como importante medida de prevenção, a fim de monitorar a doença, identificar e direcionar problemas na saúde e desenvolver cuidado, além de promover comunicação entre atenção primária e secundária. Porém, não encontraram evidência de quais componentes ou métodos de transmissão das informações poder-se-ia implementar.

$\mathrm{Na}$ busca das evidências para a construção das recomendações nas diretrizes, as bases de dados mais pesquisadas foram Medline e Cochrane Library, seguido por Embase, HealthStar e Cinahl. Duas diretrizes executaram uma busca extensa das evidências (SCOTTISH INTERCOLLEGIATE GUIDELINES NETWORK, 2001; HUTCHINSON et al., 2003). Entretanto, incluíram apenas estudos em idioma inglês. Em outras diretrizes, não houve informações nesse respeito.

As referências escritas em línguas que não a inglesa têm baixa representação nas bases de dados eletrônicas (CLARKE; OXMAN, 2000). O fato de limitar a busca apenas à língua inglesa, favorece a interferência do viés idiomático como apontaram Moher et al. (1996) e Egger et al. (1997), entendendo que as diferenças na qualidade dos estudos entre inglês e não inglês são pequenas e não significativas.

Quanto aos critérios de inclusão e exclusão dos estudos, estes apenas foram descritos na Scottish Intercollegiate Guidelines Network (2001). Duas diretrizes incluíram revisões sistemáticas e metanálise, além de estudos comparativos sobre qualidade e fatores econômicos 
(SCOTTISH INTERCOLLEGIATE GUIDELINES NETWORK, 2001; HUTCHINSON et al., 2003).

Quatro diretrizes apresentaram processos estruturados, com modelos reproduzíveis da classificação do nível de evidências dos estudos, considerando sua qualidade metodológica e correspondente grau de recomendação (MELTZER et al., 1998; VHA/DOD CLINICAL PRACTICE GUIDELINE WORKING GROUP, 2000; SCOTTISH INTERCOLLEGIATE GUIDELINES NETWORK, 2001; HUTCHINSON et al., 2003), sendo que as duas últimas as combinaram também de forma clara.

Esta condição é importante para determinar, rapidamente, o grau de consistência das recomendações em relação ao tipo de estudos utilizados, ou se elas apenas se fundamentam no consenso de especialistas, o que certamente, favorecerá a confiabilidade dos usuários.

Desse modo, observa-se que no Institute for Clinical Systems Improvement (2002), a classificação também foi apropriada e reproduzível, porém combinações nas recomendações foram omitidas, possivelmente pela natureza dos estudos selecionados.

Quanto à clareza e sensibilidade do valor das recomendações, cinco diretrizes referiram que o grupo de trabalho responsável pela elaboração das mesmas foi constituído por equipe multidisciplinar (MELTZER et al., 1998; NEW ZEALAND GUIDELINES GROUP, 2000; SCOTTISH INTERCOLLEGIATE GUIDELINES NETWORK， 2001; INSTITUTE FOR CLINICAL SYSTEMS IMPROVEMENT, 2002; HUTCHINSON et al., 2003), fato importante para contrabalançar as tendências de alguns grupos profissionais. Os grupos multidisciplinares e multiprofissionais, propiciam uma ampla visão e deliberação do valor das evidências identificadas, principalmente, quando apoiados por especialistas no método da revisão sistemática e pacientes, permitindo dessa forma, uma síntese coerente e neutralizada das recomendações.

Na Scottish Intercollegiate Guidelines Network (2001), a participação do paciente foi considerada relevante em todo o processo da elaboração das recomendações. Dessa forma, a defesa de suas necessidades e interesses foi explícita, principalmente, quando a evidência era insuficiente. $\mathrm{O}$ valor das evidências foi direcionado conforme os benefícios e prejuízos no cuidado ao paciente (SCOTTISH INTERCOLLEGIATE GUIDELINES NETWORK, 2001; HUTCHINSON et al., 2003). Meltzer et al. (1998) não descreveram como se determinaram as preferências dos pacientes. 
Resolução das incertezas e ambigüidades sobre o valor dos resultados nos estudos foi descrita apenas por Meltzer et al. (1998), Scottish Intercollegiate Guidelines Network (2001) e Hutchinson et al. (2003). Este componente deve estar explícito nas diretrizes, pois incertezas nos estudos ou discrepâncias de opinião na equipe, podem estar relacionadas à avaliação de danobenefício, custo-benefício, desconforto ou impraticabilidade da recomendação. Desse modo, documentação do grau de consenso alcançado na equipe, pode ajudar a decidir se adotar ou adaptar a recomendação entre usuários (HAYWARD et al., 1995).

A literatura revisada corresponde, em sua maioria, ao período de 1990 a 1993. Na Scottish Intercollegiate Guidelines Network (2001), intervenções mais recentes foram apresentadas em relação ao tratamento das úlceras/feridas.

Revisão das recomendações por especialistas internos foi considerada por Meltzer et al. (1998), University of Michigan Health Programm (1998), VHA/DoD Clinical Practice Guideline Working Group (2000), New Zealand Guidelines Group (2000), Scottish Intercollegiate Guidelines Network (2001), Institute for Clinical Systems Improvement (2002) e Hutchinson et al., (2003). Houve participação de especialistas externos em quatro delas (MELTZER al., 1998; NEW ZEALAND GUIDELINES GROUP, 2000; SCOTTISH INTERCOLLEGIATE GUIDELINES NETWORK, 2001; HUTCHINSON et al., 2003).

Esta fase é relevante para determinar a aplicabilidade e consistência das recomendações na prática clínica, considerando que as evidências podem ter diferentes interpretações e, por tanto, diferentes valores. A apreciação pelos especialistas, tanto internos, como externos, julgando as conclusões das diretrizes razoáveis, aumenta a confiabilidade dos usuários nas mesmas, principalmente, quando os primeiros quatro critérios metodológicos foram satisfatoriamente considerados (HAYWARD et al., 1995). A confiabilidade pode ser maior ainda, quando as recomendações foram testadas na prática e quando foi verificado se o impacto entre pacientes foi benéfico ou diminuiu os custos no serviço.

New Zealand Guidelines Group (2000), Institute For Clinical Systems Improvement (2002) e Hutchinson et al. (2003) referiram que as recomendações foram previamente testadas. Em duas delas o teste foi aplicado entre profissionais da assistência primária, sem outras informações a respeito de obstáculos ou limitações identificadas. 
Teria sido importante conhecer o impacto da utilização das recomendações entre pessoas envolvidas na assistência e pacientes. Esta informação é relevante para verificar a praticidade das mesmas, sua utilidade entre profissionais e no cuidado e segurança do paciente.

Trowbridge e Weingarten (2001) avaliando a efetividade das diretrizes clínicas na prática, incluindo revisões sistemáticas, referem que as diretrizes influenciam positivamente no processo e, em menor extensão, no resultado do cuidado, apesar, das falhas metodológicas identificadas nos estudos, que dificultaram avaliar o verdadeiro impacto.

Quanto às recomendações propriamente ditas, cinco diretrizes apresentaram suas recomendações com propriedade e coerência, estabelecendo-se os benefícios a serem alcançados (MELTZER et al., 1998; VHA/DOD CLINICAL PRACTICE GUIDELINE WORKING GROUP, 2000; SCOTTISH INTERCOLLEGIATE GUIDELINES NETWORK, 2001; INSTITUTE FOR CLINICAL SYSTEMS IMPROVEMENT, 2002; HUTCHINSON et al., 2003). Em New Zealand Guidelines Group (2000) e University of Michigan Health Systems (1998), as recomendações foram apresentadas de forma prática e sucinta.

Intervenções de prevenção com conseqüente benefício, danos e custos não foram descritas em nenhuma diretriz, com exceção do teste de screening para neuropatia periférica (SCOTTISH INTERCOLLEGIATE GUIDELINES NETWORK, 2001; HTUCHINSON et al., 2003).

Quanto ao grau de evidências das recomendações, três diretrizes utilizaram ensaios clínicos randomizados controlados, principalmente (MELTZER et al., 1998; SCOTTISH INTERCOLLEGIATE GUIDELINES NETWORK, 2001; HUTCHINSON et al., 2003), destacando-se que os resultados ainda foram inconsistentes.

Impacto das incertezas associadas às evidências e valores, somente foi apontada em Scottish Intercollegiate Guidelines Network (2001) e Hutchinson et al. (2003). Outras recomendações embasadas em opinião de especialistas e estudos observacionais, não apresentaram análise de sensibilidade dos resultados para esclarecer o verdadeiro efeito dos estudos.

Conforme os critérios incluídos na avaliação da propriedade das recomendações nas diretrizes clínicas, pode-se dizer que, a maioria delas apresentou limitações que diminuem a confiabilidade, especialmente relacionada com a ausência de informações importantes, quanto ao desenvolvimento sistematizado das diretrizes. 
Entretanto, Meltzer et al. (1998), Scottish Intercollegiate Guidelines Network (2001) e Hutchinson et al. (2003) foram mais específicos na descrição metodológica (Tabela 6.3). Desse modo, suas recomendações mostram maior credibilidade para os leitores e usuários, principalmente, porque elas se fundamentam, em grande parte, em ensaios clínicos randomizados controlados, que mesmo apresentando resultados inconclusivos quanto à evidência de efeito, constitui o que até agora se pode dispor.

Isto é importante, devido à necessidade de direcionar esforços para diminuir as complicações nos pés de pessoas com diabetes decorrentes, principalmente, do avanço inexorável da doença e de sua longevidade no período de vida, que pode terminar conduzindo, invariavelmente, a amputação do membro inferior e a outras doenças incapacitantes.

Essas diretrizes apresentaram recomendações importantes para o rastreamento e identificação precoce dos fatores de risco para lesão/ulceração, mediante intervenções simples e avaliação regular dos membros inferiores, conforme a classificação de risco identificado nas pessoas. A determinação do valor das evidências identificadas foram revistas e analisadas por equipes multidisciplinares e pacientes, além de especialistas na metodologia de revisão sistemática, cujas deliberações foram descritas com propriedade, inclusive, quando a evidência foi incerta ou ambígua, procurou-se avaliar o dano-benefício para o paciente.

A revisão precedente neste estudo, quanto à organização do serviço envolvendo a equipe que oferece cuidado às pessoas com diabetes e as intervenções educativas aplicadas diretamente nos pacientes, visando prevenção de lesão/ulceração nos pés, não têm mostrado resultados consistentes, para determinar qual o melhor modo de organizar-se na assistência primária, nem qual a melhor intervenção educativa para alcançar a redução de complicações nesse membro. Revisões prévias (MASON et al., 1998; VALK, KRIEGSMAN; ASSENDELFT, 2002), já tinham identificado essa lacuna nas pesquisas, que também foi apontada nas diretrizes (MELTZER et al., 1998; SCOTTISH INTERCOLLEGIATE GUIDELINES NETWORK, 2001; HUTCHINSON et al., 2003).

Os resultados desta revisão reforçam a necessidade de se investir no desenvolvimento de pesquisas que possam trazer contribuições consistentes na área em foco, visando preencher as lacunas identificadas e considerando aspectos relevantes no desenho metodológico, como os ensaios clínicos randomizados, que definem com clareza o efeito das intervenções preventivas/terapeuticas. 
Intervenções educativas e estratégias de organização do serviço, são necessárias para obter melhores resultados no cuidado das pessoas com diabetes. Toda a equipe cuidando dessa população, precisa estar consciente da importância do sinergismo de suas funções, visando o bom controle glicêmico e a prevenção de complicações crônicas, principalmente aquelas incapacitantes e mutilantes, como o pé diabético, que conduz a amputação e, a subseqüentes re-amputações, em curto e médio prazo afetando, significativamente, a qualidade de vida dessas pessoas.

Considerando a necessidade de avaliar intervenções básicas de prevenção de lesão/ulceração nos pés das pessoas com diabetes, a partir dos achados na revisão de ensaios clínicos randomizados controlados e de diretrizes clínicas, estruturou-se uma proposta de assistência sistematizada, nessa perspectiva, incluindo medidas de rastreamento dos fatores de risco e de sensibilização educativa.

A proposta inclui, também, sensibilização para os profissionais envolvidos no cuidado das pessoas com diabetes, como médicos e enfermeiros, para estarem alerta aos fatores de risco e a sua responsabilidade na prevenção da lesão/ulceração nos pés, mediante o desenvolvimento de estratégias de cuidado e rastreamento, além de sugestões a serem consideradas em situações especiais de risco.

Conforme os princípios regulamentados pela PBE, que promovem o desenvolvimento de ensaios clínicos randomizados, quando se trata de verificar a efetividade de uma intervenção, propôs-se na segunda parte desta pesquisa um estudo piloto para avaliar a proposta assistencial sistematizada, em uma população com diabetes acompanhadas em unidades de assistência primária (UBDS), entendendo que ações preventivas são fundamentais, principalmente, nesse nível de atendimento, para evitar o desencadeamento de complicações crônicas.

A enfermagem tem participado ativamente nas atividades de prevenção, principalmente, no que se refere às intervenções educativas e de sensibilização, pelo seu envolvimento contínuo e constante com as pessoas adoecidas. Esta inserção denota sua responsabilidade com a saúde das pessoas com diabetes, estimulando uma vida com qualidade e sua importante contribuição na meta de alcançar a meta proposta pela Declaração de Saint Vincent.

Porém, antes de proceder ao desenvolvimento do estudo de intervenção, apresenta-se a proposta de assistência sistematizada, a qual está embasada em resultados de ensaios clínicos randomizados controlados, ensaios clínicos controlados, estudos observacionais e consenso de especialistas, em ausência de evidência consistente. 
Quando as recomendações fundamentaram-se apenas, em estudos observacionais e consenso, correspondem à adaptação daquelas apresentadas nas diretrizes clínicas, considerando a relevância da intervenção, para a prevenção e cuidado das lesões/ulcerações nos pés de pessoas com diabetes (HUTCHINSON et al., 2003).

Quanto à classificação do nível de evidências dos estudos na proposta, esses foram apresentados pelo tipo de estudo que constituíram. Logo o grau de recomendação outorgado, determina a força de sua consistência e importância na prática. Como referido na metodologia, os graus variam de "A" a "D", correspondendo ao primeiro nível de evidência I (metanálise) e, o último, nível IV (consensos).

Em decorrência dos resultados identificados nos estudos, as recomendações foram categorizadas principalmente, nos graus "B" e "D" e, apenas duas no grau "A". Salienta-se que, a maioria das recomendações propostas neste estudo, condiz com as sugestões descritas nas diretrizes práticas do Consenso Internacional de Pé Diabético (GTIPD, 2001), com exceção de quatro procedimentos utilizados na avaliação da sensibilidade (percepção da vibração, discriminação, sensação tátil e reflexos).

O Consenso Brasileiro de Diabetes tem difundido as diretrizes inseridas no Consenso Internacional de Pé Diabético, nesse sentido, acredita-se que a proposta reforça a importância dessas recomendações, dada à necessidade de executá-las na prática clínica, mediante a complicação devastadora que constitui o pé diabético.

A proposta inclui duas fases: 1) Cuidado de rotina com os pés das pessoas com diabetes mellitus e 2) Cuidado com os pés das pessoas com diabetes mellitus na presença de fatores de risco. Ambos incluem suas respectivas recomendações direcionadas à organização do serviço para o cuidado pelos profissionais de saúde e quais cuidados devem ser considerados dentre as intervenções de prevenção.

\subsubsection{Proposta de assistência sistematizada}

6.1.4.1 Cuidado de rotina dos pés das pessoas com DM

Organização do cuidado

Implantar processo de agendamento regular para observar à pessoa com diabetes, considerando a inclusão de componentes específicos de cuidado com os pés.

- $\quad$ Recomendação Grau B, estudo RCT (54,92,205;93). 
A pessoa com diabetes deve consultar o clínico geral ou endocrinologista a cada três meses, utilizando agendamento automático. Essa consulta pode ser confirmada aos interessados mediante uma carta de convocação, com uma semana de antecedência.

- $\quad$ Recomendação B, estudo RCT $(54,98,93)$.

Implantar atividades educativas dirigidas aos profissionais de saúde envolvidos no cuidado da pessoa com diabetes, mediante visitas e demonstrações de reconhecimento, avaliação e manejo do "pé em risco", enfatizando as responsabilidades dos pacientes, bem como as dos profissionais.

- $\quad$ Recomendação Grau B, estudo RCT $(59,114)$.

Profissionais de saúde envolvidos na avaliação dos pés da pessoa com diabetes devem receber treinamento específico.

- Recomendação Grau D, diretriz clínica (93).

Profissionais de saúde devem solicitar à pessoa com DM que descalce seus sapatos, para efetivarem o exame nesse segmento, proporcionando e/ou reforçando a educação em cada visita conforme classificação de risco.

- Recomendação Grau B, estudo RCT (114).

\section{$\underline{\text { Monitoramento }}$}

O exame dos pés da pessoa com diabetes constitui componente integral no manejo do diabetes, cujo fim é prevenir e diminuir o risco de ulceração e amputação.

- $\quad$ Recomendação Grau A, estudo RCT (114,222; 93).

Avaliar o risco da pessoa com diabetes desenvolver úlcera e/ou amputação em membros inferiores, observando sua pele à procura de alguma alteração, considerando sensibilidade protetora plantar, doença vascular periférica, deformidades nos pés e prévia ulceração ou amputação.

- Recomendação Grau D, diretriz clínica $(93,125,169)$. 
A inspeção de membros inferiores inclui pernas e pés, nesses últimos devem ser destacadas a região plantar e dorsal e os espaços interdigitais.

- Recomendação Grau D, diretriz clínica (93).

$\mathrm{Na}$ avaliação da pele identificar a presença de vasodilatação dorsal; ressecamento, descamação e eritemas; calosidades plantares, rachaduras e físsuras; maceração interdigital, edemas e traumas; mudanças no tamanho ou na forma dos pés, além de alterações ou deformidades das unhas.

- Recomendação Grau C, estudo RCT $(19,114,163)$ e descritivo não-experimental (10).

Para a realização do screening de ulceração neuropática, o profissional utilizará escore de incapacidade neuropática clínica mediante percepção do limiar de vibração com biotensiometro ou, percepção do limiar da sensação com monofilamento de 5,07 (10 gramas). Ambos os métodos, isoladas ou associados, têm mostrado benefícios na identificação de pacientes com alto risco para úlcera.

- Recomendação Grau C, estudo descritivo não-experimental (1,105,161,200,202; 93, 169).

A identificação de risco de ulceração neuropática embasada na insensibilidade ao monofilamento de 5,07 (10 gramas) é uma técnica fácil de usar e parece ser custo-efetivo.

- Recomendação Grau D, estudo descritivo não-experimental (102,104,163; 93).

O método de screening para identificação da insuficiência vascular é menos definido. Entretanto, a ausência de pulso pedioso facilita o reconhecimento da presença de doença vascular periférica, como opção de primeira linha.

- Recomendação Grau C, estudo descritivo não-experimental (10,191;169).

O índice da pressão tornozelo-braquial pode estar falsamente elevado em pessoas com diabetes, devendo ser interpretado com precaução.

- Recomendação Grau D, estudo descritivo $(63 ; 169)$. 
Examinar os pés de adultos com DM pelo menos uma vez por ano e a intervalos freqüentes, naqueles com alto risco (pode-se utilizar a classificação de risco do GIPD).

- $\quad$ Recomendação Grau D, diretriz clínica $(93,125,169)$

\section{Educação da pessoa com diabetes}

Melhorar o conhecimento da pessoa com DM sobre os cuidados com os pés para diminuir ações adversas decorrentes do autocuidado inadequado. Os profissionais de saúde devem combinar e/ou negociar com os pacientes sobre o manejo do plano de cuidado com os pés que desejam atingir conforme classificação de risco. Isto é importante para se alcançar um nível apropriado de cuidado.

A intervenção educativa pode melhorar o conhecimento e as condutas em curto período de tempo (18 meses).

- $\quad$ Recomendação Grau B, estudo RCT $(19,24,114,159,222 ; 93,54)$.

O valor da intervenção educativa em longo prazo ainda é desconhecido. Assim, talvez seja necessária a introdução de mensagens importantes e de novos hábitos, periodicamente, para reforçar essa conduta entre pacientes e profissionais de saúde.

- Recomendação Grau D, diretriz clínica (93).

Elementos básicos no plano educacional incluem inspeção diária dos pés e cuidados preventivos, tais como: cuidados com a pele, unhas e calosidades; a quem se deve procurar quando identificado qualquer ferimento ou anormalidade; devem-se considerar também as características dos sapatos.

- $\quad$ Recomendação Grau B, estudo RCT $(19 ; 163 ; 196)$.

Atividades educativas destinadas às pessoas com diabetes devem considerar as necessidades e habilidades de cada um dos participantes.

- Recomendação Grau B, estudo RCT(159,163).

Sessões de higiene e medidas preventivas de autocuidado voltadas às pessoas com DM devem incluir técnicas de demonstração e re-demonstração, tais como: lavagem, secagem e inspeção dos pés, corte de unhas, uso de creme hidratante e realização de exercícios. 
- $\quad$ Recomendação Grau B, estudo RCT $(19,163)$.

Atividades educativas destinadas às pessoas com diabetes devem incluir de 4 a 10 participantes em cada uma das sessões programadas.

- Recomendação B, estudo RCT $(19,114)$.

Disponibilizar folhetos ilustrativos sobre cuidados e medidas preventivas com os pés e sapatos entre pessoas com diabetes.

- $\quad$ Recomendação Grau B, estudo RCT $(59,114)$.

\subsubsection{Cuidado do pé da pessoa com diabetes que apresenta fatores de risco}

Identificação do pé em risco

Dispensar cuidado especial àquelas pessoas que apresentarem fatores de risco para ulceração, como diabetes de longa duração, neuropatia, doença vascular periférica, deformidades de pés, calosidades plantares, prévia ulceração ou amputação, acuidade visual diminuída, sapato impróprio, tabagismo, privação social e isolamento, principalmente, os idosos.

- Recomendação Grau $\quad \mathrm{C}$, estudo $\mathrm{RCT} \quad(3,217)$; $\quad$ descritivo não-experimental $(1,29,34,70,105,131,161,175,200 ; 93,169)$.

A neuropatia está presente quando existe ausência de sensação ao monofilamento de 5,07 (10 gramas), em uma ou mais áreas testados sem calosidades considerando dez pontos.

- Recomendação Grau D, estudo descritivo não-experimental $(11,40,176,201,202)$.

As deformidades de pé incluem: pé cavo ou plano excessivamente, pé rígido, pé eqüino, hallux valgus e varus, dedos em martelo, dedos em garra, proeminência óssea ou neurosteoartropatia (Charcot). Na amputação, incluí-se o processo não-traumático a qualquer nível do membro inferior.

- Recomendação Grau C, estudo descritivo não-experimental $(118,161 ; 196)$.

$\mathrm{Na}$ doença vascular periférica, a ausência de pulso pedioso e tibial posterior, podem estar associados a dor em repouso, à extrema palidez de membro inferior ou à extremidade fria à palpação. Claudicação é determinada pela dor em coxa ou panturrilha que aparece durante 
caminhadas curtas (menos de um quarteirão) e se alivia com o repouso. Nesse caso, a pessoa deve ser encaminhada, imediatamente, ao cirurgião vascular.Lembrar que para cada três claudicantes existe um claudicante silencioso.

- Recomendação Grau D, estudo descritivo narrativo (140;196).

\section{Calçados da pessoa com diabetes}

Avaliar os sapatos da pessoa com DM que apresenta fatores de risco para ulceração. Entre pessoas com prévia ulceração, evidência preliminar sugere que a utilização de sapatos terapêuticos feitos sob medida pode reduzir o risco de futuras ulcerações.

- Recomendação Grau D, estudo RCT $(114,221,190 ; 93,169)$.

Ao utilizar sapatos comuns, a pressão plantar assemelha-se ao caminhar descalço. Desse modo, calçados de melhor qualidade, como tênis ou sapatos com solado acolchoado, que absorvem o impacto, podem reduzir essa pressão, embora não tanto como os sapatos terapêuticos feitos sob medida.

- Recomendação Grau C, estudo descritivo não-experimental (98,149;169).

\section{Programa estruturado de cuidado com os pés}

Encaminhar a pessoa com DM, em risco de ulceração, para o programa de proteção especializada multidisciplinar.

- Recomendação Grau A, ensaio clínico randomizado controlado (111,221,190;93).

O programa de proteção multidisciplinar permite tratamento intensivo e rápido, assim como acesso ao cirurgião vascular e ortopedista, possibilitando o controle da infecção e a revascularização, quando for o caso.

- Recomendação Grau C, estudo descritivo não-experimental $(4,66,106 ; 169)$. 


\section{2- $\quad$ ESTUDO DE INTERVENÇÃO}

Das 101 pessoas com diabetes participantes no início do ensaio, 52 foram alocadas no grupo controle e 49 no grupo de intervenção, dentre elas, 20 não completaram o ensaio, correspondendo cinco no grupo-controle e 15 no grupo intervenção. As razões para esses abandonos foram no grupo controle: desinteresse (quatro pessoas) e mudança de endereço (uma pessoa); no grupo intervenção: desinteresse (seis pessoas), mudança de endereço (quatro pessoas), incompatibilidade com horário do trabalho (duas pessoas), problemas familiares (duas pessoas) e óbito (uma pessoa). A causa de morte foi pancreatite aguda conforme atestado de óbito.

Resultados basais são apresentados a seguir, ilustrados em tabelas e expressos em médias e desvio-padrão para testes paramétricos e em medianas, amplitude semi-quartil, máximo e mínimo e percentuais para testes não paramétricos. A Tabela 6.4 inclui as características sociodemográficas, clínicas, co-morbidades e antecedentes de lesões nos pés dos participantes. Outros dados basais são apresentados nas Tabelas 6.5 a 6.8 .

Tabela 6.4 - Características socio-demográficas, clínicas, co-morbidades e antecedentes de lesões nos pés dos participantes, por grupos de estudo na avaliação basal.

\begin{tabular}{|c|c|c|c|}
\hline Variáveis & $\begin{array}{c}\text { Controle } \\
(\mathrm{n}=52)\end{array}$ & $\begin{array}{c}\text { Intervenção } \\
(\mathrm{n}=49)\end{array}$ & Valor de $\mathrm{p}$ \\
\hline Idade $(X \pm \mathrm{DP})$ & $59 \pm 9,6$ & $58 \pm 7,4$ & $0,46 \ddagger$ \\
\hline Mulheres (\%) & 75 & 67 & $0,27 \dagger$ \\
\hline Escolaridade - ensino fundamental incompleto (\%)* & 85 & 90 & $0,52 \S$ \\
\hline Estado Civil (\%)** & 73 & 73 & $0,42 \S$ \\
\hline Ocupação $(\%)^{* * *}$ & 73 & 65 & $0,14 \S$ \\
\hline Tempo de doença $(\bar{X} \pm \mathrm{DP})$ & $8,3 \pm 6,5$ & $9,6 \pm 6,8$ & $0,33 \$$ \\
\hline Tratamento com agente oral (\%) & 59 & 50 & $0,38 \S$ \\
\hline Tratamento com insulina + agente oral $(\%)$ & 21,1 & 16,3 & $0,38 \S$ \\
\hline $\operatorname{IMC}(\bar{x} \pm \mathrm{DP})$ & $31,7 \pm 4,4$ & $30,4 \pm 5,0$ & $0,17 \ddagger$ \\
\hline Hipertensão arterial sistólica (\%) & 75 & 71,4 & $0,43 \dagger$ \\
\hline Dislipidemia (\%) & 29 & 14,3 & $0,06 \dagger$ \\
\hline Doença Isquêmica do coração (\%) & 3,8 & - & $0,26 \dagger$ \\
\hline Apoplexia (\%) & - & 2 & $0,46 \dagger$ \\
\hline Retinopatia diabética (\%) & 3,2 & 8,2 & $0,31 \dagger$ \\
\hline Neuropatia diabética (\%) & - & 2 & $0,49 \dagger$ \\
\hline Byppas em MMII (\%) & 2 & - & $0,52 \dagger$ \\
\hline Outras doenças (\%) & 17 & 12 & $0,25 \dagger$ \\
\hline Antecedentes de queimadura nos pés (\%) & - & 6,1 & $0,11 \dagger$ \\
\hline Antecedentes de escoriação nos pés (\%") & - & 2,0 & $0,49 \dagger$ \\
\hline Antecedentes de bolha nos pés (\%) & 4 & 2 & $0,52 \dagger$ \\
\hline Antecedentes de corte nos pés (\%) & 4 & 4 & $0,67 \dagger$ \\
\hline Antecedentes de rachadura nos pés (\%) & 32,7 & 26,5 & $0,32 \dagger$ \\
\hline Antecedentes de unha encravada (\%) & 21,2 & 18,4 & $0,46 \dagger$ \\
\hline
\end{tabular}

*Entre 1 e 8 anos, ${ }^{* *}$ casado/amasiado, ${ }^{* * *}$ Aposentado/do lar. †teste exato de Fischer, $\$$ teste t, §teste $\mathrm{X}^{2}$. 
Observa-se na Tabela 6.4, que os grupos não apresentaram diferenças significativas para as características consideradas. A população estudada encontra-se na faixa etária de 50 a 60 anos, com maior percentual no sexo feminino, sendo aposentada e exercendo atividade do lar. Quanto ao grau de escolaridade, destaca-se que $8,9 \%$ eram analfabetas e $63 \%$ apenas tinha cursado o primário incompleto ( $10 \%$ apenas um ano e $53 \%$, de 2 a 4 anos de estudos), condição que caracteriza a população como sendo de baixa escolaridade.

Em relação aos dados clínicos, o tempo médio do diagnóstico do diabetes foi de nove anos, sendo que a maioria da população fazia tratamento medicamentoso com antidiabéticos orais e pouco menos de $25 \%$ recebiam terapia combinada.

Quanto às co-morbidades relacionadas ao diabetes destacaram-se a obesidade, hipertensão arterial e dislipidemia. O hábito de fumo e ingestão de bebida alcoólica foi semelhante nos grupos ( $\leq 20 \%$ para cada grupo). Dados relacionados com antecedentes de problemas nos pés mostraram que mais de $25 \%$ dos participantes tinham apresentado rachaduras e aproximadamente, $20 \%$ unha encravada conforme relato.

$\mathrm{Na}$ Tabela 6.5 apresentam-se dados relacionados às condições dermatológica, estrutural, circulatória e neurológica dos pés dos participantes. Na maioria dos indicadores dessas variáveis não houve diferença significativa entre grupos $(p>0,05)$, exceto pela presença de maior quantidade de pessoas com calos/rachaduras no grupo intervenção $(p<0,02)$, outros indicadores de alterações dermatológicas também se apresentaram elevados neste grupo, com uma pessoa apresentando uma úlcera venosa localizada no terço distal lateral externo da perna direita, com 2,5 centímetros de diâmetro, sem comprometimento da sensibilidade tátil pressórica plantar, nem da sensibilidade vibratória. Na avaliação estrutural, observa-se que mais de $30 \%$ dos participantes possuíam pé plano.

$\mathrm{Na}$ Tabela 6.6 apresentam-se os dados correspondentes à classificação de risco para o pé diabético de acordo com Sims, Cavanagh e Ulbrecht (1988), os quais incluíram alterações neurológicas, estruturais e antecedentes de úlcera. Para as categorias preenchidas, não se observam diferenças significativas entre grupos. No entanto que, aproximadamente, $30 \%$ dos participantes classificados na categoria zero, ou seja, sem alteração da sensibilidade protetora plantar, apresentaram algum tipo de deformidade estrutural. Nas categorias 1 e 2, todos os participantes apresentaram algum tipo de alteração dermatológica no momento da avaliação 
(Tabela 6.5), as quais podem ser consideradas fatores coadjuvantes para o risco de lesão/ulceração.

Tabela 6.5 - Características dermatológica, estrutural, circulatória e neurológica dos membros inferiores nos participantes, por grupos de estudo na avaliação basal.

\begin{tabular}{lccc}
\hline Variáveis e indicadores & $\begin{array}{c}\text { Controle } \\
(\mathrm{n}=52)\end{array}$ & $\begin{array}{c}\text { Intervenção } \\
(\mathrm{n}=49)\end{array}$ & Valor de p \\
\hline Condição dermatológica & & & \\
Higiene de pés e corte de unhas inapropriada (\%) & 69,2 & 77,6 & $0,24 \dagger$ \\
Pele ressecada/descamativa (\%) & 59,6 & 67,3 & $0,28 \dagger$ \\
Unha espessada/farináceo/onicomicose (\%) & 53,8 & 51,0 & $0,47 \dagger$ \\
Dermatite fúngica/micose interdigital (\%) & 25,0 & 16,3 & $0,20 \dagger$ \\
Calos/rachaduras (\%) & 38,5 & 61,2 & $0,02 * \dagger$ \\
Bolhas/úlceras (\%) & 1,9 & 4,1 & $0,48 \dagger$ \\
Condição estrutural & & & \\
Pé plano (\%) & 32,7 & 34,7 & $0,50 \dagger$ \\
Halux valgo (\%) & 14,3 & 11,5 & $0,45 \dagger$ \\
Dedos sobrepostos (\%) & 7,7 & 4,1 & $0,37 \dagger$ \\
Condição circulatória & & & \\
Edema (\%) & 9,6 & 12,2 & $0,46 \dagger$ \\
Claudicação (\%) & 13,5 & 18,4 & $0,34 \dagger$ \\
Pulso tibial posterior não palpável (\%) & 3,8 & 2,0 & $0,52 \dagger$ \\
Pulso pedioso não palpável (\%) & - & - & - \\
Temperatura pé ( $X$ \pm DP) & $33,1 \pm 1,5$ & $33,1 \pm 1,3$ & $0,95 \dagger$ \\
Condição neurológica & & & \\
Sensibilidade tátil pressórica comprometida (\%) & 13,5 & 16,3 & $0,45 \dagger$ \\
Sensibilidade vibratória comprometida (\%) & 11,5 & 10,2 & $0,54 \dagger$ \\
\hline
\end{tabular}

†Teste exato de Fischer, $₫$ Teste t. $* \mathrm{p}<0,05$.

Tabela 6.6 - Classificação de risco para pé diabético dos participantes, a partir da categoria de Sims, Cavanagh e Ulbrecht, por grupos de estudo na avaliação basal.

\begin{tabular}{lccc}
\hline Descrição das categorias & $\begin{array}{c}\text { Controle } \\
(\mathrm{n}=52) \\
(\%)\end{array}$ & $\begin{array}{c}\text { Intervenção } \\
(\mathrm{n}=49) \\
(\%)\end{array}$ \\
\hline Sensibilidade intacta & 0 & 86,5 & 83,6 \\
& 1 & 9,6 & 6,1 \\
Perda da sensibilidade protetora & 2 & 3,8 & 10,2 \\
$\begin{array}{l}\text { Perda da sensibilidade protetora + deformidade } \\
\text { ou aumento da pressão plantar }\end{array}$ & 2 & - & - \\
$\begin{array}{l}\text { Perda da sensibilidade protetora + história de } \\
\text { úlcera prévia }\end{array}$ & 3 & - & - \\
$\begin{array}{l}\text { Perda da sensibilidade protetora + história de } \\
\text { úlcera }+ \text { deformidade ou aumento da pressão } \\
\text { plantar }\end{array}$ & 4 & & \\
Fratura neuropática & 5 & - & - \\
\hline
\end{tabular}

Aplicação de Teste $\mathrm{X}^{2}$ 
Os dados da Tabela 6.7 referem-se ao conhecimento dos participantes sobre o diabetes, particularmente sobre a faixa do valor padrão da glicose em jejum, sintomas de hipoglicemia, hiperglicemia e de problemas nos pés, assim como, conhecimentos sobre cuidados preventivos com os pés e com os calçados e em relação ao tipo de calçado que estavam usando na ocasião da entrevista. Destaca-se que estas quatro variáveis, somadas às condições dermatológicas da Tabela 6.5 constituem as variáveis que foram avaliadas no seguimento do ensaio e, nesta única vez foram apresentadas de forma explicita com a descrição de cada um de seus indicadores.

Observa-se que não houve diferença significativa entre grupos, exceto pelo horário da compra dos calçados $(\mathrm{p}<0,04)$ e pelas características dos calçados que usavam no dia da entrevista $(p<0,01)$, cujas respostas foram mais apropriadas no grupo intervenção.

Tabela 6.7 - Conhecimento sobre o diabetes e comportamentos de cuidados com os pés e com os calçados e características dos calçados entre participantes, por grupos de estudo na avaliação basal.

\begin{tabular}{|c|c|c|c|}
\hline Variáveis e indicadores & $\begin{array}{c}\text { Controle } \\
(\mathrm{n}=52) \\
(\%)\end{array}$ & $\begin{array}{l}\text { Intervenção } \\
(n=49)(\%)\end{array}$ & $\begin{array}{c}\text { Valor de } \\
p\end{array}$ \\
\hline \multicolumn{4}{|l|}{ Conhecimento sobre o diabetes } \\
\hline Valores normais da glicemia & 21,2 & 16,3 & $0,50 \S$ \\
\hline Sintomas de hipoglicemia e hiperglicemia & 9,6 & 4,1 & $0,50 \S$ \\
\hline Sintomas de complicações nos pés & - & - & - \\
\hline \multicolumn{4}{|l|}{ Comportamento com os pés } \\
\hline Examina freqüentemente & 51,9 & 61,2 & $0,23 \dagger$ \\
\hline Realiza auto-exame & 51,9 & 63,3 & $0,17 \dagger$ \\
\hline Corte unhas apropriado & 34,6 & 24,5 & $0,19 \dagger$ \\
\hline Refere antecedentes de calosidades & 38,5 & 51,0 & $0,14 \dagger$ \\
\hline Cuidado apropriado das calosidades & 13,5 & 18,8 & $0,21 \S$ \\
\hline Seca bem entre os dedos & 88,5 & 83,7 & $0,34 \dagger$ \\
\hline Hidrata com freqüência a pele & 40,4 & 42,9 & $0,48 \dagger$ \\
\hline Cuida apropriadamente dos pés frios & 15,4 & 18,4 & $0,61 \S$ \\
\hline Costuma usar meia & 25,0 & 26,5 & $0,52 \dagger$ \\
\hline Usa meia de algodão ou lã & 28,8 & 36,7 & $0,61 \S$ \\
\hline \multicolumn{4}{|l|}{ Comportamento com os calçados } \\
\hline Inspeciona no interior & 25,0 & 36,7 & $0,14 \dagger$ \\
\hline Limpa ou areja após o uso & 32,7 & 51,0 & $0,05 \dagger$ \\
\hline Usa tipo de calçados diferentes durante o dia & 25,8 & 30,6 & $0,51 \dagger$ \\
\hline Compra calçado em horário apropriado & 11,5 & 16,3 & $0,04 * *_{\S}$ \\
\hline Refere utiliza tipo de calçado apropriado & 34,6 & 38,8 & $0,41 \dagger$ \\
\hline $\begin{array}{l}\text { Características apropriadas dos calçados } \\
\text { Calçado apropriado* }\end{array}$ & 19,2 & 42,8 & $0,01 * * \S$ \\
\hline
\end{tabular}

\footnotetext{
*observado no dia da entrevista, $* * \mathrm{p}<0,05$. $†$ Teste exato de Fischer, $\S$ Teste $\mathrm{X}^{2}$
} 
O horário indicado como apropriado para a compra de calçados, correspondeu ao período da tarde, especificamente final da tarde, devido a maior probabilidade dos pés ficarem edemaciados nesse horário e esta condição pode propiciar à pessoa selecionar calçados que proporcionem maior conforto aos pés no decorrer do dia.

Quanto aos tipos de calçados, esses foram considerados apropriados quando eram fechados, com ponta ampla quadrada/arredondada ou se protegiam grande parte da área dos pés, com salto de até cinco centímetros e confeccionado em couro macio/lona/algodão. Nesta condição foram incluídos os calçados esportivos/tênis.

Em relação aos dados relacionados com o controle metabólico e da pressão arterial dos participantes, os quais constituem variáveis importantes para determinar o grau do controle do diabetes e do risco de complicações cardiovasculares, os resultados da avaliação basal indicaram (Tabela 6.8) que também não houve diferença significativa entre grupos, exceto pelo valor de triglicerídeos $(p<0,04)$, que estavam mais elevado no grupo intervenção.

Tabela 6.8 - Parâmetros co controle metabólico e da pressão arterial dos participantes, por grupos de estudo na avaliação basal.

\begin{tabular}{|c|c|c|c|}
\hline Variáveis & Controle & Intervenção & Valor de $\mathrm{p}$ \\
\hline $\begin{array}{l}\text { Glicemia de jejum }(\mathrm{mg} / \mathrm{dl}) \\
\left(\mathrm{n} / \mathrm{Md} ; \mathrm{AS}-\mathrm{q} ; \mathrm{M}_{1} ; \mathrm{M}_{2}\right)\end{array}$ & $49 / 112,0 / 86,5 / 407 / 53^{*}$ & $46 / 164,5 / 124,5 / 318 / 59$ & $0,17 \dagger$ \\
\hline 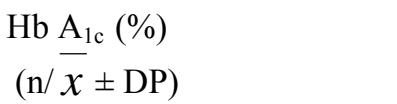 & $46 / 7,8 \pm 2$ & $39 / 7,8 \pm 1,2$ & $1,0 \ddagger$ \\
\hline $\begin{array}{l}\text { Colesterol Total (mg/dl) } \\
(\mathrm{n} / \bar{X} \pm \mathrm{DP})\end{array}$ & $47 / 185,9 \pm 34,4$ & $42 / 187,0 \pm 34,3$ & $0,88 \ddagger$ \\
\hline $\begin{array}{l}\text { HDL Colesterol }(\mathrm{mg} / \mathrm{dl}) \\
\left(\mathrm{n} / \mathrm{Md} ; \mathrm{AS}-\mathrm{q} ; \mathrm{M}_{1} ; \mathrm{M}_{2}\right)\end{array}$ & $42 / 37,8 / 8,3 / 93,0 / 24,9$ & $38 / 37,8 / 7,8 / 111,0 / 20^{*}$ & $0,85 \dagger$ \\
\hline $\begin{array}{l}\text { Triglicérides }(\mathrm{mg} / \mathrm{dl}) \\
\left(\mathrm{n} / \mathrm{Md} ; \mathrm{AS}-\mathrm{q} ; \mathrm{M}_{1} ; \mathrm{M}_{2}\right)\end{array}$ & $45 / 164,7 / 79,8 / 538,8 / 53 *$ & $42 / 189,4 / 99,7 / 684 / 66$ & $0,043 * \dagger$ \\
\hline $\begin{array}{l}\text { Creatinina }(\mathrm{mg} / \mathrm{dl}) \\
\left(\mathrm{n} / \mathrm{Md} ; \mathrm{AS}-\mathrm{q} ; \mathrm{M}_{1} ; \mathrm{M}_{2}\right)\end{array}$ & $33 / 0,9 / 0,3 / 1,2 / 0,5$ & $35 / 0,8 / 0,3 / 7,0 / 0,5^{*}$ & $0,66 \dagger$ \\
\hline $\operatorname{PAS}(\mathrm{n} / \bar{X} \pm \mathrm{DP})$ & $52 / 138,0 \pm 22$ & $49 / 138,4 \pm 21$ & $0,93 \ddagger$ \\
\hline $\operatorname{PAD}(\mathrm{n} / \bar{x} \pm \mathrm{DP})$ & $52 / 81,8 \pm 12,8$ & $49 / 79,1 \pm 12,5$ & $0,30 \ddagger$ \\
\hline PAS < 130 mmHg.(\%) & 36,2 & 32,4 & $0,81 \S$ \\
\hline PAD <80 mmHg. (\%) & 34,0 & 50,0 & $0,17 \S$ \\
\hline
\end{tabular}


Entre os participantes que realizaram exame de glicemia em jejum, o grupo intervenção mostrou um valor elevado da mediana conforme recomendações da SBD (2003). Em relação ao exame de $\mathrm{HbA}_{1 \mathrm{c}}$ os resultados obtidos mostraram um valor médio de 7,8\% para ambos os grupos, acima do recomendado pela DCCT (1993) e UKPDS (1998). Outros parâmetros entre grupos encontram-se dentro dos limites aceitáveis, exceto pelo valor do HDL colesterol que se mostrou relativamente baixo.

Destaca-se que no presente ensaio, estas variáveis foram observadas de forma secundária, considerando o estabelecimento de contato direto apenas com os participantes, sensibilizando-os para a importância da avaliação desses parâmetros, pelo menos semestralmente para acompanhar o controle da doença. Sabe-se, no entanto, que esses valores dependem fundamentalmente, da terapêutica farmacológica e do estilo de vida de cada pessoa, difíceis de serem monitorados, devido à deterioração progressiva do diabetes mellitus tipo 2, no qual existe um aumento gradativo da glicemia associado à diminuição da função das células- $\beta$, o que conduz a ajustamentos e combinações farmacológicas, conforme necessidade individual (UKPDS, 1995).

Antes da implementação da proposta sistematizada foi verificada com a gerência de cada UBDS e endocrinologistas, a possibilidade de facilitar os agendamentos dos retornos médico a cada três meses para os participantes do grupo intervenção, porém, concordou-se que este período de intervalo deveria ser aplicado a todas as pessoas com diabetes em geral, conforme normas estabelecidas para o acompanhamento do diabetes, podendo ser intervalos menores quando o controle metabólico for inadequado (SBD, 2003).

Entretanto, essa freqüência do retorno nem sempre pôde ser concretizada, devido à sobrecarga no agendamento das especialidades médicas que oferecem atendimento à população com diabetes. Atualmente, os agendamentos nas unidades de assistência à saúde são realizados mediante sistema informatizado, com abertura de agenda uma vez ao mês e, geralmente, as consultas são programadas para os próximos dois ou três meses, no mínimo, e nem sempre a pessoa encontra vaga para o período requerido, adiando subseqüentemente seu retorno a tempo imprevisível.

Quanto à proposta de assistência sistematizada, esta foi fundamentada, principalmente, nas sessões de sensibilização e educação nas consultas mensais de reforço das orientações e cuidado com os pés entre os participantes do grupo intervenção. Acredita-se que o curso desenvolvido entre profissionais despertou o interesse para rastrear os fatores de risco para lesão/ulceração nos 
pés das pessoas com diabetes e nas complicações da doença em geral, reforçando a proposta deste estudo.

Quanto a possível viés na pesquisa ressalta-se que, ao dar início ao ensaio clínico, os profissionais das respectivas unidades de estudo, não tiveram conhecimento de quais pessoas com diabetes estavam participando do ensaio, entretanto, no decorrer do mesmo esta condição pôde ser verificada por meio dos resultados de exames de sangue $\left(\mathrm{HbA}_{1 \mathrm{c}}\right)$ anexados aos prontuários, os quais foram realizados fora dos laboratórios referenciais para cada UBDS. Porém, não foi divulgado em qual grupo as pessoas estavam alocadas, pois todos os participantes do ensaio, no geral, referiam que estavam sendo acompanhados pela enfermeira responsável pela pesquisa para o cuidado dos pés. Mediante esta consideração, é pouco provável a presença de viés de cointervenção entre as pessoas participantes do estudo. Por outro lado, o desenvolvimento do curso favoreceria o cuidado a todas as pessoas com diabetes, independente de participar ou não do ensaio clínico.

Dos 49 participantes alocados no grupo de intervenção, 36 iniciaram o curso de sensibilização. Dos 36 participantes, dois abandonaram o curso antes de sua conclusão (um por problema de doença familiar e outro por desinteresse), 26 completaram o curso e oito participaram de forma irregular referindo problemas pessoais, familiares ou de doença, impedindo-as de comparecer com regularidade no curso, porém, demonstravam interesse em continuar. Destes 34 participantes, ocorreu um óbito e uma mudança de endereço. Contudo, dois participantes que não freqüentavam o curso, compareceram às últimas consultas mensais e participaram das duas avaliações programadas no período de seguimento do estudo.

Mediante o processo de composição da população do estudo, o grupo intervenção ficou conformado por 34 participantes e desses, 24 (70,6\%) participaram do curso de forma completa. O comparecimento às consultas mensais foi regular para a maioria, tendo-se obtido uma média de 5,9 (desvio-padrão 2,2) consultas por pessoa em nove meses. O tempo investido em cada consulta de enfermagem foi de 35 a 50 minutos por pessoa. Quando o participante não comparecia às consultas, a justificativa relacionava-se com motivos pessoais, familiares ou de doença. Assim, quando possível, era realizado o re-agendamento em data mais próxima, conforme disponibilidade e condição de saúde do participante. 
Com relação a perda no seguimento de 20 pacientes, os resultados apresentados pelos 81 participantes que completaram o estudo estão apresentados na Tabela 6.9, a qual inclui as variáveis primárias do estudo avaliadas no decorrer do sexto e décimo segundo mês.

Nessa tabela observa-se que das cinco variáveis consideradas, apenas duas mostraram diferença entre os grupos a seis meses e quatro ao finalizar o ensaio. As variáveis relacionadas ao conhecimento sobre diabetes e auto-relato de cuidados com os pés melhoraram significativamente aos seis meses no grupo intervenção, quando comparado ao grupo-controle, mantendo-se esta melhora até $o 12^{\circ}$ mês do ensaio ( $\mathrm{p}=0,005 ; \mathrm{p}=0,0001$, respectivamente). Outras variáveis, como as condições dermatológicas dos pés e uso de calçados apropriados também melhoraram, significativamente no $12^{\circ}$ mês ( $\mathrm{p}=0,0001 ; \mathrm{p}=0,005$, respectivamente).

A avaliação do conhecimento sobre diabetes esteve direcionada à melhor compreensão da doença por parte dos participantes, no sentido de conhecer os principais sintomas de hipo e hiperglicemia e os parâmetros desejáveis de normalidade da glicemia, bem como os problemas potencias nos pés, que poderiam conduzir a lesão/ulceração.

Certamente, o conhecimento desses aspectos, além de outros conteúdos incluídos no programa do curso, poderão estimular o autocuidado da pessoa, principalmente sabendo da variação existente na taxa glicêmica, podendo variar em uma determinada faixa, onde os muito distante dos parâmetros aceitáveis, pode gerar sintomas de descompensação do diabetes.

O indicador que contribuiu para a melhora do conhecimento na segunda avaliação foi: sintomas de hipo e hiperglicemia $(\mathrm{p}=0,0002)$, porém observou-se uma leve tendência nos sintomas de complicações nos pés $(p=0,09)$. Este último indicador foi decisivo na terceira avaliação ( $p=0,0013)$, sem outras mudanças. No geral, todos os indicadores melhoraram no grupo intervenção, mantendo-se ou diminuindo no grupo-controle.

Lembrando-se, que ao iniciar o ensaio, nenhum participante soube responder sobre os sintomas de complicações nos pés e poucos referiram, pelo menos, três sintomas de hipo e hiperglicemia (Tabela 6.7).

Considerando a baixa escolaridade dos participantes, o contato individualizado nas consultas mensais centralizava-se em tópicos específicos com auxílio de material ilustrado, focalizadas nas necessidades de cada participante em relação aos tópicos abordados no curso durante o período intensivo, com ênfase no autocuidado com os pés e calçados. Esta estratégia pode ter favorecido os resultados obtidos nesta área do conhecimento. 
Um ensaio clínico, recentemente publicado, apresentou resultados favoráveis no controle da $\mathrm{HbA}_{1 \mathrm{c}}$ utilizando estratégia semelhante para pessoas com baixa escolaridade (sessões individualizadas, contatos a cada dois ou quatro semanas, ligações telefônicas, dentre outros). Entretanto, destaca-se que os responsáveis pelas sessões educativas, paralelamente, puderam ajustar a terapêutica farmacológica, conforme algoritmo e necessidade de cada participante (ROTHMAN et al., 2004).

Entre os primeiros ensaios clínicos contendo programa educativo sistemático abrangente, encontram-se os trabalhos de Mazzuca et al. (1986), Rettig et al. (1986) e Bloomgarden et al. (1991),os quais incluíram no conteúdo, principalmente, conhecimento e habilidades relacionados com melhor entendimento da doença, complicações agudas, medicamentos diabéticos, dieta e prevenção de lesão/úlceração nos pés.

Mazzuca et al. (1986), ao avaliar o conhecimento sobre diabetes consideraram os sintomas de hipo e hiperglicemia, devendo os participantes referir, no mínimo dois deles. Após 14 meses de seguimento, dentre os nove critérios incluídos na área de conhecimento sobre a doença, apenas causas de hiperglicemia e alterações no teste de urina, tiveram diferença significativa entre grupos. Porém, os autores não descreveram qual o grau de escolaridade dos participantes, nem a periodicidade dos encontros nos quais se reforçaram os conteúdos do programa educativo.

Cabe salientar que, no presente ensaio, apesar de ter-se incluído conteúdos essenciais sobre o manejo da doença, condições de hipo e hiperglicemia dentre outros, a avaliação foi centralizada nos critérios básicos de cuidado e de prevenção, considerando a condição sociodemográfica dos participantes, embasadas nos dados apresentados em estudo prévio (PACE et al., 2005). Acredita-se que, em adultos, a incorporação de novos conhecimentos e comportamentos podem ser progressivos, portanto, mensurações nesse sentido devem acompanhar o avanço do aprendizado, com reforços contínuos e acúmulo de informações paulatinas, visando a promover o autocontrole da situação pelos próprios participantes.

Este autocontrole vem em encontro da proposta de Funell e Anderson (2004), denominada de empowerment, na qual os profissionais devem ajudar aos pacientes a descobrir e desenvolver sua capacidade inerente de ser responsável pela própria vida, reconhecendo que o cuidado no diabetes mellitus torna-se uma colaboração entre iguais, profissionais trazendo conhecimento e habilidade sobre a doença e seu tratamento e, pacientes trazendo experiência e habilidade em sua vida e com desejo de trabalhá-las. Esta proposta reforça os princípios da teoria da educação de 
adultos, na qual foram embasadas as sessões educativas e orientações de cuidado para o grupo intervenção.

Como se pôde observar em parágrafos anteriores, apenas um indicador dos três considerados na área de diabetes conseguiu mostrar diferença significativa entre grupos por semestre de avaliação. Dados que podem ser similares àqueles apresentados em ensaios prévios, que não conseguiram mudança significativa em todos critérios considerados em cada área avaliada (MAZZUCA et al., 1986; BLOOMGARDEN et al., 1991). Estes resultados demonstram que o processo de aprendizagem pode ser lento, especialmente ao considerar a inter-relação de múltiplos fatores que intervêm no processo de aprendizagem, tanto pessoais, como sociais e os quais devem ser considerados na transferência de informações (CLEMENT, 1995).

Estudos de intervenções educativas direcionadas ao melhor automanejo da doença e ao controle da glicose têm mostrado que efeitos atingidos, não são mais eficientes a longo prazo. Este resultado tem sido evidenciado também, em recente metanálise de ensaios clínicos randomizados, no qual também foi apontado, que maior tempo de contato com os pacientes aumenta os efeitos a favor do autocuidado (NORRIS et al., 2002). Porém, os autores chamam a atenção, paralelamente, à ameaça na qualidade da validade interna dos ensaios incluídos, os quais não satisfizeram totalmente os critérios considerados na avaliação.

Considerando a perda do efeito a longo prazo e as condições sociodemográficas da maioria das pessoas com diabetes, o presente ensaio investiu em um seguimento contínuo com reforço mensal das orientações, o que pode ter contribuído nos resultados obtidos pelo grupo intervenção, uma vez que o conhecimento constituí-se em um dos primeiros passos na mudança de atitudes. Nesse sentido, observa-se na Tabela 6.9, que o auto-relato dos cuidados com os pés teve mudança significativa no decorrer do período de seis a 12 meses.

Nesses cuidados, foram considerados as atividades que os participantes deveriam realizar diariamente com os pés e calçados embasados em estudos prévios (CALLE-PASCUAL et al., 2002; COLEMAN, 2002; OLIVARES et al., 1998; SPOLLETT, 1998; RÖNNEMAA et al., 1997; LITZELMAN et al., 1997; KELECHI et al., 1996; LEVIN, 1996; LITZELMAN et al., 1993; BARTH et al. 1991; FOSS; FOSS, 1991; RETTIG et al., 1986) e nas recomendações de sociedades especializadas (GLOBAL RESOURCE CENTER, 2001; GTIPD, 2001; NATIONAL DIABETES EDUCATION PROGRAM, 2000). 
Tabela 6.9 - Parâmetros do conhecimento dos participantes em relação à doença, cuidados com os pés e calçados, condições apropriadas dos pés e calçados, por grupos de estudo na segunda e terceira avaliação.

\begin{tabular}{|c|c|c|c|c|c|c|}
\hline \multirow[b]{2}{*}{ Variáveis dependentes } & \multicolumn{3}{|c|}{ Após 6 meses } & \multicolumn{3}{|c|}{ Após 12 meses } \\
\hline & $\begin{array}{c}\text { Controle } \\
(\mathrm{n}=47)\end{array}$ & $\begin{array}{c}\text { Intervenção } \\
(\mathrm{n}=34)\end{array}$ & Valor de $p$ & $\begin{array}{c}\text { Controle } \\
(n=47)\end{array}$ & $\begin{array}{c}\text { Intervenção } \\
(\mathrm{n}=34)\end{array}$ & Valor de $\mathrm{p}$ \\
\hline $\begin{array}{l}\text { Conhecimento sobre o diabetes } \\
\left(\mathrm{Md} ; \mathrm{AS}-\mathrm{q} ; \mathrm{M}_{1} ; \mathrm{M}_{2}\right)\end{array}$ & $3,0 / 1,0 / 5 / 3$ & $4,0 / 2,0 / 6 / 3$ & $0,005 * \dagger$ & $3,0 / 1,0 / 5 / 3$ & $4,0 / 2,0 / 6 / 3$ & $0,000 * \dagger$ \\
\hline $\begin{array}{l}\text { Comportamento com os pés } \\
\left(\mathrm{Md} ; \mathrm{AS}-\mathrm{q} ; \mathrm{M}_{1} ; \mathrm{M}_{2}\right)\end{array}$ & $16,0 / 2,0 / 20 / 12$ & $17,7 / 2,0 / 20 / 14$ & $0,000 * \dagger$ & $14,4 / 3,0 / 19 / 8$ & $18,0 / 2,0 / 20 / 13$ & $0,000 * \dagger$ \\
\hline $\begin{array}{l}\text { Comportamento com os calçados } \\
\left(\mathrm{Md} ; \mathrm{AS}-\mathrm{q} ; \mathrm{M}_{1} ; \mathrm{M}_{2}\right)\end{array}$ & $8,0 / 2,0 / 10 / 6$ & $8,0 / 2,0 / 10 / 6$ & $0,27 \dagger$ & $8,0 / 1,0 / 9 / 5$ & $8,0 / 1,3 / 10 / 7$ & $0,21 \dagger$ \\
\hline $\begin{array}{l}\text { Condições dermatológicas dos pés } \\
\left(\mathrm{Md} ; \mathrm{AS}-\mathrm{q} ; \mathrm{M}_{1} ; \mathrm{M}_{2}\right)\end{array}$ & $10,0 / 2,0 / 12 / 6$ & $10,0 / 2,0 / 12 / 7$ & $0,06 \dagger$ & $9,0 / 2,0 / 12 / 6$ & $10,5 / 1,0 / 12 / 8$ & $0,000 * \dagger$ \\
\hline Características dos calçados (\%) & 36,2 & 50,0 & $0,21 \S$ & 27,2 & 58,8 & $0,005 * \S$ \\
\hline
\end{tabular}


Na variável comportamento com os pés foram três os indicadores que contribuíram para a mudança por semestre de avaliação (Tabela 6.7). Aos seis meses do ensaio, o relato de corte de unha apropriado, hidratação da pele e utilização de meias de algodão foi mais freqüente no grupo intervenção, com diferença significativa entre grupos $(p=0,0031 ; p=0,0382 ; p=0,0013$, respectivamente). Esta diferença foi mantida entre os grupos até os 12 meses ( $p=0,029 ; p=0,0001$, respectivamente), exceto pelo relato do uso de meias com fios de algodão que caiu ( $p=0,328)$. No entanto, o relato de cuidado apropriado dos pés frios obteve diferença significativa $(p=0,0001)$. Todos os indicadores em geral, aumentaram substancialmente em ambos grupos (controle e intervenção), o que pode ter atenuado maiores diferenças entre eles.

Quanto ao uso de meias com fios de algodão, observou-se também aos seis meses, que houve uma tendência entre os participantes do grupo intervenção referirem que usavam meias com os calçados $(\mathrm{p}=0,083)$, fato que pode estar relacionado com o clima de inverno, considerando que a segunda avaliação foi realizado em agosto. Em geral, a influência da temperatura quente na maior parte do ano não favorece a utilização de meias no dia-a-dia. Sendo assim, houve uma diminuição no relato de uso de meias com os calçados na terceira avaliação, a qual foi realizada entre janeiro e fevereiro, no período de verão e menos de $30 \%$ dos participantes, em ambos grupos, referiram usar meia.

Com relação ao comportamento com os calçados apenas inspecioná-los antes de calçá-los mostrou diferença significativa entre grupos na última avaliação $(p=0,0196)$, contudo não foi suficiente para determinar mudança na variável. No geral, esta variável também apresentou nos indicadores melhorara, atingindo percentuais entre 80 e 100\% em inspeciona calçados no interior e, limpa ou areja após o uso.

O indicador compra calçado em horário apropriado, que no basal mostrou diferença significativa, aumentou notavelmente no grupo-controle na segunda e terceira avaliações, semelhantes às proporções do grupo intervenção, com iguais proporções entre grupos.

Estes resultados estão em concordância com alguns ensaios clínicos randomizados que consideram avaliações entre 6 e 12 meses de seguimento, examinando conhecimento e comportamento sobre cuidado e prevenção de lesão/ulceração nos pés (RÖNNEMAA et al., 1997; LITZELMAN et al., 1993; BARTH et al., 1991; RETTIG et al., 1986) e contrariamente aos resultados obtidos por Bloomgardem et al. (1987). 
No ensaio realizado por Rettig et al. (1986), os quais realizaram um seguimento de 12 meses e compararam sessões educativas domiciliares versus cuidado convencional, o conhecimento apresentou mudança significativa entre os grupos aos seis meses $(p=0,001)$. A avaliação deste conhecimento incluiu quatro áreas (dieta, teste de urina, cuidado com os pés e medicação).

Ressalta-se que nesse estudo houve aproximadamente 70 questões para avaliar essas áreas, incluindo conhecimento propriamente dito e demonstrações de habilidades. Entretanto, os autores não mostraram, nem fizeram comentários se os grupos foram semelhantes ou não nessas áreas em relação aos dados basais, apenas comentaram que mais de 70\% (média de escolaridade de 10 anos) dos pacientes já tinham participado de algum grupo educacional, portanto, poderiam dispor de uma bagagem apropriada de conhecimento.

É possível que essas duas condições tenham contribuído significativamente na obtenção desses resultados referentes ao conhecimento, contrariamente às outras variáveis como aparência dos pés, freqüência de hospitalizações, tempo de permanência hospitalar e consultas médicas, as quais não mostraram diferenças entre grupos, após 12 meses.

No ensaio de Barth et al. (1991), o programa educativo intensivo composto por nove sessões grupais versus educação convencional composto por três, mostrou melhora do conhecimento sobre cuidados com os pés e adesão a esses comportamentos desde o primeiro até o sexto mês de seguimento $(\mathrm{p}=0,001 ; \mathrm{p}=0,012$, respectivamente). Os autores referiram que essa melhora esteve associada à intervenção educativa, após análise de regressão múltipla, para desconsiderar as variáveis de confusão como idade, sexo, escolaridade, tipo de tratamento e doença vascular periférica.

Por outro lado, Litzelman et al. (1993) desenvolvendo um programa de prevenção de fatores de risco em extremidades inferiores, envolvendo pacientes, profissionais e o próprio sistema de saúde, após 12 meses de seguimento identificaram que os participantes do grupo intervenção tiveram maior probabilidade de lavar os pés, de não deixar os pés de molho, de inspecionar os pés e interior dos calçados e de secar entre os dedos depois de lavá-los, em relação ao grupo controle, 12 critérios considerados dentro de comportamento com os pés.

Neste estudo, como referido anteriormente na revisão sistemática, a segunda avaliação dos pacientes foi ajustada aos dados basais, com o propósito de testar o efeito do programa na diminuição das anormalidades em membros inferiores. Entretanto, na avaliação entre profissionais 
manteve-se os grupos randomizados. Deste modo, maior proporção dos participantes do grupo intervenção tiveram seus pés examinados pelos médicos e também receberem educação sobre como cuidá-los ( $\mathrm{p}=0,001$ para ambas medidas).

No estudo de Rönnemaa et al. (1997), orientações individualizadas de acordo às necessidades, revelaram mudança no comportamento com os pés entre os participantes do grupo intervenção considerando aspectos de higiene, uso de hidratante, auto-exame e ginástica com os pés $(\mathrm{p}<0,001)$, após 12 meses de acompanhamento. A média de consultas com o grupo intervenção foi de 4,7/ano, menor que as atingidas nos presente estudo.

Destaca-se que nestes três últimos ensaios (RÖNNEMAA et al., 1997; LITZELMAN et al., 1993; BARTH et al., 1991) os programa educativos estavam direcionados, especificamente, ao cuidado dos pés para a prevenção de complicações. No presente ensaio, a idéia inicial germinativa do projeto era conduzí-lo nessa mesma perspectiva, porém no decorrer do desenvolvimento da revisão sistemática, percebeu-se a necessidade de abranger outros aspectos importantes no cuidado do diabetes, considerando a complexidade da doença. Outro situação que motivou esta relativa abrangência foi a carência de programas educativos estruturados sistematicamente nas referidas unidades de estudo, pelo menos no que se refere às complicações agudas e crônicas no diabetes mellitus, porém foi mantida a prioridade nos cuidados com os pés.

Quanto aos cuidados com os calçados observou-se no ensaio realizado por Litzelman et al. (1993), que apenas um cuidado fora incluído no relato de comportamento com os pés: inspeciona os calçados antes de usá-los. Outros cuidados como arejá-los, horário de compra, uso alternado de calçados durante o dia e referência do tipo de calçado utilizado habitualmente pelo participante foram escassas na literatura.

Acredita-se que estes comportamentos no cotidiano são relevantes para contribuírem com a saúde dos pés. O fato de conhecer o melhor horário para adquirir calçados novos, levando em consideração as condições fisiológicas e ambientais, pode dar maior segurança às pessoas no cuidado relativo as condições externas ao próprio corpo. Entendendo que o tipo de calçados constitui um fator externo importante de risco para desencadear lesão/ulceração nos pés.

Alternar os calçados durante e/ou entre os dias representa outro cuidado importante para os pés. Uso de apenas um calçado por longo período de tempo ou, consecutivamente, entre os dias/meses, favorece a formação de pontos de pressão na parte interna dos calçados, conforme a própria estrutura anatômica dos pés. Assim, marcas de pressão podem aparecer, devido ao 
desgaste produzido pelo constante uso, fazendo com que essas marcas sejam cada vez mais profundas e ásperas, tornando-se pontos que podem lesar a pele. O revezamento entre calçados alivia esses pontos de pressão, tanto nos pés, como nos calçados, permitindo ao mesmo tempo, que os calçados possam restaurar-se no que for possível.

Em conseqüência desse efeito dos calçados, deve-se considerar que alternar os mesmos constitui uma importante medida de proteção aos pés, principalmente, entre pessoas com diabetes mellitus tipo 2, que podem apresentar comprometimento da sensibilidade dos pés, em decorrência da instalação silenciosa da neuropatia periférica, devido ao retardo no diagnóstico do diabetes. Fato que aumenta o risco da instalação progressiva das complicações crônicas micro e macrovasculares (ADA, 2004; NAZIMEK-SIEWNIAK; MOCZULSKI; GRZESZCZAK, 2000).

A insensibilidade ao monofilamento SW 10 g. nos grupos controle e intervenção ao iniciar o ensaio esteve presente em torno de $13,5 \%$ e $16,3 \%$, respectivamente, sem diferença entre grupos (Tabela 6.5). Após 12 meses de seguimento, estas proporções continuaram semelhantes entre as 81 pessoas que permaneceram $(13 \%$ e $6 \%$, respectivamente; $p=0,457)$. Dados que estão em concordância com populações de estudos anteriores, considerando o tempo do diagnóstico do

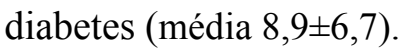

Um ensaio randomizado que avaliu a influência dos calçados comuns/habituais no risco/proteção de lesão/ulceração nos pés, mostrou que a aquisição de calçados novos nos últimos seis meses constituiu-se em uma medida de proteção, desde que a substituição de calçados velhos, desgastados e troca freqüente foram recomendáveis. Porém, os autores referem que calçados novos também podem ser prejudiciais devido à fricção e falhas para cedê-los e afrouxálos apropriadamente (LITZELMAN; MARRIOTT; VINICOR, 1997).

Por outro lado, surpreendentemente, este último estudo citado, também mostrou que calçados ajustados apropriadamente, conforme critérios de classificação utilizados, foram associados com alto risco de lesão/ulceração nos pés comparando dados basais e finais, baseados no auto-relato e na inspeção no dia da avaliação. É possível, no entanto, que o comprimento extra de $1,9 \mathrm{~cm}$ nos calçados tenha sido além do aceitável, devido espaço no interior dos calçados podem favorecer deslizamentos, tropeços e ingresso de pedrinhas ou objetos pequenos durante a caminhada. Condições que provocariam fricção nos pés e conseqüentemente, os lesariam. Outro aspecto levantado pelos próprios autores corresponde ao intervalo de 12 meses de avaliação 
considerado, sendo provável que os participantes possam ter utilizado outros tipos e estilos de calçados nesse meio tempo (LITZELMAN; MARRIOTT; VINICOR, 1997).

O referido estudo é secundário de Litzelman et al (1993) e conforme dados basais, 56,4\% dos pacientes vinham utilizando calçados de tipo e estilo apropriado (fechado e ajustável com cadarço), contudo mais do $25 \%$ foram estreitos ou pequenos. Ao final do estudo não houve mudança no estilo e na qualidade dos calçados entre ambos grupos de estudos, apesar do grupo intervenção ter recebido instrução educativa sistemática, na qual focalizava-se o cuidado com os pés e a propriedade dos calçados.

No presente ensaio, ao avaliar mediante auto-relato, dos calçados que as pessoas usavam com maior freqüência, estava-se relacionando também com o tipo e estilo habitual, ou seja, o calçado comum. O propósito disso foi saber a partir dos dados basais, se as recomendações a respeito de calçados iriam mudar a seleção do tipo habitual de calçado, conscientes da necessidade de proteger os pés de possíveis lesões/agressões ao caminhar. O estudo não teve o objetivo de avaliar o quanto eram bons os calçados na prevenção de lesões/ulcerações e/ou recidivas, o que corresponderia aos calçados terapêuticos.

Desse modo, observa-se na Tabela 6.5 que poucas pessoas, em ambos grupos, referiram usar calçados apropriados incluindo, modelo, tamanho, largura e material. No decorrer do estudo, observou-se pouca mudança em ambos grupos de estudo, os quais mantiveram diferença percentual de 10 a 15\%, sendo que na última avaliação o percentual atingido no grupo-controle foi $29,8 \%$ e $47,1 \%$ no grupo intervenção $(\mathrm{p}=0,175)$.

Para corroborar esta informação, no dia da entrevista observava-se o tipo de calçado que as pessoas estavam usando. Apesar da randomização, o maior número de participantes foi do grupo intervenção,os quais utilizavam calçados classificados como apropriado, sendo diferente significativa do grupo-controle (Tabela 6.5). Na segunda avaliação, pode-se observar que a condição de calçado, classificado como apropriado, foi aumentando em ambos grupos (Tabela 6.9). Porém, na terceira, o grupo-controle teve uma queda significativa em relação à avaliação prévia e o grupo intervenção manteve-se praticamente constante, determinando diferença significativa entre grupos $(\mathrm{p}=0,005)$.

Salienta-se que na segunda avaliação, apesar da grande proporção dos participantes comparecerem usando calçados fechados, a classificação de impróprio foi elevada pelo fato dos 
calçados serem de bico fino, estreitos/pequenos. Já na terceira, houve maior uso de sandálias rasteirinhas ou chinelos.

Uma possível explicação para este último comportamento, pode estar relacionada com a influência do clima (verão), que compele às pessoas utilizarem calçados abertos e arejados. Outra explicação, pode ser o fato das avaliações acontecerem no final de semana (sábado), devido à disponibilidade das examinadoras, o que pode ter favorecido a muitas pessoas se apresentassem usando sandálias ou chinelos, principalmente por se tratar de um dia de descanso com menor número de pessoas nas respectivas UBDS de estudo e pela proximidade de suas residências.

A diferença obtida na terceira avaliação, pode-se considerar estável, pelo contato freqüente mantido com o grupo intervenção, devido à ocorrência das consultas mensais, nas quais foram observadas maior uso de calçados apropriados e também foi identificado, interesse de alguns participantes na compra de calçados fechados conforme a recomendações. Destaca-se que, grande parte desses calçados, principalmente, no sexo feminino, constituía-se do tipo "moleca", elaborado em sola de borracha e tecido de algodão, provavelmente, pelo seu custo ser mais acessível à população.

Certamente, as condições econômicas condicionaram a compra de calçados de melhor qualidade, não sendo fácil a sua aquisição em curtos períodos de tempo, principalmente pelo fato da população encontrar-se em sua maioria, em condição de aposentada ou exercendo atividade do lar, talvez à espera de serem presenteadas pelos familiares. O preço dos calçados, nas condições aceitáveis, elaborado em couro macio/lona/tênis, sem costuras internas, se possível ajustáveis e com cadarço, no momento do estudo estava em torno de $\mathrm{R} \$ 50,00^{*}$. Desse modo, ambas condições representaram grandes barreiras para a incorporação de novos hábitos de calçar diminuindo conseqüentemente as diferenças entre grupos.

Durante um ensaio randomizado por Reiber et al. (2002), testando os calçados terapêuticos extra-profundos, associados a dois tipos de solados e comparava-os com os calçados habituais entre pessoas com diabetes que apresentaram antecedente de úlcera, ao iniciar o ensaio, os participantes não tinham deformidades graves nos pés, 56\% apresentavam insensibilidade ao monofilamento $\mathrm{SW}$ e $55,6 \%$ tinham $\geq 25$ anos de diagnóstico da doença. Os autores relatam que não encontraram existem diferenças entre os grupos na incidência/recidiva de úlceras $(15 \% ; 14 \%$ e $17 \%$, respectivamente), após 24 meses de seguimento.

* Correspondendo a $1 / 5$ de um salário mínimo vigente na época e 20,0 US\$ (maio de 2005). 
Durante o desenvolvimento do referido estudo, o contato com os participantes dos grupos foi realizado a cada 17 semanas para a avaliação da adesão aos calçados e desencadeamento de lesões nos pés com subseqüente encaminhamento para equipe de cuidado. As úlceras foram mais freqüentes entre pessoas com insensibilidade nos pés nos três grupos, sendo que os calçados foram responsáveis por 39,3\% (entre terapêuticos e habituais), trauma externo por $31 \%$ e autocuidado por $7,1 \%$.

Esses resultados são contrários aos dados apresentados por Litzelman, Marriott e Vinicor (1997), nos quais nenhuma das variáveis de prognóstico de lesão mostraram interação significante com a insensibilidade nos pés, considerando o tamanho apropriado dos calçado (comprimento e largura), o estilo e material dos calçados (interno e externo), a compra de calçados nos últimos seis meses e, se o paciente havia sido recomendado ou não usar calçados especiais/terapêuticos.

Conforme os esultados apresentados por ambos estudos (REIBER et al., 2002; LITZELMAN; MARRIOTT; VINICOR, 1997), a importância outorgada à condição, tipo e estilo dos calçados na prevenção de lesão/ulceração nos pés entre pessoas com diabetes, principalmente, na existência de insensibilidade, ainda é indeterminada, sendo necessário maiores pesquisas a respeito. Entretanto, cabe aos profissionais de saúde estarem atentos ao primeiro sinal de risco de lesão/ulceração nos pés dessas pessoas e agirem imediatamente com cuidados apropriados.

O fato de aconselhar o uso de calçados, preferencialmente, fechados e de bico amplo, de tamanho não maior que $1 \mathrm{~cm}$ (entre comprimento e largura), permite despertar à consciência aos riscos potenciais que existem no meio ambiente, não apenas considerando os múltiplos fatores fisiológicos intrínsecos, mas também, os fatores extrínsecos, que podem acontecer acidentalmente no dia-a-dia, na residência ou na rua, sobretudo ao caminhar descalço ou com calçados tipo sandálias, os quais expõem os pés a possíveis agressões.

De acordo com a literatura, uma proporção considerável de úlceras tem sido desencadeada por traumas menores, como traumas na ponta dos dedos, queimaduras, cortes, objetos introduzidos nos calçados fechados, dentre outros (GTIPD, 2001; GROSS et al., 1999; PECORARO, 1990).

Desse modo, pessoas com diabetes devem estar cientes, precocemente, da importância de proteger seus pés no decorrer da progressão da doença e assim, irem incorporando comportamentos de cuidados, que possam diminuir a gravidade de possíveis injúrias. 
Durante o desenvolvimento do segundo semestre do ensaio, um participante do grupocontrole desenvolveu lesão no segundo pododáctilo do pé esquerdo, com sinal de comprometimento vascular. Este participante já possuía insensibilidade nos pés desde a avaliação basal, com diagnóstico médico de polineuropatia. Assim, por fazer parte do projeto de pesquisa, profissionais da Unidade de Saúde comunicaram a ocorrência à pesquisadora do ensaio e a mesma foi encaminhada, pelo endocrinologista, à unidade multiprofissional de atendimento à pessoas com diabetes - Unidade de Pé Diabético (NGA-59). Paralelamente, reforçaram-se as orientações de cuidados especializados com os pés e calçados na UBDS de origem, junto à equipe de enfermagem da referida unidade. Na terceira avaliação correspondente ao ensaio, a lesão encontrava-se em boa evolução, ainda em tratamento, observando-se que os cuidados com os pés estavam sendo realizados pelo participante.

Finalmente, para determinar se o cuidado com os pés e calçados era realizado conforme orientações, analisou-se as condições dermatológicas dos pés (Tabela 6.9), que somente na terceira avaliação alcançaram diferença significativa entre grupos $(\mathrm{p}=0,0001)$. Os indicadores que contribuíram nesta melhora foram: higiene dos pés e corte de unhas apropriados $(p=0,0001)$, diminuição de pele ressecada/descamativa $(p=0,021)$ e diminuição de unha espessada/farinácea/onicomicose $(\mathrm{p}=0,003)$. No geral, todos indicadores considerados nesta variável diminuíram no grupo intervenção e aumentaram no grupo-controle. Condições que, discretamente apresentaram-se aos seis meses $(\mathrm{p}=0,068)$, com diminuição considerável nos três primeiros indicadores em ambos grupos e, aumento nos outros três, apenas no grupo-controle, contudo, nenhum indicador diferiu estatisticamente entre os grupos $(p>0,05)$.

Pele macerada com fissura nos espaços interdigitais foi observada em ambos grupos em todo percurso do ensaio clínico, com maior proporção no controle, sendo na segunda avaliação $32 \%$ para o grupo-controle e $15 \%$ no grupo intervenção ( $p=0,11)$, com um leve aumento no final do ensaio, $34 \%$ e $20,6 \%$, respectivamente $(\mathrm{p}=0,18)$.

Salienta-se que esta condição entre pacientes, geralmente é considerada secundária pelos profissionais de saúde. Uma possível explicação para este comportamento relaciona-se ao fato dos profissionais dificilmente avaliarem os pés das pessoas nas consultas, a não ser, que exista uma queixa nesse segmento. Uma outra justificativa pode relacionar-se ao fato dos pacientes não estarem habituados a exporem seus pés frente aos profissionais, pois acreditam que a micose/maceração interdigital não representa problema para a saúde ou, sentem-se constrangidos 
ao se expôr. Finalmente, o sistema público de saúde não fornece medicamento gratuito para este tipo de micose. Esses medicamentos possuem custo elevado e geralmente, tem um longo período de tratamento e muitas vezes podem não ser adquirido pelo paciente, devido à reduzida renda dos idosos aposentados ou do lar.

Para os participantes do grupo intervenção era reforçado o cuidado higiênico preventivo com os pés e, caso o problema não se resolvesse nas próximas consultas, devido à limitação de não ter estabelecido um protocolo que permita a indicação do medicamento apropriado a profissionais não médicos envolvidos no cuidado de pessoas com diabetes, solicitava-se aos pacientes que mostrassem os pés a seus respectivos médicos, assim que possível, para iniciar tratamento.

Ferimentos desta natureza, representam uma porta de entrada para infecção, situação crítica que deve ser monitorada frente à multiplicidade de fatores que exacerbam ou dificultam o processo de cura. Esta situação cria a necessidade de buscar mecanismos de padronização de medicamentos básicos para tratar problemas fúngicos na população com diabetes nas unidades de assistência primária, considerando ser este um problema freqüente. Nesse sentido, há necessidade de estabelecer protocolos que viabilizem o tratamento indicado para essas alterações, as quais podem ser resolvidas com medidas básicas de higiene e terapêutica medicamentosa de baixo custo. Intervenções de baixa complexidade, podem ser feitas por outros profissionais quando inseridas dentro de um protocolo clínico.

Apesar das discrepâncias existentes em relação aos protocolos clínicos, a sua utilidade no atendimento à saúde das pessoas tem se mostrado eficiente, principalmente, quando fundamentados na prática baseada em evidências, melhorando a qualidade da atenção (MENDES, 1998).

Quanto ao indicador presença de calos/rachaduras nos dados basais (Tabela 6,5), a diferença significativa observada no basal entre os grupos, foi estável no decorrer do estudo, sendo que diminuiu no grupo intervenção e aumentou no grupo-controle $(p=0,80 ; p=0,51)$.

$\mathrm{Na}$ terceira avaliação identificou-se presença de bolhas/úlceras em sete pessoas do grupocontrole e uma, no grupo intervenção $(\mathrm{p}=0,22)$. As lesões foram classificadas como bolhas por não atingirem tecidos profundos e incluíam queimaduras, coceiras, dermatite de contato ou provocada por calçados/sandálias e trauma. Todas as pessoas tinham sensibilidade tátil pressórica preservada, com exceção de uma do grupo controle, a qual sofreu trauma no segundo pododáctilo 
esquerdo, como referido anteriormente. Dentre essas oito pessoas, apenas uma delas já possuía bolha no pé ao iniciar o ensaio, aqual tinha sido provocado também por calçado impróprio.

Entre os ensaios clínicos randomizados que avaliaram conhecimento de cuidados com os pés e suas condições/aparência ou problemas identificaram-se dois estudos (LITZELMAN et al., 1993; BARTH et al., 1990).

No ensaio de Barth et al. (1991), os problemas nos pés, classificadas pelos autores como precisando de cuidados, apenas foi observada mudança nessa variável ao primeiro mês $(p<0,006)$, permanecendo iguais entre grupos essa necessidade ao terceiro e sexto meses de avaliação, com conseqüente diminuição de problemas no decorrer do estudo em ambos grupos, em relação aos dados basais.

Concordante com o presente estudo, Litzelman et al. (1993) referiram que, participantes do grupo intervenção tiveram menos probabilidade de apresentar pele ressecada, unhas grossas e micose em unhas quando comparadas com o grupo-controle, similares aos resultados apresentados pelo presente ensaio. Outros dados importantes também semelhantes, foram a presença elevada nos dados basais de pele ressecada/áspera, infecção micótica em unhas e maceração interdigital e após 12 meses de seguimento, não se obteve mudança na presença de maceração interdigital.

O interessante desse estudo é também do presente ensaio, relaciona-se com a participação direta de responsáveis no cuidado dos pés das pessoas com diabetes. Isto certamente, deve ter contribuído significativamente com estes resultados. Nos ensaios de Litzelman et al. (1993) e Barth et al.(1990) houve participação de podiatras de forma regular, os quais realizaram cuidados com os pés e unhas.

Outro ensaio que disponibilizou esse profissional foi Rönnemaa et al. (1997), os quais obtiveram mudança significativa na maioria dos critérios considerados no grupo intervenção, com exceção das calosidades em regiões fora do calcanhar, mostrando diferença bastante significativa entre grupos $(\mathrm{p}=0,009)$.

No presente ensaio, a pesquisadora realizou as atividades de cuidados com os pés entre participantes do grupo intervenção perseverando na hidratação da pele, tratamento de calosidades/rachaduras e corte de unhas, até os participantes demonstrarem apropriado autocuidado.

Esta intervenção é considerada de baixa complexidade de assistência (GAMBA et al., 2004) e necessita ser incluída nas atividades de cuidado com os pés das pessoas com diabetes. 
Ensaios clínicos prévios que não envolveram cuidado direto com os pés, ao finalizar do estudo não mostraram mudança nas condições dos pés (RETTIG et al., 1986; BLOOMGARDEM et al., 1997). Assim, é importante preparar profissionais que sejam responsáveis para esses cuidados, como uma medida de proteção e prevenção, o que certamente trará benefícios diminuindo os gastos públicos nos serviços de saúde, devido ao grande impacto econômico que representa o tratamento de úlceras nessa população, com conseqüente tratamento e recidivas de amputações.

Exemplo dessa contribuição pode ser visualizado no trabalho realizado no APD/DF e em outras unidades que prestam assistência, incluindo cuidado regular dos pés, os quais tem mostrado uma redução ds problemas e diminuição do tempo de recuperação das pessoas de alto risco, quando atingidas por problemas lesão/ulceração (PEDROSA et al., 1998).

Resultados semelhantes, porém, em menor escala, também estão sendo observados junto à Equipe Multiprofissional da Unidade de Pé Diabético no NGA-59, apesar das múltiplas restrições, quanto à estrutura e disponibilidade de insumos materiais.

Pela revisão previamente realizada, apresentada na primeira parte do estudo, concluiu-se que programas de intervenção educativa, envolvendo conhecimento sobre cuidados com os pés, nem sempre refletem o cuidado apropriado dos pés, considerando sua aparência física (RÖNNEMAA et al., 1997; LITZELMAN et al., 1993; BARTH et al., 1991).

Sabe-se que a obtenção de resultados positivos em curto período de tempo, não são mais evidentes no decorrer de longos períodos (HÄMÄLÄINEN et al, 1998; BARTH et al., 1991). Esta situação compele os profissionais de saúde a criarem espaços e responsabilidades nas unidades de assistência, principalmente, no nível primário, entendendo que a base prioritária das medidas preventivas está nesse nível de atendimento.

Por outro lado, é importante incluir nessas medidas preventivas, um controle metabólico apropriado, o qual é salientado como precursor da instalação das complicações crônicas micro e macrovasculares. Assim, na Tabela 6.10 estão apresentados os resultados do controle metabólico e da pressão arterial, obtidos no presente ensaio, a fim de avaliar de modo geral, como a intervenção poderia interferir no controle metabólico dos participantes do grupo intervenção.

Observa-se nessa tabela que na maioria dos indicadores considerados na avaliação bioquímica não houve mudanças, com exceção dos valores de creatinina sangüínea $(p=0,01)$ na segunda avaliação, que aumentou no grupo-controle e da pressão arterial sistólica $(p=0,009)$ na terceira avaliação, que aumentou significativamente no grupo intervenção o que expressa também que aumentou o numero de pessoas com adequado controle da pressão arterial no grupo-controle 
$(\mathrm{p}=0,038)$. É possível também identificar uma leve tendência de elevação nos valores do colesterol total $(\mathrm{p}=0,08)$ no grupo controle, na segunda avaliação.

Os resultados obtidos nos valores do controle metabólico, possivelmente refletem a falta deste conteúdo no programa de sensibilização educativa, pois constituíam parte dos objetivos secundários. Dessa forma, no desenvolvimento das consultas mensais, avaliavam-se esses valores e discutia-se com cada participante sobre a importância de mantê-los o mais próximos dos valores normais, incentivando ao adequado tratamento farmacológico, a reorganização dos hábitos alimentares e a inclusão regular de atividade física, conforme recomendações da SBD (2003) e ADA (2004).

Salientava-se também, a necessidade de comparecer às consultas médicas a cada três meses, devido às faltas observadas nos prontuários e pelo próprio auto-relato dos participantes, considerando a dificuldade em conseguir agendamento médico. Outra possível explicação, pode estar relacionada com a dificuldade no desenvolvimento integral da proposta de assistência sistematizada no estudo, como fora a primeira intenção, incluindo à equipe médica nos retornos a cada três meses, com a avaliação contínua desses dados bioquímicos, que podiam constituir subsídios para realizar ajustes farmacológicos, conforme a necessidade de cada pessoa e critério médico.

No decorrer do ensaio, observou-se que algumas pessoas do grupo intervenção melhoravam nesses resultados, pois ao desenvolverem atividade física e moderação na dieta, eles pessoalmente podiam comprovar mediante as glicemias capilares observadas nas consultas mensais, que os valores diminuíam, o que possivelmente os motivavam continuar a atingir suas metas individuais, ou seja, sem afetar a sensação de bem-estar. Porém, os dados referentes a medida da $\mathrm{Hb}_{\mathrm{Al}} \mathrm{c}$ não foram suficientes para determinar uma diferença significativa entre grupos.

Por outro lado, com freqüência, dados relacionados ao controle metabólico não obtiveram melhora em curto período de tempo, provavelmente pelo processo degenerativo da própria doença. Assim, é necessário o envolvimento de uma equipe multiprofissional, que monitore regularmente esses resultados, com possíveis ajustes na terapêutica farmacológica. Destacando-se que a população em estudo já possuía um período longo de doença. 
Tabela 6.10 - Parâmetros bioquímicos sanguíneos e de pressão arterial dos participantes, por grupos de estudo na segunda e terceira avaliação.

\begin{tabular}{|c|c|c|c|c|c|c|}
\hline \multirow{2}{*}{ Indicadores/variável } & \multicolumn{3}{|c|}{ Após 6 meses } & \multicolumn{3}{|c|}{ Após 12 meses } \\
\hline & Controle & Intervenção & Valor de $\mathrm{p}$ & Controle & Intervenção & Valor de \\
\hline $\begin{array}{l}\text { Glicemia de jejum (mg/dl) } \\
\mathrm{n} / \mathrm{Md} ; \mathrm{AS}-\mathrm{q} ; \mathrm{M}_{1} ; \mathrm{M}_{2}\end{array}$ & $47 / 155 / 82 / 378 / 77$ & $34 / 140,5 / 118,6 / 313 / 61$ & $0,53 \ddagger$ & 45/157/104/276/75 & $34 / 154,5 / 91,5 / 325 / 80$ & $0,89 \ddagger$ \\
\hline $\begin{array}{l}\mathrm{HbA}_{1 \mathrm{c}}(\%) \\
(\mathrm{n} / \bar{X} \pm \mathrm{DP})\end{array}$ & $47 / 8,2 \pm 1,9$ & $34 / 7,8 \pm 1,6$ & $0,37 \dagger$ & $47 / 7,9 \pm 1,9$ & $34 / 7,6 \pm 1,9$ & $0,56 \dagger$ \\
\hline $\begin{array}{l}\text { Colesterol Total (mg/dl) } \\
(\mathrm{n} / \bar{X} \pm \mathrm{DP})\end{array}$ & $47 / 219,6 \pm 52,1$ & $34 / 201,2 \pm 34,4$ & $0,08 \dagger$ & $45 / 221,1 \pm 49,6$ & $34 / 217,2 \pm 43,7$ & $0,71 \dagger$ \\
\hline $\begin{array}{l}\text { HDL Colesterol }(\mathrm{mg} / \mathrm{dl}) \\
\text { n/Md; AS-q; } \mathrm{M}_{1} ; \mathrm{M}_{2}\end{array}$ & $47 / 40 / 17,5 / 66,5 / 21$ & $33 / 40 / 26,4 / 59,1 / 20$ & $0,85 \ddagger$ & $45 / 48 / 17,9 / 73 / 10,1$ & $34 / 52,5 / 15,6 / 84 / 28,5$ & $0,20 \ddagger$ \\
\hline $\begin{array}{l}\text { Triglicérides }(\mathrm{mg} / \mathrm{dl}) \\
\mathrm{n} / \mathrm{Md} ; \mathrm{AS}-\mathrm{q} ; \mathrm{M}_{1} ; \mathrm{M}_{2}\end{array}$ & $47 / 224 / 140,5 / 1449 / 75$ & 34/201/107/870/73 & $0,89 \ddagger$ & $45 / 210,0 / 143,5 / 636 / 65$ & $34 / 250,5 / 186,5 / 839 / 70$ & $0,60 \ddagger$ \\
\hline $\begin{array}{l}\text { Creatinina }(\mathrm{mg} / \mathrm{dl}) \\
\mathrm{n} / \mathrm{Md} ; \text { AS-q; } \mathrm{M}_{1} ; \mathrm{M}_{2}\end{array}$ & $40 / 1,1 / 0,5 / 2,1 / 0,1$ & $32 / 0,8 / 0,4 / 3,1 / 0,2$ & $0,012 \ddagger$ & $43 / 0,9 / 0,4 / 1,7 / 0,5$ & $33 / 0,9 / 0,45 / 3,8 / 0,5$ & $0,80 \ddagger$ \\
\hline $\begin{array}{l}\text { Pressão Arterial } \\
(\mathrm{n} / \bar{x} \pm \mathrm{DP}) \quad \text { PAS }\end{array}$ & $47 / 134,5 \pm 19,2$ & $47 / 133,5 \pm 18,1$ & $0,82 \dagger$ & $34 / 130,0 \pm 20,0$ & $34 / 141,3 \pm 20,3$ & $0,009 * \dagger$ \\
\hline$(\mathrm{n} / \bar{x} \pm \mathrm{DP}) \quad \mathrm{PAD}$ & $47 / 82,0 \pm 10,7$ & $47 / 77,3 \pm 12,2$ & $0,06 \dagger$ & $34 / 79,5 \pm 11,5$ & $34 / 79,5 \pm 11,6$ & $0,99 \dagger$ \\
\hline PAS < 130 mmHg. (\%) & 36,2 & 38,23 & 1,0 & 51,1 & 26,47 & $0,038 * \S$ \\
\hline PAD <80 mmHg. (\%) & 27,7 & 41,2 & 0,23 & 40,42 & 38,23 & $1,0 \S$ \\
\hline
\end{tabular}

Md=Mediana; AS-q=Amplitude Semi-quartil; $\mathrm{M}_{1}=$ Maximo; $\mathrm{M}_{2}=$ Mínimo. $\ddagger$ Teste Mann-Whitney; $\dagger$ Teste $\mathrm{t}, \S$ Teste Fischer. ${ }^{*} \mathrm{p}<05$ 
No ensaio de Bloomgarden et al (1987), avaliações a cada três meses dos valores da glicose de jejum, $\mathrm{HbA}_{1 \mathrm{C}}$, colesterol $\mathrm{LDL}$ e triglicérides, também não mostraram diferença significativa entre os grupos estudados, após 18 meses de seguimento, nem mesmo entre o intervalo de meses considerados. Contrário aos resultados apresentados por Mazzuca et al. (1986), os quais identificaram diminuição dos valores da glicemia em jejum $(p<0,05), \operatorname{HbA}_{1 c}(p<0,05)$ e pressão arterial sistólica $(\mathrm{p}<0,05)$ no grupo intervenção.

Em ambos estudos observou-se que os valores da glicemia em jejum estiveram acima dos valores de recomendação aceitáveis $(\geq 200 \mathrm{mg} / \mathrm{dl})$ semelhantes aos valores apresentados no presente ensaio ( $\geq 140 \mathrm{mg} / \mathrm{dl})$.

Conforme recomendações da ADA (2004) e SBD (2003), estes dados demonstram que é necessário intervir na terapia de forma geral, incluindo tratamento farmacológico, dieta e atividades física, com o objetivo de melhorar o controle metabólico. Este é medido de forma específica mediante o exame de $\mathrm{HbA}_{1 \mathrm{c}}$, o qual também apresentou-se elevado nos referidos estudos. Entretanto, nos estudos de Mazzuca et al., (1986) e Bloomgardem et al. (1987), não foi possível apreciar de forma clara, qual o grau de alteração do controle metabólico, devido à ausência dos valores referenciais aceitáveis conforme técnica utilizada na dosagem da $\mathrm{HbA}_{1 \mathrm{c}}$.

No presente ensaio, os valores da $\mathrm{HbA}_{1 \mathrm{c}}$ também se encontraram acima do recomendado pela National Glycohemoglobin Standardization Program - NGSP (ADA, 2004), para exames realizados com outros métodos, que não o HPLC (High Performance Liquid Chromatography).

Os valores de colesterol total e triglicerídeos também apresentaram-se elevados nos particpantes, segundo as recomendações da SBD (2003) e do Expert Panel on Detection, Evaluation, and Tratment of High Blood Cholesterol in Adults (2001), com relativo aumento nos valores do HDL colesterol aos 12 meses, porém sem diferença entre os grupos (Tabela 6.10).

Ensaios prévios direcionados ao manejo destes valores, especificamente, nem sempre atingiram os objetivos desejados entre pessoas com diabetes mellitus tipo 2, tratadas em unidades de assistência primária (NEW et al., 2004; KO et al., 2004). Em todos os estudos houve participação de enfermeiros para reforçar o cuidado no diabetes, em pacientes com controle glicêmico insatisfatório mediante programas educacionais, por vezes, envolvendo cuidado colaborativo e utilizando algoritmo.

No ensaio de New et al.(2004), enfermeiros especialistas visitaram unidades de assistência primária selecionadas, para lembrar médicos e enfermeiros dos protocolos e metas do tratamento 
na hipertensão ou hiper-lipidemia, proporcionando também, material educativo e protocolos respectivos, incluindo manejo farmacológico. As unidades foram visitadas a cada três meses pelos especialistas, para apoiar os profissionais e encorajá-los a continuar a intervenção, devendo os pacientes serem aconselhados arealizarem mudanças no estilo de vida. Após 12 meses de seguimento não houve alterações nos grupos em relação ao colesterol e pressão arterial.

No ensaio realizado em uma população chinesa direcionado à prevenção de risco cardiovascular, enfermeiros reforçavam esses cuidados com os pacientes após as consultas médicas a cada três meses (KO et al., 2004). Os resultados mostraram leve melhora na glicemia em jejum, $\mathrm{HbA}_{1 c}$, perfil lipídeo, pressão arterial e índice de massa corporal dos participantes, porém sem diferença significativa entre grupos intervenção e controle, exceto pela circunferência da cintura $(\mathrm{p}=0,01)$.

Em contrapartida, Sarkadi e Rosenqvist (2004) após 24 meses de acompanhamento dos pacientes com diabetes, apresentaram resultados favoráveis ao controle da $\mathrm{HbA}_{1 c}$ com prévio desenvolvimento de um programa educativo realizado durante o período de 12 meses, com reuniões grupais mensais para o grupo intervenção, nos quais era reforçada a experiência do participante, utilizando isso base da aquisição de práticas e habilidades para o automanejo da doença. Esta participação colaborativa entre profissional e paciente, além de apoiar nos aspectos emocionais da doença, pode ter estimulado aos participantes a melhorar automanejo do diabetes, que foi refletido na visível redução dos valores da $\mathrm{HbA}_{1 \mathrm{c}}$ aos 6 e 24 meses $(-0,4 \%)$, com diferenças significativas entre grupos $(\mathrm{p}<0,05 ; \mathrm{p}<0,01$, respectivamente), porém sem diferença aos 12 meses.

O estudo mostra que os efeitos da intervenção educativa podem ter uma dinâmica flutuante entre participantes, induzindo a necessidade de realização de acompanhamentos após um ano, com objetivo de capturar possíveis efeitos tardios da intervenção (SARKADI; ROSENQVIST, 2004).

Este acompanhamento, vislumbra a necessidade de realizar avaliações periodicamente, não apenas como parte de um aprendizado, mas também, no cotidiano do atendimento às pessoas com diabetes, com o propósito de identificar lacunas no conhecimento sobre a doença e tratamento, a fim de reforçar constantemente o automanejo, considerando os múltiplos fatores de origem subjetivo, biológico, pessoal e social, que influenciam potencialmente nas metas propostas, além das dificuldades de acesso aos serviços públicos. 
Os resultados desses ensaios clínicos mostram a complexidade que constitui o manejo do diabetes como doença crônica, na tentativa de alcançar o controle metabólico nessa população e, ao mesmo tempo, prevenir lesões/ulcerações nos pés. Neste sentido, é necessário um trabalho sincronizado de uma equipe multiprofissional, envolvendo programas preventivos de educação, intervenções de baixa complexidade com os pés e ajustamentos na terapia farmacológica, com fluxo contínuo de informações entre profissionais, que permitam individualizar o tratamento entre pacientes, potencializando a autonomia do cuidado.

Historicamente, o sistema de saúde está voltado para a assistência de problemas agudos e das necessidades prementes dos pacientes, na perspectiva do diagnóstico, da atenuação dos sintomas e da expectativa da cura. O tratamento das condições crônicas, no qual se inclui o diabete,s vem exigir às organizações de saúde uma mudança de conceito no tratamento de problemas de saúde a longo prazo (OMS, 2003).

Nesse modelo de atendimento, Mendes (1998) propõe uma reestruturação da gestão da atenção à saúde, onde a assistência primaria seja altamente resolutiva e humanizada. Entretanto, a responsabilidade neste nível dependerá muito das habilidades e ferramentas que o pessoal de saúde possua para tratar as condições crônicas nos pacientes. Este fato, compele às organizações gestoras de saúde a redirecionarem suas prioridades na assistência da população da rede pública, tanto no nível macro - política, meso - organizações de saúde e comunidade e micro - paciente (OMS, 2003).

O presente ensaio, definido como estudo piloto, do desenvolvimento de uma proposta de assistência sistematizada para pessoas com diabetes tipo 2 , na perspectiva de prevenir lesão/ulceração nos pés, demonstrou que é possível difundir conhecimentos básicos de cuidados com os pés e motivar a incorporação de novos hábitos de cuidados ao cotidiano de pessoas de baixo risco mediante programa básico, baseado em evidências. Acredita-se que, o comparecimento às consultas mensais tenha exercido grande impacto nos resultados obtidos, devido a estratégia favorecer um contato individualizado entre participante e enfermeiro pesquisador, centrado nas necessidades e habilidade de cada pessoa, propiciando intercâmbio de experiência e de saberes, discutindo muitas vezes, as interferências pessoais/familiares e sociais no melhor automanejo da doença.

Apesar de ter-se, inicialmente, realizado reuniões grupais uma vez por semana, durante seis semanas, na quais foram desenvolvidas os conteúdos programáticos de sensibilização 
educativa, de forma intensiva, a melhora no conhecimento sobre o diabetes e suas complicações e nas condições dos membros inferiores mostrou-se evidente, apenas na segunda ou terceira consulta mensal. Esta observação reforça a necessidade de estabelecer com esta população contínuos contatos, para assim ter oportunidade de reforçar as orientações e avaliar os progressos atingidos.

É possível, que eventualmente, sejam observadas regressão nos cuidados e no conhecimento sobre o manejo da doença, em decorrência dos múltiplos fatores intercorrentes nesse processo, devendo-se considerar a degeneração progressiva do diabetes, o tempo da doença, as crenças, a cultura, a influência do meio ambiente, o acesso ao sistema de saúde, a estrutura do sistema de saúde, dentre outros.

A assistência planejada e contínua com os pacientes permite ao profissional de saúde prestar apoio e reforço em momentos mais oportunos, atendendo às necessidades individuais dos mesmos. Neste sentido, os resultados do estudo mostram a necessidade de se estabelecer a consulta de enfermagem, como um atendimento de rotina para as pessoas com diabetes mellitus nas unidades de assistência primária, destacando o desenvolvimento de intervenções de baixa complexidade, principalmente, entre pessoas com limitações para o autocuidado.

Na revisão sistemática realizada por Norris et al. (2002), foi identificada que o maior contato com os paciente no decorrer do tratamento estão associado com a melhor resposta no controle metabólico, sendo necessário para isto 23.6 horas de contato educativo com o paciente para reduzir $1 \%$ de $\mathrm{HbA}_{1 c}$. Desta forma, pode-se dizer que dispensar maior tempo e freqüência de contatos às pessoas com diabetes, pode trazer grandes benefícios ao paciente e ao sistema de saúde, paralelo à satisfação profissional do enfermeiro.

Pela revisão realizada previamente, não existe um modelo específico de intervenção educativa a ser seguido para a prevenir lesões/ulcerações nos pés entre pessoas de baixo risco, apenas experiências que apresentam subsídios isolados, que se agrupados coerentemente, poderiam aplicar-se na prática clínica avaliando o custo-benefício entre pacientes.

O presente ensaio apresentou importantes limitações. Inicialmente, todos os participantes realizavam tratamento nas respectivas unidades e foram auto-selecionados a partir da resposta às cartas de convocação recebidas e ao interesse em participar no grupo de cuidado de complicações nos pés. Esta condição pode ter despertado maior motivação nos participantes para aderir aos 
comportamentos esperados (efeito Hawthorne), apesar da randomização realizada para seleção do grupo intervenção e grupo-controle.

Outro viés a se considerar constitui a grande perda de pacientes ocorrido no grupo intervenção (31\%) diferenciada do grupo-controle $(9,6 \%)$, o que pode ter interferido na obtenção de um efeito mais consistente no grupo intervenção. Destaca-se que foram realizados múltiplos contatos com as pessoas para a manutenção da participação nos respectivos grupos.

É possível também que o viés de contaminação tenha sido introduzido no grupo-controle. O fato de participar de uma reunião semestral, como membro do grupo-controle, onde foram utilizados os mesmos materiais pela pesquisadora, pode ter despertado a motivação das pessoas para desempenharem comportamentos importantes na prevenção de complicações crônicas e de cuidados com os pés. Por outro lado, havia muitos questionamentos pelos participantes do grupocontrole, na intenção de melhor se cuidarem, considerando que para muitos era absolutamente novo os dois conteúdos apresentados conforme descrito na metodologia. Existe também, a possibilidade de fluxo de informação entre grupos, pois na randomização não foi considerada a proximidade das residências na vizinhança.

O reduzido tamanho da amostra, também deve ser considerado, limitando o poder de extrapolar estes resultados para outras populações semelhantes, entretanto, espera-se ampliar a aplicação desta proposta em estudos posteriores. Finalmente as avaliações foram mantidas cegas aos grupos de estudo.

Como previamente referido, o presente estudo traz importantes contribuições à prática clínica, na perspectiva de oferecer subsídios na prevenção de lesão/ulceração nos pés de pessoas com diabetes mellitus de baixo risco, atentos a identificação precoce de possíveis complicações, com orientações contínuas de cuidados com os pés e realização de cuidados básicos, com especial interesse entre pessoas que apresentam condições e habilidades limitadas.

Os resultados sugerem que as estratégias utilizadas podem ajudar as pessoas a cuidar melhor de seus pés e controlar o diabetes, de modo geral, dispondo de um profissional que de forma permanente ofereça serviços de educação e dê suporte nos cuidados com os pés.

O enfermeiro, previamente treinado, é habilitado para contribuir no cuidado das pessoas com diabetes e no rastreamento precoce de alterações estruturais, comprometimento da sensibilidade pressórica plantar e da doença vascular, enfatizando o adequado controle metabólico nas consultas de enfermagem, a qual devia ser implantadas de forma regular. Entretanto, o estudo 
também mostrou que, trabalhos isolados, não refletem o adequado controle metabólico, na diminuição do risco cardiovascular. Desta forma, nas unidades de assistência primária, é necessária uma equipe multiprofissional preparada, para se responsabilizar pelo cuidado integral das pessoas com diabetes, trabalhando de forma organizada e complementar, com uma comunicação permanente sobre danos e obstáculos identificados nos pacientes, permitindo ir além das próprias especialidades.

Apesar da inconsistência das intervenções de prevenção, não se pode omitir aresponsabilidade de somar-se ao projeto de diminuir a incidência de úlceras e amputações entre pessoas com diabetes e de conscientizar á população da ameaça que constitui o diabetes mau controlado, no propósito de melhorar a qualidade de vida dessas pessoas.

Nessa perspectiva, o presente estudo, provavelmente, represente um estímulo para que as unidades de assistência básicas distritais de saúde, estabeleçam mecanismos de organização e coloquem na prática as medidas aqui expostas, com o envolvimento e sensibilização das equipes de atendimento básico, representado pelo médico, enfermeiro e auxiliar de enfermagem. 


\section{CONCLUSÕES}

As conclusões estão apresentadas de acordo com os objetivos propostos e conforme os resultados obtidos no decorrer do estudo, considerando os dois respectivos estudos complementares.

\section{1- Quanto à revisão sistemática}

Os estudos primários identificados, envolvendo organização do serviço para o cuidado da pessoa com diabetes e educação, não mostraram consistência nas suas intervenções propostas.

Falhas metodológicas foram identificadas em todos os ensaios clínicos, que comprometem as conclusões, principalmente, relacionadas com carência de informações importantes, que enfraquecem a consistência de seus resultados, demonstrando que não há evidência do efeito.

No geral, não houve mascaramento dos avaliadores para os grupos de estudo, com número reduzido de participantes e um curto período de seguimento, estas condições podem ter influenciado nesses resultados.

Os ensaios clínicos não descreveram a evolução das possíveis complicações nos pés, que poderiam estar relacionadas com as intervenções propostas, provavelmente, devido a baixa condição de risco dos participantes.

Desta forma, não está claramente definido, qual o melhor modelo de organização do serviço que a equipe de assistência primária deve implantar, nem qual a periodicidade das consultas para prevenir lesão/ulceração nos pés das pessoas com DM de baixo risco. Quanto às conseqüências das intervenções educativas avaliadas no estudo, houve melhora no conhecimento sobre autocuidado com os pés. Entretanto, nem sempre ocorreu melhora na aparência dos pés. Observou-se que, o conhecimento pode até se manter por longo prazo, porém as condutas são incorporadas ao cotidiano por breve período de tempo. Assim, também não existe um modelo educativo a adaptar que se tenha demonstrado eficaz, na prevenção de lesão/ulceração nos pés entre pessoas de baixo risco. 
Quanto às diretrizes clínicas, Meltzer et al. (1998), Scottish Intercollegiate Guidelines Network (2001) e Hutchinson et al. (2003) apresentaram recomendações com maior credibilidade, principalmente, porque elas se fundamentaram em ensaios clínicos randomizados controlados, que mesmo apresentando resultados inconclusivos, os mesmos foram coerentemente discutidos e sustentados na metodologia envolvendo equipe multidisciplinar, pacientes e especialistas no método, cujas deliberações foram descritas com propriedade, inclusive, quando a evidência foi incerta ou ambígua.

\section{2- Quanto à elaboração da proposta de assistência sistematizada}

As recomendações consideradas na proposta assistencial se fundamentam nos achados identificados na revisão sistemática, principalmente, nas diretrizes clínicas. A maioria dessas recomendações apresenta-se com graus "B" e "D", em decorrência dos resultados inconclusivos dos estudos quanto à evidência de efeito.

O processo de agendamento regular foi destacado, como uma estratégia para observar à pessoa com diabetes, considerando a inclusão de componentes específicos de cuidado com os pés.

Intervenções educativas constituem medidas fundamentais entre profissionais e pacientes, com reforços regulares, sendo que profissionais envolvidos na avaliação dos pés da pessoa com diabetes devem receber treinamento específico.

Profissionais de saúde devem solicitar à pessoa com diabetes que descalce seus sapatos, para efetivarem o exame nesse segmento, proporcionando e/ou reforçando a educação em cada visita conforme classificação de risco. Elementos básicos no plano educacional incluem inspeção diária dos pés e cuidados preventivos, tais como: cuidados com a pele, unhas e calosidades e a quem se deve procurar quando identificado qualquer ferimento ou anormalidade.

Recomenda-se a realização de screening para identificação precoce dos fatores de risco para lesão/ulceração, mediante intervenções simples e avaliação regular dos membros inferiores, considerando avaliação de alterações estruturais, comprometimento da sensibilidade periférica e vascular periférica, história de úlcera, controle glicêmico e aconselhamento sobre a propriedade dos calçados, com especial atenção ás pessoas apresentando alto risco. 


\section{3- Quanto à efetividade das propostas de assistência sistematizada}

O desenvolvimento da proposta de assistência sistematizada, mediante a sensibilização educativa e desenvolvimento de cuidados com os pés no grupo intervenção, mostrou-se efetivo na melhora do conhecimento e comportamento desses participantes aos seis e doze meses de avaliação em relação ao grupo-controle.

A variável referente ao conhecimento foi a primeira área a mostrar melhora aos seis meses, incluindo conhecimento sobre diabetes $(\mathrm{p}=0,005)$ e auto-relato de comportamentos de cuidados com os pés $(\mathrm{p}<0,000)$. Ambos conhecimentos mantiveram-se constantes até o final do ensaio $(p<0,000)$ entre os participantes do grupo intervenção, contrário ao cuidado com os calçados que não mostrou diferença entre grupos no decorrer do estudo $(p=0,21 ; p=0,21)$. As condições dermatológicas dos pés apresentaram melhoria apenas aos 12 meses $(p<0,000)$, paralelo à utilização de calçados considerados de características apropriadas $(\mathrm{p}=0,005)$.

As variáveis bioquímicas relacionadas com o controle metabólico mantiveram-se estáveis no decorrer do estudo incluindo glicemia em jejum, $\mathrm{HbA}_{1 \mathrm{c}}$, colesterol total, triglicérides e creatinina $(p>0,05)$. O controle da pressão arterial sistólica apresentou aumento relativo no grupo intervenção aos dozes meses em relação ao grupo controle $(p=0,009)$, com aumento significativo do número de pessoas com adequado controle da dessa pressão arterial. 


\section{IMPLICAÇÕES}

As condições crônicas representam uma necessidade a enfrentar, perante a qual devem-se desenvolver novas estratégias para gerenciar a saúde na população. Dentre as doenças responsáveis pelas condições crônicas, destaca-se o diabetes mellitus, que vem assumindo proporções preocupantes na sociedade, considerando o elevado numero de pessoas atingidas e o ônus que dispensa o setor saúde para o controle de suas complicações graves, quando não se institui um tratamento apropriado e oportuno.

Em decorrência dessa problemática, o sistema de saúde brasileiro tem proposto algumas metas, na tentativa de direcionar maiores esforços para melhorar a assistência à população com diabetes, como objetivo de reestruturar as estratégias de tratamento e de prevenção até agora vigentes.

A reestruturação das estratégias de tratamento significa inová-las e estabelecer mecanismos que facilitem o cuidado e manejo das necessidades dessa população, envolvendo as políticas de saúde, a estrutura organizacional do sistema de saúde e as formas de interação com os pacientes. Nessa perspectiva, o modelo assistencialista do tratamento para os casos agudos, deve ser substituído pela ênfase na prevenção, promovendo um sistema de saúde integrado e garantindo o fluxo contínuo de informações sobre os pacientes nos diferentes cenários da assistência no decorrer do tempo. Salienta-se a necessidade de criar novos modelos de equipe de saúde para administrar as condições crônicas, de preferência com base em evidências (OMS, 2003).

Os profissionais atuando no nível primário devem possuir habilidades para enfrentar e desenvolver relações apropriadas com os pacientes, considerando a necessidade de conhecimento atualizado de práticas e de intervenções mais resolutivas de baixa complexidade e de disponibilizar de recursos materiais correspondentes nas unidades de assistência, nos quais devem ser criados espaços para melhor acolhimento e atendimento dessas pessoas. 
O aumento crescente das doenças crônicas, face ao aumento da expectativa de vida e do envelhecimento populacional, contribui para a maior demanda de cuidados preventivos e de manutenção. Este fato revela a importante contribuição que o enfermeiro pode proporcionar ao sistema de saúde, no cuidado dessas pessoas. No entanto, observa-se uma escassez desse recurso humano no sistema de saúde, impondo o desenvolvimento de atividades não-assistenciais, em detrimento do cuidado direto das pessoas. Nesse sentido chama-se a atenção para estabelecer mecanismos que viabilizem a execução da consulta de enfermagem, visando a direcionar esforços para diminuir as condições crônicas incapacitantes, destacando as relacionadas com o diabetes como amputação, cegueira, hemodiálise e cardiovasculares.

A implantação de intervenções de baixa complexidade para prevenir lesão/ulceração nos pés de pessoas com diabetes, mostrou ser efetiva no estudo, o que traz importantes contribuições à prática clínica principalmente, por fundamentar-se nas evidências disponíveis nos estudos. Dessa forma, a consulta de enfermagem nas unidades da rede básica representa uma necessidade imediata, a fim de intensificar o rastreamento e identificar, precocemente, os fatores de risco para úlcera e/ou amputação nessa população.

A implantação da consulta de enfermagem, com ênfase na prevenção das complicações crônicas do diabetes, vem ao encontro das metas estabelecidas pela Secretaria Municipal de Saúde de Ribeirão Preto, de conformidade com a Proposta Básica a Assistência ao Diabético no Município. Deste modo, é necessário designar enfermeiros responsáveis pelo cuidado às pessoas com diabetes voltados ás atividades de sensibilização e educação permanente, com atendimento oportuno e regular, com treinamento especial em cuidado dos pés e realização de screening.

As recomendações descritas neste estudo a respeito da assistência sistematizada à pessoa com diabetes, visando a prevenção do risco de lesão/ulceração nos pés, representam ações de baixa complexidade, porém de apropriada resolutividade.

Uma prática assistencial fundamentada em evidências procedentes das pesquisas de intervenção, proporciona um melhor desempenho no cuidado ao paciente. Entretanto, para isto ser concretizado, é necessário que o enfermeiro possua pensamento crítico e reflexivo, a 
fim de julgar apropriadamente os resultados das pesquisas. O que exige a introdução de transformações no processo de formação profissional e no ambiente do trabalho.

Caliri (2002) salienta que estas transformações e o seus resultados dependem da integração, colaboração e compromisso de todas as partes que compõem esses sistemas. A integração enfermeiro/docentes e enfermeiros da prática clínica, alunos de graduação e pósgraduação, empenhada em trabalhar em torno de um problema comum, pode produzir sinergismo para estabelecer mudanças em todo o sistema social da enfermagem e da sociedade.

Parcerias entre universidades e instituições de saúde são essenciais para concretizar as mudanças no atual sistema de saúde, identificando problemas para serem pesquisados, cujos resultados podem ser voltados á prática clínica, em prol da melhora na qualidade do cuidado oferecido as pessoas.

É necessário, ainda, estruturar novos estudos de intervenção entre pessoas de baixo risco, visando a prevenção do risco de lesão/úlcera nos pés, no sentido de proporcionar maior consistência aos resultados obtidos neste estudo, considerando o tamanho da amostra e os critérios de um ensaio clínico randomizado controlado, o que proporcionará evidências consistentes para atendimento da enfermagem. 


\section{REFERÊNCIAS}

001. ABBOTT, C.A. et al. Multicenter study of the incidence of and predictive risk factors for diabetic neuropathic foot ulceration. Diabetes Care, v.21, n.7, p.1071-5, 1998.

002. AHRONI, J.H.; BOYKO, E.J.; FORSBERG, R.C. Clinical correlates of plantar pressure among diabetic veterans. Diabetes Care, v.22, n.6, p.965-72, jun. 1999.

003. ADLER, A.I. et al. Lower-extremity amputation in diabetes: the independence effects of peripheral vascular disease, sensory neuropathy, and foot ulcers. Diabetes Care, v.22, n.7, p.102935, jul. 1999.

004. ALBRKTSEN, S.B.; HENRIKSEN, B.M.; HOLSTEIN, P.E. Minor amputations on the feet after revascularization for gangrene. Acta Orthop Scand, v.68, n.3, p.291-33, 1997.

005. AMADIO, A.C.; SACCO, C.N. Considerações metodológicas de biomecânica para a avaliação da distribuição da pressão plantar. Diabetes Clín., v.3, n.1, p.42-9, 1999.

006. AMERICAN DIABETES ASSOCIATION. Diagnosis and classification of diabetes mellitus. Diabetes Care, v.27, p.5-10, jan. 2004. Supplement 1.

007. AMERICAN DIABETES ASSOCIATION. Implications of the United Kingdom Prospective Diabetes Study. Diabetes Care, v.27, p.28-32, jan. 2004. Supplement 1.

008. AMERICAN DIABETES ASSOCIATION. Preventive foot care in people with diabetes. Diabetes Care, v.27, p.56-7, jan. 2004. Supplement 1.

009. AMERICAN DIABETES ASSOCIATION. Screening for type 2 diabetes. Diabetes Care, v.24, p.11-14, jan. 2004. Supplement 1.

010. APELQVIST, J.; LARSSON, J.; AGARDH, C.D. The importance of peripheral pulses, peripheral oedema and local pain for the outcome of diabetic foot ulcers. Diabetic Medicine, v.7, p.590-4, 1990.

011. ARMSTRONG, D.G. Loss of protective sensation: a practical evidence-based definition. J. Foot \& Ankle Surgical, v.38, n.1, p.79.80, 1999.

012. ARMSTRONG, D.G.; HARKLESS, L.B. Outcomes of prospective care in a diabetic foot specialty clinic. J. Foot \& Ankle Surgery, v.37, n.6, p.460-6. Nov/dec, 1998.

013. ASOCIACIÓN LATINOAMERICANA DE DIABETES. Conceptos básicos sobre medicina basada en evidencia. Rev. Asoc. Latinoamericana Diabetes, p.107-10, 2000. Suplemento 1.

014. ASOCIACIÓN LATINOAMERICANA DE DIABETES. Definición y diagnóstico de la diabetes mellitus. Rev. Asoc. Latinoamericana Diabetes, p.121-23, 2000. Suplemento 1.

015. ASOCIACIÓN LATINOAMERICANA DE DIABETES. Epidemiología de la diabetes tipo 2 en Latinoamérica. Rev. Asoc. Latinoamericana Diabetes, p.116-18, 2000. Suplemento 1. 
016. ATAllah, N.A.; CASTRO, A.A. Medicina Baseada em Evidências: o elo entre a boa ciência e a boa prática clínica. Disponível em: $<$ http://www.epm.br/cochrane/ebm.htm $>$. Acesso em: 23 de mar. 1999.

017. ATAlLAH, N.A.; CASTRO, A.A. Revisão sistemática da literatura e metanálise. Disponível em: <http://www.epm.br/cochrane/ebm.htm>. Acesso em: 23 de mar. 1999.

018. BARCELÓ, A.; RAJPATHAK, S. Incidence and prevalence of diabetes mellitus in the Americas. Rev. Pan. Salud Publica/Pan. Am. J. Public Health, v.10, n.5, p.300-8, 2001.

019. BARTH, R. et al., Intensive education improves knowledge, compliance, and foot problems in type 2 diabetes. Diabetic Medicine, v.8, p.111-7, 1991.

020. BERARDIS de, G. et al. Quality of care and outcomes in type 2 diabetic patients. Diabetes Care, v.27, n.2, p.398-406, feb. 2004.

021. BEYEA, S.C.; NICOLL, LH. Developing clinical practice guidelines as an approach to evidence-based practice. AORN J., v.67, n.5, p.1037-8, may. 1998.

022. BILD, D.E. et al. Lower-extremity amputation in people with diabetes epidemiology and prevention. Diabetes Care, v.12, n.1, p.24-31, 1989.

023. BIRKE, J.A.; FRANKS, B.D.; FOTO, J.G. First ray joint limitation, pressure, and ulceration of the first metatarsal head in diabetes melltus. Foot \& Ankle International, v.16, n.5, p.277-84, may. 1995.

024. BLOOMGARDEN, Z.T. et al.. Randomized, controlled trial of diabetic patient education: improved knowledge without improved metabolic status. Diabetes Care, v.10, n.3, p.263-72, 1987.

025. BOIKE, A.M.; HALL, J.O. A practical guide for examining and treating the diabetic foot. Clev. Cl. J. Med, v.69, n.4, p.342-8, 2002.

026. BOULTON AJM Lowering the risk of neuropathy, foot ulcers and amputations. Diabetic Medicine, v.15, p.57-9, 1998. Supplement 4.

027. BOYKO, E.J. et al. Increased mortality associated with diabetes foot ulcer. Diabetic Medicine, v.13, p.967-72, 1996.

028. CABANA, M.D. et al. Why don't physicians follow clinical practice guidelines? a framework for improvement. JAMA, v.282, n.15, p.1458-65, oct. 1999.

029. CADDICK, S.L. et al. Hospital admissions and social deprivation of patients with diabetes mellitus. Diabetic Medicine, v.11, p.981-3, 1994.

030. CALIRI, M.E.L. A utilização da pesquisa na prática clínica de enfermagem. Limites e possibilidades. 2002. 143 f. Tese (Livre-Docência junto ao Departamento de Enfermagem Geral e Especializada) - Escola de Enfermagem de Ribeirão Preto, Universidade de São Paulo, Ribeirão Preto, 2002.

031. CALIRI, M.E.L.; MARZIALE, M.H.P. A prática de enfermagem baseada em evidências. conceitos e informações disponíveis on-line. Rev. Latino-Am Enf., v.8, n.4, p.103-4, 2000.

032. CAVANAGH, P.R.; ULBRECHT, J.S.; CAPUTO, G.M. Biomecânica do pé no diabetes melito. In. BOWKER, J.O.; PFEIFER, M.A. Levin e O’Neal o pé diabético. 6.ed, Rio de Janeiro: Di-Livros, 2002. Cap.6, p.125-95. 
033. CHACRA, A.R. et al. Diabete e coração. Rev Soc. Card. Estado de São Paulo, v.6, n.4, p.427-30, jul/ago. 1996.

034. CHATURVEDI, N. et al. The relationship between socioeconomic status and diabetes control and complications in the EURODIAB IDDM complications study. Diabetes Care, v.19, n.5, p.423-30, may. 1996.

035. CHIN, M.H.; ZHANG, J.X.; MERREL, K. Specialty differences in the care of older patients with diabetes. Medical Care, v.38, n.2, p.131-40, 1999.

036. CILISKA, D.; CULLUM, N.; MARKS, S. Evaluation of systematic reviews of treatment or prevention interventions. Evidence-Based Nursing, v.4, n.4, p.100-4, 2001.

037. CLOSS, S.J.; CHEATER, F.M. Evidenced for nursing practice: a clarification of the issues. J. Adv. Nursing, v.30, n.1, p.10-7, 1999.

038. COATE, V.E. Learning theories as a basis for patient education. In: COATE, V.E. Education for patients and clients. London: Routledge, 1999. Cap.3, p.49-65.

039. COLEMAN, W. Calçados para a prevenção de traumatismos: correlação com a categoria de risco. In. BOWKER, J.O.; PFEIFER, M.A. Levin e O’Neal o pé diabético. 6.ed, Rio de Janeiro: Di-Livros, 2002. Cap.20, p.620-34.

040. COLLIER J.H.; BRODBECK, M.S.N. Assessing the diabetic foot: plantar callus and pressure sensation. Diabetes Care, v.19, n.16, p.503-8, nov/dec. 1993.

041. COLYER, H.; KAMATH, P. Evidence-based practice. A philosophical and political analysis: some matters for consideration by professional practitioners. J. Adv. Nursing, v.29, n.1, p.188-93, 1999.

042. COOK, D.J.; MULROW, C.D.; AHYNES, R.B. Systematic review: synthesis of best evidence for clinical de decisions. Ann. Int. Med., v.126, p.376-80, mar. 1997.

043. COUTINHO, E.S.F. Meta-análise. In: MEDRONHO, R.A. et al. Epidemiologia. São Paulo: Atheneu, 2003. Cap.30, p.447-55.

044. COUTINHO, M. Como aplicar a medicina baseada em evidências (MBE) à prática clínica e ao ensino. In. DRUMMOND J.P.; SILVA, E. Medicina Baseada em Evidências novo paradigma assistencial e pedagógico. São Paulo: Atheneu, 1998. Cap.5, p.115-34.

045. CULLETON, J.L. Preventing diabetic foot complications: tight glucose control and patient education are the keys. Postgraduate Medicine, v.106, n.1, p.74-83, jul. 1999.

046. CUMMINGS, S.R.; GRADY, D.; HULLEY S.B. Delineando um experimento: ensaios clínicos I. in: HULLEY, S.B. et al. Delineando a pesquisa clínica: uma abordagem epidemiológica. 2. ed. São Paulo: Artmed, 2003. Cap.10, p.165-79.

047. DAGOGO-JACK, S D.C.C.T. results and diabetes care in developing countries. Diabetes Care, v.18, n.3, p.416-17, 1995.

048. DAHMEN, R. et al. Therapeutic footwear for the neuropathic foot. Diabetes Care, v.24, n.4, p.705-9, 2001.

049. D`ERAMO-MELKUS, G. Type II non-insulin-dependent diabetes mellitus. Diabetes, v.28, n.1, p.25-33, 1993. 
050. DCCT RESEARCH GROUP. The effect of intensive diabetes therapy on the development and progression of neuropathy. Ann. Medicine, v.122, n.8, p.561-8, apr.1995.

051. DCCT RESEARCH GROUP. The effect of intensive treatment diabetes on the development and progression of long-term complications in insulin-dependent diabetes mellitus. New Eng. $\mathbf{J}$. Medicine, v.329, n.14, p.977-86, sep.1993

052. DIABETES CARE AND RESEARCH. Diabetes care and research in Europe: the Saint Vincent Declaration. Diabetic Medicine, v.7, p.360, 1990.

053. DIABETES COALITION OF CALIFORNIA; CALIFORNIA DIABETES CONTROL PROGRAM. Basic Guidelines for diabetes care. 2002. Disponível em: $<$ http://www.dhs.ca.gov/diabetes> Acesso em: 14 de mar. 2003.

054. DIABETES INTEGRATED CARE EVALUATION TEAM. Integrated care for diabetes: clinical, psychosocial, and economic evaluation. BMJ, v.308, p.1208-12, 1994.

055. DICENSO, A.; COLLUM, N. Implementing evidence-based nursing. Evidence-Based Nursing, v.1, n.2, p.38-40, 1998.

056. DICKERSIN, K. The existence of publication bias and risk factors for its occurrence. J. Am. Medical Association, v.263, n.10, p.1385-9, 1990.

057. DOAK, C.C.; DOAK, L.G.; ROOT, J.H. Applying theory in practice. In: DOAK, C.C.; DOAK, L.G.; ROOT, J.H. Teaching patient with low literacy skills. 2.ed. Philadelphia: J.B. Lippincott Company, 1995. Cap.2, p.11-26.

058. DONATELli, R. Normal biomechanics of the foot and ankle. J. Orthop. Sports Phys Therapy, v.7, n.3, p.91-5, 1985

059. DONOHOE, M. et al. Improving foot care for people with diabetes mellitus: a randomized controlled trial of an integrated care approach. Diabetic Medicine, v.17, p.58107, 2000.

060. DRIEVER, M.J. Are evidence-based practice and best practice the same? Western J. Nurs. Research, v.24, n.5, p.591-7, 2002.

061. DRUMMOND JP O que é Medicina Baseada em Evidências? In. DRUMMOND J.P.; SILVA, E. Medicina Baseada em Evidências novo paradigma assistencial e pedagógico. São Paulo: Atheneu, 1998. Cap.1, p.1-21.

062. EGGER, R. et al. Language bias in randomized controlled trials published in English and German. Lancet, v.350, p.326-9, 1997.

063. EMANUELE, M.A. et al. Elevated leg systolic pressures and arterial calcification in diabetic occlusive vascular disease. Diabetes Care, v.4, n.2, p.289-92, 1981;

064. EXPERT PANEL ON DETECTION, EVALUATION, AND TREATMENT OF HIGH BLOOD CHOLESTEROL IN ADULTS. Executive summary of the Third Report of the National Cholesterol Education Program (NCEP) Expert panel on detection, evaluation, and treatment of high blood cholesterol in adults (Adults Treatment panel III). JAMA, v.285, n.19, p.2486-97, may. 2001.

065. FAGLIA E; FAVALES F; MORABITO A New ulceration, new major amputation, and survival rates in diabetic subjects hospitalized for foot ulceration from 1990 to 1993. Diabetes Care, v.24, n.1, p.78-83, 2001. 
066. FAGLIA, E. et al. Change in major amputation rate in a center dedicated to diabetic foot care during the 1980s: prognostic determinants for major amputation. J. Diabetic Complications, v.12, p.96-102, 1998.

067. FELDMAN, E. et al. A practical two-step quantitative clinical and electrophysiological assessment for the diagnosis and stating of diabetic neuropathy. Diabetes Care, v.17, n.11, p.1281-88, 1994.

069. FERNANDO, D.J.S. et al. Relationship of limited joint mobility to abnormal foot pressures and diabetic foot ulceration. Diabetes Care, v.14, n.1, p.8-11, 1991.

70 FERRAZ, A.E.P. et al. Atendimento multiprofissional ao paciente com diabetes mellitus no Ambulatório de Diabetes no HCFMRP-USP. Rev. Medicina, v.33, n.2, p.170-5, 2000.

071. FLETCHER, A.K.; DOLBEN, J. A hospital Survey of the care of elderly patients with diabetes mellitus. Age and Ageing, v.25, p.349-52, 1996.

072. FRANCO, L.J. et al. Estudo multicentrico sobre a prevalência do diabetes mellitus no Brasil. Inf. Epidemiológico SUS, ano 1, n.3, p.47-53, 1992.

073. FRENCH, P. The development of evidence-based nursing. J. Adv. Nursing, v.26, n.1, p.728, 1999.

074. FRITSCHI, C. Preventive care of the diabetic foot. Nurs. Clin. North America, v.36, n.2, p.303-21, 2001.

075. FRYKBERG, R.G. et al. Role of neuropathy and high foot pressures in diabetic foot ulceration. Diabetes Care, v.21, n.10, p.1714-19, may. 1998.

076. FUNELL, M.M.; ANDERSON, R.M. Empowerment and self-management of diabetes. Cinical Diabetes, v.22, n.3, p.123-27, 2004.

077. GALVÃO, C.M. A prática baseada em evidências: uma contribuição para a melhoria da assistência de enfermagem perioperatória. 2002. 114 f. Tese (Livre-Docência junto ao Departamento de Enfermagem Geral e Especializada) - Escola de Enfermagem de Ribeirão Preto, Universidade de São Paulo, Ribeirão Preto, 2002.

078GAMBA, M.A. et al. Amputações de extremidades inferiores por diabetes mellitus: estudo de caso-controle. Rev. Saúde Pública, v.38, n.3, p.399-404, 2004.

079. GLOBAL RESOURCE CENTER Action plan for persons with diabetes. Disponível em: $<$ http://www.diabetesresource.com/html/footcare >. Acesso em: 17 de nov. 2001.

080. GOODE, C.J. What constitutes the "evidence" in evidence-based practice? Applied Nurs. Research, v.13, n.4, p.222-5, nov. 2000.

081. GOMES, M.M.; KALE, P.L. Qualidade das evidências: desenhos de pesquisa. In. GOMES, M.M. Medicina baseada em evidências princípios e práticas. Rio de Janeiro, Reichmann \& Affonso, 2001. Cap. 2:17-35.

082. GROSS, J.L. et al. Detecção e tratamento das complicações crônicas do diabetes melito. Consenso Brasileiro. Arq. Brás. Endocrinol. Metab., v.43, n.1, p.7-13, fev. 1999.

083. GRUPO DE TRABALHO INTERNACIONAL SOBRE PÉ DIABÉTICO - GTIPD. Consenso internacional sobre pé diabético. Tradução Ana Claudia de Andrade; Hermelinda Cordeiro Pedrosa. Brasília: Secretaria de Estado de Saúde do Distrito Federal, 2001. 
084. HADORN, D.C. et al. Rating the quality of evidence for clinical practice guidelines. J Clin. Epidemiol., v.49, n.7, p.749-54, 1996.

085. HARRIS, M.I. et al. Onset of NIDDM occurs at least 4-7 yr before clinical diagnosis. Diabetes Care, v.15, n.7, p.815-19, jul. 1992.

086. HARRIS, M.; EASTMAN, R.; COWIE, C. Symptoms of sensory neuropathy in adults with NIDDM in the U.S. population. Diabetes Care, v.16, n.11, p.1446-52, nov. 1993.

087. HARRIS, R. et al. Screening adults for type 2 diabetes: a review of the evidence for the U.S. Preventive Services Task Force. Ann. Int. Medicine, v.138, n.3, p.215-34, feb. 2003.

088. HAYWARD, R.S.Q. et al. User's guides to the medical literature. VIII. How to use clinical practice guidelines. A are the recommendations valid? JAMA, v.274, p.570-4, 1995.

089. HERMAN, W.H. Glycaemic control diabetes. BJM, 319:104-6, jul, 1999. Disponível em: $<\mathrm{http} / /$ :www.medicalcomputingtoday.com/0nvdm.html> Acesso em: 14 de mar. 2001.

090. HO, M. et al. Is the quality of diabetes care better in a diabetes clinic or in a general medicine clinic?. Diabetes Care, v.20, n.4, p.472-5, ape. 1997.

091. HUMPHRIS, D. Types of evidence. In: HAMER, S.; COLLINSON, G. Achieving evidencebased practice: a handbook for practitioners. London: Baillère Tindall, 1999. Chap. 2:13-40.

092. HURWITZ, B.; GOODMAN, C.; YUDKIN, J. Prompting the clinical care of non-insulin dependent (type II) diabetic patients in an inner city area: one model of community care. BMJ, v.306, p.624-30, 1993.

093. HUTCHINSON, A. et al. Clinical Guidelines and Evidence Review for type 2 diabetes: prevention and management of foot problems. London: Royal College of General Practitioners, 2003. Disponível em: <http://www.rcgp.org.uk/rcgp/clinspec/guidelines/diabetes/index.asp>. Acesso em: 17 de mai. 2001; 30 de jul. 2003.

094. INSTITUTE FOR CLINICAL SYSTEMS IMPROVEMENT. Health care guideline: management of type 2 diabetes mellitus. 2002. Disponível em: $<$ http://www.icsi.org $>$ Acesso em: 10 de mai. 2003.

095. JENNINGS, B.M.; LOAN, L.A. Misconceptions among nurses about evidence-based practices. J. Nursing Scholarship, v.33, n.2, p.121-7, 2001.

096. JOHNSON, B. Evidence-based nursing for older people. Nursing Times, v.96, n .16, p.45-7, apr. 2000.

097. JOYCE, L. Development of practice. In. HAMER, S.; COLLINSON, G. Achieving evidence-based practice: a handbook for practitioners. London: Baillère Tindall, 1999. Chap. 6:109-27.

098. KASTENBAUER, T. et al. Running shoes for relief of plantar pressure in diabetic patients. Diabetic Medicine, v.15, p.518-22, 1998.

099. KELECHI, T. Foot care in the home: nursing and agency responsibilities. Home Healthcare Nurse, v.14, n.9, p.721-30, 1996.

100. KING, H.; AUBERT, R.E.; HERMAN, W.H. global burden of diabetes, 1995-2025. Diabetes Care, v.21, n.9, p.1414-31, 1998. 
101. KLEIN, R. Hyperglycemia and microvascular and macrovascular disease in diabetes. Diabetes Care, v.18, n.2, p.258-8, feb. 1995.

102. KLENERMAN, L. Screening for patients at risk of diabetic foot ulceration in a general diabetic outpatient clinic. Diabetic Medicine, v.13, p.561-3, 1996.

103. KO, G.T.C.et al. Effects of a structured health education programme by a diabetic nurse on cardiovascular risk factors in Chinese type 2 diabetic patient: a 1-year prospective randomized study. Diabetic Medicine, v.21, p.1274-9, 2004.

104. KUMAR, S. et al. Semmes-Weinstein monofilaments: a simple, effective and inexpensive screening device for identifying diabetic patients at risk of foot ulceration. Diabetes Research and Clin. Practice, v.13, p.63-8, 19991.

105. KUMAR, S. et al. The prevalence of foot ulceration and its correlates in type 2 diabetic patients: a population-based study. Diabetic Medicine, v.11, p.480-4, 1994.

106. LARSSON, J. et al. Decreasing incidence of major amputation in diabetic patients: a consequence of multidisciplinary foot care team approach? Diabetic Medicine, v.12, p.770-6, 1995.

107. LAVERY, L.A. et al. Reducing plantar pressure in the neuropathic foot: a comparison of footwear. Diabetes Care, v.20, n.11, p.1706-9, 1997.

108. LAVERY, L.A. et al. Practical criteria for screening patient at high risk for diabetic foot ulceration. Arch. Int. Medicine, v.158, p.157-62, 1998.

109. LEE, J.S. et al. Lower-extremity amputation: incidence, risk factors, and mortality in the oklahoma Indian diabetes study. Diabetes, v.42, p.876-82, jun, 1993.

110. LEHTO, S. et al. Risk factors predicting lower extremity amputations in patients with NIDDM. Diabetes Care, v.19, n.6, p.607-12, jun. 1996.

111. LESSA, I.; MENDONÇA, G.A.S.; TEIXEIRA, M.T.B. Doenças não transmissíveis no Brasil: dos fatores de risco ao impacto social. Bol Oficina Sanitaria Panamericana, v.120, n.5, p.389-409, 1996.

112. LEVIN, M.E. Foot lesions in patients with diabetes mellitus. Endoc. Metab. Clinic North Am., v.25, n.2, p.447-62, jun. 1996.

113. LEVIN, M.E. Patogenia e tratamento geral das lesões do pé em pacientes diabéticos. In. BOWKER, J.O; PFEIFER, M.A. Levin e O’Neal o é diabético. 6.ed., Rio de Janeiro: Di-Livros, 2002. Cap.9:221-61.

114. LITZELMAN, D.K. et al. Reduction of lower extremity clinical abnormalities in patients with non-insulin-dependent diabetes mellitus a randomized, controlled trial. Ann. Int. Medicine, v.119, n.1, p.36-41, 1993.

115. LITZELMAN, D.K.; MARRIOTT, D.J.; VINICOR, F. the role of footwear in the prevention of foot lesions in patients with NIDDM: conventional wisdom or evidence-based practice? Diabetes Care, v. 20, n,2, p.156-62, 1997.

116. MADIGAN, E.A. Evidence-based practice in home healthcare: a springboard for discussion. Home Healthcare Nurse, v.16, n.6, p.411-5, 1998.

117. MAGAREY, J.L. Elements of a systematic review. Int. J. Nurs. Practice, v.7, p.376-82, 2001. 
118. MALERBI, D.A.; FRANCO, L.J. Multicenter study of the prevalence of diabetes mellitus and impaired glucose tolerance in the urban brazilian population aged 30-69 yr. Diabetes Care, v.15, n.11, p.109-16, nov. 1992.

119. MASER, R.E. Epidemiological correlates of diabetes neuropathy: report from Pittsburgh epidemiology of diabetes complications study. Diabetes, v.38, p.1456-61, nov. 1989.

120. MASON, J. et al. A systematic review of foot ulcer in patient with type 2 diabetes. 1: prevention. Diabetic Medicine, v.16, p.801-12, 1999.

121. MAYFIELD, J.A. et al. Preventive foot care in people with diabetes. Diabetes Care, v.21, n.12, p.2161-77, 1998.

122. MAZZUCA, S.A. et al. The diabetes education study: a controlled trial of the effects of diabetes patient education. Diabetes Care, v.9, n.1, p.1-10, 1986.

123. MCKINNELL, I.; ELLIOTT, J., editores. Systematic review and the Cochrane Collaboration. In. MCKINNELL, I.; ELLIOTT, J., editores. The Cochrane Library: self training guide and notes - 1998 Issue 2. Cap.1, p.3-11. Disponível em: $<$ http://www.inifesp.br/suplem/cochrane/>. Acesso em: 19 de ago. 2002.

124. MCNEELY, M.J. et al. The independent contributions of diabetic neuropathy and vasculopathy in the foot ulceration. Diabetes Care, v.18, n.2, p.216-19, feb. 1995.

125. MELTZER S. et al. 1998 clinical practice guidelines for the management of diabetes in Canada. CMAJ, v.158, p.1-29, out. 1998. Supplement.

126. MENDES, E.V. A reengenharia do sistema de serviços de saúde no nível local: a gestão da atenção à saúde. In. MENDES, E.V. Uma agenda para saúde. São Paulo, Hucitec, 1998. Cap.2:57-85.

127. MOHER, D. et al. Completeness of reporting of trials published in language other than English: implications for conduct and reporting of systematic reviews. Lancet, v.347, p.363-6, 1996.

128. MOLONEY, R.;MAGGS, C. A systematic review of the relationships between written manual nursing care planning, record keeping and patient outcomes. J. Adv. Nursing, v.30, n.1, p.51-7, 1999.

129. MOST, R.S.; SUNNOCK, P. The epidemiology of lower extremity amputations in diabetic individuals. Diabetes Care, v.6, p.87-91, 1983.

130. MUELLER, M.J.; STRUBE, M.J.; ALLEN, B.T. Therapeutic footwear can reduce plantar pressures in patient with diabetes and transmetatarsal amputation. Diabetes Care, v.20, n.4, p.637-41, 1997.

131. MURRAY, H.J. et al. The association between callus formation, high pressures and neuropathy in diabetic foot ulceration. Diabetic Medicine, v.13, p.879-82, 1996.

132. NATIONAL DIABETES EDUCATION PROGRAM Cuide sus pies durante toda su vida. Disponível em: <http://www.ndep.nih.gov>. Acesso em: 20 de mai. 2000.

133. NATIVIO, D.G. Guidelines for evidence-based clinical practice. Nurs. Outlook, v.48, n.2, p.58-9, mar/apr. 2000. 
134. NAZIMEK-SIEWNIAK, B.; MOCZULSKI, D.; GRZESZCZAK, W. Risk of macrovascular and microvascular complications in type 2 diabetes results of longitudinal study design. $\mathbf{J}$ Diabetes Complications, v.16, p.271-6, 2000.

135. NELSON, R.G. et al. Lower-extremity amputations in NIDDM: 12-yr follow-up study in pima indians. Diabetes Care, v.11, p.10:8-16, jan, 1988.

136. NEW, J.P. et al. Education outreach in diabetes to encourage practice nurses to use primary care hypertension and hyperlipidaemia guidelines (EDEN): a randomized controlled trial. Diabetes Medicine, v.21, p.599-603, 2004.

137. NEW ZEALAND GUIDELINES GROUP. Primary care guidelines for the management of core aspects of diabetes care. 2000. Disponível em: $<$ http//:www.nzng.org.nz/library/gl_complete/diabetes/index> Acesso em: 14 de mar. 2003.

138. NORRIS, S.L. et al. Self-management education for adults with type 2 diabetes. Diabetes Care, v.25, n.7, p.1159-71, jul. 2002.

139. OHKUBO, Y. et al. Intensive insulin therapy prevents the progression of diabetic microvascular complications in Japanese patients with non-insulin-dependent diabetes mellitus: a randomized prospective 6-year study. Diabetes Research Clin. Practice, v.28, p.103-17, apr. 1995.

140. ORCHARD, I.J.; STRANDNESS, E.JR. Assessment of peripheral vascular disease in diabetes. Diabetes Care, v.16, n.8, p.11991209, aug. 1993.

141. ORGANIZAÇÃO MUNDIAL DA SAÚDE. Cuidados inovadores para condições crônicas: componentes estruturais de ação: relatório mundial. OMS, Brasília, 2003.

142. OXMAN, A., CLARKE, M. Manual de revisores (versão espanhola de "Cochrane Revievews" Handbook) [atualização junho de 2000]. Barcelona: Centro Cohrane Iberoamericano, 2001.

143. OXMAN, A.D.; SACKETT, D.L.; GUYATT, G.H. Users' guides to the medical literature: I, how to get started. JAMA, v.270, p.2093-5, 1993.

144. PACE, A.E. et al. Fatores de risco para complicações em membros inferiores em pacientes com diabetes mellitus. Rev. Brás. Enfermagem, v.55, n.5, p.514-21, 2002.

145. PACE, A.E. et al. O conhecimento sobre diabetes mellitus no processo de autocuidado. Artigo. Mimeografado. 2005.

146. PECORARO, R.E.; REIBER, G.E.; BURGESS, E.M. Pathways to diabetic limb amputation. Diabetes Care, v.13, n.5, p.513-21, 1990.

147. PEDROSA, H.C. et al. O desafio do projeto salvando o pé diabético. Terp. Diabetes, v.4, n.19, p.1-10, 1998.

148. PERISSÉ, A.R.S.; GOMES, M.M.; NOGUEIRA, S.A. Revisões sistemáticas (inclusive metanálises) e diretrizes clínicas. In. GOMES, M.M. Medicina baseada em evidências princípios e práticas. Rio de Janeiro: Reichmann \& Affonso, 2001. Cap. 9:1131-48.

149. PERRY, J.E. et al. The use running shoes to reduce plantar pressures in patients who have diabetes. J. Bone Joint Surgery, v.77, n.12, p.1819-28, de. 1995.

150. PHAM, H. et al. Screening techniques to identify people at high risk for diabetic foot ulceration: a prospective multicenter trial. Diabetes Care, v.23, n.5, p.606-11, 2000. 
151. PITEL, D.L. et al. Plantar pressures are elevated in the neuroischemic and the neuropathic diabetic foot. Diabetes Care, v.22, n.12, p.196670, dec. 1999.

152. POLIT, D.F.; HUNGLER, B.P. Research designs for quantitative studies. In: POLIT, D.F.; HUNGLER, B.P. Nursing Research: principles and methods. 6.th, Philadelphia, Lippincott, 1999. Cap. 8:175-218.

153. PORTER, A.M.D.. Organization of diabetic care, BMJ, v.285, p.1121, 1982.

154. RAMSEY, S.D. et al. Incidence, outcomes, and cost of foot ulcers in patients with diabetes. Diabetes Care,v.22, n.3, p.382-7, 1999.

155. REIBER, G.E. Epidemiologia das úlceras e amputações do pé diabético. In. BOWKER, J.O.; PFEIFER, M.A. Levin e O'Neal o pé diabético. 6.ed, Rio de Janeiro: Di-Livros, 2002. Cap.2:1333.

156. REIBER, G.E. et al. The burden of diabetic foot ulcers. The Am. J. Surgery, v.176, p.5-10, 1998. Supplement 2A.

157. REIBER, GE The epidemiology of diabetic foot problems: proceedings of the second international symposium on the diabetic foot. Diabetic Medicine, v.13, p.6-11, 1996. Supplement.

158. REIBER, GE; BOYKO EJ; SMITH DG Lower extremity foot ulcers and amputations in diabetes. (Summary) In: Diabetes in America. 2ed. 1995. Disponível em: $<\mathrm{http} / / / w w w . d i a b e t e s r e s o u r c e . c o m / h t m l / e d u 10 . h t m>$. Acesso em: 16 de ago. 2000.

159. RETTIG, B.A. et al. A randomized study of the effects of a home diabetes education program. Diabetes Care, v.9, n.2, p.173-8, 1986.

160. RICHARD, J.L. Como rastrear o risco pedológico no paciente diabético? Diabetes \& Metabolismo, v.1, n.4, p.168-72, 1997.

161. RITH-NAJARIAN, S.J.; STOLUSKY, T.; GOHDES, D.M. Identifying diabetic patients at high risk for lower-extremity amputation in a primary health care setting: a prospective evaluation of simple screening criteria. Diabetes Care, v.15, n.10, p.1386-1209, aug. 1993.

162. ROBERTS, J.; DICENSO, A. Identifying the best research designs to fit the question. Part 1: quantitative designs. Evidence-Based Nursing, v.2, n.1, p.4-6, 1999.

163. RÖNNEMAA, T. et al. Evaluation if the impact of podriatrist care in the primary prevention of foot problems in the Diabetic subjects. Diabetes Care, v.20, n.12, p.1833-7. 1997.

164. ROSSWURM, M.A.; LARRABE, J.H. A model for change to evidence-based practice. IMAGE: Clin. Scholarship, v.31, n.4, p.317-22, 1999.

165. SACKETT, D.L. et al. Como fazer perguntas clínicas que podem ser respondidas. In: SACKETT, D.L., et al. Medicina baseada em evidências: prática e ensino. 2ed. Porto Alegre: Artmed, 2003. Cap. 2:31-45.

166. SACKETT, D. et al. Evidenced-Based Medicine: what it is and what it isn't. BMJ, v.312, p.71-2, 1996.

167. SANTANA, M.E. Fístula faringocutânea após laringectomia total: revisão sistemática e implicações para a enfermagem. 2004. 186 f. Tese (Doutor em Enfermagem Fundamental) Escola de Enfermagem de Ribeirão Preto, Universidade de São Paulo, Ribeirão Preto, 2004. 
168. SARKADI, A.; ROSENQVIST, U. Experience-based group education in type 2 diabetes a randomised controlled trial. Patient Education Counseling, v.53, p.291-8, 2004.

169. SCOTTISH INTERCOLLEGIATE GUIDELINES NETWORK. SIGN 50: a guideline developers handbook. 2002. Disponível em: http://www.sign.ac.uk> Acesso em: 20 de abr. 2003.

170. SCOTTISH INTERCOLLEGIATE GUIDELINES NETWORK. SIGN 55 Management of diabetes: a national clinical guideline. 2001. Disponível em: $<\mathrm{http} / /$ www.sign.ac.uk $>$ Acesso em: 15 de mar. 2003.

171. SIMS, D.S.; CAVANAGH, P.R.; ULBRECHT, J.S. Risk factors in the diabetic foot: recognition and management. Physical Therapy, v.68, n.12, p.1887-1902, dec. 1988.

172. SOARES, A.; ATALlAH, A.N. Pé diabético: tratamento e prevenção. Disponível em: $<$ http://www.unimeds.com.br/ADMCDC/layouts/materia/impressao>. Acesso em: 5 de nov. 2002

173. SOCIEDADE BRASILEIRA DE DIABETES. Consenso brasileiro de conceitos e condutas para o diabetes mellitus recomendações da Sociedade Brasileira de Diabetes para a prática clínica - 1997. São Paulo, 1997.

174. SOCIEDADE BRASILEIRA DE DIABETES. Consenso brasileiro sobre diabetes 2002: diagnóstico e classificação do diabetes melito e tratamento do diabetes melito tipo 2 . Rio de Janeiro: Diagraphic, 2003.

175. SONNAVELLE, J.J.J. et al. the prevalence and determinants of foot ulceration in type II diabetic patients in a primary health care setting. Diabetes Research and Clinical Practice, v.35, p.149-56, 1997.

176. SOSENKO, JM et al. Use of the semmes-weisntein monofilament in the strong heart study. Diabetes Care, v.22, n.10, p.1715-21, oct. 1999.

177. SPOLLETT, G.R. Preventing amputations in the diabetic population. Nurs. Clin. North America, v.33, n.4, p.629-41, 1998.

178. STANDL, E. Overview of the management of type 2 diabetes. Diabetes Metab. Rev., v.14, p.13-7, 1998. Supplement.

179. STETLER, C.B. et al. Evidence-based practice and the role of nursing leardership. JONA, v.28, n.7/8, p.45-53, 1998.

180. SOUKUP, S.M. The center for advanced nursing practice evidence-based model promoting the scholarship of practice. Nurs. Clin. North America, v.35, n.2, p.301-9, jun. 2000.

181. STESS, R.M.; JENSEN, S.R.; MIRMIRAN, R. The role of dynamic plantar pressures in diabetic foot ulcers. Diabetes Care, v.20, n.5, p.855-9, 1997.

182. STOTTS, N. Evidence-Based Practice: what is it and how is it used in wound care? Nurs. Clin. North America, v.34, n.4, p.955-63, 1999.

183. SUMPIO, B. Foot ulcers. New Eng. J. Medicine, v.343, n.11, p.787-93, 2000.

184. TANENBERG, R.J. et al. Problemas neuropáticos das extremidades inferiores dos pacientes diabéticos. In. BOWKER, J.O.; PFEIFER, M.A. Levin e O’Neal o pé diabético. 6.ed, Rio de Janeiro: Di-Livros, 2002. Cap.3:34-65. 
185. THE SEVENTH REPORT OF THE JOINT NATIONAL COMMITTEE ON PREVENTION, DETECTION, EVALUATION, AND TREATMENT OF HIGH BLOOD PRESSURE. JAMA, v.289, p.2560-72, 2003.

186. TORQUATO, M.T.C.G. et al. Prevalence of diabetes mellitus and impaired glucose tolerant in the urban population aged 30-69 years in Ribeirão Preto (São Paulo), Brazil. São Paulo Medical J., v.121, n.16, p.224-30, 2003.

187. TRIVOLET, C. et al. Measuring vibration sensations with graduated tuning fork. Diabetes Care, v.13, n.10, p.1077-80, out. 1990.

188. TROWBRIDGE, R.; WEINGARTEN, S. Practice guidelines. In. SHOJANIA, KG. et al.(Edt.). Making health care safer: a critical analysis of patient safety practices. Evidence Report/Technology Assessment No. 43, AHRQ Publication No. 01-E058. Rockville: Agency for Health Research Quality, July 2001. Cap. 51:581-6.

189. TULDER VAN, M.W. et al. Method guidelines for systematic reviews in the cochrane collaboration back review group spinal disorders. Spine, v.22, n.2, p.2323-30, oct. 1997.

190. UCCIOLI, L. et al. Manufactured shoes in the prevention of diabetic foot ulcers. Diabetes Care, v.18, n.10, p.1376-8, 1995.

191. U.K.P.D.S. GROUP. Intensive blood-glucose control with sulphonylureas or insulin compared with conventional treatment and risk of complications in patients with type 2 diabetes (UKPDS 33). Lancet, v.352, n.12, p.83753, sep. 1998.

192. U.K.P.D.S. GROUP. Overview of 6 years therapy of type II diabetes: a progressive disease. Diabetes, vol.44, n.1249-58, nov. 1995.

193. U.K.P.D.S. GROUP. UK prospective diabetes study XII: differences between Asian, AfroCaribbean and while Caucasian type 2 diabetic patients at diagnosis of diabetes. Diabetic Medicine, v.11, p.670-77, 1994.

194. UNIVERSITY OF MICHIGAN HEALTH SYSTEMS. Management of diabetes mellitus : guidelines for clinical care. 1998. Disponível em: $<$ http://www.guidelines.gov $>$ Acesso em: $10 \mathrm{de}$ mai. 2003.

195. U.S. PREVENTIVE SERVICES TASK FORCE. Screening for type 2 diabetes mellitus in adults: recommendations and rationale. Ann. Int. Médicine, v.138, p.212-4, 2003. Disponível em: <http://www.ahrp.gov/clinic/3rduspstf/diabscr/diabtrr.thm> Acesso em: 14 de mar. 2003.

196. VA/DoD CLINICAL PRACTICE GUIDELINES WORKING GROUP - VETERANS HEALTH ADMINISTRATION; DEPARTAMENT OF VETERANS AFFAIRS AND HEALTH AFFAIRS; DEPARTAMENT OF DEFENSE. Management of patients eith diabetes mellitus in the primary care setting. 2003. Disponível em: $<\mathrm{http} / /$ :www.va.gov/ $>$ Acesso em: 10 de mai. 2003.

197. VERHAGEN, A.P. et al. The delphi list: a criterial list for quality assessment of randomized clinical trials for conducting systematic reviews developed by delphi consensus. J. Clin. Epidemiol., v.51, n.12, p.1235-41, 1998.

198. VEVES, A. et al. The risk of foot ulceration in diabetic patients with high foot pressure: a prospective study. Diabetologia, v.35, p.660-3, 1992.

199. VILEIKYTE, L. et al. The tactile circumferential discriminator. Diabetes Care, v.20, n.4, p.623-6, 1997. 
200. WALTERS, D.P. et al. The distribution and severity of diabetic foot disease: a community study with comparison to a non-diabetic group. Diabetic Medicine, v.9, p.354-8, 1991.

201. WUNDERLICH, R.P. et al. Defining loss of protective sensation in the diabetic foot. Adv. Wound Care, v.11, n.3, p.23-8, may/jun. 1998.

202. YOUNG, M.J. et al. The prediction of diabetic neuropathic foot ulceration using vibration perception thresholds: a prospective study. Diabetes Care, v.17, n.6, p.557-60, jun. 1994.

198. ZAVALA, A.V.; BRAVER, D. Semiologia do pé prevenção primária e secundária do pé diabético. Diabetes Clínica, v.4, p.137-44, 2000. 


\section{REFERÊNCIAS EXCLUÍDAS NA REVISÃO SISTEMÁTICA}

\section{1- Estudos relacionados com organização do serviço}

203. BRUCKNER, M. et al. Project LEAP of New Jersey: lower extremity amputation prevention in persons with type 2 diabetes. Am. J. Managed Care, v.5, n.5, p.609-16. May, 1999.

204. CLARK JR, C.H. et al. A systematic approach to risk stratification and intervention within a managed care environment improves diabetes outcomes and patient satisfaction. Diabetes Care, v.24, n.6, p.1079-86, 2001.

205. DARGIS, V. et al, Benefits of a multidisciplinary approach in the management of recurrent diabetic foot ulceration in lithuania. Diabetes Care, v.22, n.9, p.1428-31, 1999.

206. FRIJLING, B.D. et al. Multifaceted support to improve clinical decision making in diabetes care: a randomized controlled trial in general practice. Diabetic Medicine, v.19, p.836-42, 2002.

207. GREY, N. et al. Improving care of diabetic patients through a collaborative care model. Connec Medicine, v.66, n.1, p.7-11, 2002.

208. HAYES, T.M.; HARRIES, J. Randomized controlled trial of routine hospital clinic care versus routine general practice care for type 2 diabetics. BMJ, v.289, n.22, p.728-30, 1984.

209. HOSKINS, P.L. et al. Sharing the care of diabetic patients between hospital and general practitioners: do it work? Diabetic Medicine, v.10, p.81-6, 1992.

210. KIEFE, C.I. et al. Improving quality improvement using achievable benchmarks for physician feedback a randomized controlled trial. JAMA, v.285, n.22, p.2871-9, 2001.

211. PIETTE, J.D. et al. Impact of automated calls with nurse follow-up on diabetes treatment outcomes in department of veterans affairs health care system: a randomized controlled trial. Diabetes Care, v.24, n.2, p.202-8. Feb, 2001.

\section{2- Estudos relacionados com interveções educativas}

212. ARMSTRONG, D.G.; HARKLESS, L.B. Outcomes of prospective care in a diabetic foot specialty clinic. J. Foot \& Ankle Surgery, v.37, n.6, p.460-6. Nov-dec, 1998.

213. BORSSEN, B.; BERGENHEIM, T.; LITNER, F. Preventive treatment of foot deformities in type 2 diabetic patients aged 15-50 years - an epidemiological and prospective study. J. Int. Medicine, v.240, p.219-225, 1996.

214. CALLE-PASCUAL. A.L. et al. A preventive foot care programme for people with diabetes with different stages of neuropathy. Diabetes Research Clin. Practice, v.57, p.111-7, 2002.

215. EDMONDS, M.E. et al. Improved survival of the diabetic foot: the role of a specialized foot clinic. QJM, v.60, n.232, p.763-71, 1986. 
216. GRIFFITHS, G.D.; WIEMAN, T.J. Meticulous attention to foot care improves the prognosis in the ulceration of the foot. Surgery Gynecology Osbt., v.174, p.49-51, 1992.

217. HÄMÄLÄINEN, et al. Long-term effects of one year of intensified podiatric activities on foot-care knowledge and self-care habits in patients with diabetes. Diabetes Educator, v.24, n.6, p.734-40, 1998.

218. KRONSBEIN, P. et al. Evaluation of a structured treatment and teaching programme on noninsulin-dependent diabetes. Lancet, v.17, p.1407-10, 1988.

219. KRUGER, S.; GUTHRIE, D. Foot care: knowledge retention and self-acre practices. Diabetes Educator, v.18, n.6, p.487-90, 1992.

220. LEDDA, M.A. et al. Development and formative evaluation of a foot self-care program for African Americans with diabetes. Diabetes Educator, v.23, n.1, p.48-51, 1995.

221. McCABE, C.J.; STEVENSON, R.C.; DOLAN, A.M. Evaluation of a diabetic foot screening and protection programme. Diabetic Medicine, v.15, p.80-4, 1998.

222. MALONE, M.J. et al. Prevention of amputation by diabetic education. Am. J. Surgical, v.158, p.520-4, 1989.

223. PETERS, A.L.; DAVINSON, M.B. Application of diabetes manager care program. Diabetes Care, v.21, n.7, p.1037-43. Jul, 1998.

224. PIEBER, T.R. et al. Evaluation of a structured teaching and treatment programme for type 2 diabetes in general practice in a rural area of Austria. Diabetic Medicine, v.12, p.349-54, 1995.

225. PINZUR, M.S. et al. Development of a nurse-provided health system strategy for diabetic foot care. Foot \& Ankle Int, v.22, n.9, p.744-6, 2001.

226. SUICO, J.G. et al. Behaviors predicting foot lesions in patients with non-insulin-dependent diabetes mellitus. J. General Int. Medicine, v.13, p.482-4. Jul, 1998.

227. WARD, A. et al. Foot education improves knowledge and satisfaction among patients at high risk for diabetic foot ulcer. Diabetes Educator, v.25, n.4, p.560-7, 1999.

\section{3- Revisões sistemáticas}

228. MELVILLE, A. et al. Complications of diabetes: screening for retinopathy and management of foot ulcers. Quality Health Care, v.9, n.2, p.137-41, 2000.

229. RITH-NAJARIAN, S.J.; REIBER, G.E. Prevention of foot problems in persons with diabetes. J. Fam. Practice, v.49, n.11, p.30-9, 2000. Supplement

230. HUNT, D. Using evidence in practice foot care in diabetes. Endocrinol. Metab. Clin. North Am., v.31, p.603-11, 2002

231. GASTER, B.; HIRSCH, I. The effects of improved glycemic control on complications in type 2 diabetes. Arch. Int. Medicine, v.158, p.134-40. Jan, 1998.

232. KALTENTHALER, E. et al. The prevention an treatment of diabetic foot ulcers: a review of clinical effectiveness studies. J. Clin. Effect., v.3, n.3, p.99-104, 1998.

233. MASON, J. A systematic review of foot ulcer in patients with type 2 diabetes mellitus II: treatment. Diabetic Medicine, v.16, p.889-909, 1999. 
234. O'CONNOR, P.J.; SPANN, S.J.; WOOLF, S.H. Care of adults with type 2 diabetes mellitus: a review of the evidence. J. Fam. Practice, v.47, n.5, p.13-22, 1998. Supplement.

235. SPENCER, S. Pressure relieving interventions for preventing and treating diabetic foot ulcers (Cochrane Review). The Cochrane Library, v.4, 2002.

236. VIJAN, S. et al. Screening, prevention, counseling, and treatment for the complications of type II diabetes mellitus: putting evidence into practice. JGIM, v.12, n.9, p.567-80, 1997.

\section{4- Diretrizes clínicas}

237. AMERICAN ASSOCIATION OF CLINICAL ENDOCRINOLOGIST; AMERICAN COLLEGE OF ENDOCRINOLOGY - 2002. The American of Clinical Endocrinologists Medical Guidelines for the Management of Diabetes Mellitus: The AACE System of Intensive Diabetes Self-Management -2002 Update. Endocrine Practice, 8:40-85. jan/feb. 2002. Supplement 1. Disponível em: $<\mathrm{http} / /$ :www.guidelines.gov $>$ Acesso em: 14 de mar. 2003.

238. AMERICAN DIABETES ASSOCIATION. Preventive foot care in people with diabetes. Preventive foot care in people with diabetes. Diabetes Care, v.26, p.56-7, jan. 2003. Supplement 1.

239. AMERICAM HEALTHWAYS. Inpatient Management Guidelines for People with Diabetes. 2002. Disponível em: <http//:www.americanhealthways.com ou http//:www.guidelines.gov> Acesso em: 14 de mar. 2003.

240. DIABETES GUIDELINES WORK GROUP - MASSHEALTH PCC PLAN, 2001. Massachusetts Guidelines for Adult Diabetes Care. Disponível em: <http://www.guidelines.gov> Acesso em: 14 de mar. 2003.

241. FRYKBERG, R.G. et al. Diabetic foot disorders: a clinical practice guidelines. J. foot \& Ankle Surgery, 39(5):1-60, 2000. Supplement.

242. INDIAN COLLEGE OF PHYSICIANS. Indian guidelines for management of type 2 diabetes - 2002. JAPI, 50:295-366, 2002.

243. INTERNATIONAL DIABETES FEDERATION. Guidelines for diabetes care: a desktop guide to type 2 diabetes mellitus. 1999. Disponível em: $<$ http://www.staff.newcastle.ac.uk/philip.home./guidelines> Acesso em: 20 de mai. 2003.

244. MAZZE, R.S. et al. Internacional Center Diabetes: Type 2 diabetes practice guidelines (Resumo). 2001. Disponível em: <http://www.guidelines.gov> Acesso em: 14 de mar. 2003.

245. NATIONAL DIABETES ADVISORY. The prevention and treatment of five complications of diabetes: a guide for primary care physicians. Metabolism, v.33(1):15-7, 1984.

246. ZOOROB, R.J.; HAGEN, M.D. Guidelines on the care of diabetic nephropathy, retinopathy and foot disease. Am. Fam. Physician, v.56(8):2021-8, 1997.

\section{5- Diretrizes clínicas não adquiridas}

247. NEDERLANDSE DIABETES FEDERATIE. CBO - guidelines of diagnostic, treatment and prevention of complication in diabetes mellitus: retinopathy, foot ulcers, nephropathy and 
cardiovascular diseases. Ducth Institute for Quality Assurance. Ned. Tijdschr Geneeskd, v.144, n.9, p.413-8. Feb, 2000.

248. AGENCE NATIONALE D'ACCRÉDITATION ET D'EVALUATION EN SANTÉ. Follow-up of a patient with type 2 diabetes with the exclusion of follow-up of complications. Presse Med., v.28, n.19, p.22-9. May, 1999. 


\section{Anexo 1 \\ Categorias de qualidade da evidência \\ Adaptado de Hadorn et al. (1995)*}

\section{Seleção dos pacientes}

Falhas mayores

a. Os critérios diagnósticos da doença em estudo não foram descritos

b. Os critérios de inclusão e exclusão do estudo não foram especificados

c. A decisão de inclusão e exclusão do estudo foi algumas vezes foi realizada após ter dado ao tratamento em pesquisa.

d. A população em estudo não foi representativa para a maioria das pessoas com a condição em pesquisa.

e. Em estudos de coorte, os grupos em estudo não foram tratados concomitantemente

Falhas menores

a. Os critérios diagnósticos da doença em estudo foram inadequadamente descritos

b. Os critérios de inclusão e exclusão do estudo foram inadequadamente descritos

c. Os pacientes foram excluídos desde os grupos em estudo, porém não se descreveu as causas desta exclusão em uma listagem ou tabela

\section{Alocação dos pacientes para os grupos em tratamento}

Ensaio clínico randomizado

Falhas maiores

a. Descrição no artigo sugere que os pacientes não foram randomicamente alocados nos grupos

b. Fatores prognósticos ou confundidores conhecidos para os desfechos de interesse não foram mensurados nos dados basais, ou não houve comparação dos valores dessas variáveis entre os grupos de estudo

Falhas menores

a. Pacientes não foram alocados nos grupos de estudo com modelo apropriadamente randomizado (exemplo. randomização por data de nascimento, a cada paciente foi dado o tratamento placebo)

*Dois primeiros critérios considerados na lista de Hadorn et al. (1995) de nove apresentados. 


\section{Anexo 2}

\section{Avaliação Crítica de Estudos sobre Terapia ou Prevenção \\ Adaptado de Stotts (1999)}

\section{Os resultados são validos?}

\section{Guias Primárias}

A designação dos pacientes ao tratamento foi randomizada?

Todos os pacientes incluídos no estudo foram considerados?

O seguimento completo?

Os pacientes foram analisados nos respectivos randomizados?

\section{Guias secundárias}

Os pacientes, profissionais de saúde e pessoal envolvido foram mantidos "cegos” ao tratamento?

Os grupos eram semelhantes ao iniciar o estudo?

Além da intervenção experimental, os grupos foram tratados igualmente?

\section{Quais foram os válidos?}

Qual foi extensão do efeito do tratamento?

Qual foi a precisão da estimativa o efeito do tratamento?

\section{Os resultados me auxiliarão no cuidado aos meus pacientes?}

Os resultados podem ser aplicados no cuidado aos meus pacientes?

Todos os resultados clinicamente importantes foram considerados?

Os prováveis benefícios do tratamento valem a pena em relação aos danos e custo potenciais? 


\section{Anexo 3}

\section{Lista Final Delphi \\ Adaptado de Verhagem et al. (1998)}

1 Alocação dos tratamentos

a) Foi realizado um método de randomização? Sim/Não/Não sabe

b) A alocação aos tratamentos foi ocultado? Sim/Não/Não sabe

2 Os grupos foram semelhantes nos dados basais entre os Sim/Não/Não sabe indicadores de prognósticos mais importantes?

$3 \quad$ Foram especificados os critérios de elegibilidade?

Sim/Não/Não sabe

$4 \quad$ Foi mascarado o avaliador dos resultados?

Sim/Não/Não sabe

$5 \quad \mathrm{O}$ fornecedor dos cuidado esteve mascarado?

Sim/Não/Não sabe

$6 \quad$ Os pacientes foram mascarados aos grupos?

Sim/Não/Não sabe

7 O ponto de estimação e mensuração da variabilidade foi Sim/Não/Não sabe apresentado para os resultados iniciais?

8 O tratamento da análise incluiu uma análise com intenção a Sim/Não/Não sabe tratar? 


\section{Anexo 4}

\section{Lista de critérios para avaliar a qualidade metodológica Adaptado de Tulder Van et al. (1997)}

Seleção de pacientes

a. O critério de elegibilidade foi especificado?

Sim/Não/Não sabe

b. Alocação de tratamento

1) Foi realizado um método de randomização?

Sim/Não/Não sabe

2) Foi realizado um tratamento de alocação cegada?

Sim/Não/Não sabe

c. Foram os grupos semelhantes no basal em relação aos mais importantes indicadores dos prognósticos?

Sim/Não/Não sabe

Intervenções

d. Foram a listagem das intervenções e o grupo controle descritos explicitamente?

e. Foram os provedores de cuidado cegados para o grupo de intervenção?

Sim/Não/Não sabe

f. Foram as co-intervenções evitadas ou comparáveis?

Sim/Não/Não sabe

g. Foi a aderência aceitável em todos os grupos?

Sim/Não/Não sabe

h. Foram os pacientes cegados para a intervenção?

Sim/Não/Não sabe

Sim/Não/Não sabe

Medidas dos resultados

i. Foi o assessor do resultado encoberto à intervenção?

Sim/Não/Não sabe

j. Foram relevantes os resultados medidos?

k. Foram descritos os efeitos adversos?

l. Foram os índices de perdas/abandonos descritos e aceitáveis?

Sim/Não/Não sabe

Sim/Não/Não sabe

$\mathrm{m}$. O seguimento foi medido no tempo apropriado?

Sim/Não/Não sabe

1) A mensuração foi realizada em curto período de tempo?

2) A mensuração foi realizada em longo período de tempo?

Sim/Não/Não sabe

Sim/Não/Não sabe

n. A medida dos resultados foram comparáveis em ambos grupos?

Sim/Não/Não sabe

Estatísticas

o. Foi descrito o tamanho da amostra para cada grupo?

Sim/Não/Não sabe

p. A analise incluída foi por intenção a tratar?

Sim/Não/Não sabe

q. O ponto de estimação e mensuração da variabilidade foi apresentado para

Sim/Não/Não sabe as medidas dos resultados iniciais? 


\section{Anexo 5 \\ Revisão crítica sistematizada sobre diretrizes clínicas \\ Adaptado de Hayward et al. ( 1995)}

\section{Validade das Recomendações}

Guias primárias:

a. Especificação de todas as opções importantes e efeitos clínicos

b. Processo explícito e sensível usado para identificar, selecionar e combinar evidência.

Guias secundárias:

c. Processo explícito e sensível usado para considerar o valo relativo de diferentes efeitos clínicos

d. Consideração de descobertas importantes e recentes

e. Submissão à revisão por peritos e testagem

\section{As recomendações}

a. Recomendações práticas e clinicamente importantes

b. Grau das recomendações

c. Impacto da incerteza associada à evidência e valores usados nas diretrizes

\section{Utilidade na prática pessoal das recomendações}

a. Objetivo primário das diretrizes compatíveis com os seus objetivos

b. Recomendações aplicadas aos pacientes. 


\section{Anexo 6}
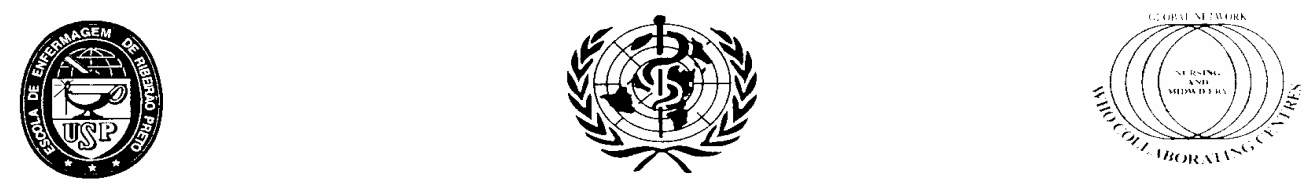

ESCOLA DE ENFERMAGEM DE RIBEIRÃO PRETO - UNIVERSIDADE DE SÃO PAULO CENTRO COLABORADOR DA ORGANIZACCÃO MUNDIAL DA SAÚDE PARA

O DESENVOLVIMENTO DA PESQUISA EM ENFERMAGEM

Avenida Bandeirantes. 3900 - Campus Universitário - Ribeirào Preto-CFP 14040902 . Sào Paulo Brasil

IAX: $55016-633-3271 / 55-016-630-2561 /$ TELEFONFS: 55 - 016 633-0379/602-3382

\section{COMITÊ DE ÉTICA EM PESQUISA DA EERPIUSP}

Of.CEP-EERP/USP - 021/2002

Ribeirão Preto, 20 de março de 2002.

Prezada Senhora,

Comunicamos que o projeto de pesquisa, abaixo especificado, foi analisado e considerado APROVADO pelo Comitê de Ética em Pesquisa da Escola de Enfermagem de Ribeirão Preto da Universidade de São Paulo, em sua $37^{\text {a }}$ Reunião Ordinária, realizada em 20 de março de 2002.

Protocolo: $\quad \mathrm{n}^{\circ} 0242 / 2002$

Projeto: $\quad$ Prevenção de complicações nas extremidades inferiores em portadores de diabetes mellitus: uma abordagem da prática baseada em evidências

Pesquisadores: Ana Emília Pace (Orientadora)

Kattia Ochoa Vigo

Em atendimento à Resolução 196/96, deverá ser encaminhado ao CEP o relatório final da pesquisa e a publicação de seus resultados, para acompanhamento, bem como comunicada qualquer intercorrência ou a sua interrupção.

Atenciosamente,

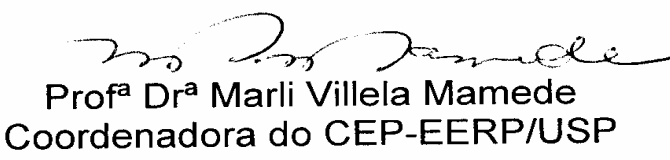

Ilma. Sra.

Profa. Dra. Ana Emília Pace

Departamento de Enfermagem Geral e Especializada da EERP/USP 


\section{Anexo 8}

\section{Instrumento de coleta de dados}

Primeira parte: (dados sócio-demográficos, dados clínicos, cuidados com pés e calçados).

Dados demográficos

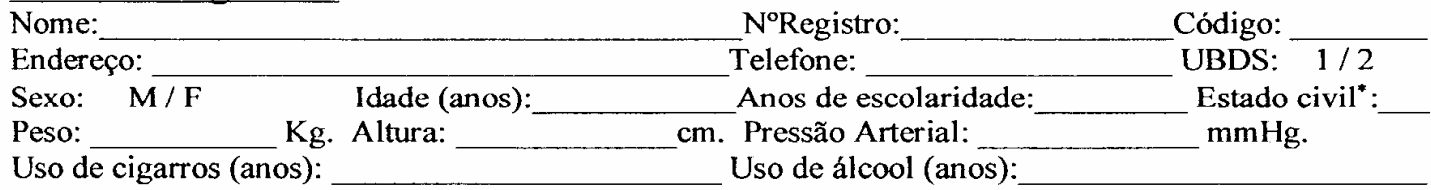

Dados sobre a doença e bioquímica sanguínea

Assinale com xis $(X)$ a condição interrogada quando presente.

Tempo do diagnóstico do diabetes (anos):

Tratamento atual: Insulina ( ), Agente oral ( ), Só dieta ()

Glicemia de jejum:

Triglicérides Creatinina HDL Colesterol

\section{História médica}

Doença isquêmica do coração (); Apoplexia ( ); Retinopatia diabética ( ); Nefropatia diabética (); Bypas arterial em membro inferior ( ); Ulceras prévias ( ); Outros:

Ferimento nos pés após desenvolver diabetes: bolha (), Corte ( ), rachadura ( ), unha encravada

( ), queimadura ( ), escoriação ( ), outros

Sintomas de descompensação no diabetes

01. O senhor (a) lembra os valores normais da glicose no sangue Sim () Não ( )

02. O senhor (a) lembra quais são os e sintomas de: glicose baixa no sangue (hipoglicemia)

glicose alta no sangue (hiperglicemia)

03. O senhor lembra quais sinais e sintomas pode apresentar nos pés por causa do diabetes?

Cuidados com os pés

04. O senhor (a) costuma examinar seus pés em busca de lesões? Sim (), Não, ( ).

05. O responsável desta atividade é: você mesmo ( ), familiar ( ), outros

06. Como o senhor (a) costuma cortar as unhas dos pés?

Redonda ( ), retas ( ), retas com bordas lixadas ( ), outras formas

07. O senhor (a) apresenta ou já teve calosidades nos pés? $\operatorname{Sim}(), \overline{N a ̃ o ~(~) . ~}$

08. Para o cuidado dos calos já foi usado ou ainda é usado: gilete (), lixa de metal (), produto químico ( ), pedra-pomes (), lixa de papel (), deixa os pés de molho () outros ( )

09. Ao lavar os pés o senhor (a) tem cuidado de secar entre os dedos? Sim ( ), Não ( ).

10. O senhor (a) usa algum tipo de creme para hidratar os pés? $\operatorname{Sim}($ ), Não ( ).

11. O que o senhor (a) fez?

Calçou meias ( ), pôs bolsa de água quente ( ), ambas ( ), não fez nada ( ), outros

12. O senhor costuma usar meias? Sim ( ), Não ( ),

13. As meias são de fios de: algodão ( ), sintéticos ( ), lã ( ), outros

Cuidados com os calçados

14. O senhor (a) costuma inspecionar os sapatos por dentro antes de calçá-los? Sim ( ), Não ( ).

15. O senhor (a) costuma arejar ou limpar os sapatos diariamente? Sim (), Não ().

*1. Solteiro (a); 2. Casado/amasiado (a); 3. Divorciado/separado (a); 4. Viuvo (a). 
16. Habitualmente, o senhor (a) usa um mesmo sapato o dia tudo? $\operatorname{Sim}($ ), Não ( ).

17. Quando o senhor (a) compra um sapato novo, em que horário costuma fazê-lo?

Pela manhã ( ), pela tarde ( ), no final da tarde ( ), não tem horário ( )

18. Comumente seus sapatos são de: bico fino ( ), salto maior de $5 \mathrm{~cm}$. (), abertos/sandálias ( ), fechados/macios ( ), fechados/apertados ( ), Outros

Segunda parte: (exame de membros inferiores)

Encerrar em semicírculo (o) a palavra que se apresenta como questão quando contem mais de uma opção e com xis (X) o estado identificado como problema (s).

\section{Avaliação Dermatológica}

19. Higiene dos pés incluindo corte de unhas: adequada (), inadequada ( ).

20. Pele ressecada/Descamativa: presente (), ausente ().

21. Unha espessada/aspecto farináceo/onicomicose: Presente (), Ausente ().

22. Dermatite fúngica: presente (), ausente ().

23. Calos e calosidades: presente ( ), ausente ().

24. Bolhas/úlceras: presente ( ), ausente ( ).

\section{Avaliação Estrutural}

25. Pé plano/Espalmado/Cavo: presente ( ), ausente ( ).

26. Halux valgo: ( ), Ausente ().

27. Dedos sobrepostos/martelo: presente (), ausente ().

\section{Avaliação Circulatória}

28. Edema $(+/+++),(+H+1+),(++H / H+t)$ : presente () , ausente () .

29. Claudicação: presente (), ausente ().

30. Pulso tibial posterior: presente (), ausente ().

31. Pulso pedioso: presente (), ausente ( ).

32. Temperatura: MID MIE

\section{Avaliação Neurológica}

33. Sensibilidade vibratória dorsal: presente (1), ausente (2), NS** (3)

Pé direito
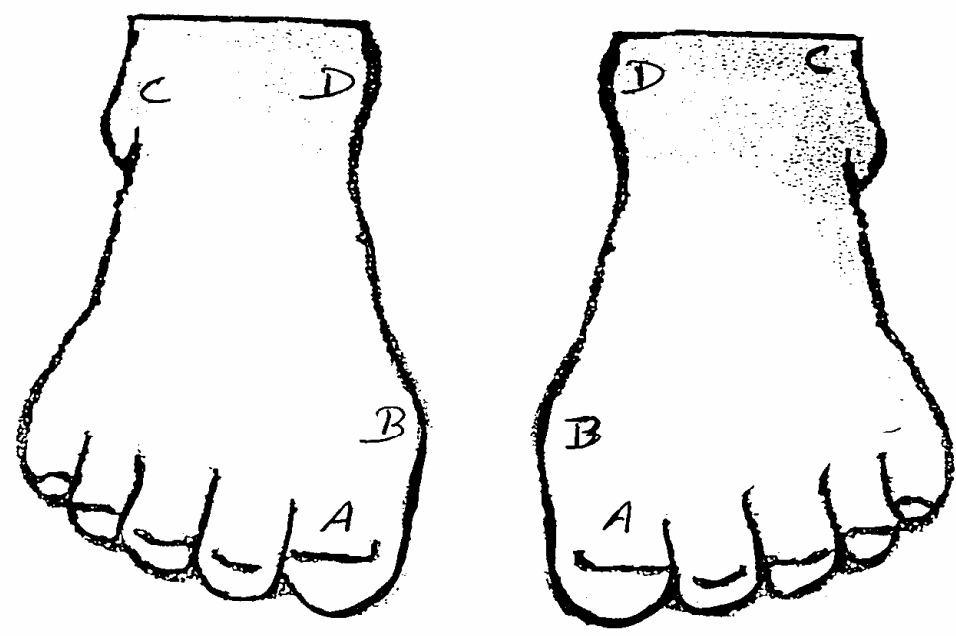

pé esquerdo

"* Não Sabe 
34. Sensibilidade tátil pressórica dorsal/plantar: presente (1), ausente (2), NS (3).

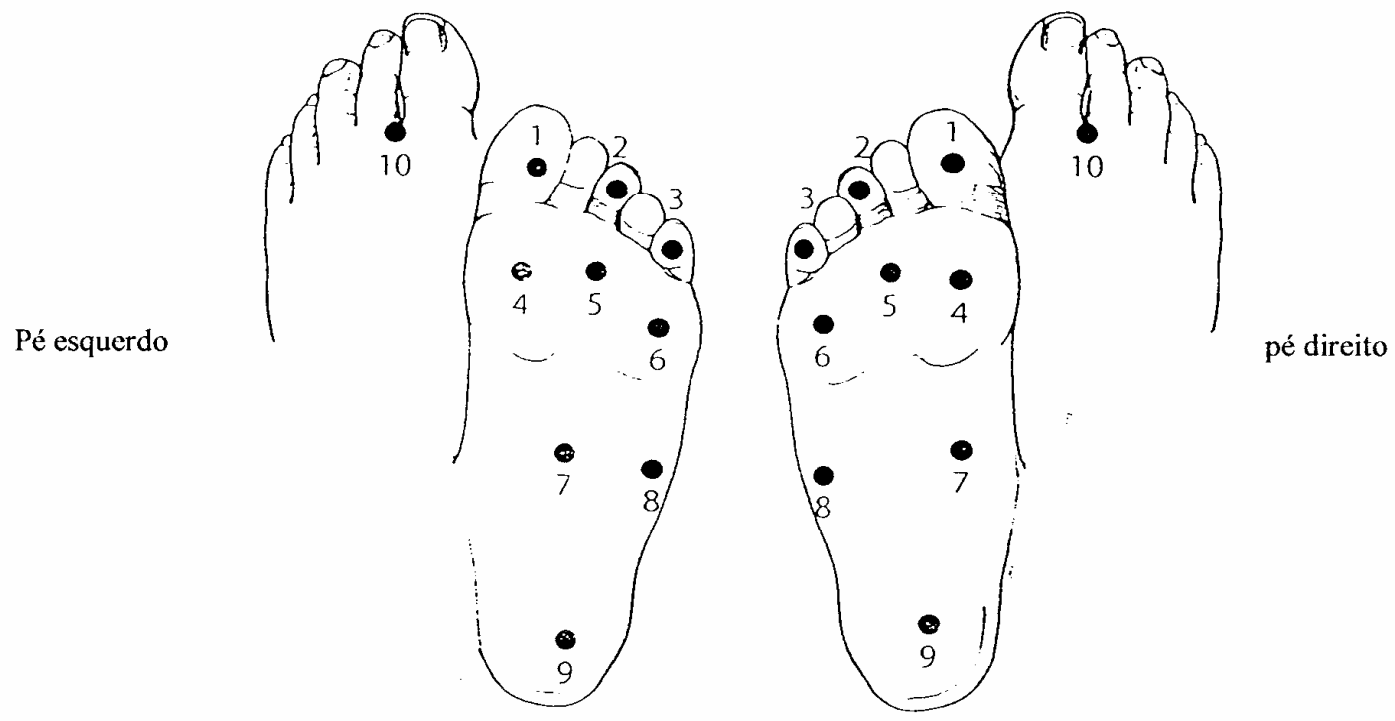

35. Reflexo de Aquileus pé

direito normal/diminuído/ausente; esquerdo normal/diminuído/ausente

Características do calçado no momento da entrevista

36. Estilo dos sapatos: Mocassim (), Botina (), Tênis $<5 \mathrm{~cm}$ (), Tênis $\geq 5 \mathrm{~cm}$. (),

Sapatilhas ( ), Sapatos com dedos fechados ( ), Sandálias (), Outros

37. Largura do sapato: adequado ( ), amplo/flutuante ( ), estreito/reduzido ( ).

38. Cumprimento do sapato: adequado ( ), pequeno ( ), longo ( ).

39. Material do sapato: pele/couro ( ), lona/algodão ( ), vinil/plástico ( ), outros 


\section{Anexo 7}

\section{COMITÊ DE ÉTICA EM PESQUISA DA ESCOLA DE ENFERMAGEM DE RIBEIRĀO PRETO \\ DA UNIVERSIDADE DE SÃO PAULO}

Avenida Bandeirantes, 3900 - Campus Universitário - Riebeirão Preto - CEP 14048-900 - São Paulo - Brasil

\section{TERMO DE CONSENTIMENTO LIVRE E ESCLARECIDO}

NOME DA PESQUISA: "Prevenção de complicações nas extremidades inferiores em portadores de diabetes mellitus: uma abordagem da Prática Baseada em Evidências"

PESQUISADOR RESPONSÁ VEL: Doutoranda Kattia Ochoa Vigo -

COREn/SP N $N^{\circ} 00739 / 01$

Estamos realizando um estudo junto às pessoas com diabetes mellitus tipo 2, atendidas em duas Unidades Básicas e Distritais de Saúde da Secretária Municipal de Saúde de Ribeirão Preto, objetivando avaliar a aplicabilidade de uma proposta de assistência a esta clientela, com vistas a prevenir e/ou diminuir o risco de desenvolver complicações em membros inferiores

Para tanto, realizamos entrevistas, avaliações dos membros inferiores, orientações e demonstrações especificas sobre cuidados com os pés, para facilitar sua realização no domicilio, sendo que cuidados a serem desenvolvidos não oferecem riscos para a saúde no percurso do estudo

Quando for identificada alguma alteração que necessite de avaliação médica especializada será feito encaminhamento para a Unidade de Referência

No início e término do estudo serão, coletadas amostras de sangue para realização de exames para verificar os niveis de açúcar e gordura no sangue e avaliar o funcionamento dos rins. Estes procedimentos podcrão causar incomodo proprio a qualquer punção de veia.

O acompanhamento das pessoas que aceitem participar do estudo será feito pelos pesquisadores, durante um período de 12 meses, nos quais serão estabelecidos contantos em datas previamente programadas.

As pessoas que concordarem em participar deste estudo serão divididas em dois grupos. Um deles receberá orientações e seguimento padrão da Unidade que está sendo atendido e o outro grupo orientações de acordo com a proposta do presente estudo, que inclue uma maneira específica de cuidados com os pés.

Os dados registrados no estudo em nenhum momento serão divulgados com a sua identificação. A sua participação no estudo não envolve nenhuma despesa e nem mesmo gratificação, tendo você total liberdade para recusar sua participação na pesquisa e também a de retirar o seu consentimento se consideraar necessário em qualquer momento do estudo, bem como o de solicitar novos esclarecimentos sobre o estudo a qualquer momento 
El

R G abaixo assinado, tendo recebido as informaçôes acima, e ciente dos meus direitos abaixo relacionados, concordo em participar desta pesquisa que será realizada sob a responsabilidade de Kattia Ochoa Vigo da EERP - USP, pois estou ciente que em nenhum momento serei exposto a riscos devido a minha participação e poderei a qualquer momento recusar continuar sem nenhum prejuizo para minha pessoa.

Sei também que os dados por mim respondidos no questionário e na avaliação serão somente usados para fins cientificos com a garantia de que não serei identificado.

Foi informado que não terei nenhum tipo de despesa e nem receberei pagamento ou gratificação pela minha participação nesse estudo e que terei acesso aos resultados da pesquisa, uma vez que os memos sejam publicados em períodicos cientificos.

Pelo exposto, concordo voluntariamente em participar do referente estudo.

Ribeirão Preto, de de

Assinatura do participante

Enfa. Kattia Ochoa Vigo

Pesquisador responsável

Av. do Café 1715 - Apto. 318

CEP: 14050-230 - Ribeirão Preto, SP

Telf. 0166330448

Profa. Dra. Ana Emília Pace

Orientador

Av. Bandeirantes, 3900

CEP: 14048-900 - Ribeirão Preto, SP

Telf. 0166023401 - 0166125911 


\section{Anexo 9}

\section{Prefeitura Municipal de Ribeirão Preto \\ Estado de São Paulo \\ Secretaria da Saúde \\ www.saude.ribeiraopreto.sp.gov.br}

Ribeirão Preto, 14 julho de 2004.

Prezado(a) Senhor(a),

Segundo estatísticas, o Diabetes Mellitus é responsável por mais de $50 \%$ das amputações não traumáticas, as quais freqüentemente são precedidas por úlceras.

As úlceras nos pés em pessoas com D.M. são responsáveis por grande percentual de morbimortalidade e hospitalização, sendo estas geralmente prolongadas e recorrentes, com maior número de consultas ambulatoriais e necessidade de cuidado especializado. Desta forma identifica-se que o manejo dos pés das pessoas com D. M. constitui um problema complexo, pois inclui uma estreita colaboração e responsabilidade dos pacientes e dos profissionais de saúde.

Mediante esta problemática, elaborou-se uma proposta assistencial sistematizada para as pessoas com Diabetes Mellitus tipo 2, com ênfase na prevenção e/ou diminuição de fatores de risco, a partir de urna revisão sisiemática, a quai está em fase de teste, por meio de um estudo piloto, o qual compōe a tese de doutorado da enfermeira Kattia Ochoa-Vigo, sob orientação da Profa. Dra. Ana Emilia Pace, junto ao Programa de Pós Graduação da Escola de Enfermagem de Ribeirăo Preto-USP.

Este estudo piloto está em desenvolvimento em duas Unidades Distritais de Saúde localizadas nos bairros Vila Virgínia e Quintino II. Na primeira etapa foram envolvidos os pacientes com diabetes e na segunda, pretende-se expor os objetivos e projeto aos profissionais, com a finalidade de consolidar a proposta de intervenção em parceria entre a Secretaria Municipal da Saúde e Escola de Enfermagem de Ribeirão Preto-USP. Para isso, convidamos um Médico e um Enfermeiro desta Unidade de saúde para participar do curso: "Diabetes Mellitus: Prevenção de Complicação em Pés", segue programação anexo.

Sendo só para o momento, despedimo-nos.

Atenciosamente,

DR. JOÃO VITOR ABDALLA

DIRETOR DEPTO DE ATENÇÃo À SAÚdE dAS PESSOAS

Enfermagem.Geral.Curso Diabetes.Doc. 


\section{Prefeitura Municipal de Ribeirão Preto \\ Estado de Săo Paulo \\ Secretaria da Saúde \\ www.saude.ribeiraopreto.sp.gov.br}

\section{Curso de Atualização}

\section{Diabetes Mellitus: Prevenção de complicações em pés.}

Período: $20,26 / 08$ e 03/09 de 2004

Local: UBDS Vila Virgínia

Coordenação: SMS-RP / EERP-USP

\begin{tabular}{|c|c|c|c|}
\hline Data & Horário & Conteúdo & Responsável \\
\hline $20 / 08$ & $14-17 \mathrm{~h}$ & $\begin{array}{l}\text { Abertura do Curso } \\
\text { Apresentação da proposta do projeto de pesquisa } \\
\text { Epidemiologia do DM e das complicações crônicas } \\
\text { Estrutura e função dos pés } \\
\text { Biomecânica da marcha } \\
\text { Calçados e Órteses } \\
\text { Mobilidade Articular Limitada }\end{array}$ & $\begin{array}{l}\text { Dra. Maria Teresa Torquato } \\
\text { Enfa. Emilia Ma. Chayamiti } \\
\text { Enfa. Kattia Ochoa-Vigo } \\
\text { Dra. Maria Teresa Torquato } \\
\text { Dr. Luiz Pasqualin } \\
\text { Dr. Luiz Pasqualin } \\
\text { Dr. Luiz Pasqualin } \\
\text { Dr. Luiz Pasqualin }\end{array}$ \\
\hline $26 / 08$ & $9-12 \mathrm{~h}$ & $\begin{array}{l}\text { Neuropatia Diabética } \\
\text { Doença Vascular Periférica } \\
\text { Dermatopatias em diabetes } \\
\text { Fisiopatologia do pé diabético }\end{array}$ & $\begin{array}{l}\text { Dr. Stenio Miranda } \\
\text { Dr. Romeu Alioti } \\
\text { Dr. Marco Andrey Cipriani } \\
\text { Profa. Dra. Ana Emilia Pace }\end{array}$ \\
\hline $03 / 09$ & 14-17h & $\begin{array}{l}\text { Prevenção do pé diabético } \\
\text { Avaliação dos pés }\end{array}$ & $\begin{array}{l}\text { Enfa. Kattia Ochoa-Vigo } \\
\text { Dra. Maria Teresa Torquato } \\
\text { Profa. Dra. Ana Emilia Pace } \\
\text { Enfa. Kattia Ochoa-Vigo }\end{array}$ \\
\hline
\end{tabular}




\section{Prefeitura Municipal de Ribeirão Preto \\ Estado de São Paulo \\ Secretaria da Saúde \\ www.saude.ribeiraopreto.sp.gov.br}

\section{Curso de Atualização}

\section{Diabetes Mellitus: Prevenção de complicações em pés.}

Período: 10, 17 e 24/setembro de 2004

Local: UBDS Distrito Norte

Coordenação: SMS-RP / EERP-USP

\begin{tabular}{|l|c|l|l|}
\hline Data & Horário & \multicolumn{1}{|c|}{ Conteúdo } & \multicolumn{1}{|c|}{ Responsável } \\
\hline $10 / 09$ & $8-11$ & $\begin{array}{l}\text { Abertura do Curso } \\
\text { Apresentação da proposta do projeto de pesquisa }\end{array}$ & $\begin{array}{l}\text { Dra. Maria Teresa Torquato } \\
\text { Enfa. Emilia Ma. Chayamiti }\end{array}$ \\
& $\begin{array}{l}\text { Enfa. Kattia Ochoa-Vigo } \\
\text { Estrutura e função dos pés } \\
\text { Biomecánica da marcha } \\
\text { Calçados e Orteses } \\
\text { Mobilidade Articular Limitada }\end{array}$ & $\begin{array}{l}\text { Neuropatia Diabética } \\
\text { Doença Vascular Periférica } \\
\text { Dermatopatias em diabetes } \\
\text { Fisiopatologia do pé diabético }\end{array}$ & $\begin{array}{l}\text { Dr. Luiz Pasqualin } \\
\text { Dr. Luiz Pasqualin }\end{array}$ \\
\hline $17 / 09$ & $8-11$ & $\begin{array}{l}\text { Prevenção do pé diabético } \\
\text { Drangalin }\end{array}$ \\
\hline $24 / 09$ & $8-11$ & $\begin{array}{l}\text { Avaliação dos pés } \\
\text { Dr. Stenio Miranda } \\
\text { Dr. Romeu Alioti } \\
\text { Dr. Marco Andrey Cipriani } \\
\text { Profa. Dra. Ana Emilia Pace }\end{array}$ \\
\hline
\end{tabular}

